\title{
Bolted Connection Strength in Pultruded Glass Fiber Reinforced Polymer Structural Shapes
}

\author{
Kayla Danielle Weimert
}

Follow this and additional works at: https://researchrepository.wvu.edu/etd

\section{Recommended Citation}

Weimert, Kayla Danielle, "Bolted Connection Strength in Pultruded Glass Fiber Reinforced Polymer Structural Shapes" (2015). Graduate Theses, Dissertations, and Problem Reports. 6933.

https://researchrepository.wvu.edu/etd/6933

This Thesis is protected by copyright and/or related rights. It has been brought to you by the The Research Repository @ WVU with permission from the rights-holder(s). You are free to use this Thesis in any way that is permitted by the copyright and related rights legislation that applies to your use. For other uses you must obtain permission from the rights-holder(s) directly, unless additional rights are indicated by a Creative Commons license in the record and/ or on the work itself. This Thesis has been accepted for inclusion in WVU Graduate Theses, Dissertations, and Problem Reports collection by an authorized administrator of The Research Repository @ WVU. For more information, please contact researchrepository@mail.wvu.edu. 


\title{
Bolted Connection Strength in Pultruded Glass Fiber Reinforced Polymer Structural Shapes
}

\author{
Kayla Danielle Weimert \\ Thesis submitted to the \\ Benjamin M. Statler College of Engineering and Mineral Resources \\ at West Virginia University \\ in partial fulfillment of the requirements for the degree of
}

\author{
Master of Science \\ in \\ Civil Engineering
}
Approved by
Hota V. S. GangaRao, Ph.D., Committee Chair
Mark Skidmore, PE
P. V. Vijay, Ph.D.

\section{Department of Civil and Environmental Engineering}

\author{
Morgantown, West Virginia \\ 2014
}

Keywords: Pultruded Glass Fiber Reinforced Polymer (FRP), Bolted Connection, Load and Resistance Factor Design (LRFD), Pin-Bearing Strength, Composites

Copyright 2015 Kayla Weimert 


\title{
ABSTRACT \\ Bolted Connection Strength in Pultruded Glass Fiber Reinforced Polymer Structural Shapes
}

\author{
Kayla Danielle Weimert \\ Constructed Facilities Center, West Virginia University
}

With the drive for high strength, lightweight component design, the desire for composite materials for structural applications has been increasing in recent years. High strength-to-weight ratio, high stiffness, high fatigue and impact resistance, corrosion resistance, and ease of fabrication are just a few of the advantageous properties of pultruded fiber reinforced polymer (FRP) composites. The various structural applications of pultruded materials typically require the joining of composites either to composites or to metals. Despite introducing high stress concentrations in the composite material, bolted joints are the most practical connection for civil engineering applications. Bolted connections in glass FRP composites have been studied for years; however, accurate prediction models to determine failure strength and failure modes of these bolted connections are still being developed and confirmed. The American Society of Civil Engineers (ASCE), in conjunction with the American Composites Manufacturers Association (ACMA) are working to develop the Pre-Standard for Load \& Resistance Factor Design (LRFD) of Pultruded Fiber Reinforced Polymer (FRP) Structures. The eighth chapter of the pre-standard focuses on the design of bearing-type connections.

The study presented herein is intended to increase the understanding of bolted joints in pultruded composites, while analyzing the effectiveness of existing failure prediction methods. Specifically, bolted connections in cooling tower tie lines are investigated for their bearing failure. Two types of samples were tested: (1) full cooling tower tie lines, which represented a single bay in cooling tower designs, and (2) shorter column-to-tie connection samples, intended to specifically test the bolted connection strength. The connections between the column and tie were either singly bolted or doubly bolted. Researchers performed compression testing on over one hundred samples until the point of failure. Failed specimens were inspected for cracks and fracture patterns. The results were analyzed and compared to values found using the strength equations provided in the pre-standard, as well as other existing methods. Since all twenty-four column-to-tie connection samples presented as bearing failures, the evaluation of existing failure prediction methods focused on the pin-bearing strength. It was found that the failures in the boltloaded pultruded samples could be predicted reasonably well with the proposed formulae in the pre-standard. 


\section{ACKNOWLEDGEMENTS}

Thank you to everyone who has supported me throughout my graduate education at West Virginia University. There are many of you, and without your help, I would not have been able to accomplish this goal so efficiently. In particular, I would like to thank the following people and organizations:

Dr. Hota GangaRao, my committee chair, and my academic advisor, thank you for providing me with the opportunity to pursue and earn a Master of Science degree, serving as the chair of my graduate advisory committee, and your guidance throughout this whole process.

Mark Skidmore, your instruction on operating lab equipment and continual feedback on research has been beneficial to my education and success at WVU. Thank you for agreeing to serve on my graduate advisory committee and for assisting me throughout my time as a graduate student.

Dr. P. V. Vijay, thank you for agreeing to serve on my graduate advisory committee and provide feedback throughout my graduate studies.

Jerry Nestor, thank you for your guidance and instruction in the lab. I truly appreciate the time and support you provided me. Additionally, I would like to thank Brian Walker and Jerry Nestor for the countless hours spent assisting me in order to complete my experimental lab work.

Cooling Towers of Texas, located in Texas, USA, supplied all the pultruded GFRP samples for use in the testing completed at WVU-CFC for this research project.

Bedford Reinforced Plastics, located in Pennsylvania, USA, thank you for supplying sample test data to supplement the calculations necessary to complete my thesis work.

My family and friends, most importantly, I want to thank for the endless support and encouragement for whatever I have chosen tackle in life. During one of one the biggest challenges of my life thus far, the reassuring words have been more valuable than I can say. 


\section{TABLE OF CONTENTS}

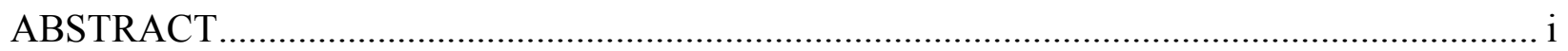

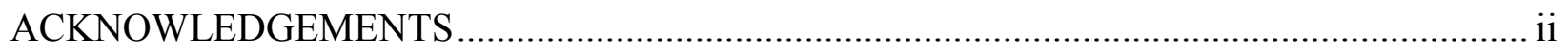

TABLE OF CONTENTS ............................................................................................ ii

LIST OF FIGURES ............................................................................................ vi

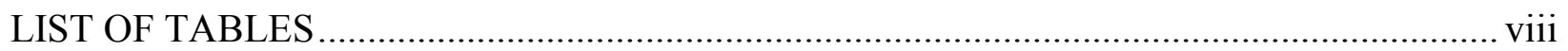

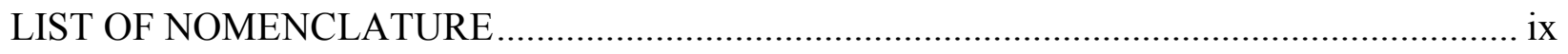

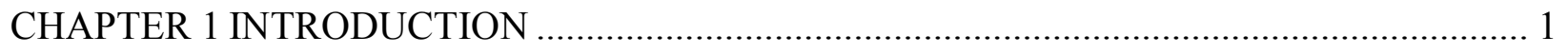

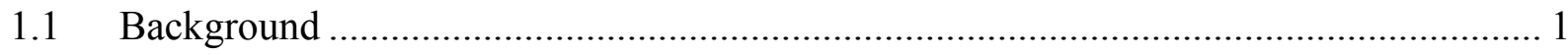

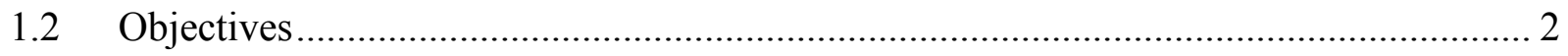

1.3 Scope and Organization of Thesis........................................................................ 3

CHAPTER 2 LITERATURE REVIEW ...................................................................... 4

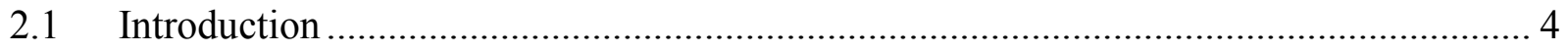

2.2 Bolted Connections in FRP Structures............................................................. 4

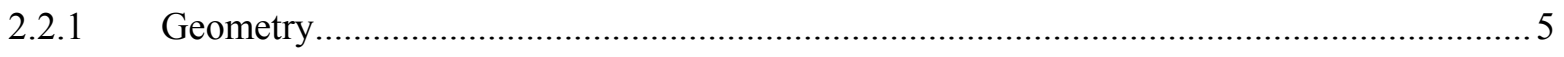

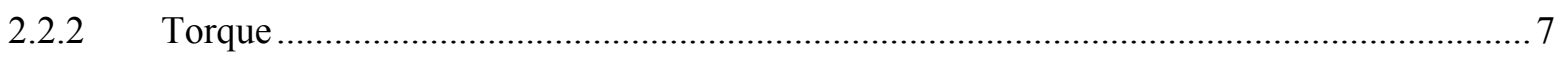

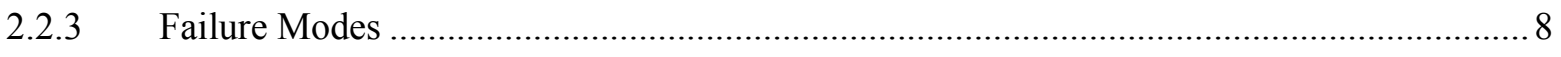

2.3 Flexure Members in FRP Structures .......................................................... 15

2.3.1 Bolted Connections between Flexure Members …......................................................... 15

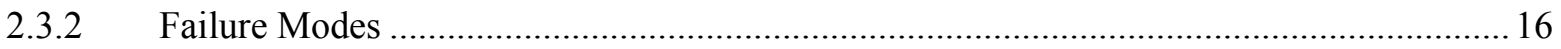

2.4 FRP Structural Shapes in Cooling Tower Structures ............................................ 18 


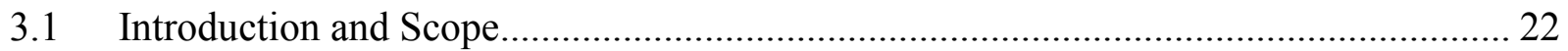

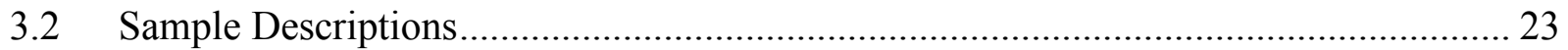

3.3 Test Procedure and Instrumentation................................................................... 26

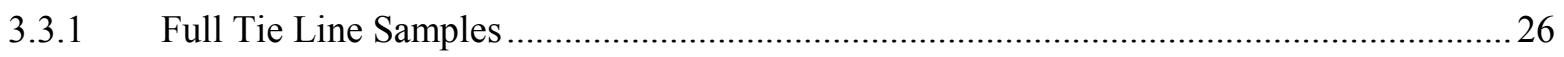

3.3.2 Column-to-Tie Line Connection Samples .................................................................... 28

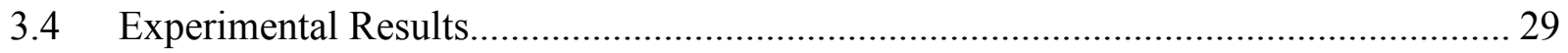

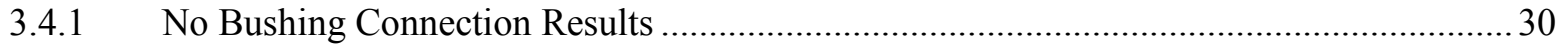

3.4.2 Bushing in Column Only Connection Results .................................................................. 35

3.4.3 Bushing in Both Column and Tie Connection Results .................................................. 40

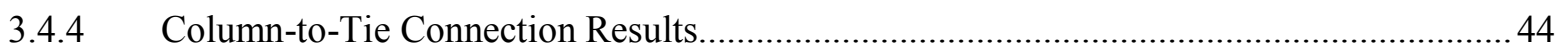

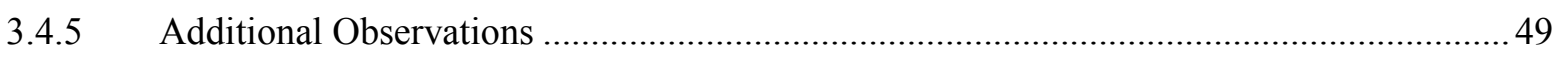

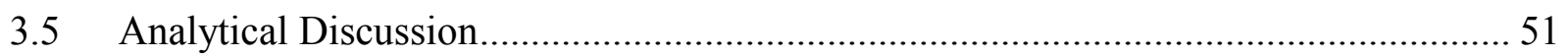

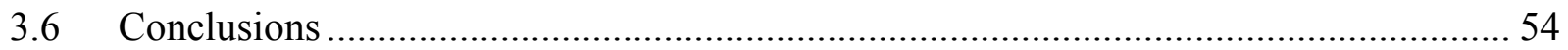

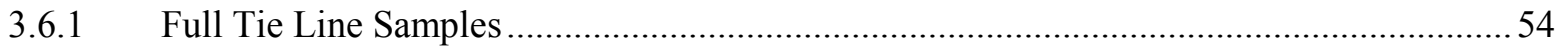

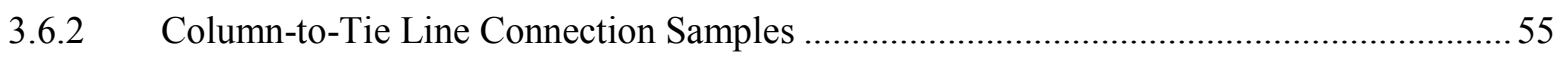

CHAPTER 4 BOLTED CONNECTION STRENGTH PREDICTION ................................... 57

4.1 Pre-Standard for LRFD Pin-Bearing Failure Load Prediction................................... 57

4.1.1 Column-to-Tie Connection Geometry ……..................................................................... 57

4.1.2 Pin-Bearing Strength Formula and Calculation ..............................................................5 59

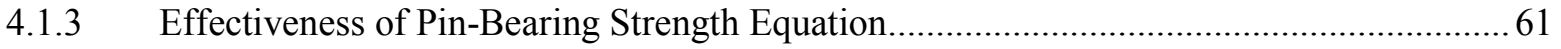

4.2 Ascione, Feo, and Maceri Pin-Bearing Failure Load Prediction ............................... 64

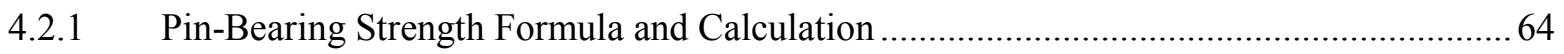

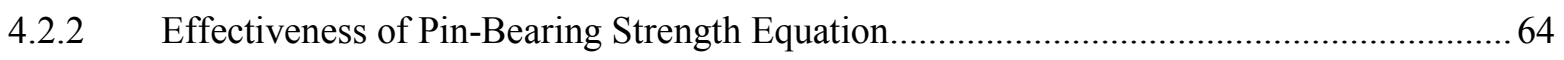

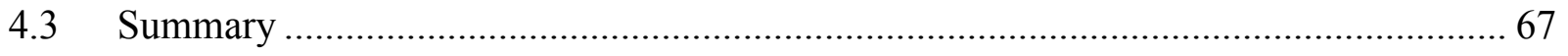

CHAPTER 5 CONCLUSIONS AND RECOMMENDATIONS ….......................................... 68 


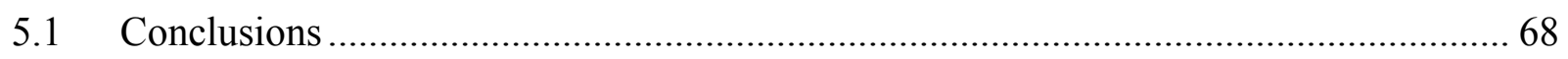

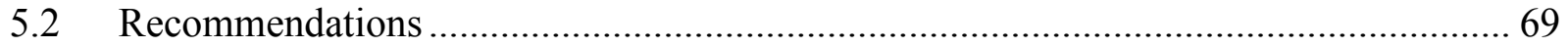

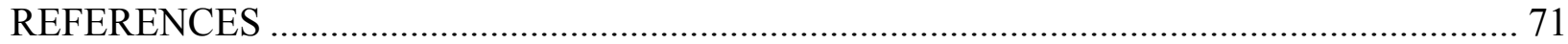

APPENDIX A - Load vs Deflection Plots .......................................................................... 75

APPENDIX B - Diagrams of Sample Construction ...................................................... 106

APPENDIX C - Photographs (Samples Under Loading) ................................................ 110

APPENDIX D - Bearing Strength Data from Bedford Reinforced Plastics .......................... 134 


\section{LIST OF FIGURES}

Figure 2-1: Connection Geometry and Definition of Row of Bolts (from Mottram 2009) ........... 6

Figure 2-2: Modes of Failure for Bolted Joints in FRP Composites (Duthinh 2000).................. 9

Figure 2-3: Plate-to-plate Distinct Modes of Failure with a Single Steel Bolt; (a) bearing, (b) net

tension, (c) shear-out, (d) cleavage (Mottram and Zafari 2011) .......................................... 9

Figure 2-4: FRP Cooling Tower (from Cooling Towers of Texas) ......................................... 19

Figure 2-5: FRP Cooling Tower Structure (from Cooling Towers of Texas) ......................... 20

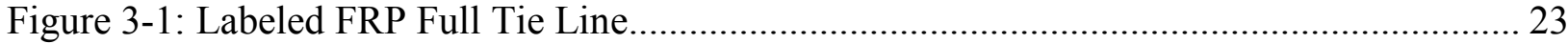

Figure 3-2: Connection Hardware - Stainless Steel Bolts and Hard Plastic Bushings ............... 25

Figure 3-3: FRP Tie Line Variations: tie size, sample length, column-to-tie connections........... 25

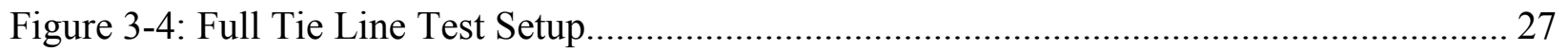

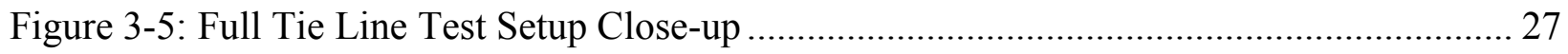

Figure 3-6: Column-to-Tie Connection Test Setup ............................................................ 28

Figure 3-7: Typical Load vs. Transverse Deflection (or Position) for Connections with No

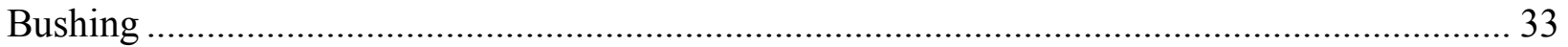

Figure 3-8: Sample Failure Modes: Local Instability/Lateral-Torsional Buckling in FRP 3.5x1.54 No \#1 (Top Left), Local Instability/Material Rupture in FRP 4x1.375-4 No \#2 (Top Right), Local Instability in FRP 6x 1.625-6 No \#1 (Bottom) ........................................................... 34

Figure 3-9: Typical Load vs. Transverse Deflection (or Position) for Connections with Bushing

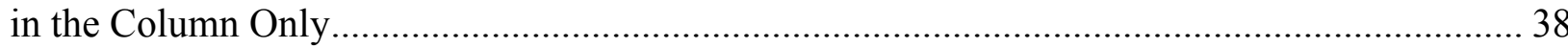


Figure 3-10: Sample Failure Modes: Local Instability in FRP 4x1.25-4 Bush-Col 1 (Top Left), Lateral-Torsional Buckling in FRP 4x1.375-6 Bush-Col 3 (Top Right), Local Instability/Material

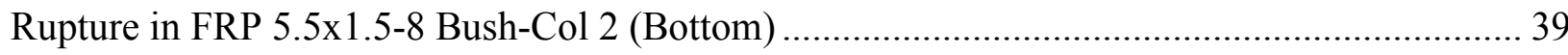

Figure 3-11: Typical Load vs. Transverse Deflection (or Position) for Connections with Bushing

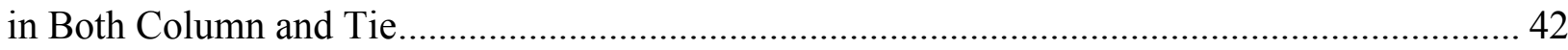

Figure 3-12: Sample Failure Modes: Material Rupture in FRP 3.5x1.5-4 Bush-Both 2 (Top Left), Local Instability in FRP 4x1.375-6 Bush-Both 2 (Top Right), Local Instability/Lateral-Torsional

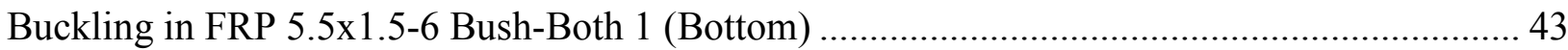

Figure 3-13: Load vs. Position for Connections with FRP 3.5x1.5 Ties ...................................... 47

Figure 3-14: Load vs. Position for Connections with FRP 5.5x1.5 Ties ..................................... 47

Figure 3-15: Bearing Failure of FRP 6x1.625 with No Bushing ................................................. 48

Figure 3-16: Bearing Failure of FRP 3.5x1.5 with Bushing in Column Only ............................. 48

Figure 3-17: Bearing Failure of FRP 4x1.375 with Bushing in Both Column and Tie................ 48

Figure 3-18: Example Failures of Samples: FRP 4x1.25-6 No \#2 (Top Left), FRP 4x1.375-8

Bush-Both 1 (Top Right), FRP 3.5x1.5-6 Bush-Col 1 (Bottom) ………..................................... 50

Figure 4-1: Connection Geometry Labeled on FRP 4x1.375 (Singly Bolted) Sample ................. 58

Figure 4-2: Connection Geometry Labeled on FRP 5.5x1.5 (Doubly Bolted) Sample................. 59 


\section{LIST OF TABLES}

Table 2-1: Minimum Requirements for Bolted Connection Geometries (from ASCE/ACMA

2010) 6

Table 3-1: Results for No Bushing Connections, Full Tie Line and Column-to-Tie Connection

Tests 32

Table 3-2: Results for Bushing in Column Only Connections, Full Tie Line and Column-to-Tie

Connection Tests. 36

Table 3-3: Results for Bushing in Both Column and Tie Connections, Full Tie Line and Column-

to-Tie Connection Tests .................................................................................................... 41

Table 3-4: Results for All Column-to-Tie Connections ...................................................... 46

Table 4-1: Connection Geometries in Column-to-Tie Bolted Connections ............................. 59

Table 4-2: Pre-Standard for LRFD Pin-Bearing Strengths Based on Tie Size.......................... 61

Table 4-3: Connection Test Results with LRFD Pin-Bearing Strengths for Comparison........... 61

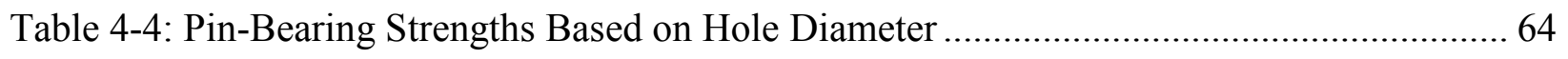

Table 4-5: Connection Test Results with Calculated Pin-Bearing Strengths for Comparison ..... 65 


\section{LIST OF NOMENCLATURE}

\begin{tabular}{|c|c|}
\hline$d$ & Nominal bolt diameter \\
\hline$d_{b}$ & Diameter of bolt \\
\hline$d_{h}$ & Diameter of hole \\
\hline$e_{1, \min }$ & End distance \\
\hline$e_{2, \min }$ & Edge distance \\
\hline$F_{\theta}^{b r}$ & $\begin{array}{l}\text { Characteristic pin-bearing strength for the orientation of the resultant } \\
\text { force at the bolt/FRP contact with respect to the direction of pultrusion }\end{array}$ \\
\hline$F_{L}^{b r}$ & Characteristic pin-bearing strength in the longitudinal direction of FRP \\
\hline$F_{T}^{b r}$ & Characteristic pin-bearing strength in the transverse direction of FRP \\
\hline$F_{u}^{(\alpha)}$ & Pin-bearing failure load (Ascione et al. 2010) \\
\hline$F_{u}^{0}$ & Experimental bearing failure load for $\alpha$ equal to $0^{\circ}$ \\
\hline$F_{u}^{(\pi / 2 m)}$ & Experimental bearing failure load for $\alpha$ equal to $\pi / 2 m$ \\
\hline$F_{u}^{(\pi / 4 m)}$ & Experimental bearing failure load for $\alpha$ equal to $\pi / 4 m$ \\
\hline$g_{\min }$ & Gage spacing \\
\hline$g_{s, \min }$ & Gage spacing with staggered bolts \\
\hline$l_{s, \min }$ & Stagger distance \\
\hline$m$ & Replicability module \\
\hline$R_{b r}$ & Pin-bearing strength per bolt (Pre-standard for LRFD) \\
\hline$R_{n}$ & Nominal connection strength \\
\hline$s_{\min }$ & Pitch spacing \\
\hline$t$ & Thickness of the FRP component and/or member \\
\hline$t_{\text {tot.plies }}$ & Total laminate thickness \\
\hline$t_{\text {plies }}^{0}$ & Thickness of plies in $0^{\circ}$ direction \\
\hline$\alpha$ & $\begin{array}{l}\text { Fiber inclination angle between the direction of the external applied } \\
\text { force and the } 0^{\circ} \text { direction }\end{array}$ \\
\hline$\emptyset_{c}$ & Resistance factor for FRP connections \\
\hline$\theta$ & $\begin{array}{l}\text { Angle of loading, between the direction of the connection force and the } \\
\text { direction of pultrusion }\end{array}$ \\
\hline$\xi$ & Reduction factor \\
\hline
\end{tabular}




\section{CHAPTER 1 INTRODUCTION}

\subsection{Background}

Composite material is a multiphase material consisting of fibers embedded in or bonded to a matrix with distinct interfaces between them. Both fibers and matrix retain their physical and chemical identities while producing a combination of properties that cannot be obtained with either constituent alone (Mallick 1993). Fiber reinforced polymer (FRP) composites are increasingly becoming more desirable in structural applications as they offer a variety of favorable properties. Among these are the high strength-to-weight ratio, high stiffness, high fatigue and impact resistance, superior corrosion resistance, low thermal and electrical conductivity, ease of fabrication, low cost of installation, and low life-cycle cost (Liang and GangaRao 2013). As FRP composites gain wider acceptance for use in the development and rehabilitation of infrastructure, the need to develop reliable Load and Resistance Factor Design (LRFD) specifications, including design approaches and examples for FRP composites, is necessary. However, since pultruded structural shapes demonstrate anisotropic behavior, the analysis and designs of these materials are far more complex than those of isotropic materials (Zureick 1998).

The American Society of Civil Engineers (ASCE), in coordination with the American Composites Manufacturers Association (ACMA), has been developing the Pre-Standard for Load and Resistance Factor Design (LRFD) of Pultruded Fiber Reinforced Polymer (FRP) Structures since 2008. The eighth chapter of the pre-standard focuses on the design of bearingtype connections under different failure modes. A majority of the tests used to characterize the strengths and modes of failure of singly bolted connections have been with flat sheet rectangular 
specimens of constant thickness across the width (ASCE/ACMA 2010). Research performed at the West Virginia University Constructed Facilities Center (WVU-CFC) sought to verify the equations provided in the most recent draft version of the pre-standard are still adequate for other structural combinations. While the equations proved effective for bolted connections between channels and box sections, the equations could be developed further to more accurately predict the failure loads.

An accurate prediction model for bolted connection strength based on easy-to-use design formulas is necessary to assure the quality and safety of FRP structural systems by reducing the possibility of design and construction errors. The current model proposed by the ASCE/ACMA pre-standard involves the comparison of multiple strength equations, the lowest calculated strength being used as the design load, which can increase the chance of design errors or the chance of overdesign.

\subsection{Objectives}

The objectives of this study are:

- To perform experimental evaluation of glass fiber reinforced polymer (GFRP) structural connections and analyze the associated ultimate failure load of each connection.

- To perform experimental evaluation of GFRP structures and analyze the acquired data in order to identify the buckling load, ultimate load and failure mode.

- To analyze the accuracy and consistency of existing prediction models for the bolted connection strength of GFRP structural connections.

- To analyze the accuracy and consistency of existing prediction models for the critical load for given failure modes. 


\subsection{Scope and Organization of Thesis}

After this introductory section, the paper is structured as follows:

Chapter 2 provides a literature review of published books and journal articles related to the experimental objectives of this study. The behavior and geometry of bolted connections in FRP structures are discussed including the failure modes associated with these connections. Also included in the discussion are previous studies related to the ultimate capacity, specifically the pin-bearing strength of bolted connections in FRP structures. Research also pertained to flexure members in FRP structures and the failure modes associated with these members. The final topic of discussion is the use of FRP structural shapes in cooling tower structures.

Chapter 3 details the experimental testing and subsequent analysis of data for GFRP structures and structural connections. A full description of the samples, testing procedures and instrumentation are provided in this chapter. The experimental results including the yield/buckling load and ultimate load are presented.

Chapter 4 provides an analysis of existing prediction models in comparison to the results

of the experiment outlined in Chapter 3. The analyses of the pre-standard for LRFD as well as of an equation developed by Ascione, Feo, Maceri (2010) were performed.

Chapter 5 provides a summary of the results presented within Chapter 3 and Chapter 4. Conclusions previously stated in those chapters are expanded on, with recommendations provided for the future improvement of the model proposed within. 


\section{CHAPTER 2 LITERATURE REVIEW}

\subsection{Introduction}

Advances in pultrusion technology for composite materials now allows for the production of larger parts capable of serving as structural members in load-bearing applications (Bakis et al. 2002). With the drive for high strength, lightweight component design, the desire for these composite materials for structural applications has been increasing in recent years. Composite materials possess excellent mechanical properties, including high specific strength and specific stiffness, which make them more desirable. Additionally, pultruded composites allow for continuous production and offer benefits such as corrosion resistance and design flexibility. The structural applications of pultruded materials are many, and typically require the joining of composites either to composites or to metals. Despite introducing high stress concentrations in the composite material, bolted joints are the most practical connection for civil engineering applications. Therefore, accurate prediction models must exist to determine failure strength and failure modes of these bolted connections. Bolted connections in glass fiber reinforced polymer (FRP) composites have been studied for years; however, methods for the design and verification of structural joints (both adhesive and bolted) are still being developed and confirmed.

\subsection{Bolted Connections in FRP Structures}

Due to the ease of assembly or disassembly, mechanical fasteners are commonly used for transferring loads between structural components. While bolted connections possess the highest load carrying capacity in FRP structures, they also present some vulnerability. In FRP structures, the bolted connections can not only sever the reinforcing fibers, reducing the overall 
strength of the composite, but also introduce high stress concentrations, promoting fracture (Oppe and Knippers 2011). The high stress concentration around the fastening holes becomes a source of weakness and often a source of the joint failure (Pisano et al. 2013, Doyle 1991). For this reason, it is necessary to develop an understanding of the mechanical joint behavior in terms of evaluation of the peak load related to the joint endurance strength and in terms of prediction of the joint failure mode (Pisano et al. 2013). In addition to the ultimate load, it is desirable to obtain the entire load deflection curve because the material "yield" strength from such curve can provide further insight and a better understanding of the behavior of the bolted connection than the ultimate bearing strength alone (Manalo 2012).

Research shows that material and geometric parameters can affect the failure load and the failure modes of jointed plates. Joint performance depends on the laminate lay-up, ply orientation, stacking sequence, and material properties of the composite components (Duthinh 2000, Pisano et al. 2013). Additionally, the behavior of bolted joints depends on the geometric dimensions of the connection, including the edge distance, width, and pitch between the bolts (Hassan et al. 1996). The number of bolts, the bolt pattern, the bolt torque and the fit between the bolt and the fastener hole can also influence the joint performance (Pisano et al. 2013).

The subsequent sections discuss some of the parameters that influence bolt strength, as well as the possible failure modes that can occur in bolted connections in FRP structures.

\subsubsection{Geometry}

The ASCE/ACMA Pre-Standard for LRFD of pultruded FRP structures defines connection geometry for use with the equations provided. Figure 2-1 (similar to that found in the prestandard) illustrates the connection geometry and the definition of a row of bolts. As shown, a row of bolts is defined to have its centerline normal to the direction of the connection force. The 
minimum requirements for end distance $e_{1}$, edge distance $e_{2}$, pitch $s$ (the bolt spacing between bolt rows) and gage distance $g$ (the bolt spacing across a row) are listed in Table 2-1.

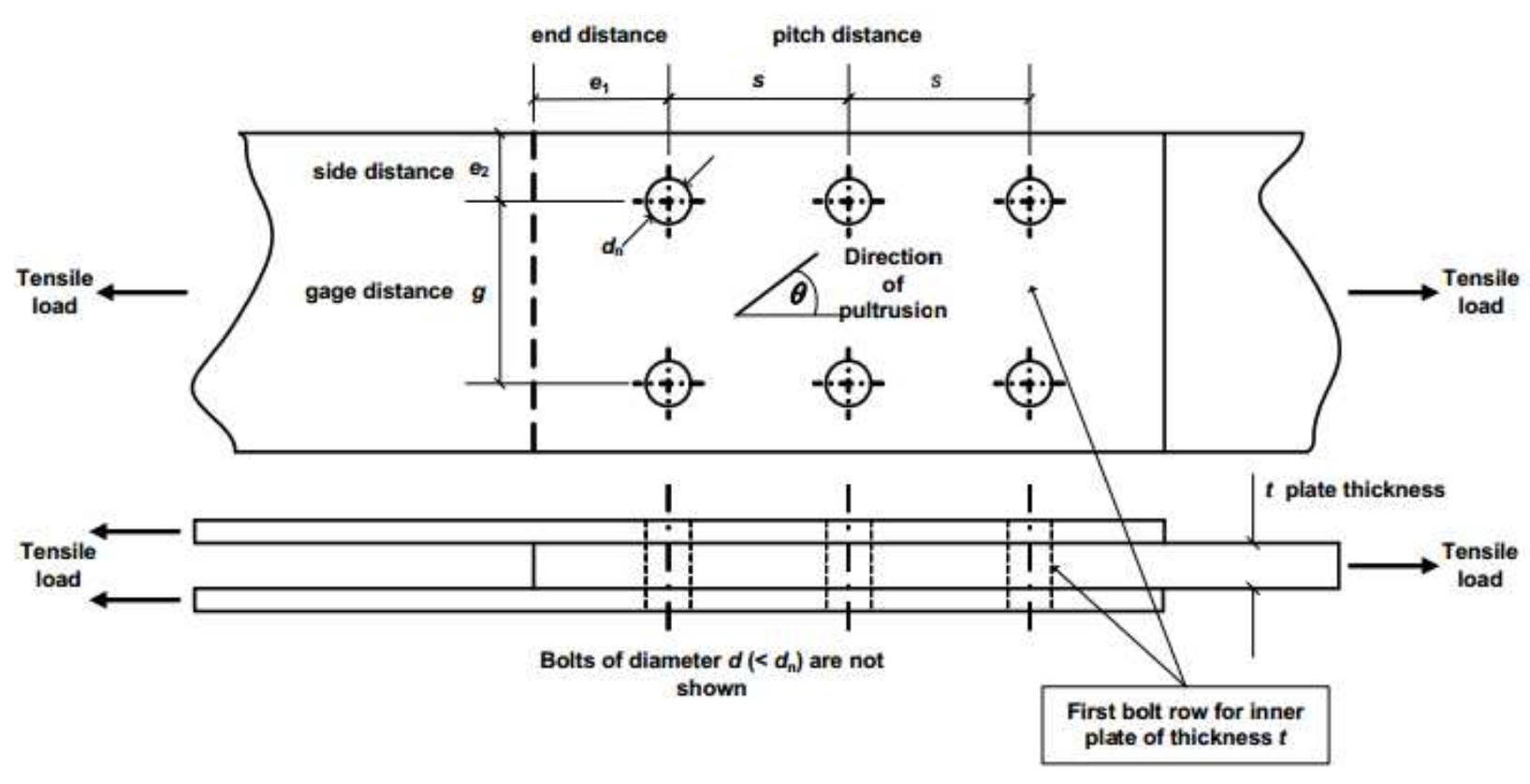

Figure 2-1: Connection Geometry and Definition of Row of Bolts (from Mottram 2009)

Table 2-1: Minimum Requirements for Bolted Connection Geometries (from ASCE/ACMA 2010)

\begin{tabular}{|l|l|c|}
\hline \multirow{2}{*}{ Notation } & \multicolumn{1}{|c|}{ Definition } & $\begin{array}{c}\text { Minimum Required Spacing (or distance } \\
\text { in terms of bolt diameter) }\end{array}$ \\
\hline \multirow{2}{*}{$e_{1, \text { min }}$} & $\begin{array}{c}\text { Single row of bolts } \\
\text { Two or three rows of bolts }\end{array}$ & $\begin{array}{c}\text { Tension load } \\
4 d^{*} \\
2 d\end{array}$ \\
\cline { 2 - 3 } & End distance All connections & $\begin{array}{c}\text { Compression load } \\
2 d\end{array}$ \\
\hline$e_{2, \text { min }}$ & Edge distance & $1.5 d$ \\
\hline$s_{\text {min }}$ & Pitch spacing & $4 d$ \\
\hline$g_{\min }$ & Gage spacing & $2 d$ \\
\hline$g_{\mathrm{s}, \min }$ & Gage spacing with staggered bolts & $2.8 d$ \\
\hline$l_{\mathrm{s}, \text { min }}$ & Stagger distance & $4 d$ \\
\hline
\end{tabular}

$* d$ is the nominal bolt diameter 


\subsubsection{Torque}

Several studies considering the influence of bolt torque on joint performance and strength in FRP structures have been completed. Although over-tightening of bolts may cause surface damage to the material, lateral constraint due to clamping pressure can significantly increase joint strength, even more so than just considering the extra load transfer due to friction (Duthinh 2000, Doyle 1991). Essentially, the bolt acts as a prestressing device assisting the load resistance of the friction between the material and the washer. Higher lateral constraint due to higher clamping pressure reduces the out-of-plane deformation in FRP members (Manalo 2012). Providing the material a specific clamping pressure for a given torque is a challenge though. Manalo performed a study in 2012 to consider the influence of bolt torque on FRP members in both full scale and coupon tests. Washers were not installed with the bolts. The load deflection curves from Manalo's study revealed that since slipping of the connections occurred at the initial loading stage, there was little friction resistance. Manalo observed that the little resistance provided by the joint could be due to the stress relaxation due to creep in the through thickness direction of the material, which relieves some of the clamping pressure provided by the bolt torque (Manalo 2012). Manalo resolved that an applied torque of approximately $14.75 \mathrm{ft}-1 \mathrm{bs}$ was reasonable for bolted connections of full-scale FRP beams. Snug tight, or finger-tight, connections were not considered by Manalo, but were in a previous study by Doyle. In 1991, Doyle completed research on the behavior of bolted and adhesive connections in glass FRP members. Part of this study considered the influence of bolt torque in FRP members with constant edge distances. Hex flange screws and washers were utilized in the experiment to better distribute the clamping force through the material. The finger-tight bolts of Doyle's study failed in cleavage (combination of shear and tension), while the torqued bolts all 
failed in bearing. From this, it was determined that the clamping pressure affects failure modes, allowing for more efficient use of the end distance of the members. Clamping pressure can improve joint strength through three mechanisms within the joint: (1) friction between bolt washers and material, (2) frictional resistance between the materials being connected, and (3) restricting failure modes associated with delamination (Doyle 1991).

\subsubsection{Failure Modes}

To best understand the behavior of a bolted connection in an FRP structure, the failure must be analyzed. Bolted FRP joints share the same basic failure modes with metals; however, the mechanisms by which damage initiates and propagates can be fundamentally different. Therefore, the traditional metal failure criteria are not always appropriate (Duthinh 2000). Figure 2-2 and Figure 2-3 illustrate common failure modes in bolted connections. The actual mode of failure depends on the material, the loading, and the dimensions of the specimen (Prabhakaran et al. 1996).

Most often, for a singly bolted connection, the main failure modes include tension (through-the-thickness), bearing, net tension, and shear-out. Secondary modes, which are a combination of these modes, can occur as well (Pisano et al. 2013). Examples of secondary modes include cleavage and tear-out (the connector pulling through the laminate) (Duthinh 2000). When multi-bolted connections are considered the real failure modes can be more complex for the mutual interaction of the bolts affected by their geometrical distribution (Pisano et al. 2013).

Failure mode can be made to change by varying certain geometric ratios, including $e_{1} / d_{\mathrm{n}}$, and $w / d_{\mathrm{n}}$, with $w=2 e_{2}$, or by varying bolt tightness (Mottram 2009, 2, Doyle, 1991). 

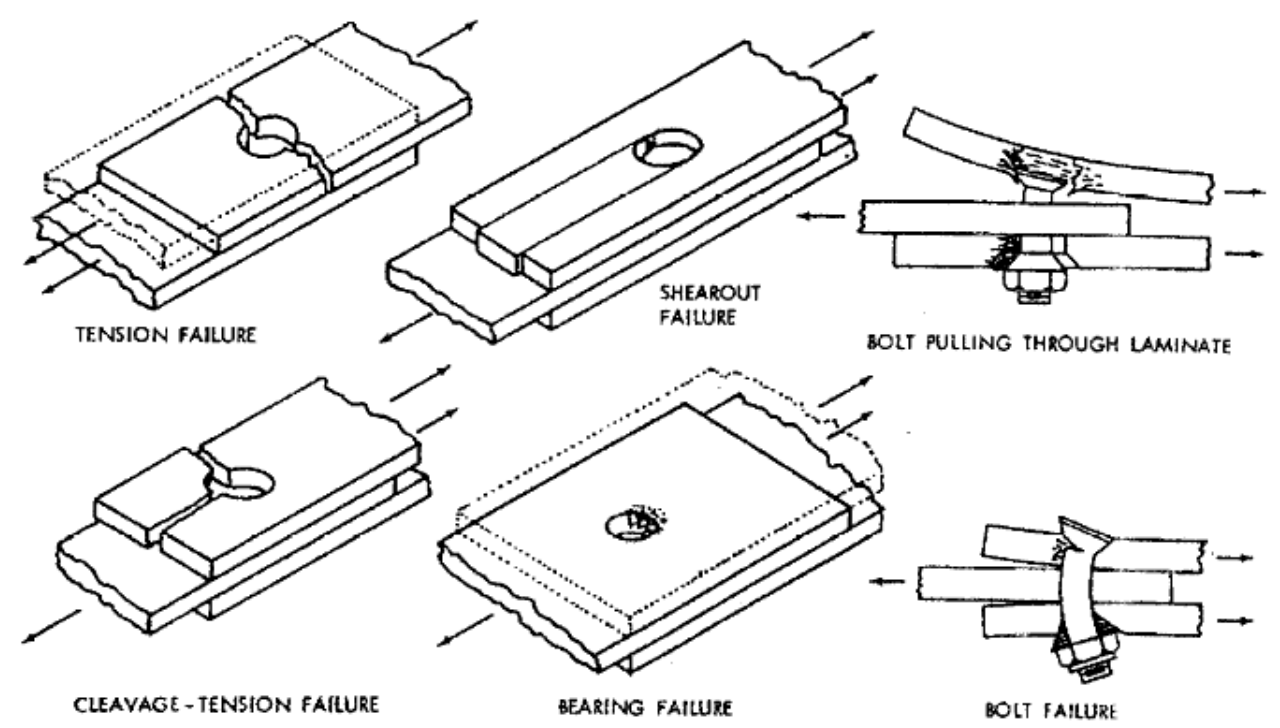

Figure 2-2: Modes of Failure for Bolted Joints in FRP Composites (Duthinh 2000)

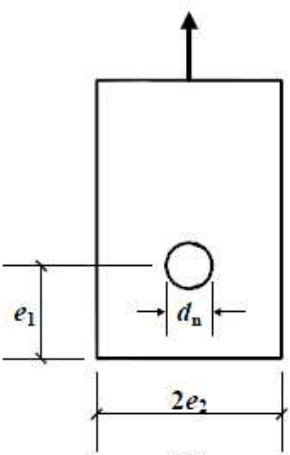

(a)

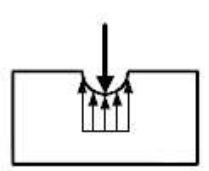

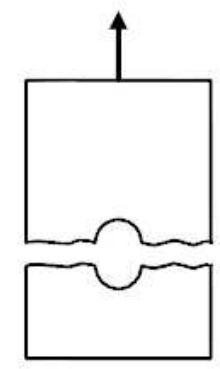

(b)

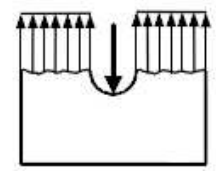

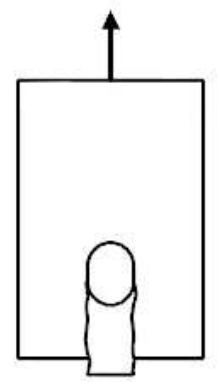

(c)

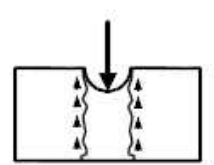

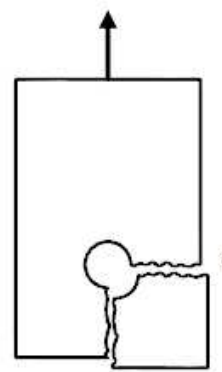

or

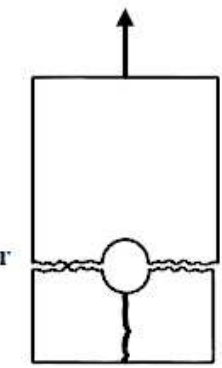

(d)
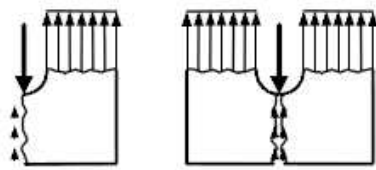

Figure 2-3: Plate-to-plate Distinct Modes of Failure with a Single Steel Bolt; (a) bearing, (b) net tension, (c) shear-out, (d) cleavage (Mottram and Zafari 2011) 


\subsubsection{Tension (through-the-thickness) Strength}

Also known as the pull-through resistance, the through-the-thickness tension failure mode can show as a punching shear mode of failure. The through-the-thickness failure sometimes presents as the splitting and/or separating of a laminated material into layers. This delamination is a form of failure associated with FRP materials and their relatively low through-thickness tensile strength (ASCE / ACMA 2010).

\subsubsection{Bearing Strength}

Characterized by high compressive stresses localized around the bolt, bearing failure, shown in Figure 2-3(a), is a gradual and progressive failure mode of non-catastrophic nature (Pisano et al. 2013). Bearing strength represents the strength of the FRP material upon which the smooth shank of the bolt bears, when there is no lateral restraint afforded by tightening of the bolting. This strength will be lower if bolt thread is involved in transferring the bearing force. Regardless of the type of bolt that will change the fastener strength, the same FRP material bearing strengths apply (ASCE / ACMA 2010). The bearing failure mode of FRP depends on the following main factors:

1. Joint geometry: bolt diameter $\left(d_{n}\right)$, plate width $(w)$, end distance $\left(e_{1}\right)$, and thickness of the composite laminates $(t)$;

2. Matrix type and fiber nature;

3. Fiber inclination angle;

4. Stacking sequence of the laminates (Ascione et al. 2010).

If the specimen boundaries are sufficiently far from the bolt hole, the failure will initiate as bearing. (Prabhakaran et al. 1996). 


\subsection{Pre-Standard for LRFD Pin-Bearing Failure Load}

Chapter 8 of the Pre-Standard for LRFD of pultruded FRP pertains to the design of bolted bearing-type connections between, and to, pultruded FRP members and other FRP and metallic components. The nominal pin-bearing strength is determined according to Section 8.3.2.3.

In the pre-standard for LRFD for pultruded FRP composites, the pin-bearing strength, $R_{\mathrm{br}}$, is given by the projected area of bolt bearing multiplied by the characteristic pin-bearing strength, $F_{\theta}^{b r}$, for the orientation, $\theta$, of the resultant force at the bolt-FRP contact with respect to the direction of pultrusion. The formula per bolt is given as

$$
\begin{aligned}
& R_{b r}=t d F_{\theta}^{b r} \\
& \emptyset_{c}=0.8
\end{aligned}
$$

where

$\mathrm{t}=$ Thickness of the FRP component and/or member

$\mathrm{d} \quad=$ Nominal diameter of bolt

$F_{\theta}^{b r} \quad=$ Characteristic pin-bearing strength for the orientation of the resultant force at the bolt/FRP contact with respect to the direction of pultrusion, given by Equation

$\emptyset_{c} \quad=$ Resistance factor for FRP connections

$$
\begin{aligned}
F_{\theta}^{b r} & =F_{L}^{b r} \text { when } \theta \text { is } \leq 5^{\circ} \\
& =F_{T}^{b r} \text { when } 5^{\circ}<\theta \leq 90^{\circ}
\end{aligned}
$$

Equation 2-2

where

$\theta \quad=$ Angle of loading, between the direction of the connection force and the direction of pultrusion 
$F_{L}^{b r} \quad=$ Characteristic pin-bearing strength in the longitudinal direction of FRP

$F_{T}^{b r} \quad=$ Characteristic pin-bearing strength in the transverse direction of FRP

Characteristic pin-bearing strength data should be acquired in accordance with ASTM D953.

\subsection{Ascione, Feo, and Maceri Pin-Bearing Failure Load}

Ascione, Feo, and Maceri (2010), in an experimental study, developed a formula for the prediction of the pin-bearing ultimate load of symmetrical GFRP laminates. The formula is based on the idea that the pin-bearing failure load for any fiber inclination angle, $\alpha$, can be determined by means of only three test values, for a given diameter and a given type of laminate. The proposed generalization takes into account the hole and bolt diameters as well as their influence on the failure load. As a result, the pin-bearing failure load $F_{u}{ }^{(\alpha)}$ can be expressed as follows:

$$
F_{u}^{(\alpha)}=\xi F_{u}^{0}\left[\left(1-\frac{F_{u}^{(\pi / 2 m)}}{F_{u}^{0}}\right)\left(A_{\alpha}\right)^{5}+\frac{F_{u}^{(\pi / 2 m)}}{F_{u}^{0}}+C(m \alpha)^{3}\left(A_{\alpha}\right)^{3}\right]
$$

where

$$
\begin{aligned}
& \xi=1+1.3\left(\frac{t_{\text {tot.plies }}}{t_{\text {plies }}^{0}}\right)\left(\frac{d_{b}-\left(d_{h}-1\right)}{\left(d_{h}-1\right)}\right)=\text { reduction factor } \\
& A_{\alpha}=\frac{\pi / 2-(m \alpha)}{\pi / 2} \\
& C=\left(\frac{\pi}{8}\right)^{-3}\left[\frac{F_{u}^{(\pi / 4 m)}}{F_{u}^{0}}-\left(1-\frac{F_{u}^{(\pi / 2 m)}}{F_{u}^{0}}\right)\left(\frac{1}{2}\right)^{5}-\frac{F_{u}^{(\pi / 2 m)}}{F_{u}^{0}}\right]
\end{aligned}
$$


$\alpha \quad=$ fiber inclination angle between the direction of the external applied force and the $0^{\circ}$ direction

$t_{\text {tot.plies }}=$ total laminate thickness

$t_{\text {plies }}^{0}=$ thickness of plies in $0^{\circ}$ direction

$d_{b} \quad=$ diameter of bolt

$d_{h} \quad=$ diameter of hole

$F_{u}^{0} \quad=$ experimental bearing failure load for $\alpha$ equal to $0^{\circ}$

$F_{u}^{(\pi / 2 m)}=$ experimental bearing failure load for $\alpha$ equal to $\pi / 2 m$

$F_{u}^{(\pi / 4 m)}=$ experimental bearing failure load for $\alpha$ equal to $\pi / 4 m$

$m \quad=$ replicability module $=1$ for unidirectional laminates or $=2$ for bidirectional (cross-ply) laminates

Based on this experimental procedure and analysis, the pin-bearing failure load can be interpreted, in the case of unidirectional laminates, as the product of the projected areas of the bearing bolt $\left(t \mathrm{x} d_{b}\right)$ and a material constant, e.g. the material's pin-bearing strength. For general type laminates, this product form is meaningless because in this case the "material's pin-bearing strength" depends on the fiber volume fraction in strengthening directions, that is on the laminate's structure (Ascione et al. 2010).

\subsubsection{Net Tension Strength}

If the specimen width is too small, net tension failure occurs (Prabhakaran et al. 1996). Net tension, commonly due to excessive tensile stresses, is catastrophic and dangerous for bolt 
performance (Pisano et al. 2013). In a net tension failure, the force resisted by a bearing-type connection creates a direct stress distribution across the effective width of the connection component or member. When this force acts toward the end there is a stress distribution across the net-section, as shown in Figure 2-3(b). The tensile stress in not constant and has its highest value at the perimeter of the hole (ASCE / ACMA 2010).

\subsubsection{Shear-out Strength}

Shear-out failure depends on the value of the specified in-plane shear strength (ASCE / ACMA 2010). When an excessive shear stress value is attained on the areas emanating from the bolt hole edges parallel to the loading direction, shear-out failure typically presents (Pisano et al. 2013), as shown in Figure 2-3(c). Shear-out failure can occur when either the end distance ratio $e_{1} / d$ is much lower than the minimum requirement, or when there is a relatively high proportion of unidirectional roving reinforcement in the direction of the connection force (ASCE / ACMA 2010). As with net tension, this failure can be catastrophic and dangerous for bolt performance (Pisano et al. 2013).

\subsubsection{Cleavage Strength}

As a secondary failure mode, cleavage occurs only after bearing failure, and normally when the joint has attained its endurance strength (Pisano et al. 2013). If the specimen dimensions are favorable, cleavage failure will present along a path involving tension on one plane and shear on a perpendicular plane (Prabhakaran et al. 1996, Doyle 1991). As shown in Figure 2-3(d), there are two possible mechanisms that have been observed for a cleavage failure. The left-sided mode is less likely to occur in a single bolted connection with the hole centrally placed; however, 
it is more likely to occur when there is a row of two or three bolts and the edge distance $e_{2}$ is less than the gage spacing $g$.

\subsection{Flexure Members in FRP Structures}

The production of FRP structural profiles of I-sections, channels, angles, box and tubular sections for use as load-carrying members in structures has been increasing in recent years. Therefore, efforts for the development of a practical code for the design and construction using these FRP structural shapes have also been increasing in recent years (Zureick 1998). The limited published studies address a number of limit states related to deflection serviceability and strength of members subjected to axial or transverse loading (Zureick 1998); however, these studies pertain particularly to I-sections and box sections. For singly symmetric sections, such as channels and angles, little experimental data is available (ASCE / ACMA 2010). However, recent studies on FRP beam responses under axial, bending, and torsion have provided further insights into the behavior of FRP structures under a wide range of load conditions.

\subsubsection{Bolted Connections between Flexure Members}

As discussed previously, Manalo conducted research on bolted connections in FRP members. The experiment considered both coupon and full scale (approximately 12 foot) beams with variances in the connections. Manalo found that with the continuous application of load, the beams showed a slight, but steady decrease in stiffness. This was attributed to the slipping of the bolts and the gap provided between the beam end faces, which allowed the specimen to rotate (Manalo 2012). After the load was released, Manalo observed that the beam deflected to a greater degree than expected and that there were no signs of failure in the bolts or in the 
composite around the hole. The failure occurred at the compression flange of the beam, not in the bolted joints.

\subsubsection{Failure Modes}

FRP members subjected to bending about one principal axis including doubly symmetric sections and singly symmetric sections can show material rupture, local instability, or lateraltorsional buckling failure modes. These failure modes are described in the following sections.

Bending effects are amplified by minor eccentricities credited to initial imperfections and manufacturing defects, such as miss alignment of fibers, crookedness, or miss alignment of the beam during test set-up (Blandford 2010).

\subsubsection{Material Rupture}

At low loads, beams plastically bend and stretch without rupture. At a critical load, the stretching of the material is followed by rupture (either tensile or shear) (McShane et al. 2008). Non-homogeneous sections have different strength properties in their web(s) and flange(s), and although the strains are assumed to be linearly varying through the cross-section, the stresses may be discontinuous at the flange-web intersections. Therefore, locations with the highest stresses in the web(s) and flange(s), as well as the extreme fiber of the flange, and the extreme fiber of the web need to be checked for rupture due to flexure (ASCE / ACMA 2010). Rupture appears as the tearing and separating of the fibers in the member and can be gradual or sudden.

\subsubsection{Local Instability}

Often recognized as the buckling of a compression element which could induce failure of the whole structure, local instability occurs when individual elements of a section buckle in-plane due to compressive stresses (ASCE / ACMA 2010, Blandford 2010). The failure mode in which 
the flange in compression buckles in flexure has been observed experimentally by several researchers. Under an axial load, a beam acts in pure compression; therefore, bending effects are typically not anticipated in local buckling (Blandford 2010).

\subsubsection{Lateral-Torsional Buckling}

The behavior of pultruded FRP open sections, such as channels, is often influenced by large local deformations due to a high strength-to-stiffness ratio, making these sections highly susceptible to global buckling failures, including lateral-torsional buckling (LTB). LTB is a type of geometric instability which develops in the compression zone of a transversely loaded beam (Estep 2014). The failure will occur when the section is not sufficiently braced against lateral displacement and rotation of the cross-section (ASCE / ACMA 2010). The common type of LTB failure observed in engineering applications is characterized by a gradual twisting and deformation as the applied load increases, making it difficult to pinpoint an exact critical buckling load (Estep 2014). When applying axial load to samples in an experimental setting, global buckling effects be identified in load versus deflection plots when the test sample experiences an increase in deflection without a substantial increase in applied loading (Blandford 2010).

In a study of lateral-torsional buckling of pultruded I-sections performed by Barbero and Raftoyiannis in 1994, it was revealed that due to low stiffness in the transverse direction, pultruded open sections of certain dimensions are susceptible to a failure known as distortional buckling, which is a coupling of local buckling and lateral-torsional buckling. Distortional buckling failure can drastically reduce the overall buckling capacity of a member (Estep 2014).

Further research into lateral-torsional buckling of FRP members and FRP structures is continually being pursued, including research that is currently ongoing at the West Virginia University Constructed Facilities Center. 


\subsection{FRP Structural Shapes in Cooling Tower Structures}

FRP pultuded shapes, both standard and custom, are now found in the design and construction of bridge and building structures, as well as in non-building structural markets, such as transmission towers, light poles and highway guardrails, after a significant increase in the use of pultruded structural shapes for general construction in the 1990s (Bakis et al. 2002). Additionally, because FRP composites exhibit resistance to chemical environments and to degradation from wet conditions, and offer low maintenance requirements, the material was and continues to be a popular choice in a number of tank and pipe applications (Gilby 1999). In an effort to increase the industry, pultruded FRP structural shapes were used in industrial cooling tower structures. For cooling tower structures, there is a customized building system of pultruded components that was developed between the 1980s and 1990s (Bakis et al. 2002).

Cooling towers are large heat exchangers used primarily by power generation plants and manufacturing facilities to cool water (Howard and Belinky 1999). The industrial processes associated with cooling tower operation introduce the construction materials utilized in the construction to a variety of conditions, including chemical and biological attack and a harsh environment (Howard and Belinky 1999). Although, cooling towers were originally constructed from wood (Redwood and Douglas Fir), steel and/or concrete, pultruded FRP structural shapes have become more prominent due to the many advantages they offer compared to the existing materials. Currently, cooling towers are constructed from either standard pultruded shapes (angles, tubes, channels and I-sections) (called "stick built") or customized components (called "modular"), both produced by a variety of manufacturers (Bakis et al. 2002). In the absence of an American National Standards Institute approved design guide for pultruded structures, 
designers generally rely on engineering judgment, fundamental mechanics principles, experience, and manufacturer-produced "design guides" (Bakis et al. 2002).

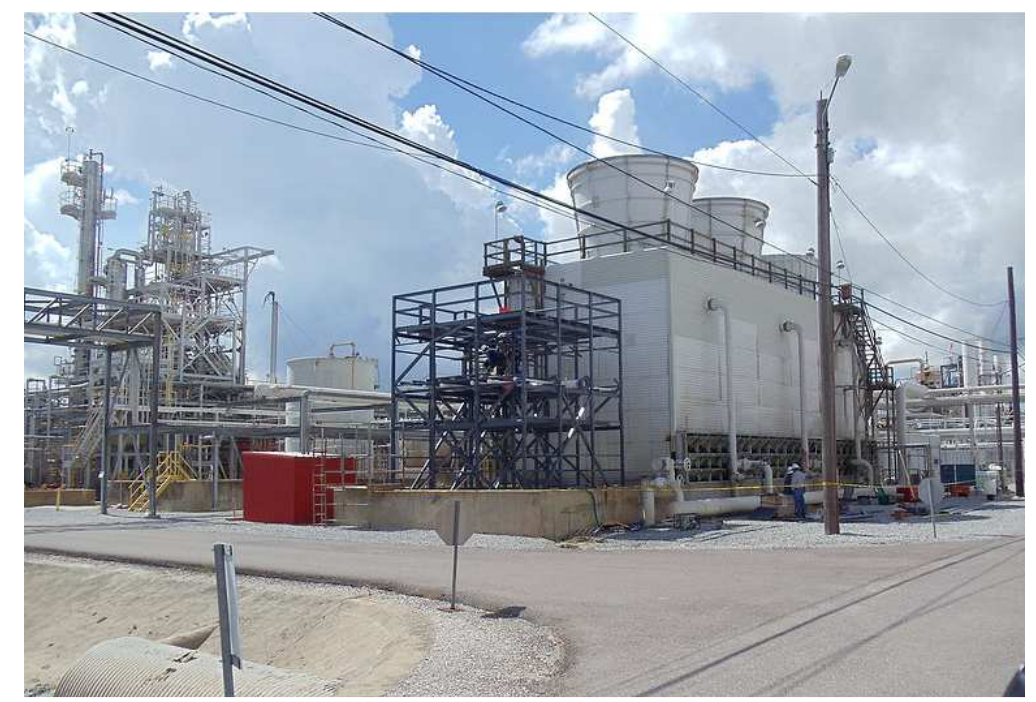

Figure 2-4: FRP Cooling Tower (from Cooling Towers of Texas)

Wooden structures are threatened by biological decay, chemical decay, and fire, while corrosion and chemical decay are threats to concrete and steel structures (Howard and Belinky 1999). FRP composites are designed against biological and chemical decay and corrosion, and to retard the spread of fire making them a superior option for use as structural elements in cooling tower construction. Overall, FRP structures are also lighter than wood, steel and concrete. Weight of the overall structure is a critical issue for cooling towers since lighter structures require a less extensive basin foundation, which keeps overall construction costs down (Howard and Belinky 1999). Additionally, FRP parts are virtually maintenance free compared to wood, steel or concrete parts in cooling tower applications as they only require a visual inspection for damage once a year (Howard and Belinky 1999).

According to Howard and Belinky, in 1999, the shapes used in cooling tower structures are composed of three different types of glass materials: 
(1) a roving, aligned with the longitudinal direction of the parts to provide the highest strength and stiffness possible,

(2) a continuous strand E-glass mat to add bulk to the part, and to aid in load transfer between the longitudinal and off-axis directions, and

(3) a polyester veil that provides the part with a smooth resin-rich surface which aids construction crews in handling and protects the parts against UV degradation and chemical attack.

The structural design of a FRP industrial cooling tower can be a concentrically braced frame design, a shear wall design, or a moment resistant frame design (Howard and Belinky 1999).

Lateral loads imposed on a structure can be broken down into two primary categories: wind loads and earthquake loads. In concentrically braced frames, lateral loads are first transferred through the tie lines (horizontal members), then to the diagonal members and finally, from the diagonal members, down to the basin floor. The diagonal members are typically designed to resist either tension or compression axial loads depending on the direction of the applied load (Howard and Belinky 1999). Figure 2-5 shows example images of existing cooling towers constructed of FRP composites.
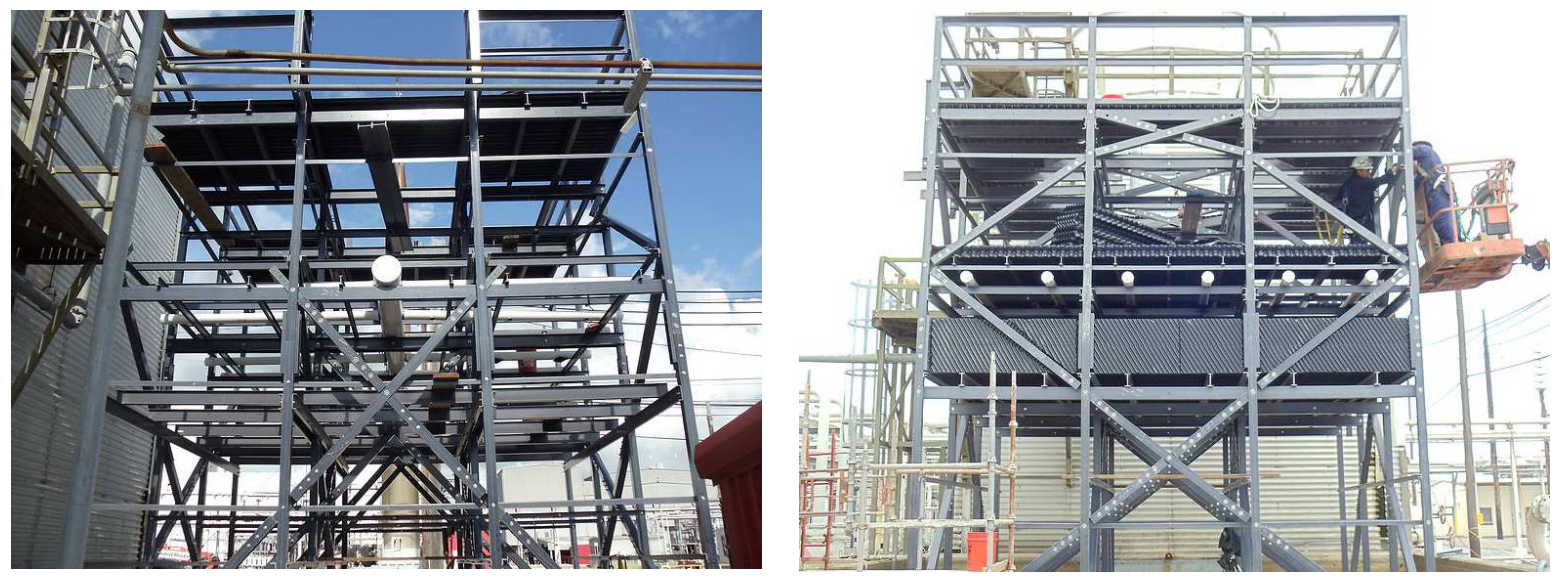

Figure 2-5: FRP Cooling Tower Structure (from Cooling Towers of Texas) 
In the study that follows, one example of construction of a cooling tower bay is considered. The constructed bay consists of two simulated ties (FRP channels) and two simulated columns (FRP box sections). In a previous study performed by the West Virginia University Constructed Facilities Center (WVU-CFC) at the request of American Electric Power (AEP), it was found that the corners of the FRP columns introduce a point of weakness. That study has not been released to the public. 


\section{CHAPTER 3 TYPICAL TIE-LINE TESTING}

\subsection{Introduction and Scope}

Many failures in FRP cooling towers occur at joints and connections. Since there are no accurate predictions for load transfer at joints or serviceability limits of joints, Cooling Towers of Texas (CTofTX) developed a plan for standardization of connections in cooling tower structures. CTofTX provided the West Virginia University Constructed Facilities Center (WVUCFC) the opportunity to carry out a testing program to permit a better understanding of the behavior of these standard bolted connections, as well as that of the various tie lines used in cooing tower construction.

Tie lines are typically composed of redwood lumber or Fiber Reinforced Polymer (FRP) structural C-channels oriented horizontally in a cooling tower to provide lateral support to the columns. The study described herein focused on FRP tie lines. The varying FRP samples tested represent different options in terms of section size, length and connection details for cooling tower structural tie designs.

The tie lines are the primary load carrying members under wind loads, resulting in axial loads imparted onto the tie lines. Thus, the primary focus of this study was to determine the axial load capacity of the tie lines themselves and the ultimate load capacity of the connections between the tie lines and columns. In order to simulate the behavior under horizontal loads, samples of Fiber Reinforced Polymer (FRP) structural shapes were assembled to replicate one bay of a typical cooling tower design. An axial load was applied squarely on the ends of the ties as lateral loading, similar to that a cooling tower experiences from wind. To simplify the testing 
program, the samples were oriented vertically for testing with 1-foot column stubs installed. A total of 97 of these full tie line load tests were completed.

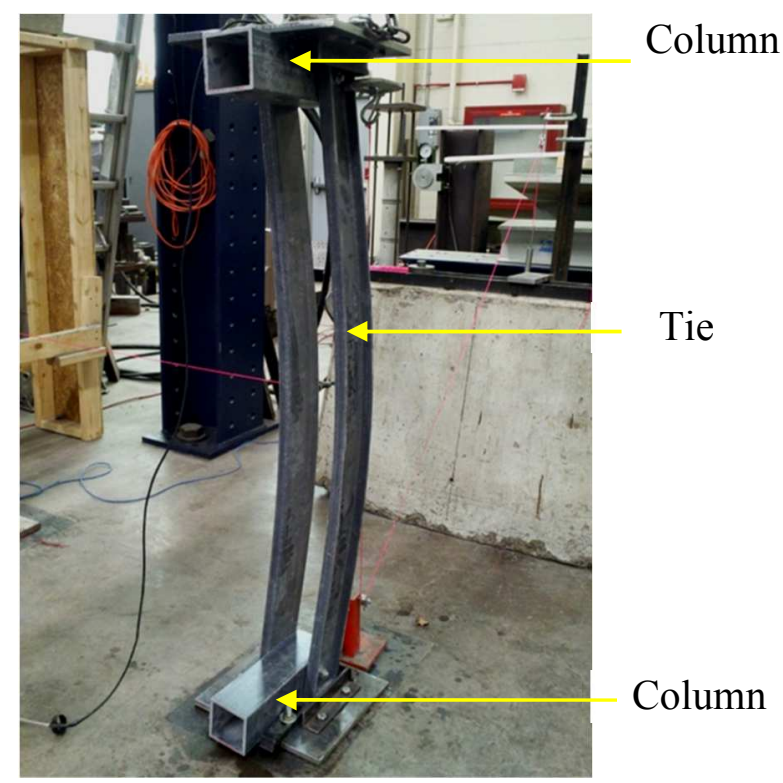

Figure 3-1: Labeled FRP Full Tie Line

In addition to the full tie line load testing, tests were performed on column-to-tie line connections used in cooling towers to better understand the performance of these connections. These connections utilize different bushing options between the tie lines and columns. The bushings enable a higher load transfer by spreading the tear-out stresses associated with a bolted connection over a greater area. A total of 24 column-to-tie line connection tests were performed.

\subsection{Sample Descriptions}

Each sample consisted of two simulated ties and two simulated columns. One of five different size FRP channels simulated the ties, while 3-1/2" FRP square tubes simulated the columns.

Samples were four, six or eight feet in length. A single 3-1/2" square tube compression block was installed at the center of all eight feet FRP samples. Additionally, a compression 
block was installed at the center of four six foot samples as well (FRP 3.5x1.5-6 Bush-Col 3, FRP 4x1.25-6 Bush-Col 3, FRP 4x1.375-6 No 1, and FRP 5.5x1.5-6 Bush-Col 3). The name of these four samples include " $\mathrm{w} / \mathrm{cb}$ ", meaning with compression block, at the end of the sample label. No other samples incorporated compression blocks. Sample diagrams can be found in APPENDIX B - Diagrams of Sample Construction.

The connection between the columns and ties varied in several designs. There are three variations to the column-to-tie connections for the FRP samples:

(1) No bushing, only stainless steel hardware (No)

(2) Plastic bushing installed in FRP column only with stainless steel hardware (Bush-Col)

(3) Plastic bushing installed in both FRP column and tie with stainless steel hardware (Bush-Both)

For these variations, indicated in the parenthesis is the abbreviation used to indicate the columnto-tie line connection in the sample name. Connections either consisted of one or two 3/8-inch diameter bolts with the nuts installed finger-tight. These bolts, shown in Figure 3-2, were made of grade 304 stainless steel (marked "F593C THE"). The number of bolts per sample was based on the simulated tie size as follows: (1) 3/8-inch bolt was used for FRP 3.5-inch by 1.5 -inch, 4inch by 1.25-inch, and 4-inch by 1.375-inch channels, while (2) 3/8-inch bolts were used for FRP 5.5-inch by 1.5 -inch and 6-inch by 1.625 -inch channels. The hard plastic bushings, shown in Figure 3-2, were fit snug-tight into the hole with an outer diameter of 1 inch and an inner diameter of $1 / 2$ inch. 


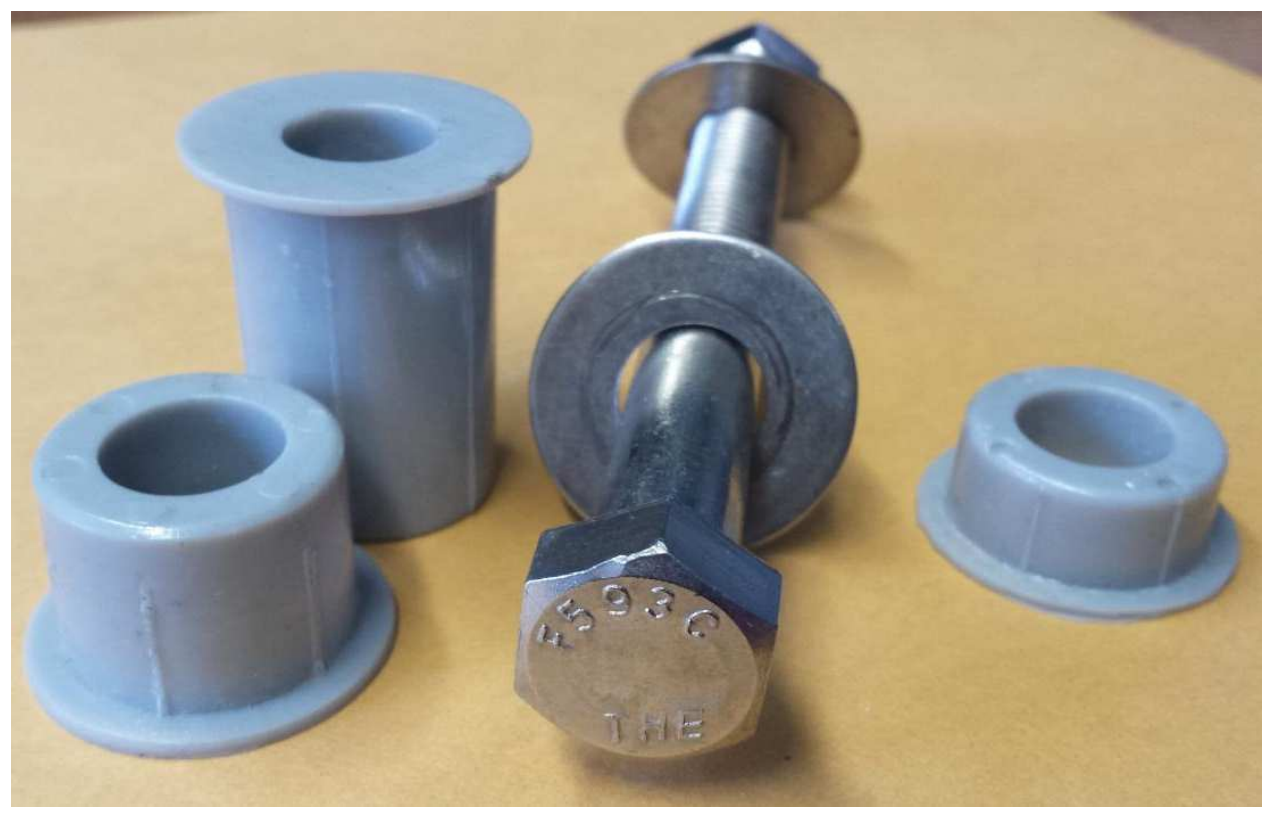

Figure 3-2: Connection Hardware - Stainless Steel Bolts and Hard Plastic Bushings

FRP $\left\{\begin{array}{c}3.5 " x 1.5 " \\ 4 " x 1.25 " \\ 4 " x 1.375 " \\ 5.5 " x 1.5 " \\ 6 " x 1.625 "\end{array}\right\}\left\{\begin{array}{l}4, \\ 6, \\ 8, \\ 6, \\ 8,\end{array}\right\}\left\{\begin{array}{l}\text { No bushing } \\ \text { Bushing in FRP column only } \\ \text { Bushing in both FRP column and tie }\end{array}\right.$

Figure 3-3: FRP Tie Line Variations: tie size, sample length, column-to-tie connections

Figure 3-3 illustrates the different combinations of material, tie size, length and columnto-tie connection possible for the samples.

The names of the samples include a description of the sample material, the size of the tie, the length of the samples and a description of the column/tie connection, e.g. "Sample Material. Tie Size - Sample Length. Column-to-Tie Connection”.

In order to test the strength of the different connection designs, twelve full tie line samples were cut down to approximately one foot samples to eliminate buckling failure in the ties. Each of the full samples provided two short samples for connection testing. A square tube was clamped to the free end of the sample to ensure the cut ties remained static. 


\subsection{Test Procedure and Instrumentation}

The following sections describe the procedures used to test each sample type. Also included are the instrumentation utilized in these test procedures.

\subsubsection{Full Tie Line Samples}

Each sample was placed in the testing apparatus such that loading was applied squarely and evenly on both ties of the sample. The square tube columns were constrained to remain static. Load was applied by a hand-operated hydraulic ram (Model R6010, 60 tons capacity for 6 foot and 8 foot samples; Model R315, 30 tons capacity for 4 foot samples) until the point of yield and then ultimate failure. The load was measured using an Omega LC8400 load cell (25 kips capacity). Two linear variable differential transformers (LVDTs) (RDP: HDCDCTH2000, range $+/-2$ inches) were used to measure deflections in the tie line. In the middle of the ties, halfway between the columns, an LVDT was positioned to measure the transverse deflection. The LVDT to measure transverse deflection was attached to only one; therefore, the results of these tests only provide the deflection of that one tie. For analysis purposes, it was assumed the deflection of the individual ties was equivalent. The second LVDT was setup at the end of the tie, near the column, to measure the axial deflection. Figure 3-4 and Figure 3-5 illustrate this test set up. 


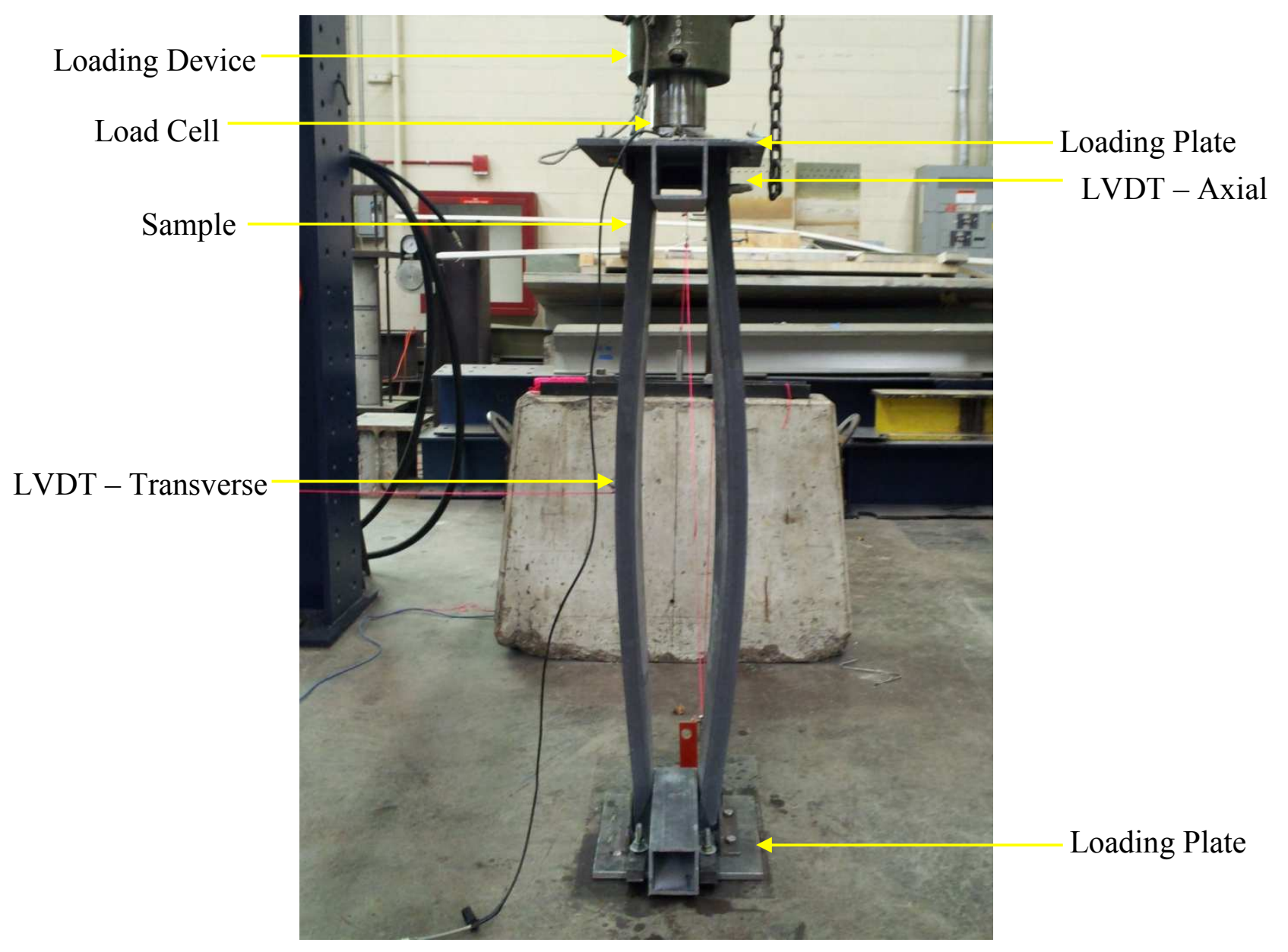

Figure 3-4: Full Tie Line Test Setup

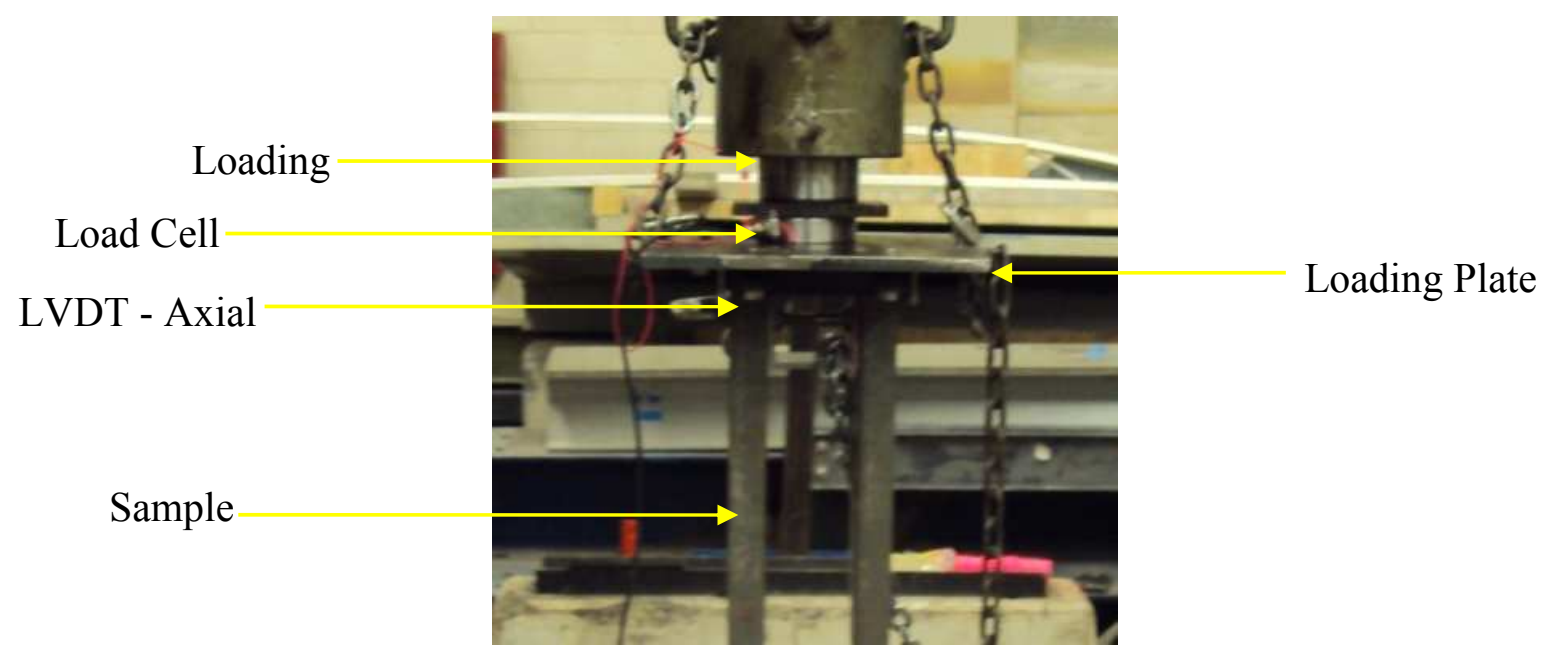

Figure 3-5: Full Tie Line Test Setup Close-up 
The load was applied across the ties and column. To ensure consistent loading, the ties were cut evenly with the column, creating a level surface for the loading apparatus.

\subsubsection{Column-to-Tie Line Connection Samples}

All the column-to-tie connection tests were performed using the Instron 1000 HDX (approximately 225 kips capacity). Each sample was placed in the Instron such that loading was applied squarely and evenly to the column. As shown in Figure 3-6, a steel plate, 3-1/2" wide by $1 / 2$ " thick, was placed between the simulated column and the loading device to ensure the load was being applied on the connection, i.e. the load in the plate only transferred to column, then through the bolted connection where resistance was only provided by the tie lines. Load was applied at a rate of approximately $4000 \mathrm{lbs}$ per minute until the point of yield and then ultimate failure.

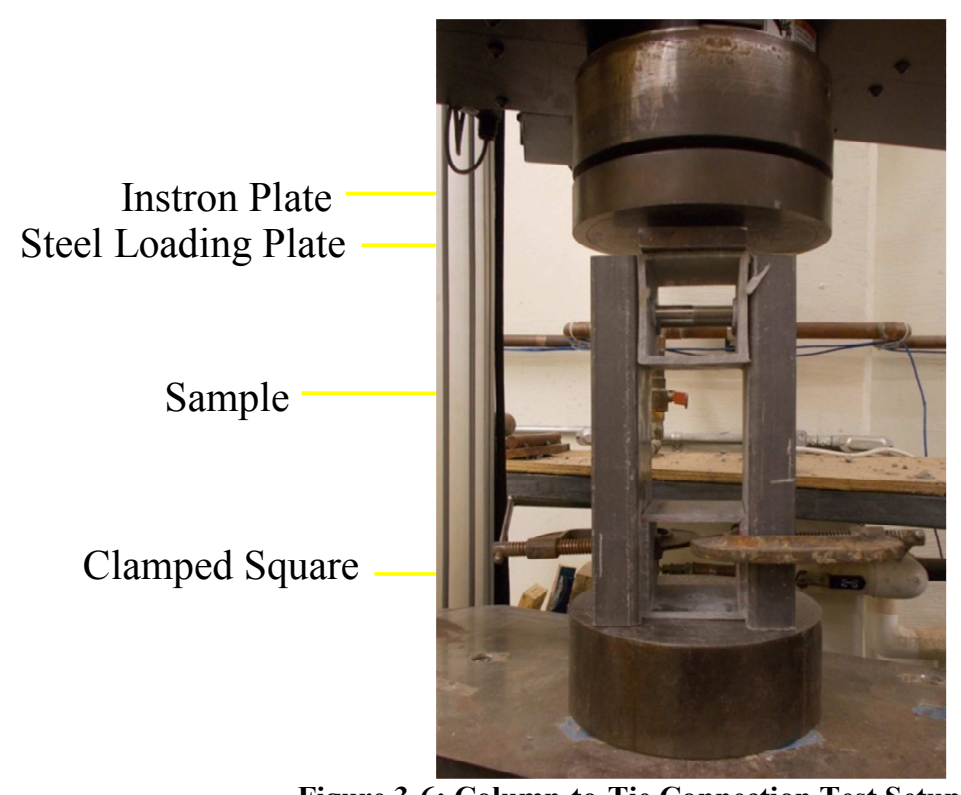


With this Instron setup, the axial deformation throughout the test is determined by the position of the Instron plate. Therefore, for the column-to-tie connection samples, the position given in the results includes the fixture movement in addition to the sample deformation.

\subsection{Experimental Results}

For each sample, the test data were plotted as load versus position (both axial and transverse deflection, for full samples). Analyses of these plots, focused on the loading portion of the test, revealed the yield load and the ultimate load of each sample. For the full tie line samples, the yield load is more accurately the buckling load. This yield, or buckling, load was determined first by examining each plot with the best engineering judgment and then verified by two additional engineers. The buckling load is marked on the plots with an "X". For some samples, the buckling load may be listed the same as the ultimate load, due to these particular samples not presenting with a clear yield or buckling load. The ultimate load is the maximum load measured for a given sample regardless of sample failure. In some cases, the ultimate load was also the breaking load of the sample, but in most cases, the ultimate load refers to the point at which increasing the stroke of the ram resulted in large deflection increases with minimal or no increases in load. To differentiate between these two results, if the ultimate load corresponded to the fracture of the sample, it was recorded as such. The ultimate load is marked with an "O" on the plots.

It is important to note that in the graphical results, the sign of the deflection is not significant. A negative deflection simply indicates that the sample bent or buckled in the direction opposite the rest of the other samples shown, i.e. one sample deflected to the right (positive deflection) and one sample deflected to the left (negative deflection). 
The presentation of the results in the tables following are grouped first by the connection type (No Bush, Bush-Column, or Bush-Both), then by the width \& depth of the tie (3.5x1.5, $4 \times 1.25$, etc.) and finally by the length of the sample $(4,6$, or 8 foot). Results, including yield/buckling load, ultimate load, and failure mode, are listed in a table for each connection type followed by a typical plot of the load versus the transverse deflection for a full tie-line sample and a typical plot of the load versus the position for a column-to-tie connection sample. The load versus the transverse deflection plots were found to more clearly show the buckling load of the full tie-line samples. As stated previously, with the Instron setup for the column-to-tie connection tests, "position" is the position of the Instron plate. Therefore, for these samples, the position given in the results includes the fixture movement in addition to the sample deformation. Plots for all test samples are included in APPENDIX A - Load vs Deflection Plots, organized by tie size and sample length. Also included with the plots are additional tables of results with more detailed descriptions of each failure. A selection of photographs follows the tables and graphs to illustrate the different failure modes, with additional photographs in APPENDIX C - Photographs (Samples Under Loading).

\subsubsection{No Bushing Connection Results}

A total of 36 samples with no bushing in the connection were tested (30 full tie line load tests and 6 column-to-tie connection tests). On average, the load (both buckling and ultimate) carried by the sample increased as the tie length shortened, meaning the 4-foot samples carried higher loads throughout the test. The results of the column-to-tie connection tests indicate that the connection, typically, carries a load similar to that of the 6-foot samples. Compared to the 8foot samples, the connection is stronger than the full tie line, as the connection tests yielded and failed at a higher load. 
The common failure mode of these samples was local instability. As load was applied, the channels would bow, either apart from one another or both in the same direction. For some samples, the bowing led to material rupture in the channel at the point of curvature, while in other samples, the bowing was accompanied by twisting in the channels. 
Table 3-1: Results for No Bushing Connections, Full Tie Line and Column-to-Tie Connection Tests

\begin{tabular}{|c|c|c|c|c|}
\hline & Sample & $\begin{array}{l}\text { Buckling } \\
\text { Load (Ib) }\end{array}$ & $\begin{array}{l}\text { Ultimate } \\
\text { Load (Ib) }\end{array}$ & Failure Mode \\
\hline \multirow{9}{*}{ 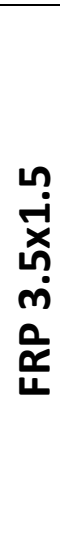 } & FRP.3.5x1.5-4.No 1 & 11614 & $15471^{*}$ & Distortional Buckling \\
\hline & FRP.3.5x1.5-4.No 2 & 18533 & 19647 & $\begin{array}{l}\text { Distortional Buckling/Material } \\
\text { Rupture }\end{array}$ \\
\hline & Full 4-foot Sample Average = & 15073 & 17559 & \\
\hline & FRP.3.5x1.5-6.No 1 & 6787 & $9490 *$ & Distortional Buckling \\
\hline & FRP.3.5x1.5-6.No 2 & 6171 & $8972 *$ & Distortional Buckling \\
\hline & Full 6-foot Sample Average = & 6479 & 9231 & \\
\hline & FRP.3.5x1.5-8.No 1 & 3086 & $4340 *$ & Lateral-Torsional Buckling \\
\hline & FRP.3.5x1.5-8.No 2 & 3105 & 3206 & $\begin{array}{l}\text { Distortional Buckling/Material } \\
\text { Rupture }\end{array}$ \\
\hline & Full 8-foot Sample Average = & 3096 & 3773 & \\
\hline \multirow{11}{*}{ 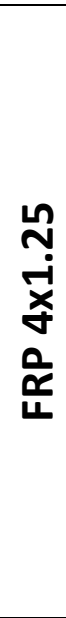 } & FRP.4x1.25-4.No 1 & 11462 & 13367 & $\begin{array}{l}\text { Local Instability/Material } \\
\text { Rupture }\end{array}$ \\
\hline & FRP.4x1.25-4.No 2 & 8072 & $11123^{*}$ & Local Instability \\
\hline & FRP.4x1.25-4.No Bush 1 & 9750 & $11047^{*}$ & Local Instability \\
\hline & Full 4-foot Sample Average = & 9761 & 11845 & \\
\hline & FRP.4x1.25-6.No 1 & 3880 & $4239 *$ & Local Instability \\
\hline & FRP.4x1.25-6.No 2 & 4153 & $4691 *$ & Distortional Buckling \\
\hline & FRP.4x1.25-6.No 3 & 3822 & $5595^{*}$ & Local Instability \\
\hline & Full 6-foot Sample Average = & 3952 & 4841 & \\
\hline & FRP.4x1.25-8.No 1 & 1032 & $3931 *$ & Local Instability \\
\hline & FRP. $4 \times 1.25-8$. No 2 Test 2 & 4021 & $4854^{*}$ & Local Instability \\
\hline & Full 8-foot Sample Average = & 2527 & 4393 & \\
\hline \multirow{12}{*}{ 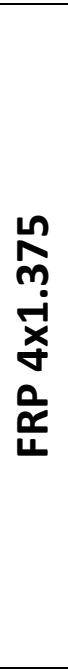 } & FRP.4x1.375-4.No 1 & 14204 & $16133^{*}$ & Local Instability \\
\hline & FRP.4x1.375-4.No 2 & 9428 & 12369 & $\begin{array}{l}\text { Local Instability/Material } \\
\text { Rupture }\end{array}$ \\
\hline & Full 4-foot Sample Average = & 11816 & 14251 & \\
\hline & FRP.4x1.375-6.No $1 \mathrm{w} / \mathrm{cb}$ & 4792 & $5820 *$ & Local Instability \\
\hline & FRP.4x1.375-6.No 2 & 4640 & $5622 *$ & Local Instability \\
\hline & Full 6-foot Sample Average = & 4716 & 5721 & \\
\hline & FRP.4x1.375-8.No 1 & 2610 & $3117^{*}$ & Distortional Buckling \\
\hline & FRP.4x1.375-8.No 2 & 2712 & $3752 *$ & Local Instability \\
\hline & Full 8-foot Sample Average = & 2661 & 3434 & \\
\hline & FRP 4x1.375 No Sample 1 & 4595 & $5883^{*}$ & Bearing \\
\hline & FRP 4x1.375 No Sample 2 & 4497 & $6773^{*}$ & Bearing \\
\hline & Connection Test Average = & 4546 & 6328 & \\
\hline \multirow{5}{*}{ 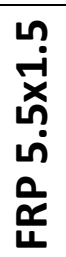 } & FRP.5.5x1.5-6.No 1 & 4430 & $8298^{*}$ & Local Instability \\
\hline & FRP.5.5x1.5-6.No 2 & 10032 & $11703^{*}$ & Local Instability \\
\hline & FRP.5.5x1.5-6.No 3 & 11170 & $12077^{*}$ & Local Instability \\
\hline & Full 6-foot Sample Average = & 8544 & 10693 & \\
\hline & FRP.5.5x1.5-8.No 1 & 4324 & $9436 *$ & Local Instability \\
\hline
\end{tabular}




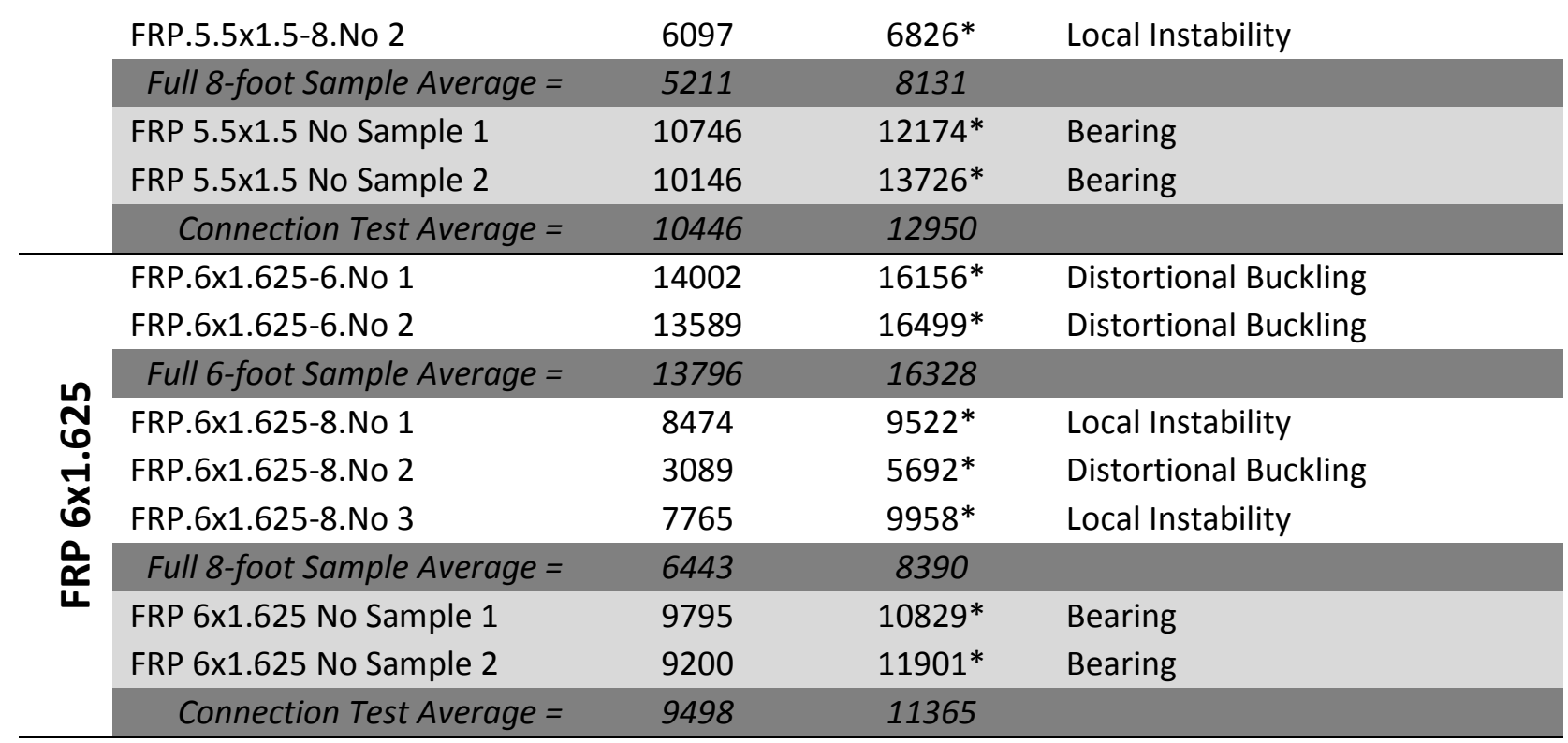

*Ultimate load is maximum load of test, not breaking load. Samples did not fracture.

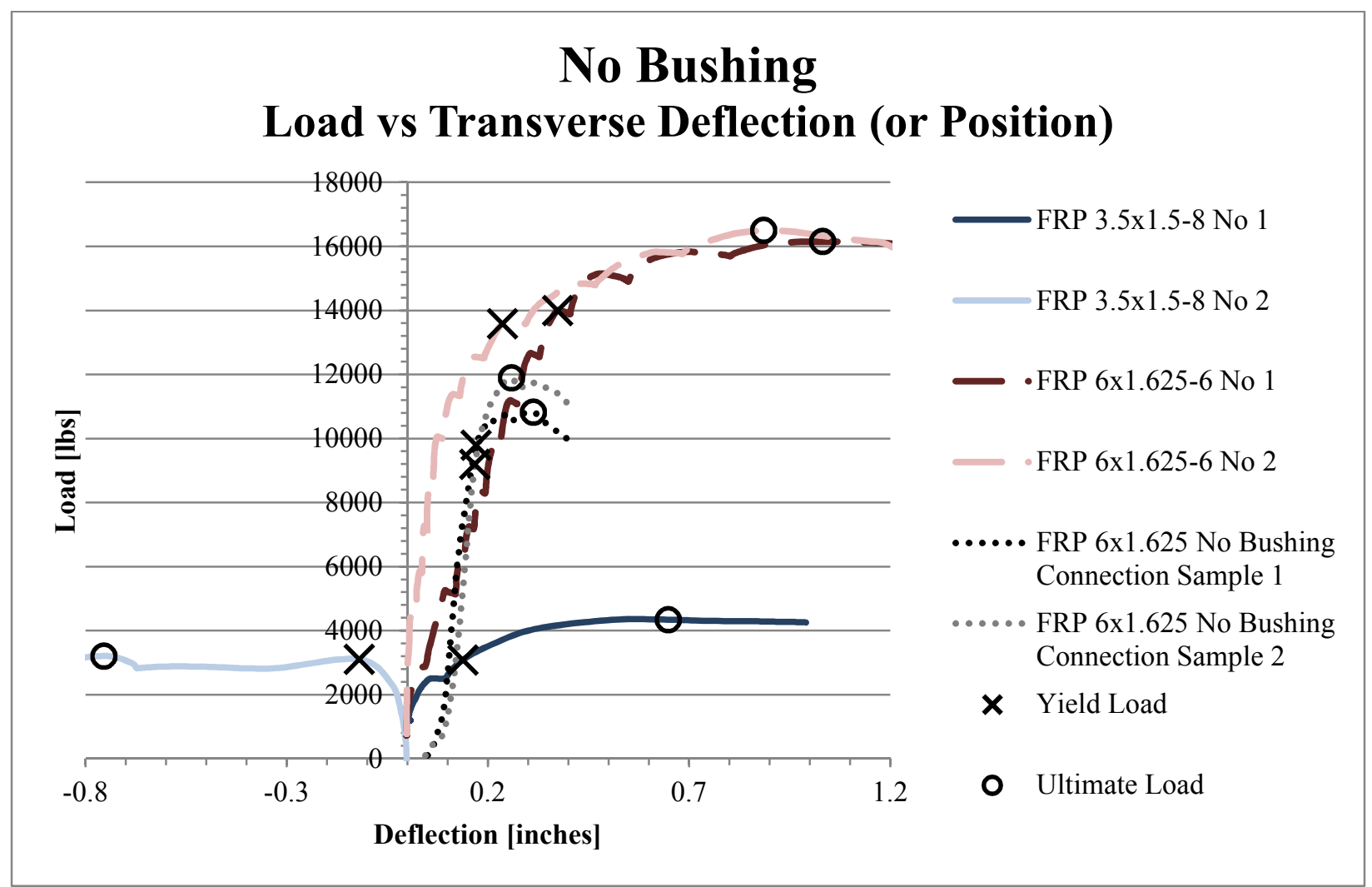

Figure 3-7: Typical Load vs. Transverse Deflection (or Position) for Connections with No Bushing 

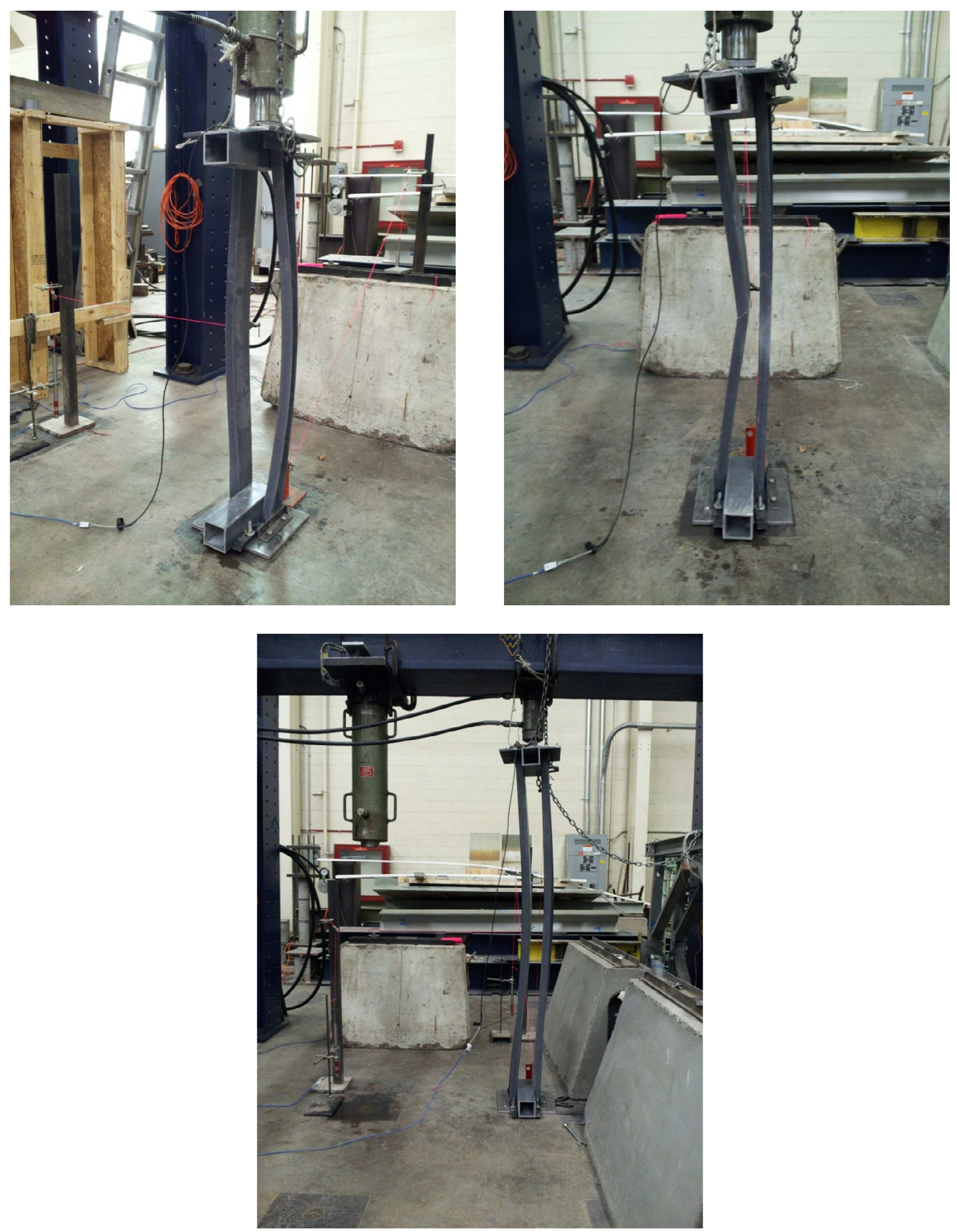

Figure 3-8: Sample Failure Modes: Local Instability/Lateral-Torsional Buckling in FRP 3.5x1.5-4 No \#1 (Top Left), Local Instability/Material Rupture in FRP 4x1.375-4 No \#2 (Top Right), Local Instability in FRP 6x1.625-6 No \#1 (Bottom) 


\subsubsection{Bushing in Column Only Connection Results}

Forty four samples containing bushing in the column only (34 full tie line load tests and 10 column-to-tie connection tests) were tested. As stated with the "no bushing" samples, the load (both buckling and ultimate) carried by the sample increased as the tie length shortened, meaning the 4-foot samples carried higher loads throughout the test. However, unlike with the "no bushing" samples, that only applies to the smaller channel samples, including FRP $3.5 \times 1.5$, FRP 4x1.25, and FRP 4x1.375. For the larger channel samples, FRP 5.5x1.5 and FRP 6x1.625, the buckling load increased as the tie length shortened, but the ultimate load decreased as the tie length shortened. The results of the column-to-tie connection tests for these larger channel samples indicate that the connection is stronger than the full tie line as the yield and ultimate loads of the connection tests are, on average, greater than the buckling and ultimate loads of the full tie line samples. For the smaller channel samples, the column-to-tie connections, typically, carried a load similar to that of the 6-foot samples. Compared to the 8-foot samples, the connection tests yielded and failed at a higher load suggesting the connection is stronger than the full tie line.

As was true for the "no bushing" samples, the common failure mode of these full tie line samples was local instability. 
Table 3-2: Results for Bushing in Column Only Connections, Full Tie Line and Column-to-Tie Connection Tests

\begin{tabular}{|c|c|c|c|c|}
\hline & Sample & $\begin{array}{l}\text { Buckling } \\
\text { Load (lb) }\end{array}$ & $\begin{array}{l}\text { Ultimate } \\
\text { Load (Ib) }\end{array}$ & Failure Mode \\
\hline \multirow{14}{*}{ 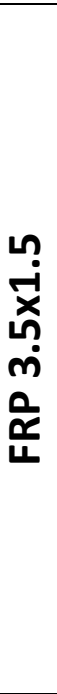 } & FRP.3.5x1.5-4.Bush-Col 1 & 5360 & $17527^{*}$ & Local Instability \\
\hline & FRP.3.5x1.5-4.Bush-Col 2 & 8068 & $13893^{*}$ & Distortional Buckling \\
\hline & Full 4-foot Sample Average = & 6714 & 15710 & \\
\hline & FRP.3.5x1.5-6.Bush-Col 1 & 3432 & $6191^{*}$ & Local Instability \\
\hline & FRP.3.5x1.5-6.Bush-Col 2 & 6487 & $11497^{*}$ & Local Instability \\
\hline & FRP.3.5x1.5-6.Bush-Col 3 w/ cb & 3417 & $4009 *$ & Distortional Buckling \\
\hline & Full 6-foot Sample Average = & 4445 & 7232 & \\
\hline & FRP.3.5x1.5-8.Bush-Col 1 & 4480 & $6666^{*}$ & Local Instability \\
\hline & FRP.3.5x1.5-8.Bush-Col 2 & 3927 & $5458 *$ & Local Instability \\
\hline & FRP.3.5x1.5-8.Bush-Col 3 & 2976 & $4547^{*}$ & Local Instability \\
\hline & Full 8-foot Sample Average = & 3794 & 5557 & \\
\hline & FRP 3.5x1.5 Bush-Col Sample 1 & 5006 & $7088^{*}$ & Bearing \\
\hline & FRP 3.5x1.5 Bush-Col Sample 2 & 4646 & $6771^{*}$ & Bearing \\
\hline & Connection Test Average $=$ & 4826 & 6930 & \\
\hline \multirow{14}{*}{ 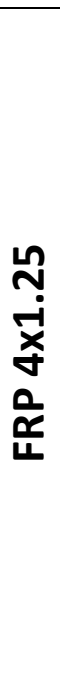 } & FRP.4x1.25-4.Bush-Col 1 & 8657 & $9685^{*}$ & Local Instability \\
\hline & FRP.4x1.25-4.Bush-Col 2 & 7348 & $11049 *$ & Local Instability \\
\hline & FRP.4x1.25-4.Bush-Col 3 & 9000 & $11886^{*}$ & Local Instability \\
\hline & Full 4-foot Sample Average = & 8335 & 10873 & \\
\hline & FRP.4x1.25-6.Bush-Col 1 & 4609 & $6019 *$ & Local Instability \\
\hline & FRP.4x1.25-6.Bush-Col 2 & 3292 & $3619 *$ & Local Instability \\
\hline & FRP.4x1.25-6.Bush-Col $3 \mathrm{w} / \mathrm{cb}$ & 6393 & $8349 *$ & Local Instability \\
\hline & Full 6-foot Sample Average = & 4765 & 5996 & \\
\hline & FRP.4x1.25-8.Bush-Col 1 & 2793 & $4554^{*}$ & Local Instability \\
\hline & FRP.4x1.25-8.Bush-Col 2 & 2112 & $5622^{*}$ & Local Instability \\
\hline & Full 8-foot Sample Average = & 2453 & 5088 & \\
\hline & FRP 4x1.25-8 Bush-Col Sample 1 & 9104 & $9104^{*}$ & Bearing \\
\hline & FRP 4x1.25-8 Bush-Col Sample 2 & 5521 & $6202^{*}$ & Bearing \\
\hline & Connection Test Average $=$ & 7313 & 7653 & \\
\hline \multirow{14}{*}{ 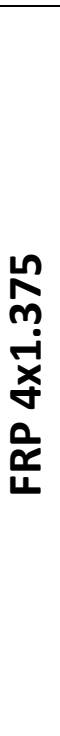 } & FRP.4x1.375-4.Bush-Col 1 & 11984 & 17758 & $\begin{array}{l}\text { Local Instability/Material } \\
\text { Rupture }\end{array}$ \\
\hline & FRP.4x1.375-4.Bush-Col 2 & 14540 & 16055 & Local Instability \\
\hline & Full 4-foot Sample Average = & 13262 & 16906 & \\
\hline & FRP.4x1.375-6.Bush-Col 1 & 5595 & $5789 *$ & Local Instability \\
\hline & FRP. $4 \times 1.375-6$. Bush-Col 2 & 5536 & $9151 *$ & Local Instability \\
\hline & FRP.4x1.375-6.Bush-Col 3 & 3323 & $5665^{*}$ & Lateral-Torsional Buckling \\
\hline & Full 6-foot Sample Average = & 4818 & 6868 & \\
\hline & FRP.4x1.375-8.Bush-Col 1 & 1126 & $5579 *$ & Local Instability \\
\hline & FRP.4x1.375-8.Bush-Col 2 & 5828 & $6089 *$ & Local Instability \\
\hline & FRP.4x1.375-8.Bush-Col 3 & 1699 & $3066^{*}$ & Local Instability \\
\hline & Full 8-foot Sample Average = & 2884 & 4911 & \\
\hline & FRP 4x1.375-4 Bush-Col Sample 1 & 4743 & $6601^{*}$ & Bearing \\
\hline & FRP 4x1.375-4 Bush-Col Sample 2 & 5007 & $5811^{*}$ & Bearing \\
\hline & Connection Test Average $=$ & 4875 & 6206 & \\
\hline
\end{tabular}




\begin{tabular}{|c|c|c|c|c|}
\hline \multirow{10}{*}{ 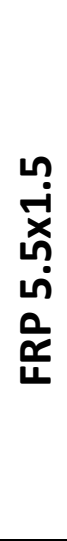 } & FRP.5.5x1.5-6.Bush-Col 1 & 4465 & $9307^{*}$ & Local Instability \\
\hline & FRP.5.5x1.5-6.Bush-Col 2 & 7648 & 9159* & Local Instability \\
\hline & FRP.5.5x1.5-6.Bush-Col 3 w/ cb & 3974 & $7772^{*}$ & Local Instability \\
\hline & Full 6-foot Sample Average $=$ & 5362 & 8746 & \\
\hline & FRP.5.5x1.5-8.Bush-Col 1 & 4422 & $10737 *$ & Local Instability \\
\hline & FRP.5.5x1.5-8.Bush-Col 2 & 5115 & 8750 & $\begin{array}{l}\text { Local Instability/Material } \\
\text { Rupture }\end{array}$ \\
\hline & Full 8-foot Sample Average $=$ & 4769 & 9744 & \\
\hline & FRP 5.5x1.5-8 Bush-Col Sample 1 & 13230 & 14926* & Bearing \\
\hline & FRP 5.5x1.5-8 Bush-Col Sample 2 & 13249 & $15484 *$ & Bearing \\
\hline & Connection Test Average $=$ & 13240 & 15205 & \\
\hline \multirow{10}{*}{ 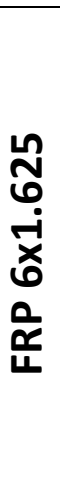 } & FRP.6x1.625-6.Bush-Col 1 & 8302 & $10012 *$ & Distortional Buckling \\
\hline & FRP.6x1.625-6.Bush-Col 2 & 8489 & $9074 *$ & Distortional Buckling \\
\hline & Full 6-foot Sample Average $=$ & 8396 & 9543 & \\
\hline & FRP.6x1.625-8.Bush-Col 1 & 5376 & $9868^{*}$ & Distortional Buckling \\
\hline & FRP.6x1.625-8.Bush-Col 2 & 7453 & $15112 *$ & Local Instability \\
\hline & FRP.6x1.625-8.Bush-Col 3 & 6389 & $8298^{*}$ & Local Instability \\
\hline & Full 8-foot Sample Average $=$ & 6406 & 11093 & \\
\hline & FRP $6 \times 1.625$ Bush-Col Sample 1 & 13799 & 15997* & Bearing \\
\hline & FRP 6x1.625 Bush-Col Sample 2 & 11499 & $15016 *$ & Bearing \\
\hline & Connection Test Average $=$ & 12649 & 15507 & \\
\hline
\end{tabular}

*Ultimate load is maximum load of test, not breaking load. Samples did not fracture. 


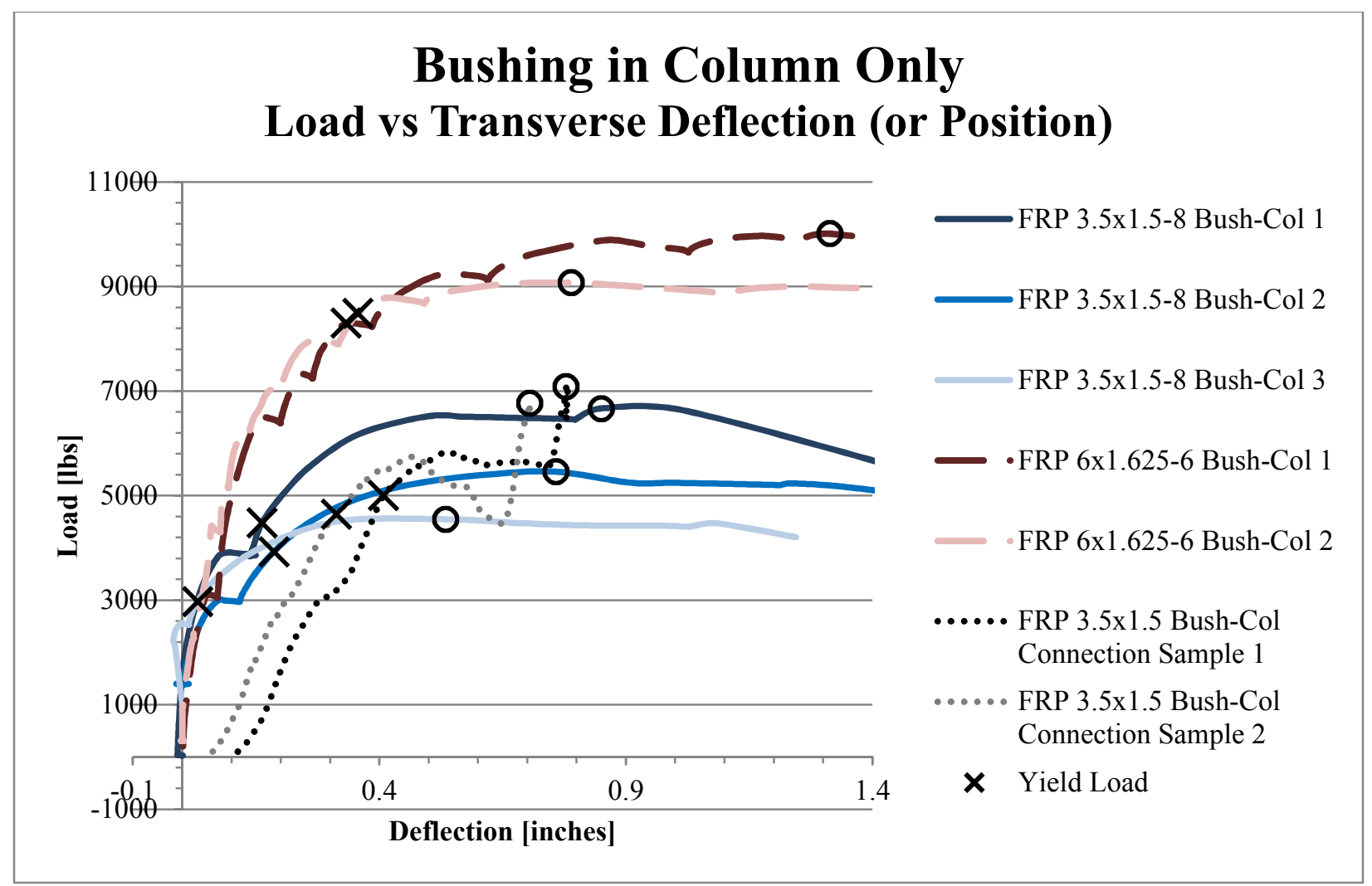

Figure 3-9: Typical Load vs. Transverse Deflection (or Position) for Connections with Bushing in the Column Only 

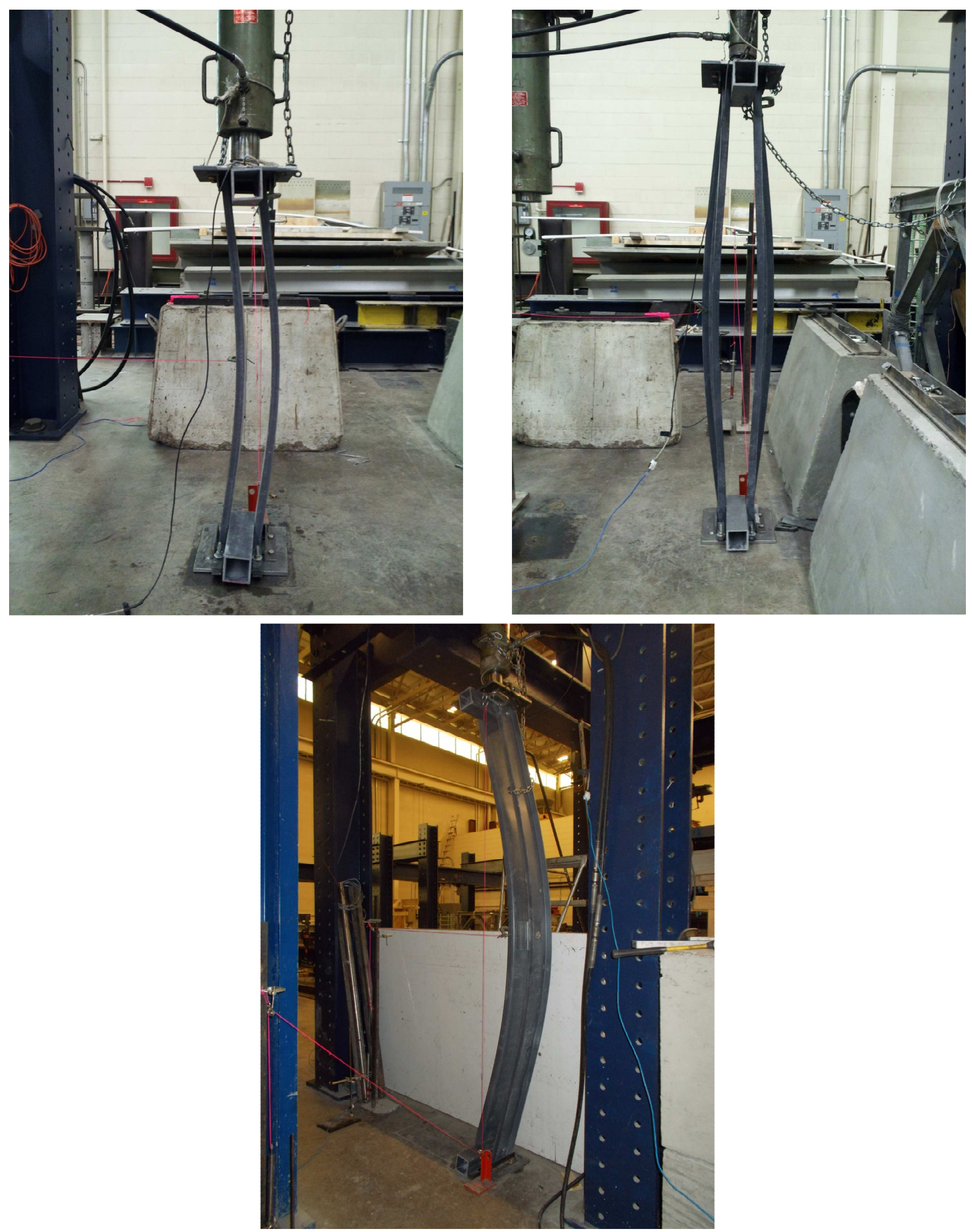

Figure 3-10: Sample Failure Modes: Local Instability in FRP 4x1.25-4 Bush-Col 1 (Top Left), Lateral-Torsional Buckling in FRP 4x1.375-6 Bush-Col 3 (Top Right), Local Instability/Material Rupture in FRP 5.5x1.5-8 Bush-Col 2 (Bottom) 


\subsubsection{Bushing in Both Column and Tie Connection Results}

A total of 41 samples with bushing in both the column and tie were tested (33 full tie line load tests and 8 column-to-tie connection tests). Most often, the load (both buckling and ultimate) carried by the sample increased as the tie length shortened, meaning the 4-foot samples carried higher loads throughout the test, with the FRP $3.5 \times 1.5$ and FRP $4 \times 1.25$ samples being the exceptions. The average buckling and ultimate load of the 8-foot FRP $3.5 \times 1.5$ samples were higher than that of the 6-foot samples, but were still less than that of the 4-foot samples. For the FRP $4 \times 1.258$-foot samples, the average buckling load of the 8-foot samples was higher than that of the 6-foot samples, but the ultimate load was less than that of the 6-foot samples. The column-to-tie connection samples carried a load (yield and ultimate) higher than the average loads of the 6-foot and 8-foot samples, suggesting the connections are stronger than the full tie line samples at these lengths.

Yet again, the common failure mode of the samples was local instability. Lateraltorsional buckling was observed in several samples and material rupture occurred in a few samples as well. 
Table 3-3: Results for Bushing in Both Column and Tie Connections, Full Tie Line and Column-to-Tie Connection Tests

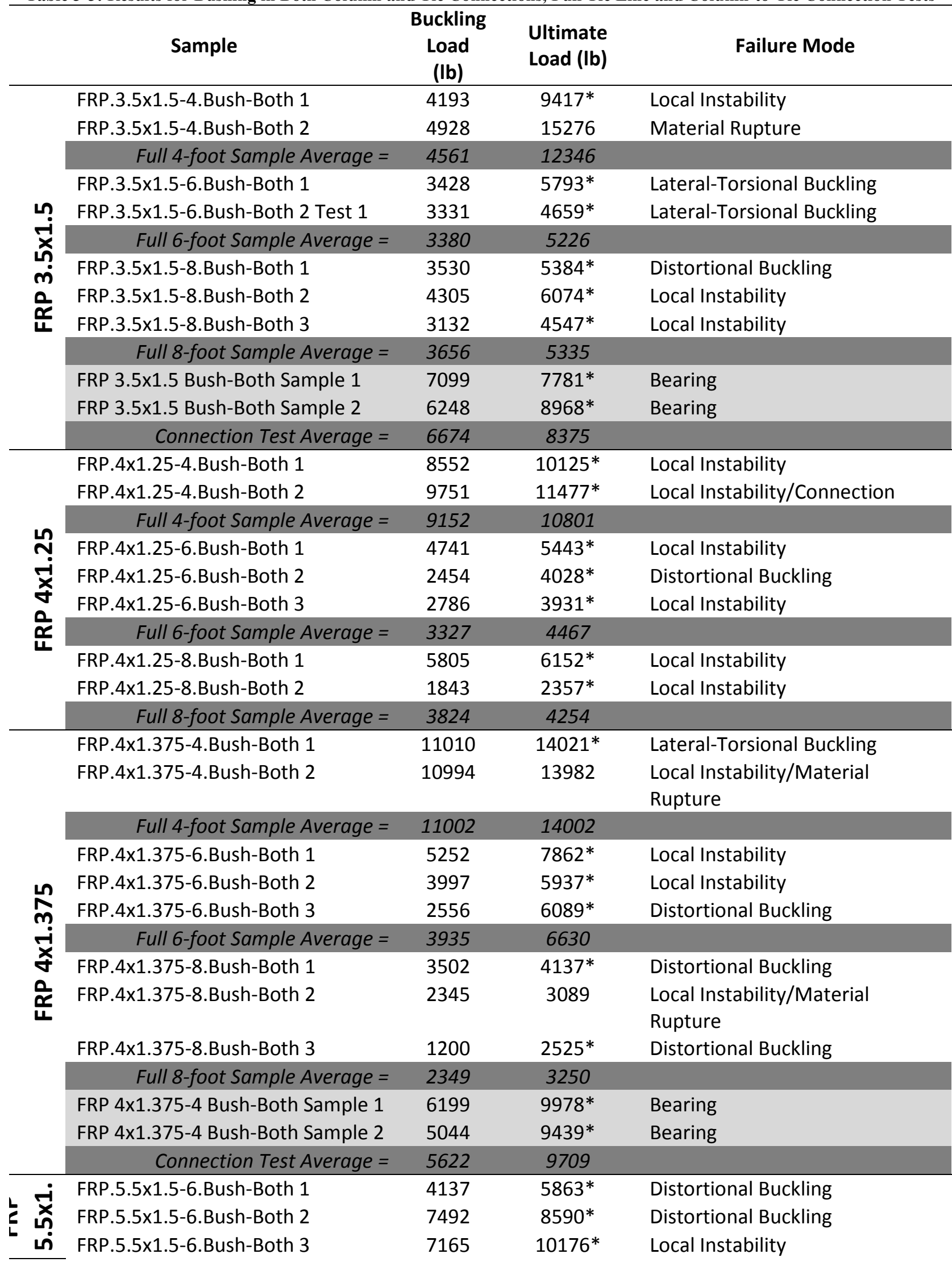




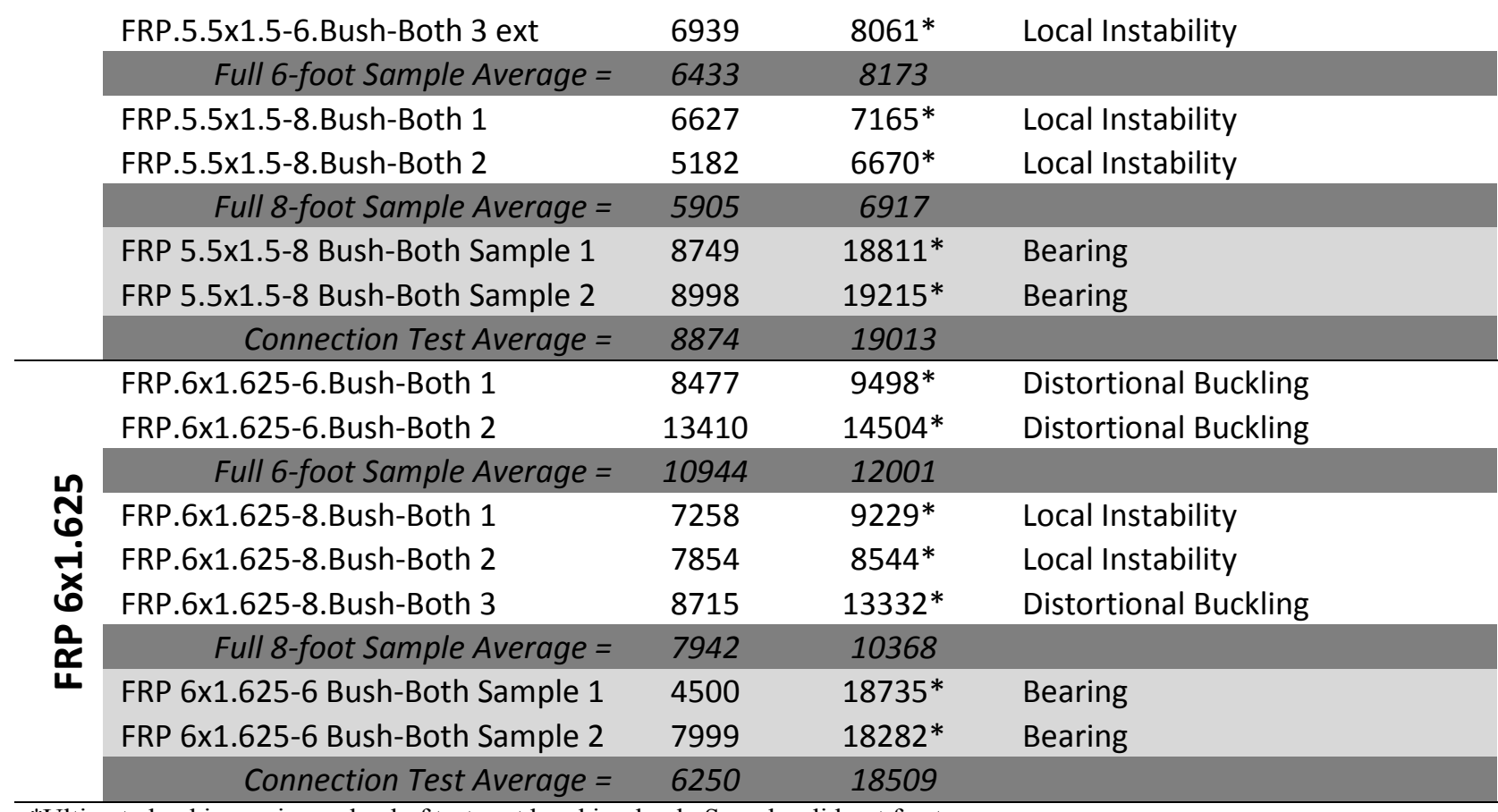

*Ultimate load is maximum load of test, not breaking load. Samples did not fracture.

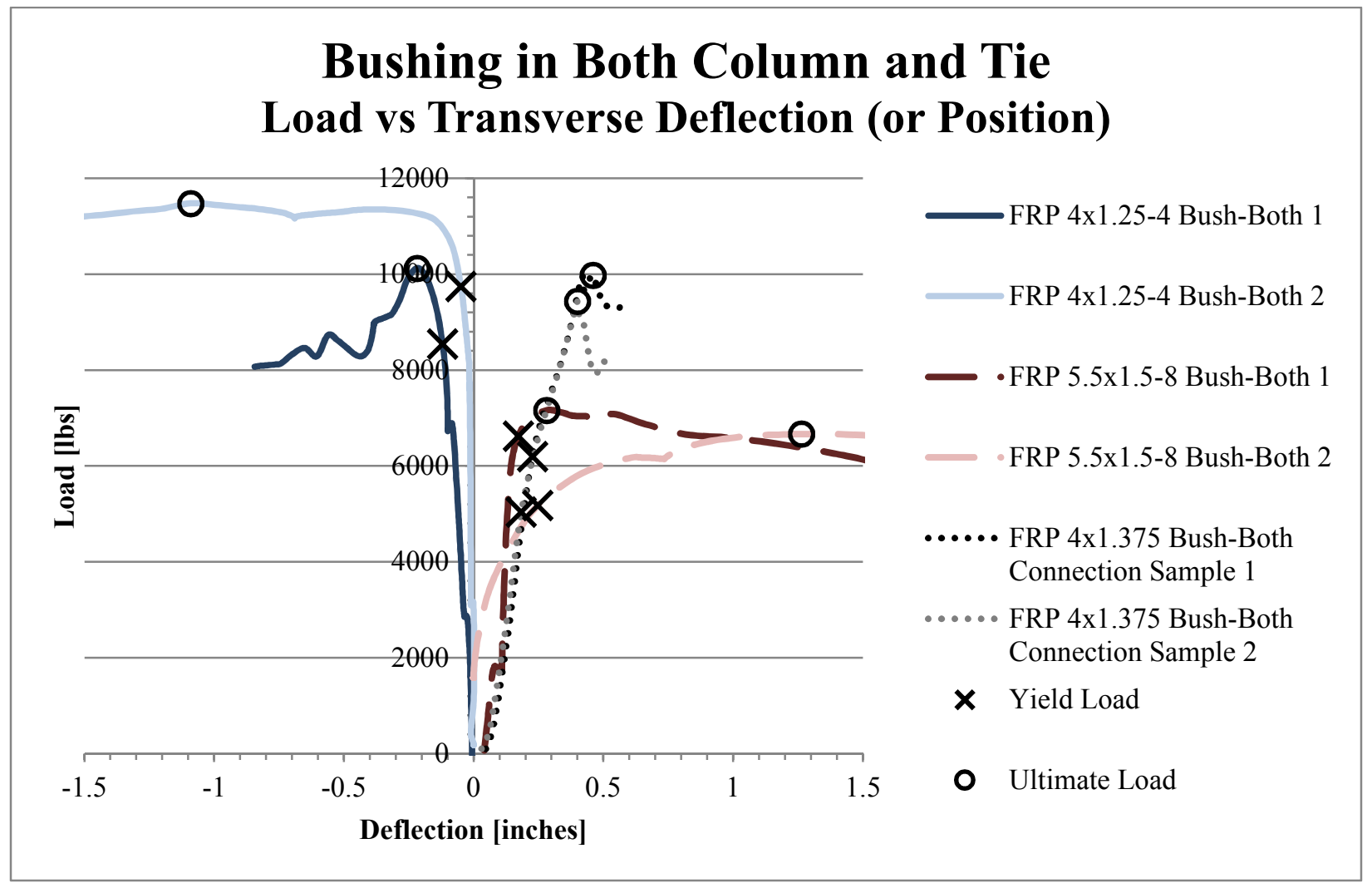

Figure 3-11: Typical Load vs. Transverse Deflection (or Position) for Connections with Bushing in Both Column and Tie 

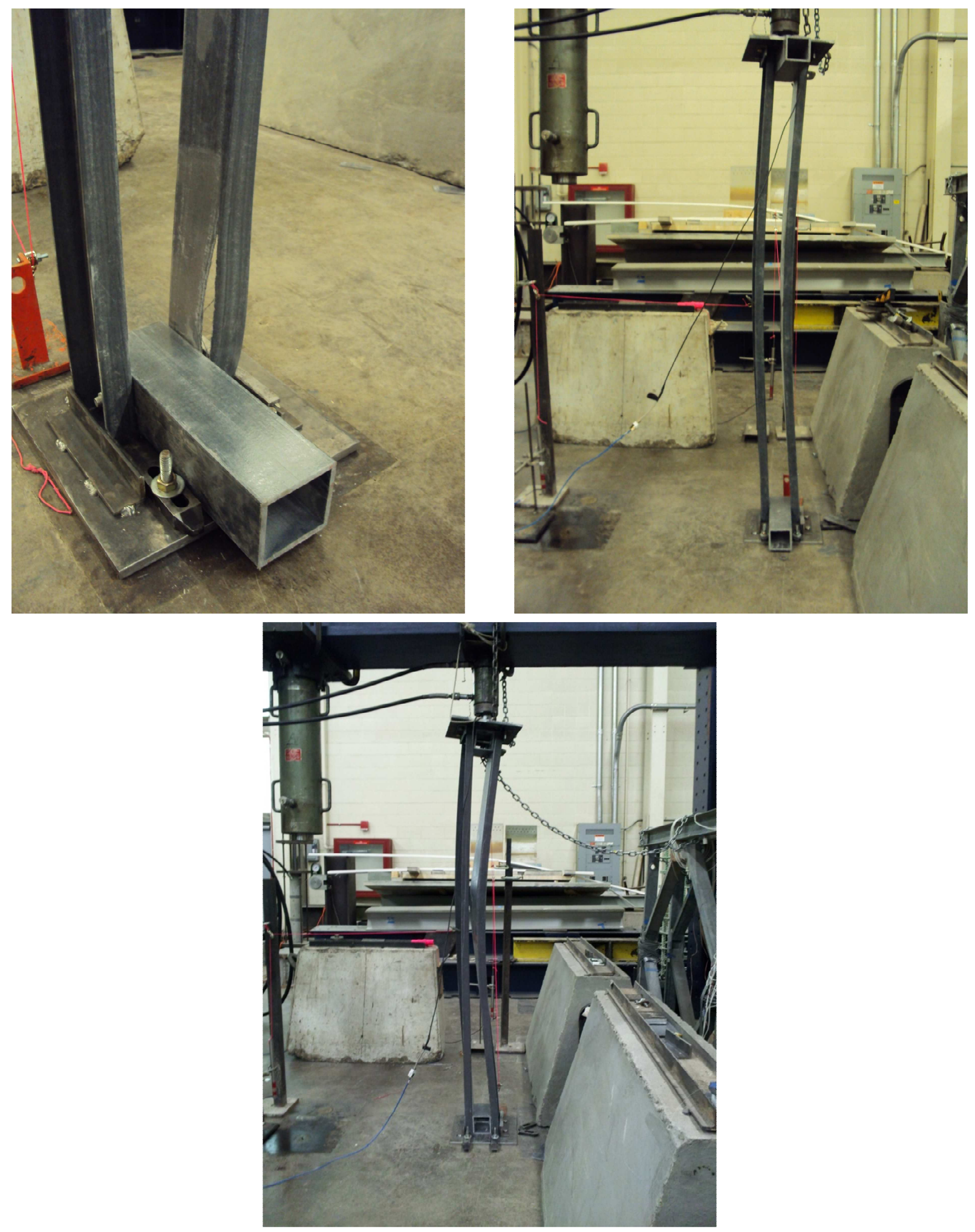

Figure 3-12: Sample Failure Modes: Material Rupture in FRP 3.5x1.5-4 Bush-Both 2 (Top Left), Local Instability in FRP 4x1.375-6 Bush-Both 2 (Top Right), Local Instability/Lateral-Torsional Buckling in FRP 5.5x1.5-6 Bush-Both 1 (Bottom) 


\subsubsection{Column-to-Tie Connection Results}

A total of 24 column-to-tie connection samples were tested. The purpose of these tests was to determine the strength of the three different connection types and compare the results to the full tie line samples. The failure mode of the column-to-tie connection samples was consistently bearing.

Considering the average load, the ultimate load of the sample increased as the amount of bushing increased, meaning the samples with bushing in both the column and ties held the highest ultimate load while the samples with no bushing carried the lowest ultimate load. The same can be said of the yield load for the smaller channel sizes, including FRP 3.5x1.5, FRP 4x1.25 and FRP 4x1.375. For the larger channel sizes, including FRP 5.5x1.5 and FRP 6x1.625, the samples with bushing in the column only showed the highest average yield load and the samples with bushing in the column and ties showed the lowest average yield load.

The load versus position curves reveal the connection provided little friction resistance after the slipping occurred in the initial loading stage. After slipping, for some connections, the load versus position curve becomes almost linear indicating the connection (bolts or bolts and bushings) slipped into bearing with the FRP members. The yield load for the column-to-tie connections indicates the point at which the load versus position curve became nonlinear until final failure. The nonlinear behavior is due to the initiation of bearing failure in the FRP members, most often combined with bending of the bolts.

From the load versus position plot for connections with bushing in both the column and the ties, more than one slope change was noticed. Due to the load transferring first from the column (FRP box) to the bushing, then crushing of the bushing and finally from the bushing to the bolt, three instances of frictional slipping occurred. For these samples, two sections of linear 
behavior occurred, however, the yield load for these samples was interpreted at the first change in slope. The difference between the load at which nonlinear behavior was observed and the ultimate load was typically smaller for these samples than for samples with no bushing.

Figure 3-13 and Figure 3-14 follow the results table to represent the typical graph of the results. Additional graphs of column-to-tie connection results are included in APPENDIX A Load vs Deflection Plots. 
Table 3-4: Results for All Column-to-Tie Connections

\begin{tabular}{|c|c|c|c|c|}
\hline Sample & $\begin{array}{c}\text { Yield } \\
\text { Load (Ib) }\end{array}$ & $\begin{array}{l}\text { Ultimate } \\
\text { Load (Ib) }\end{array}$ & $\begin{array}{l}\text { Failure } \\
\text { Type }\end{array}$ & Failure Comments \\
\hline FRP 3.5x1.5 Bush-Col Sample 1 & 5006 & 7088 & Bearing & $\begin{array}{l}\text { bushing cracked, tearing of channel } \\
\text { only }\end{array}$ \\
\hline FRP 3.5x1.5 Bush-Col Sample 2 & 4646 & 6771 & Bearing & $\begin{array}{l}\text { bushing pulled up, tearing of channel } \\
\text { only }\end{array}$ \\
\hline FRP $3.5 \times 1.5$ Bush-Both Sample 1 & 7099 & 7781 & Bearing & $\begin{array}{l}\text { bushing and bolt tore, tearing of box } \\
\text { only }\end{array}$ \\
\hline FRP $3.5 \times 1.5$ Bush-Both Sample 2 & 6248 & 8968 & Bearing & $\begin{array}{l}\text { bushing and bolt tore and pulled up, } \\
\text { tearing of box only }\end{array}$ \\
\hline FRP 4x1.25 Bush-Col Sample 1 & 9104 & 9104 & Bearing & $\begin{array}{l}\text { bolt pulled up, tearing of bushing and } \\
\text { box }\end{array}$ \\
\hline FRP 4x1.25 Bush-Col Sample 2 & 5521 & 6202 & Bearing & bolt pulled up, tearing of box \\
\hline FRP $4 \times 1.375$ No Sample 1 & 4595 & 5883 & Bearing & bolt pulled up, tearing of box only \\
\hline FRP $4 \times 1.375$ No Sample 2 & 4497 & 6773 & Bearing & bolt pulled up, tearing of box only \\
\hline FRP 4x1.375 Bush-Col Sample 1 & 4743 & 6601 & Bearing & $\begin{array}{l}\text { bushing pulled up on one side, } \\
\text { tearing of channel only }\end{array}$ \\
\hline FRP 4x1.375 Bush-Col Sample 2 & 5007 & 5811 & Bearing & $\begin{array}{l}\text { bushing pulled up, tearing of box and } \\
\text { channels }\end{array}$ \\
\hline FRP $4 \times 1.375$ Bush-Both Sample 1 & 6199 & 9978 & Bearing & $\begin{array}{l}\text { bushing pulled up, tearing of box and } \\
\text { channels }\end{array}$ \\
\hline FRP $4 \times 1.375$ Bush-Both Sample 2 & 5044 & 9439 & Bearing & $\begin{array}{l}\text { bushing pulled up, tearing of box and } \\
\text { channels }\end{array}$ \\
\hline FRP $5.5 \times 1.5$ No Sample 1 & 10746 & 12174 & Bearing & bolt pulled up, tearing of box only \\
\hline FRP $5.5 \times 1.5$ No Sample 2 & 10146 & 13726 & Bearing & bolt pulled up, tearing of box only \\
\hline FRP 5.5x1.5 Bush-Col Sample 1 & 13230 & 14926 & Bearing & $\begin{array}{l}\text { bolt pulled up, tearing of box and } \\
\text { channels }\end{array}$ \\
\hline FRP 5.5x1.5 Bush-Col Sample 2 & 13249 & 15484 & Bearing & $\begin{array}{l}\text { bolt and bushing pulled up, tearing of } \\
\text { channels }\end{array}$ \\
\hline FRP 5.5x1.5 Bush-Both Sample 1 & 8749 & 18811 & Bearing & $\begin{array}{l}\text { bolt and bushing pulled up, tearing of } \\
\text { box }\end{array}$ \\
\hline FRP 5.5x1.5 Bush-Both Sample 2 & 8998 & 19215 & Bearing & $\begin{array}{l}\text { bolt and bushing pulled up, tearing of } \\
\text { box and channels }\end{array}$ \\
\hline FRP $6 \times 1.625$ No Sample 1 & 9795 & 10829 & Bearing & $\begin{array}{l}\text { bolt pulled up, tearing of box, } \\
\text { cracking of channels }\end{array}$ \\
\hline FRP $6 \times 1.625$ No Sample 2 & 9200 & 11901 & Bearing & bolt pulled up, tearing of box \\
\hline FRP 6x1.625 Bush-Col Sample 1 & 13799 & 15997 & Bearing & $\begin{array}{l}\text { bushing pulled up, cracking around } \\
\text { bushing in box, tearing of channel }\end{array}$ \\
\hline FRP 6x1.625 Bush-Col Sample 2 & 11499 & 15016 & Bearing & $\begin{array}{l}\text { bolt and bushing pulled up, cracking } \\
\text { and tearing of box, tearing of channel }\end{array}$ \\
\hline FRP $6 \times 1.625$ Bush-Both Sample 1 & 4500 & 18735 & Bearing & $\begin{array}{l}\text { bolt and bushing pulled up, tearing of } \\
\text { box and channel }\end{array}$ \\
\hline FRP $6 \times 1.625$ Bush-Both Sample 2 & 7999 & 18282 & Bearing & $\begin{array}{l}\text { bolt and bushing pulled up, tearing of } \\
\text { box only }\end{array}$ \\
\hline
\end{tabular}




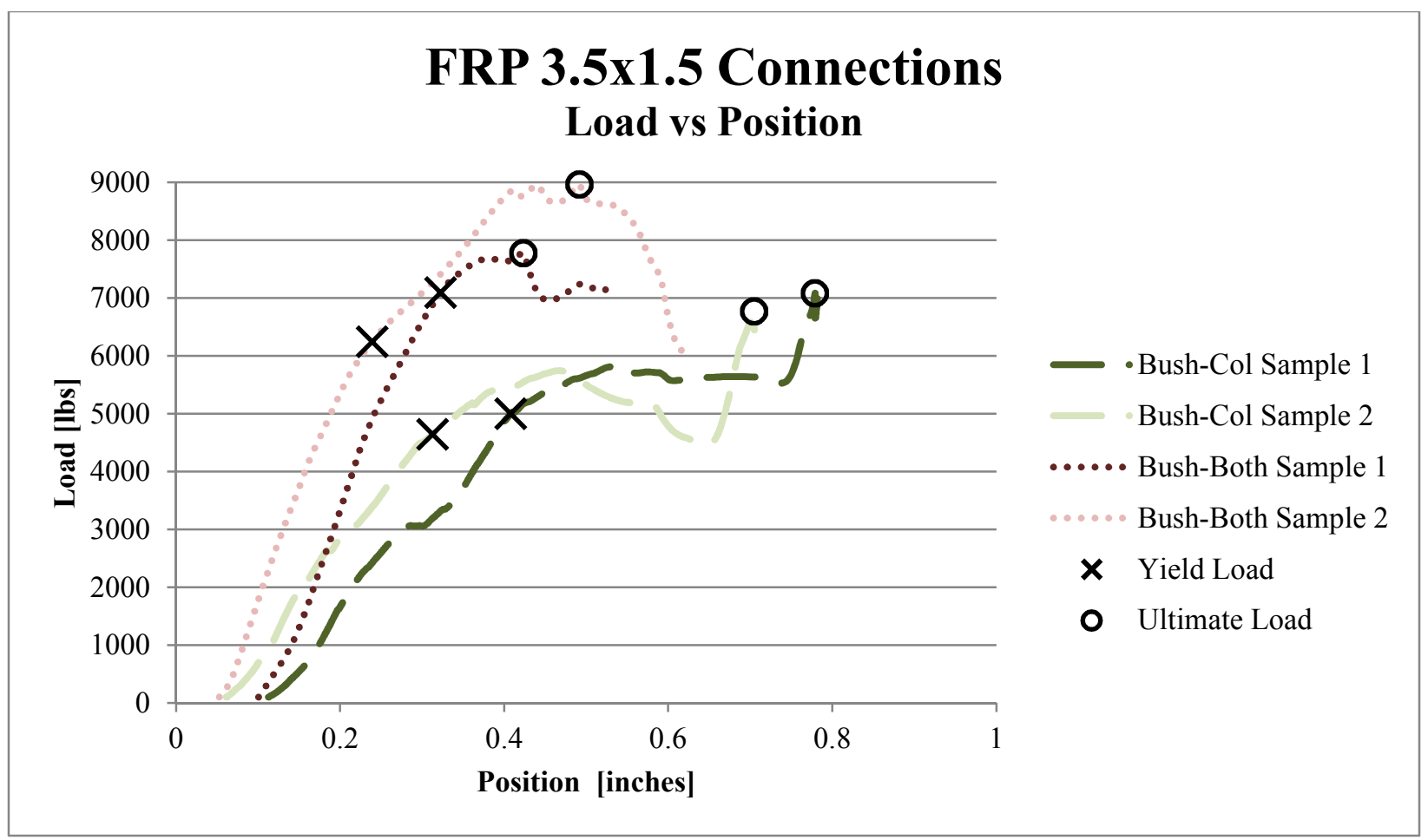

Figure 3-13: Load vs. Position for Connections with FRP 3.5x1.5 Ties

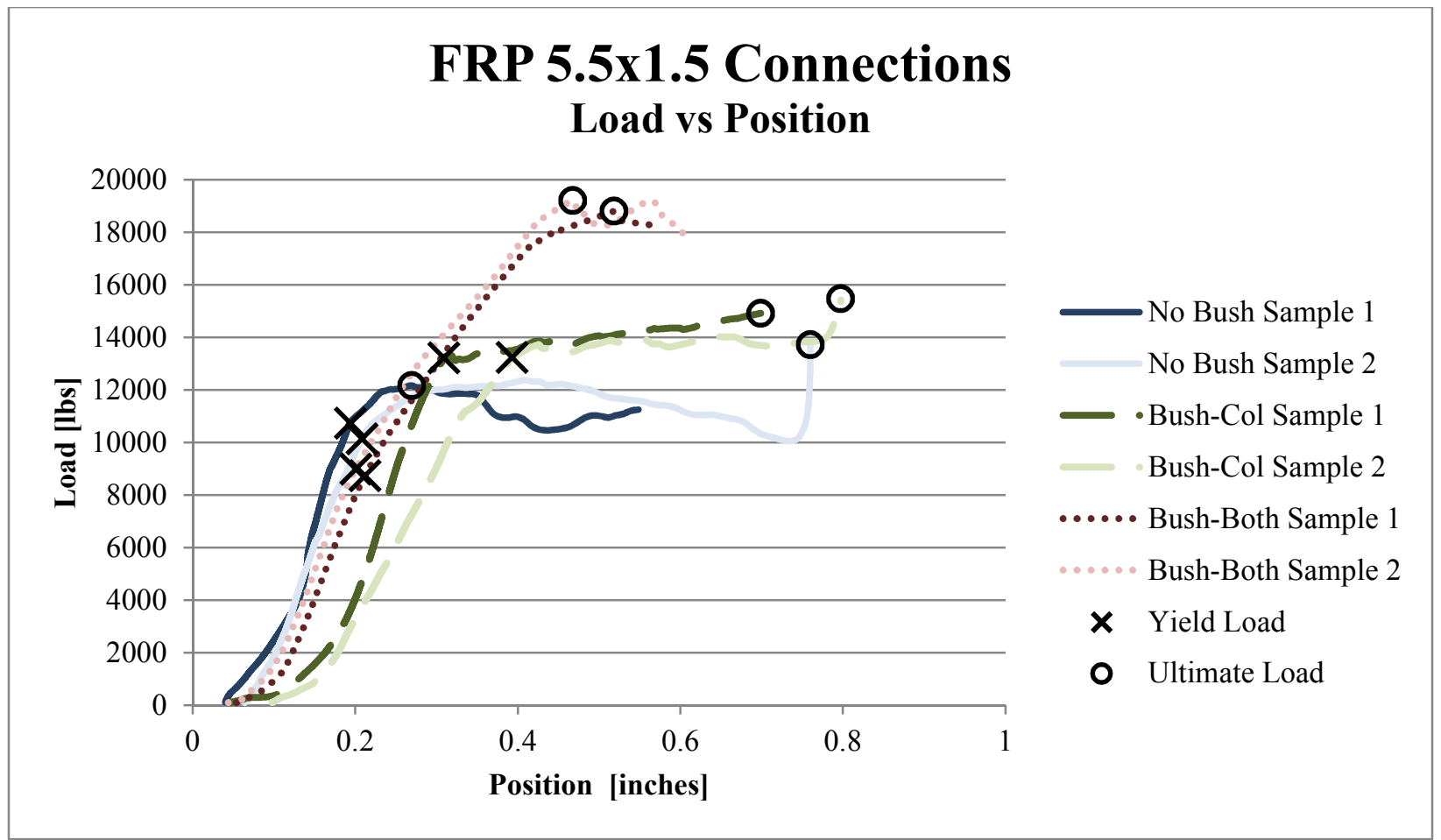

Figure 3-14: Load vs. Position for Connections with FRP 5.5x1.5 Ties 

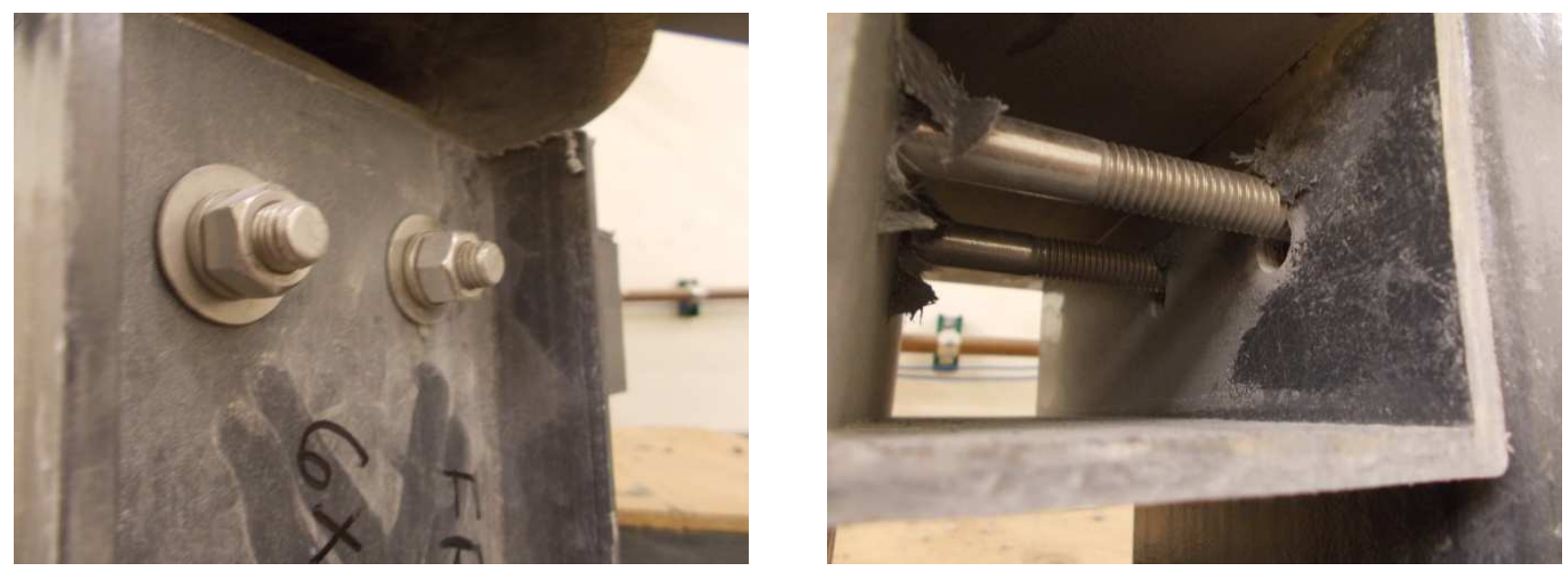

Figure 3-15: Bearing Failure of FRP 6x1.625 with No Bushing
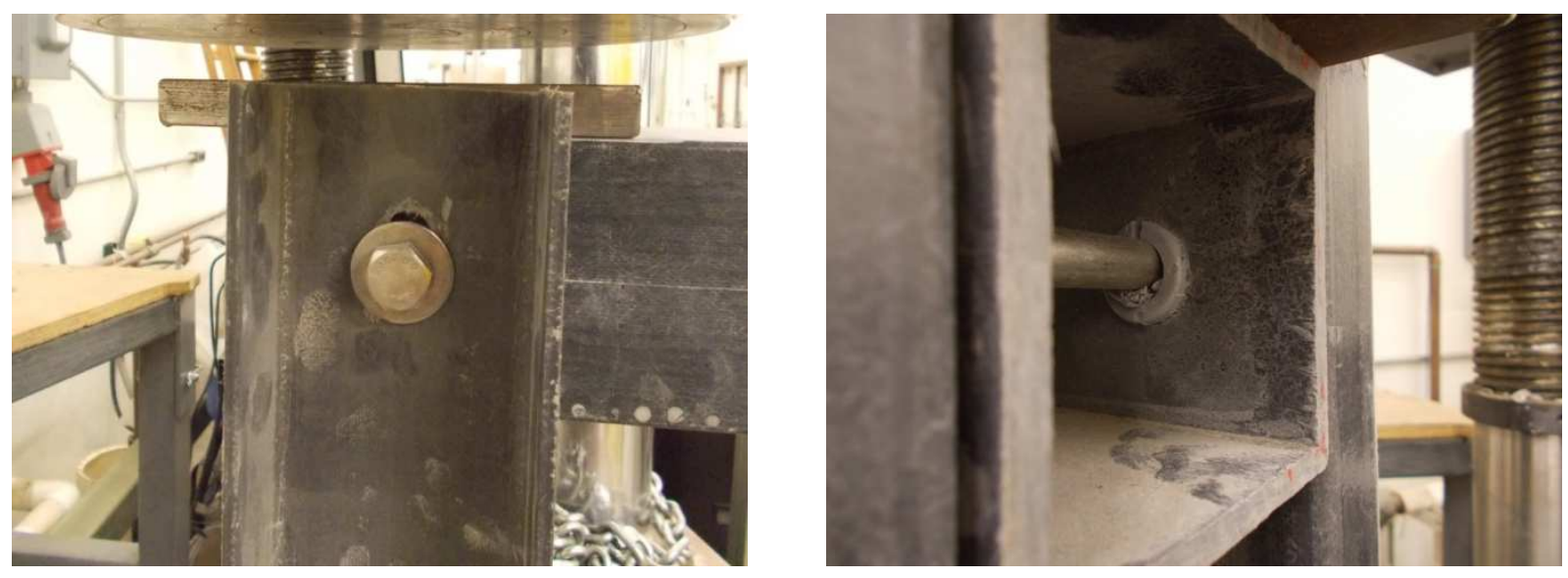

Figure 3-16: Bearing Failure of FRP 3.5x1.5 with Bushing in Column Only
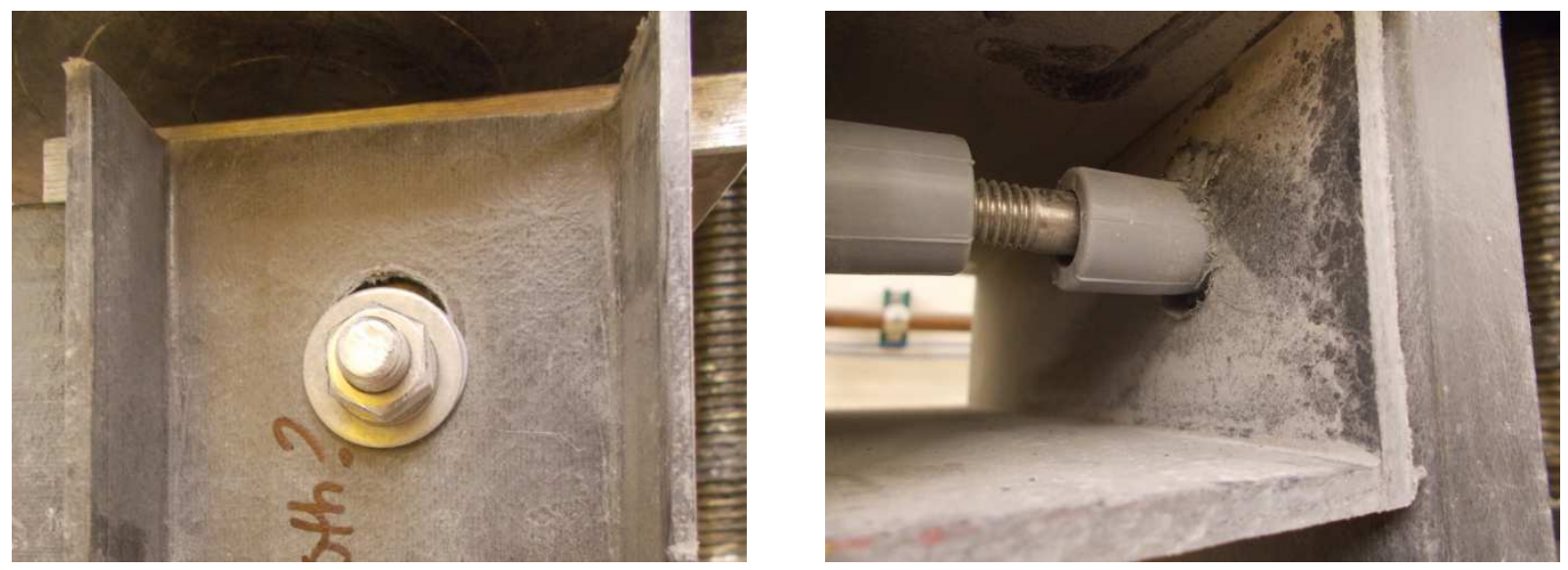

Figure 3-17: Bearing Failure of FRP 4x1.375 with Bushing in Both Column and Tie 


\subsubsection{Additional Observations}

Although the majority of the experimental tests went as expected, some test results cannot be as easily described or explained. The typical failure mode for the full tie line samples was local instability. Sometimes, this failure mode was accompanied by material rupture and/or lateral-torsional buckling. While the sample failure mode can be easily summarized, the actual behavior may not so easily fall into a particular category. For example, in some longer samples (6-foot and 8-foot full tie lines) the upper half of the sample twisted almost $90^{\circ}$ under loading and immediately returned back to the original position after the load was removed from the sample, demonstrating an elastic failure, and for some samples each simulated tie behaved differently, suggesting the behave independent of one another despite the connection. These tests, as well as some other unique tests, may require further investigation and analysis in order to better understand the material behavior. There could be a number of reasons and explanations for why certain samples behaved in these ways, but a more in depth analytical study may be necessary, especially considering no obvious patterns existed in the failure modes of the full tie line samples.

An initial observation that could begin to explain the unusual results was noted during the test setup. Intermittently, researchers noticed samples that were not level across the loading area, meaning the two channels and the square tube were not all level at the top and bottom, indicating errors during the manufacturing/construction of the samples. An un-level loading area could cause jolts as the sample leveled under the load causing sudden shift in the load and deflection graphs, etc.

A sample of photographs of these results is shown in Figure 3-18. Additional photographs are included in APPENDIX C - Photographs (Samples Under Loading). 

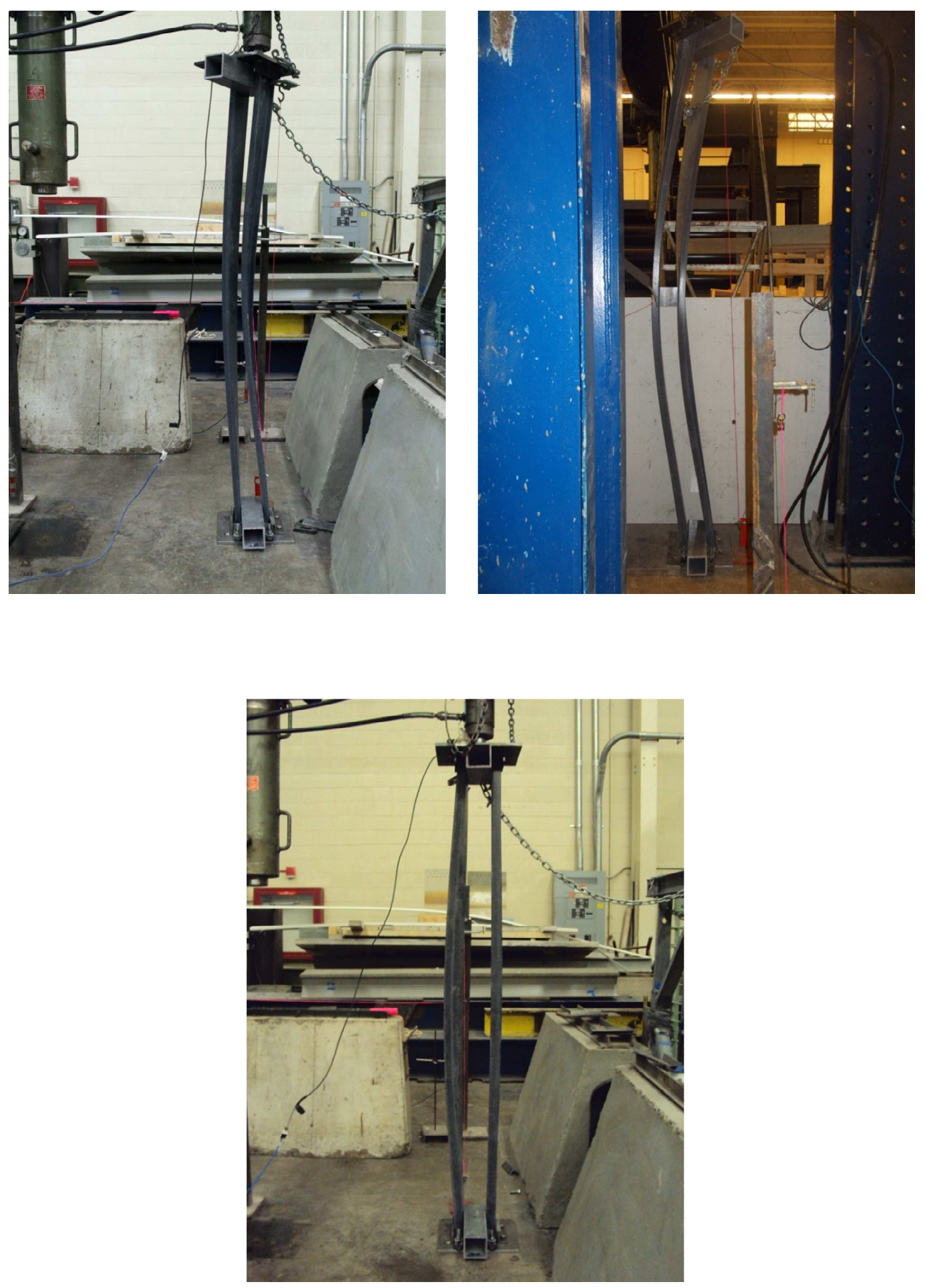

Figure 3-18: Example Failures of Samples: FRP 4x1.25-6 No \#2 (Top Left), FRP 4x1.375-8 Bush-Both 1 (Top Right), FRP 3.5x1.5-6 Bush-Col 1 (Bottom) 


\subsection{Analytical Discussion}

An initial interpretation of the experimental results reveals that the samples behaved predictably, with a few exceptions. The inclusion of both full tie line samples and column-to-tie connection samples was to ensure the results provided a full understanding of the behavior of tie lines under axial loading. Analysis of the experimental results will compare not only the results of the various full tie line samples, but the results of the column-to-tie connection samples to the full tie line samples. Further analysis will look specifically at the connections.

As stated previously, the yield load and ultimate load were determined from the load versus deflection plots for each sample. For the full tie line samples, the yield load is considered as the buckling load. The buckling load and the yield load, for the column-to-tie connection tests, were designated at a point where there was a noticeable change in slope on the load versus deflection plots. A change in slope was taken to indicate a frictional slip at the joint, meaning there was force transfer through the joint before a member(s) buckled in some way. For some samples, the buckling load may be listed the same as the ultimate load, due to these particular samples not presenting with a clear yield or buckling load. The ultimate load is the maximum load measured for a given sample regardless of sample failure. In some cases, the ultimate load was also the breaking load of the sample, but in most cases, the ultimate load refers to the point at which increasing the stroke of the ram resulted in large deflection increases with minimal or no increases in load.

Most often the failure mode of the full tie line samples was local instability. As the load was applied, the simulated ties would bow, either apart from one another or both in the same direction. For some samples, the bowing led to material rupture in the channel around the point of curvature, while in other samples, the bowing was accompanied by lateral-torsional buckling 
in the channels (distortional buckling). When material rupture presented in a test specimen, it was characteristically in the corner of the channel. This supports the concept that corners in FRP structural shapes introduce a point of weakness under loading, as was noted in the study WVUCFC performed for American Electric Power (AEP). Only once was a connection failure observed in a full tie line sample (FRP 4x1.25-4 Bush-Both 2); the connection failed in conjunction with local instability in the channels.

The purpose of the shorter column-to-tie samples was to determine the strength of the column-to-tie connection as opposed to the strength of the entire bay. Comparing the average yield loads (to average buckling load) and average ultimate loads, no column-to-tie connection provided higher loads than the 4-foot samples; on the other hand, each column-to-tie connection type provided higher loads than the 8 -foot samples. Samples with no bushing in the connections had loads similar to the 6-foot samples of the same connection type. This also applies to smaller channel samples (FRP 3.5x1.5, FRP 4x1.25 and FRP 4x1.375) with bushing in the column only. For larger channel samples with bushing in the column only and all samples with bushing in both the column and ties, the yield and ultimate loads of the connection are, on average, greater than the buckling and ultimate loads of the full tie line samples (6-foot and 8-foot).

When analyzing the column-to-tie connection results separate from the full tie line results, the average ultimate load of the sample increased as the amount of bushing increased, meaning the samples with bushing in both the column and ties held the highest ultimate load while the samples with no bushing carried the lowest ultimate load. However, when comparing the full tie line results based on connection type, the previous statement does not always remain true. For example, when considering the 4-foot and 6-foot FRP 3.5x1.5 samples, those with no bushing in the connection carried the highest average loads (both buckling and ultimate) while 
those with bushing in the column and the ties carried the lowest average loads. In fact, no full tie line samples with bushing in both the column and ties presented the highest average ultimate load. Most often, these samples carried the lowest average ultimate load. The same can be said of the average yield load for the smaller channel sizes, including FRP 3.5x1.5, FRP 4x1.25 and FRP $4 \times 1.375$. When analyzing the column-to-tie connection results separate from the full tie line results for the larger channel sizes, including FRP 5.5x1.5 and FRP 6x1.625, the samples with bushing in the column only showed the highest average yield load and the samples with bushing in the column and ties showed the lowest average yield load. This is not true when considering full tie lines based on connection type. For the full tie line samples with the larger channels, the samples with bushing in the column only always exhibited the lowest average yield load.

Reviewing the full tie line results, on average, the load (both buckling and ultimate) carried by the sample increased as the tie length shortened, meaning the 4-foot samples carried higher loads throughout the test. Although this holds true for all samples with no bushing in the connections, it only holds true for some samples with bushing in the connection. For samples with bushing in the column only, that only applies to the smaller channel samples, including FRP 3.5x1.5, FRP $4 \times 1.25$, and FRP $4 \times 1.375$. For the larger channel samples, FRP $5.5 \times 1.5$ and FRP $6 \times 1.625$, the buckling load increased as the tie length shortened, but the ultimate load decreased as the tie length shortened. The FRP $3.5 \times 1.5$ and FRP $4 \times 1.25$ samples are the exceptions to that for the samples with bushing in both the column and ties. The average buckling and ultimate load of the 8-foot FRP 3.5x1.5 samples were higher than that of the 6-foot samples, but were still less than that of the 4-foot samples. For the FRP 4x1.25 8-foot samples, the average buckling 
load of the 8-foot samples was higher than that of the 6-foot samples, but the ultimate load was less than that of the 6-foot samples.

\subsection{Conclusions}

Discussed in this section are observations regarding the results shown in the tables above and from the plots included above and in the appendix. Further investigation of these results follows in CHAPTER 4.

\subsubsection{Full Tie Line Samples}

The results of the full tie line test prove, as expected, that shorter length ties can withstand higher loads. When using shorter ties, the unbraced length is shortened thus reducing the chance of buckling. As the length of the ties increases, the load at which the sample buckles, and ultimately fails, decreases. A compression block installed in the center of the ties does not help to increase load carrying capabilities, based on the results of the four 6-foot samples with compression blocks installed and the 8-foot samples. For the longer samples (6-foot or 8-foot), the larger ties (FRP 5.5x1.5 and 6x1.625) allowed for higher load capacities. When considering the 4-foot samples, the FRP 3.5 -inch by 1.5 -inch channel ties generally provided for greater load capacities than the 4 -inch by 1.25 -inch or 4 -inch by 1.375 -inch channel ties.

Although the load results of the full tie line samples based on connection type does not correlate with the load results of the column-to-tie connection samples, the joint still has an impact on the load carrying capacities of the full tie line sample as load transfer through the sample is influenced by the connection type. Bushing in a connection causes extra bending. The extra bending could be due to ineffective or uneven load distribution through the sample; therefore, failure of samples where the connections included bushing in both the column and ties 
was typically a coupling of axial and bending. The samples with these connections are the ones that presented with more than one slope change in the load versus deflection plot, indicating that the bushing may not provide load distribution as effectively as the bolts alone. On the load versus deflection plots of full tie line samples where excessive deflection occurs under a constant load, most likely frictional slipping in the joint takes place; again suggesting that the connection type does impact load, but does not control the load.

Design of 6-foot and 8-foot full tie line samples is controlled by the design of the connection, whereas the design of the 4-foot samples is controlled by the simulated tie size. When considering the channel size, the thickness may need to be considered. With a thickness of 0.25 inch, the 4-foot FRP 4x1.25 samples consistently carried the lowest average ultimate loads. The thickness of both the FRP $3.5 \times 1.5$ and FRP 4x1.375 channels was 0.1875 inch, suggesting that a greater channel thickness may hinder load transfer thus reducing the load carrying capacities of the ties. Further research would be necessary to confirm the complete influence of thickness on the failure load.

It is important to note that ensuring the ties utilized are cut and attached to the columns both squarely and evenly. The failure of certain full tie line samples suggest that the ties may have been cut out-of-square and/or with discontinuities, which would significantly reduce the bearing area of the members. Also, if the ties are not installed squarely with the columns, the load will be applied unevenly potentially reducing the load carrying capacities of the structure.

\subsubsection{Column-to-Tie Line Connection Samples}

For all of the column-to-tie connection samples, failure can be described as local crushing at the bolt hole, indicating bearing failure. As a progressive, non-catastrophic failure, this is 
ideal for structural applications. The geometry of the connections provide a large enough edge distance so as to prevent more sudden and catastrophic failures, such as net tension or shear.

A connection is considered stronger than the full tie line samples itself when the connection has a yield load higher than the buckling load of the full tie line sample and an ultimate load that is also higher. Based on this definition, all connection types are stronger than the 8-foot samples, but no connection type is stronger than the 4-foot samples. The inclusion of bushing should allow for higher ultimate load capacity in the connection; however, due to the process of load transfer through the bushing, if bushing is installed in both the column and ties, the yield load may be reduced.

The results and the discussions of this section are based on samples where the bolts were installed finger-tight. Additional research, similar to that done by Doyle in 1991 and Manalo in 2012, to explore the influence of highly torqued bolts on the load transfer and behavior of bolted connections in cooling tower structures would provide insight into improvements to current cooling tower construction and effectiveness of connections. 


\section{CHAPTER 4 BOLTED CONNECTION STRENGTH PREDICTION}

\subsection{Pre-Standard for LRFD Pin-Bearing Failure Load Prediction}

Chapter eight of the Pre-Standard for LRFD of pultruded FRP pertains to the design of bolted bearing-type connections between, and to, pultruded FRP members and other FRP and metallic components. The connection types covered in this chapter of the Pre-Standard for LRFD are lap shear configuration with the loading principally in plane of the connecting components and members. The chapter does not apply to bolted connections with more than three bolts in a line that is parallel to the direction of the connection force and/or with three or more bolts in a single line with the connection force acting normal to this bolt. In the prestandard, the strength of a bolted connection shall be determined on the basis of the strength of its basic components. The nominal connection strength, $R_{n}$, is taken as the minimum of the bolt strength, the tension (through-the-thickness) strength, pin-bearing strength, net tension strength, shear-out strength, and cleavage strength. Since the mode of failure for all of the connections was pin-bearing, as previously stated, the following sections focus on the nominal pin-bearing strength determined according to Section 8.3.2.3 of the Pre-Standard for LRFD.

\subsubsection{Column-to-Tie Connection Geometry}

Before utilizing the equations in the pre-standard, it was necessary to confirm the column-to-tie connections satisfied the minimum requirements for bolted geometries, as described in Section 2.2.1. Stated previously, the connections were either singly bolted or 
doubly bolted, depending on the size of the FRP channel tie. The geometry of the column-to-tie connections are shown in Figure 4-1 for a singly bolted connection and Figure 4-2 for a doubly bolted connection. Table 4-1 compares the end distance, edge distance and gage spacing in the column-to-tie connection samples to the minimum required in the pre-standard, verifying that all requirements were met in all samples.

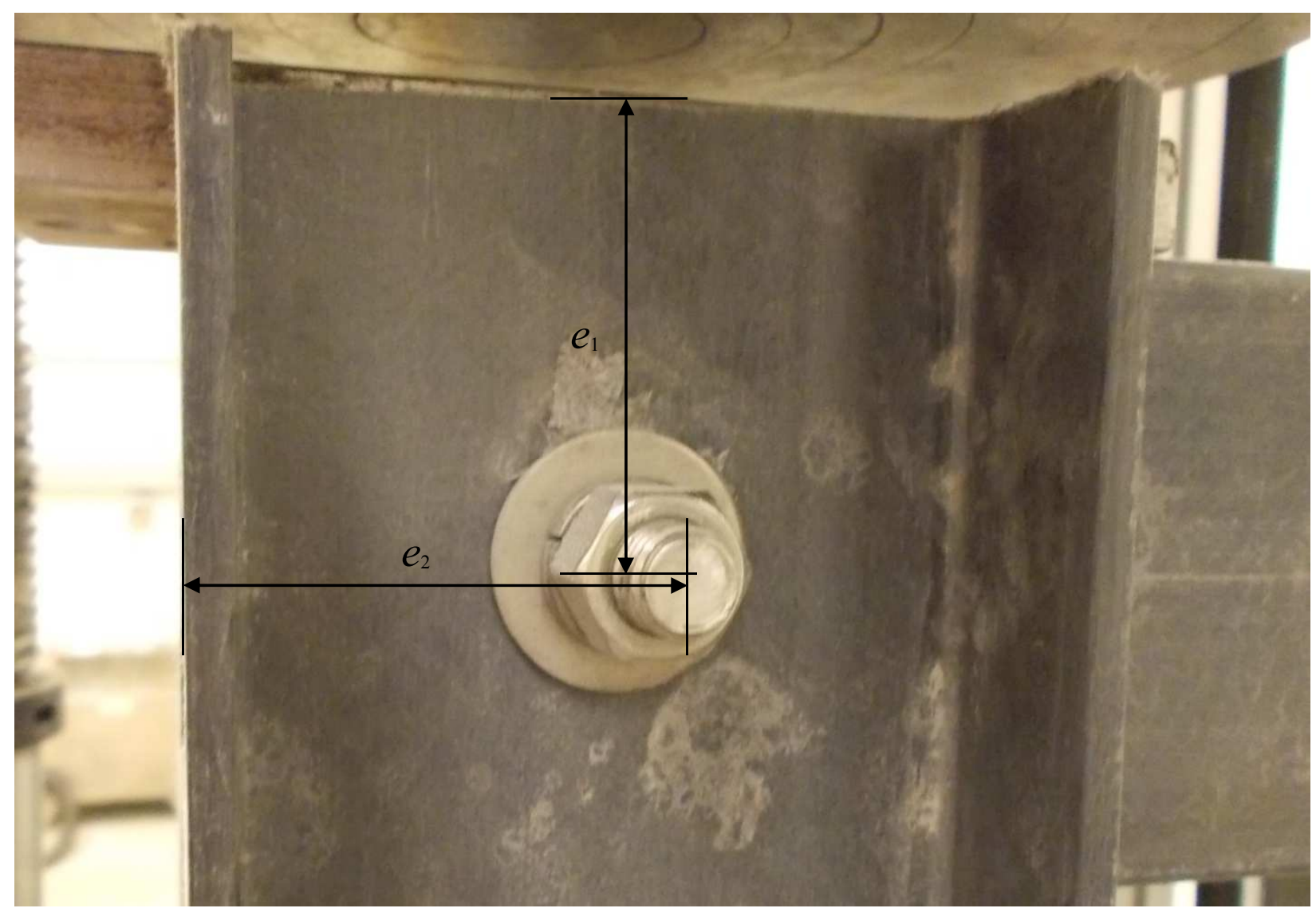

Figure 4-1: Connection Geometry Labeled on FRP 4x1.375 (Singly Bolted) Sample 


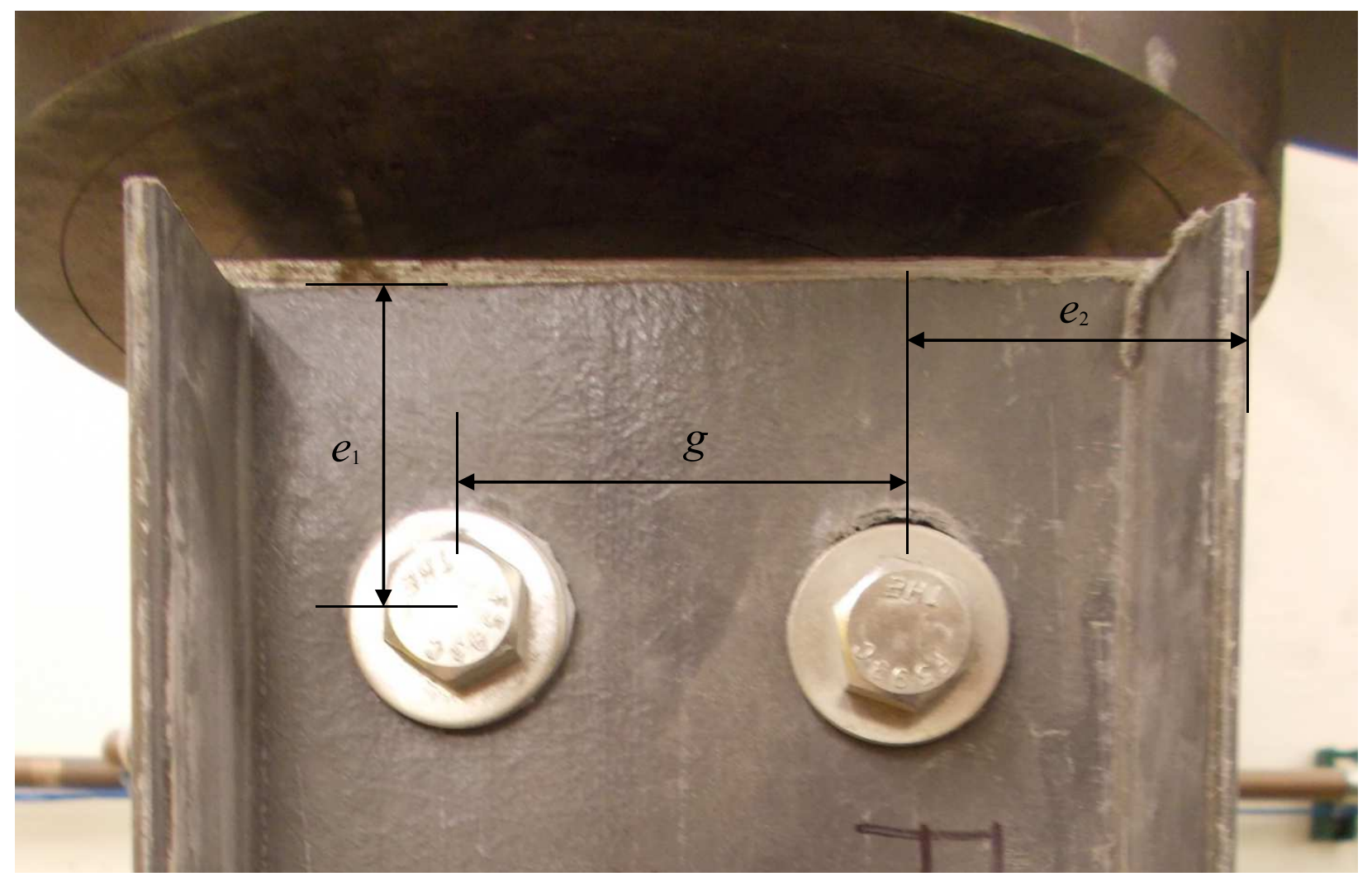

Figure 4-2: Connection Geometry Labeled on FRP 5.5x1.5 (Doubly Bolted) Sample

Table 4-1: Connection Geometries in Column-to-Tie Bolted Connections

\begin{tabular}{|c|c|c|c|c|c|c|}
\hline \multirow{2}{*}{ Dimension } & \multirow{2}{*}{$\begin{array}{l}\text { Minimum } \\
\text { Required }\end{array}$} & \multicolumn{5}{|c|}{ FRP Channel Size } \\
\hline & & $3.5 " \times 1.5 "$ & $4 " x 1.25 "$ & $4 " x 1.375 "$ & $5.5 " x 1.5 "$ & $6 " x 1.625 "$ \\
\hline$e_{1}$ & $2 d=3 / 4$ & 2 & 2 & 2 & 2 & 2 \\
\hline$e_{2}$ & $1.5 d=9 / 16$ & $7 / 4$ & 2 & 2 & $3 / 2$ & $7 / 4$ \\
\hline$g$ & $4 d=3 / 2$ & N/A & N/A & $\mathrm{N} / \mathrm{A}$ & 2.5 & 2.5 \\
\hline$t$ & N/A & $3 / 16$ & $1 / 4$ & $3 / 16$ & $3 / 16$ & $1 / 4$ \\
\hline
\end{tabular}

*All values listed are in inches.

\subsubsection{Pin-Bearing Strength Formula and Calculation}

In the pre-standard for LRFD for pultruded FRP composites, the pin-bearing strength,

$R_{\mathrm{br}}$, is given by the projected area of bolt bearing multiplied by the characteristic pin-bearing 
strength, $F_{\theta}^{b r}$, for the orientation, $\theta$, of the resultant force at the bolt-FRP contact with respect to the direction of pultrusion. The formula per bolt is given as

$$
\begin{aligned}
& R_{b r}=t d F_{\theta}^{b r} \\
& \emptyset_{c}=0.8
\end{aligned}
$$

Equation 4-1

where

$\mathrm{t} \quad=$ Thickness of the FRP component and/or member

$\mathrm{d} \quad=$ Nominal diameter of bolt

$F_{\theta}^{b r}=$ Characteristic pin-bearing strength for the orientation of the resultant force at the bolt/FRP contact with respect to the direction of pultrusion, given by Equation

$\emptyset_{c} \quad=$ Resistance factor for FRP connections

$$
\begin{aligned}
F_{\theta}^{b r} & =F_{L}^{b r} \text { when } \theta \text { is } \leq 5^{\circ} \\
& =F_{T}^{b r} \text { when } 5^{\circ}<\theta \leq 90^{\circ}
\end{aligned}
$$

Equation 4-2

where

$\theta \quad=$ Angle of loading, between the direction of the connection force and the direction of pultrusion

$F_{L}^{b r} \quad=$ Characteristic pin-bearing strength in the longitudinal direction of FRP

$F_{T}^{b r} \quad=$ Characteristic pin-bearing strength in the transverse direction of FRP

Bedford Reinforced Plastics provided West Virginia University with appropriate pinbearing strength data obtained in accordance with ASTM D953. The average of the maximum 
load data supplied was used for $F_{L}^{b r}$ and $F_{T}^{b r}$. Tables in APPENDIX D - Bearing Strength Data from Bedford Reinforced Plastics show the original data.

Equation 4-1 is applicable for this study as there is a washer and either a nut or the bolt head on both sides of the connection and the bolting is snug tight as stated in the previous chapter. The pin-bearing strengths listed in Table 4-2 were found using Equation 4-1 and the values provided by Bedford Reinforced Plastics. These pin-bearing strength values do not include the resistance factor, $\emptyset_{\mathrm{c}}$.

Table 4-2: Pre-Standard for LRFD Pin-Bearing Strengths Based on Tie Size Channel Dimensions, web depth $x$ flange width $x$ thickness LRFD Pin-Bearing Strength, $\mathbf{R}_{\mathrm{br}}$ (Ibs) (in)

\begin{tabular}{cc}
\hline $3.5 \times 1.5 \times 0.1875$ & 3778 \\
$4 \times 1.25 \times 0.25$ & 5037 \\
$4 \times 1.375 \times 0.1875$ & 3778 \\
$5.5 \times 1.5 \times 0.1875$ & 7556 \\
$6 \times 1.625 \times 0.25$ & 10075 \\
\hline
\end{tabular}

\subsubsection{Effectiveness of Pin-Bearing Strength Equation}

For every sample, as desired, the calculated LRFD pin-bearing strength (without resistance factor) was less than the actual ultimate load, as shown in Table 4-3.

Table 4-3: Connection Test Results with LRFD Pin-Bearing Strengths for Comparison

\begin{tabular}{|c|c|c|c|c|c|}
\hline Sample & $\begin{array}{l}\text { Yield } \\
\text { Load } \\
\text { (lbs) }\end{array}$ & $\begin{array}{l}\text { Ultimate } \\
\text { Load (lbs) }\end{array}$ & $\begin{array}{c}\text { Average } \\
\text { Ultimate } \\
\text { Load (lbs) }\end{array}$ & $\mathbf{R}_{\mathrm{br}}$ (Ibs) & $\begin{array}{c}R_{\mathrm{u}}=\phi_{\mathrm{c}} \mathbf{R}_{\mathrm{br}} \\
(\mathrm{lbs})\end{array}$ \\
\hline FRP $4 \times 1.375$ No Sample 1 & 4595 & 5883 & \multirow{2}{*}{6328} & \multirow{2}{*}{3778} & \multirow{2}{*}{3022} \\
\hline FRP $4 \times 1.375$ No Sample 2 & 4497 & 6773 & & & \\
\hline FRP 5.5x1.5 No Sample 1 & 10746 & 12174 & \multirow{2}{*}{12950} & \multirow{2}{*}{7556} & \multirow{2}{*}{6045} \\
\hline FRP 5.5x1.5 No Sample 2 & 10146 & 13726 & & & \\
\hline FRP 6x1.625 No Sample 1 & 9795 & 10829 & \multirow{2}{*}{11365} & \multirow{2}{*}{10075} & \multirow{2}{*}{8060} \\
\hline FRP 6x1.625 No Sample 2 & 9200 & 11901 & & & \\
\hline FRP 3.5x1.5 Bush-Col Sample 1 & 5066 & 7088 & 6930 & 3778 & 3022 \\
\hline
\end{tabular}




\begin{tabular}{|c|c|c|c|c|c|}
\hline FRP 3.5x1.5 Bush-Col Sample 2 & 4646 & 6771 & \multirow{3}{*}{7653} & \multirow{3}{*}{5037} & \multirow{3}{*}{4030} \\
\hline FRP $4 \times 1.25$ Bush-Col Sample 1 & 9104 & 9104 & & & \\
\hline FRP 4x1.25 Bush-Col Sample 2 & 5521 & 6202 & & & \\
\hline FRP 4x1.375 Bush-Col Sample 1 & 4743 & 6601 & \multirow{2}{*}{6206} & \multirow{2}{*}{3778} & \multirow{2}{*}{3022} \\
\hline FRP 4x1.375 Bush-Col Sample 2 & 5007 & 5811 & & & \\
\hline FRP 5.5x1.5 Bush-Col Sample 1 & 13230 & 14926 & \multirow{2}{*}{15205} & \multirow{2}{*}{7556} & \multirow{2}{*}{6045} \\
\hline FRP 5.5x1.5 Bush-Col Sample 2 & 13249 & 15484 & & & \\
\hline FRP 6x1.625 Bush-Col Sample 1 & 13799 & 15997 & \multirow{2}{*}{15507} & \multirow{2}{*}{10075} & \multirow{2}{*}{8060} \\
\hline FRP $6 \times 1.625$ Bush-Col Sample 2 & 11499 & 15016 & & & \\
\hline FRP 3.5x1.5 Bush-Both Sample 1 & 7099 & 7781 & \multirow{2}{*}{8375} & \multirow{2}{*}{3778} & \multirow{2}{*}{3022} \\
\hline FRP 3.5x1.5 Bush-Both Sample 2 & 6248 & 8968 & & & \\
\hline FRP $4 \times 1.375$ Bush-Both Sample 1 & 6199 & 9978 & \multirow{2}{*}{9709} & \multirow{2}{*}{3778} & \multirow{2}{*}{3022} \\
\hline FRP $4 \times 1.375$ Bush-Both Sample 2 & 5044 & 9439 & & & \\
\hline FRP 5.5x1.5 Bush-Both Sample 1 & 8749 & 18811 & \multirow{2}{*}{19013} & \multirow{2}{*}{7556} & \multirow{2}{*}{6045} \\
\hline FRP 5.5x1.5 Bush-Both Sample 2 & 8998 & 19215 & & & \\
\hline FRP $6 \times 1.625$ Bush-Both Sample 1 & 4500 & 18735 & \multirow{2}{*}{18509} & \multirow{2}{*}{10075} & \multirow{2}{*}{8060} \\
\hline FRP $6 \times 1.625$ Bush-Both Sample 2 & 7999 & 18282 & & & \\
\hline
\end{tabular}

The calculated LRFD pin-bearing strength, $\mathrm{R}_{\mathrm{br}}$, ranges from $39 \%$ to $89 \%$ of the average ultimate load for all samples. The accuracy of the LRFD pin-bearing strength is generally best for the samples with no bushing in the connection and worst for samples with bushing in both the column and ties. For any connection type, the LRFD pin-bearing strength equation was more accurate for the samples with 0.25 inch thick channels (FRP 4x1.25 and FRP 6x1.625) than the samples with 0.1875 inch thick channels (FRP 3.5x1.5, FRP 4x1.375 and FRP 5.5x1.5). The percentage of LRFD pin-bearing strength to the average ultimate load was at between $58 \%$ and $89 \%$ for these samples with no bushing. When considering the ratio of LRFD pin-bearing strength to the average yield load for samples with no bushing, the range was between $72 \%$ and $106 \%$. For the samples with bushing in both the column and ties, the comparison ranged from $39 \%$ to $54 \%$ when considering average ultimate load and $57 \%$ to $161 \%$ when considering average yield load. When there was bushing in only the column, the values of LRFD pin-bearing 
strength were anywhere from $50 \%$ to $66 \%$ of the average ultimate load and $57 \%$ to $80 \%$ of the average yield load.

The LRFD equation, as it is currently written, does not allow for the influence of hard plastic bushings on failure load to be considered. Installing additional hardware to a connection, beyond the bolt, washers and nut that are stipulated in the pre-standard, introduces new reactions and behaviors in the joint. For example, when hard plastic bushings are installed, the load is distributed over a different area. The hole drilled in the FRP sections needs to be larger, introducing different stress concentrations into the member. The gap between the bolt and the inner bushing diameter was more often larger than the spacing between the bolt and the FRP section (when bushing was not installed), allowing for more area for load transfer from the column ultimately to the bolt. Additionally, the load is transferred in a different pattern, as it must first transfer through (and sometimes crush) the bushings before transferring to the bolt. None of these factors are incorporated into the current LRFD equation. Utilizing the bushing diameter in place of the bolt diameter in Equation 4-1 does not increase the effectiveness of the equation in predicting load for connections with bushing. In fact, it does the opposite.

No matter the connection type (bushing or no bushing), in the LRFD pin-bearing equation, bolt diameter is still used. Although considered in the analysis process, the outer bushing diameter is not effective in predicting an accurate and/or safe load for connections with bushing in the column or in the column and ties. When the outer bushing diameter was used in place of the bolt diameter, $d$, in Equation 4-1 the LRFD pin-bearing strength increased by approximately $150 \%$. For example, the LRFD pin-bearing strength of FRP 6x1.625 samples with bushing increased from the 10075 lbs listed in Table 4-2 to 26027 lbs. Therefore, only bolt diameter should ever be used with Equation 4-1, never outer or inner bushing diameter. 


\subsection{Ascione, Feo, and Maceri Pin-Bearing Failure Load Prediction}

As discussed in Section 2.2.3.2.2, Ascione, Feo, and Maceri (2010) developed a formula that utilizes only three test values to predict the pin-bearing ultimate load of symmetrical GFRP laminates of a given diameter and given laminate type. The intention of the experimental effort was to evaluate the influence of bolt diameter on the pin-bearing failure load of GFRP laminates. In the study, the lateral restraint due to bolt tightening was neglected.

\subsubsection{Pin-Bearing Strength Formula and Calculation}

The pin-bearing failure load $F_{u}^{(\alpha)}$ can be expressed as follows:

$$
F_{u}^{(\alpha)}=\xi F_{u}^{0}\left[\left(1-\frac{F_{u}^{(\pi / 2 m)}}{F_{u}^{0}}\right)\left(A_{\alpha}\right)^{5}+\frac{F_{u}^{(\pi / 2 m)}}{F_{u}^{0}}+C(m \alpha)^{3}\left(A_{\alpha}\right)^{3}\right]
$$

The proposed generalization takes into account the hole and bolt diameters as well as their influence on the failure load.

The pin-bearing strengths found using the above formula are listed in Table 4-4 with the associated value for hole diameter, $\mathrm{d}_{\mathrm{h}}$.

Table 4-4: Pin-Bearing Strengths Based on Hole Diameter

\begin{tabular}{cc}
\hline Hole Diameter, $\mathbf{d}_{\mathbf{h}}$ & Pin-Bearing Strength, $\mathbf{F}_{\mathbf{u}}{ }^{(\boldsymbol{\alpha})}$ (Ibs) $^{(\mathrm{b})}$ \\
\hline Bolt Hole (0.5 in) & 1330.342317 \\
Inner Bushing Diameter $(9 / 16 \mathrm{in})$ & 1108.52462 \\
Outer Bushing Diameter $(31 / 32 \mathrm{in})$ & 393.915743 \\
\hline
\end{tabular}

\subsubsection{Effectiveness of Pin-Bearing Strength Equation}

The pin-bearing failure loads presented above proved highly inaccurate for prediction of bearing failure load in the cooling tower column-to-tie connections. For every sample, as 
desired, the calculated pin-bearing strength was less than the actual ultimate load, as shown in Table 4-5.

Table 4-5: Connection Test Results with Calculated Pin-Bearing Strengths for Comparison

\begin{tabular}{|c|c|c|c|c|}
\hline Sample & $\begin{array}{l}\text { Yield Load } \\
\quad \text { (Ibs) }\end{array}$ & $\begin{array}{l}\text { Ultimate } \\
\text { Load (Ibs) }\end{array}$ & $\begin{array}{c}\text { Average } \\
\text { Ultimate } \\
\text { Load (Ibs) }\end{array}$ & $F_{u}^{(\alpha)}(\mathrm{lbs})$ \\
\hline FRP $4 \times 1.375$ No Sample 1 & 4595 & 5883 & \multirow{2}{*}{6328} & \multirow{6}{*}{1330} \\
\hline FRP $4 \times 1.375$ No Sample 2 & 4497 & 6773 & & \\
\hline FRP 5.5x1.5 No Sample 1 & 10746 & 12174 & \multirow{2}{*}{12950} & \\
\hline FRP 5.5x1.5 No Sample 2 & 10146 & 13726 & & \\
\hline FRP $6 \times 1.625$ No Sample 1 & 9795 & 10829 & \multirow{2}{*}{11365} & \\
\hline FRP $6 \times 1.625$ No Sample 2 & 9200 & 11901 & & \\
\hline FRP 3.5x1.5 Bush-Col Sample 1 & 5066 & 7088 & \multirow{2}{*}{6930} & \multirow{10}{*}{1109} \\
\hline FRP 3.5x1.5 Bush-Col Sample 2 & 4646 & 6771 & & \\
\hline FRP 4x1.25 Bush-Col Sample 1 & 9104 & 9104 & \multirow{2}{*}{7653} & \\
\hline FRP 4x1.25 Bush-Col Sample 2 & 5521 & 6202 & & \\
\hline FRP 4x1.375 Bush-Col Sample 1 & 4743 & 6601 & \multirow{2}{*}{6206} & \\
\hline FRP 4x1.375 Bush-Col Sample 2 & 5007 & 5811 & & \\
\hline FRP 5.5x1.5 Bush-Col Sample 1 & 13230 & 14926 & \multirow{2}{*}{15205} & \\
\hline FRP 5.5x1.5 Bush-Col Sample 2 & 13249 & 15484 & & \\
\hline FRP 6x1.625 Bush-Col Sample 1 & 13799 & 15997 & \multirow{2}{*}{15507} & \\
\hline FRP 6x1.625 Bush-Col Sample 2 & 11499 & 15016 & & \\
\hline FRP 3.5x1.5 Bush-Both Sample 1 & 7099 & 7781 & \multirow{2}{*}{8375} & \multirow{8}{*}{1109} \\
\hline FRP $3.5 \times 1.5$ Bush-Both Sample 2 & 6248 & 8968 & & \\
\hline FRP 4x1.375 Bush-Both Sample 1 & 6199 & 9978 & \multirow{2}{*}{9709} & \\
\hline FRP 4x1.375 Bush-Both Sample 2 & 5044 & 9439 & & \\
\hline FRP 5.5x1.5 Bush-Both Sample 1 & 8749 & 18811 & \multirow{2}{*}{19013} & \\
\hline FRP 5.5x1.5 Bush-Both Sample 2 & 8998 & 19215 & & \\
\hline FRP $6 \times 1.625$ Bush-Both Sample 1 & 4500 & 18735 & \multirow{2}{*}{18509} & \\
\hline FRP $6 \times 1.625$ Bush-Both Sample 2 & 7999 & 18282 & & \\
\hline
\end{tabular}

The calculated pin-bearing strength was at most $21 \%$ of the average ultimate load for each sample type. The calculated pin-bearing strength predicted as low as only $6 \%$ of the average ultimate load for each sample type. For a connection with no bushing, the ratio of the calculated pin-bearing strength to the average ultimate load was typically higher than the ratio for connections with bushing. An initial explanation for this could be that the formula developed by 
Ascione, Feo, and Maceri does not consider the impact of bushing in a connection. For connections with no bushing, the diameter of the hole ( 0.5 inches) was used as $\mathrm{d}_{\mathrm{h}}$ in Equation 4-3, and for connections with bushing in the column or in the column and ties, the inner diameter of the bushing was used. If the outer diameter of the bushing was used for $\mathrm{d}_{\mathrm{h}}$, the calculated values for pin-bearing strength were less than $5 \%$ of the average ultimate load of each sample type. Therefore, when the connection includes bushings, the inner diameter of the bushings should be used as the diameter of the bolt hole in the provided formula.

For samples with no bushing, the ratio of the calculated pin-bearing strength to the average ultimate load ranged from $10 \%$ to $21 \%$. When considering the ratio for the average yield load, that range is increased to $13 \%$ to $29 \%$. With bushing in both the column and ties, the ratio ranged from $6 \%$ to $13 \%$ when considering the average ultimate load and from $12 \%$ to $20 \%$ when considering the yield load. For samples with bushing in only the column, the values of pinbearing strength ranged from $7 \%$ to $18 \%$ of the average ultimate load and from $8 \%$ to $23 \%$ of the average yield load. Based on these ratios, Equation 4-3 is not effective in predicting the ultimate load, or even yield load, for these column-to-tie connection samples. The formula does not consider the any dimensions of the sample beyond the diameter of the hole. The study that produced this formula was considering the influence of bolt hole on pin-bearing strength; however, many other parameters impact the pin-bearing strength of a connection. If the formula were developed further, to incorporate more of those parameters, including connection and/or sample geometry, it could be more effective in predicting the pin-bearing strength of a connection in FRP structures. The idea that the pin-bearing failure load can be determined by means of only three test values, which Ascione, Feo, and Maceri (2010) based the formula on, is not a fully supported concept based on these results. 


\subsection{Summary}

Various connections between FRP column and ties in cooling tower structures were tested to determine the ultimate failure load. Three connection types were tested with different tie (FRP channel) sizes: (1) no bushing, only stainless steel bolts; (2) plastic bushing installed in FRP column only with stainless steel bolts; and (3) plastic bushing installed in both FRP column and tie with stainless steel bolts. The connection type did not impact the failure mode of the sample. All column-to-tie connection tests resulted in bearing failures. The average ultimate load for each sample type was compared to the predicted pin-bearing failure load. The pinbearing failure load was calculated by two different equations for comparison. The two equations include the pre-standard for LRFD pin-bearing strength equation and the pin-bearing strength equation developed by Ascione, Feo, and Maceri. The LRFD pin-bearing strength equation was effective in predicting the pin-bearing strength for most samples, while the equation developed by Ascione predicted well below the actual ultimate load. Both equations, however, proved more accurate for the connections with no bushing. When bushing is installed, the behavior of the connection is affected. Current equations for bolted connection strength do not account for the different joint behavior. For the LRFD equation, the bolt diameter should always be used as $d$, even if the connection contains bushing. In the equation developed by Ascione, the hole diameter should be used as $d_{h}$ when calculating for connections with no bushing, while the inner bushing diameter should be used as $d_{h}$ when calculating for connections with bushing in the column or in the column and tie. The equation provided in the pre-standard for LRFD can be considered effective for predicting the strength of connections between columns and ties in cooling tower structures; however, the equation provided by Ascione cannot effectively predict the pin-bearing strength of connections between columns and ties. 


\section{CHAPTER 5 CONCLUSIONS AND RECOMMENDATIONS}

\subsection{Conclusions}

Chapter eight of the ASCE / ACMA Pre-Standard for Load and Resistance Factor Design (LRFD) of Pultruded Fiber Reinforced Polymer (FRP) Structures pertains to the design of bolted bearing-type connections between, and to, pultruded FRP members and other FRP and metallic components. The pre-standard has undergone several revisions since its development began in 2008. The objective of the research presented in this paper was to analyze the accuracy of existing prediction models for determining the bolted connection strength in FRP structures. Through extensive testing performed at the West Virginia University Constructed Facilities Center (WVU-CFC), researchers could conclude the equations provided in the most recent draft version of chapter eight of the pre-standard have shown to be effective for bolted connections between FRP channels and square tubes for cooling tower structures. This study includes a literature review of previous studies related to prediction of bolted connection strength, as well as background information to assist in the understanding of the research effort, including failure modes of FRP connections and members.

Cooling Towers of Texas (CTofTX) provided the WVU-CFC the opportunity to carry out the testing program to better understand the behavior of various tie lines and the associated bolted connections used in cooing tower construction. The varying FRP samples tested represented different options in terms of section size, length and connection details for cooling tower structural tie designs. Tests were performed on full tie line samples as well as on shorter samples for column-to-tie line connections. These connections utilized different bushing options 
between the tie lines and columns. The bushings proved to enable a higher load transfer by spreading the tear-out stresses associated with a bolted connection over a greater area. The shortest full tie line samples tested, the 4-foot samples, proved the most effective design when considering highest load carrying capabilities. For these samples, the chance of buckling is reduced. If possible, it is recommended 4-foot bays be used in cooling tower structures. The load carried by 6-foot and 8-foot ties does not compare well to the 4-foot ties. Design of tie line structures will be controlled by the connection when the ties are the longer 6-foot or 8-foot. Most often these samples failed due to buckling, either globally or locally, despite attempts to brace against local instabilities.

All column-to-tie line connections showed as bearing failures, meaning the connection type did not impact the failure mode of the sample; thus, analysis and evaluation of the results pertained to pin-bearing failure loads. Ultimate loads from experimental testing were compared with pin-bearing failure loads calculated from the pre-standard for LRFD and loads calculated from pin-bearing strength equations developed by Ascione.

\subsection{Recommendations}

Results of the LRFD equation exhibit good precision and low accuracy, while the equation developed by Ascione predicts with low precision and low accuracy. Both equations, however, proved most accurate for the connections with no bushing. The ratio of the predicted load from the LRFD equation to the ultimate load from the test is fairly consistent for each connection type; however, the predicted value was less accurate when more bushing was installed in the connection. Current equations for bolted connection strength do not account for the different joint behavior, including load distribution and transfer, associated with hard plastic bushings. In order for the LRFD equation to be considered effective, the bolt diameter must 
always be used as $d$, even if the connection contains bushing. As the equation is now established, the inclusion of bushing in the connection does not influence the failure load; however, from experimental data, the opposite is shown to be true. In structural applications, the inclusion of bushing in the connections allows the structure to carry higher loads. LRFD equations should be modified to incorporate the influence that the hard plastic bushings have on the connection strengths. However, the current LRFD equation could be used for connections without any additional hardware, such as hard plastic bushings.

Examination of previously published works on the analytical and experimental behavior of pultruded FRP members show that while the subject has been explored to some degree, reliable and accurate design criteria are still lacking. While current equations can be considered partially effective, further development is necessary to ensure effectiveness for different construction conditions and applications. 


\section{REFERENCES}

American Society of Civil Engineers / American Composite Manufacturers Association (2010). "Pre-Standard for Load and Resistance Factor Design (LRFD) of Pultruded Fiber Reinforced Polymer (FRP) Structures.” Chapter 8.

Ascione, L., Giordano, A., \& Spadea, S. (2011). "Lateral buckling of pultruded FRP beams." Composites Part B: Engineering, 42(4), 819-824.

Ascione, F., Feo, L., \& Maceri, F. (2010). "On the pin-bearing failure load of GFRP bolted laminates: an experimental analysis on the influence of bolt diameter." Composites Part B: Engineering, 41(6), 482-490.

Bakis, C., Bank, L. C., Brown, V., Cosenza, E., Davalos, J. F., Lesko, J. J. ... \& Triantafillou, T. C. (2002). "Fiber-Reinforced Polymer Composites for Construction - State-of-the-Art Review.” Journal of Composites for Construction, 6(2), 73-87.

Blandford, M. M. (2010). “Critical buckling strength prediction of pultruded GFRP composite columns.” M.S. thesis, West Virginia University, Morgantown, WV.

Doyle, J. R. (1991). "Behavior of bolt and adhesive connections in glass fiber reinforced plastic members.” M.S. thesis, West Virginia University, Morgantown, WV.

Duthinh, D. (2000). “Connections of fiber-reinforced polymer (FRP) structural members: a 
review of the state of the art." National Institute of Standards and Technology, Maryland, Chapter 2.

Estep, D. D. (2014). "Bending and shear behavior of pultruded glass fiber reinforced polymer composite beams with closed and open sections.” M.S. thesis, West Virginia University, Morgantown, WV.

Gilby, J. (1999). "Cooling tower shows end users the benefits of FRP.” Reinforced Plastics, 43(9), 34-36.

Hassan, N. K., Mohamedien, M. A., \& Rizkalla, S. H. (1996). "Finite element analysis of bolted connections for PFRP composites." Composites Part B: Engineering, 27(3), 339-349.

Howard, B., \& Belinky, A. (1999). "Pultruded FRP proves ideal for cooling towers." Reinforced Plastics, 43(3), 48-50.

Liang, R. and GangaRao, H. V. S. (2013). "Fiber-reinforced polymer (FRP) composites in environmental engineering applications." Developments in fiber-reinforced polymer (FRP) composites for civil engineering, N. Uddin, ed., Woodhead Publishing, Philadelphia, PA, 410-468.

Mallick, P. K. (1993). Fiber-reinforced composites: materials, manufacturing, and design. CRC press. 
Manalo, A., \& Mutsuyoshi, H. (2011). "Behaviour of fibre-reinforced composite beams with mechanical joints." Journal of composite materials, 0021998311418263.

McShane, G. J., Stewart, C., Aronson, M. T., Wadley, H. N. G., Fleck, N. A., \& Deshpande, V. S. (2008). "Dynamic rupture of polymer-metal bilayer plates." International Journal of Solids and Structures, 45(16), 4407-4426.

Mottram, J. T. (2009). "Design guidance for bolted connections in structures of pultruded shapes: gaps in knowledge." Proceedings of the 17th International Conference on Composite Materials (ICCM17) (No. Paper A1: 6, pp. 1-10). IOM Communications Ltd..

Mottram, J. T. (2009). "Determination of pin-bearing strength for the pin-design of bolted connections with standard pultruded profiles."

Mottram, J. T., \& Turvey, G. J. (2003). "Physical test data for the appraisal of design procedures for bolted joints in pultruded FRP structural shapes and systems." Progress in Structural Engineering and Materials, 5(4), 195-222.

Mottram, J. T., and Zafari, B. (2011). "Pin-bearing strengths for bolted connections in fibrereinforced polymer structures." Proceedings of the Institution of Civil Engineers: Structures and Buildings, 164(5), 291-305. 
Mottram, J. T., \& Zheng, Y. (1996). "State-of-the-art review on the design of beam-to-column connections for pultruded frames." Composite structures, 35(4), 387-401.

Oppe, M. W., and Knippers, J. (2011). “Application of bolted connections in fibre-reinforced polymers." Proceedings of the Institution of Civil Engineers: Structures and Buildings, $164(5), 321-332$.

Pisano, A. A., Fuschi, P., \& De Domenico, D. (2013). "Failure modes prediction of multi-pin joints FRP laminates by limit analysis." Composites Part B: Engineering, 46, 197-206.

Prabhakaran, R., Razzaq, Z., \& Devara, S. (1996). “Load and resistance factor design (LRFD) approach for bolted joints in pultruded composites." Composites Part B: Engineering, 27(3), 351-360.

Zafari, B., \& Mottram, J. T. (2011). "Pin-bearing strengths for design of bolted connections in pultruded structures." Advances in FRP Composites in Civil Engineering, 99-102. Springer Berlin Heidelberg.

Zureick, A. (1998). "FRP pultruded structural shapes." Progress in Structural Engineering and Materials, 1(2), 143-149. 


\section{APPENDIX A - LOAD VS DEFLECTION PLOTS}

\section{FRP $-3.5 \times 1.5$ Ties}

\begin{tabular}{|c|c|c|c|c|}
\hline Sample & $\begin{array}{c}\text { Buckling } \\
\text { Load } \\
\text { (lb) } \\
\end{array}$ & $\begin{array}{l}\text { Ultimate } \\
\text { Load } \\
\text { (lb) } \\
\end{array}$ & Failure Mode & Failure Description \\
\hline FRP.3.5x1.5-4.No 1 & 11614 & $15471 *$ & $\begin{array}{l}\text { Distortional } \\
\text { Buckling }\end{array}$ & $\begin{array}{l}\text { Channels bowed and } \\
\text { twisted apart }\end{array}$ \\
\hline FRP.3.5x1.5-4.No 2 & 18533 & 19647 & $\begin{array}{c}\text { Distortional } \\
\text { Buckling/Material } \\
\text { Rupture }\end{array}$ & $\begin{array}{l}\text { Channels bowed and } \\
\text { twisted apart; tore along } \\
\text { channel corners }\end{array}$ \\
\hline No Bush Average $=$ & 15073 & 17559 & & $N / A$ \\
\hline $\begin{array}{l}\text { FRP.3.5x1.5-4.Bush- } \\
\text { Col } 1\end{array}$ & 5360 & $17527 *$ & Local Instability & Channels bowed \\
\hline $\begin{array}{l}\text { FRP.3.5x1.5-4.Bush- } \\
\text { Col } 2\end{array}$ & 8068 & $13893^{*}$ & $\begin{array}{l}\text { Distortional } \\
\text { Buckling }\end{array}$ & $\begin{array}{l}\text { Channels bowed and } \\
\text { twisted together }\end{array}$ \\
\hline Bush-Col Average $=$ & 6714 & 15710 & & $N / A$ \\
\hline $\begin{array}{l}\text { FRP. } 3.5 \times 1.5-4 . \text { Bush- } \\
\text { Both } 1\end{array}$ & 4193 & $9417 *$ & Local Instability & Channels bowed \\
\hline $\begin{array}{l}\text { FRP. } 3.5 \times 1.5-4 . \text { Bush- } \\
\text { Both } 2\end{array}$ & 4928 & 15276 & Material Rupture & $\begin{array}{l}\text { Tore along channel } \\
\text { corner }\end{array}$ \\
\hline Bush-Both Average = & 4561 & 12346 & & $N / A$ \\
\hline Average $($ all $)=$ & 8783 & 15205 & & $N / A$ \\
\hline
\end{tabular}

*Ultimate load is maximum load of test, not breaking load. Samples did not fracture. 

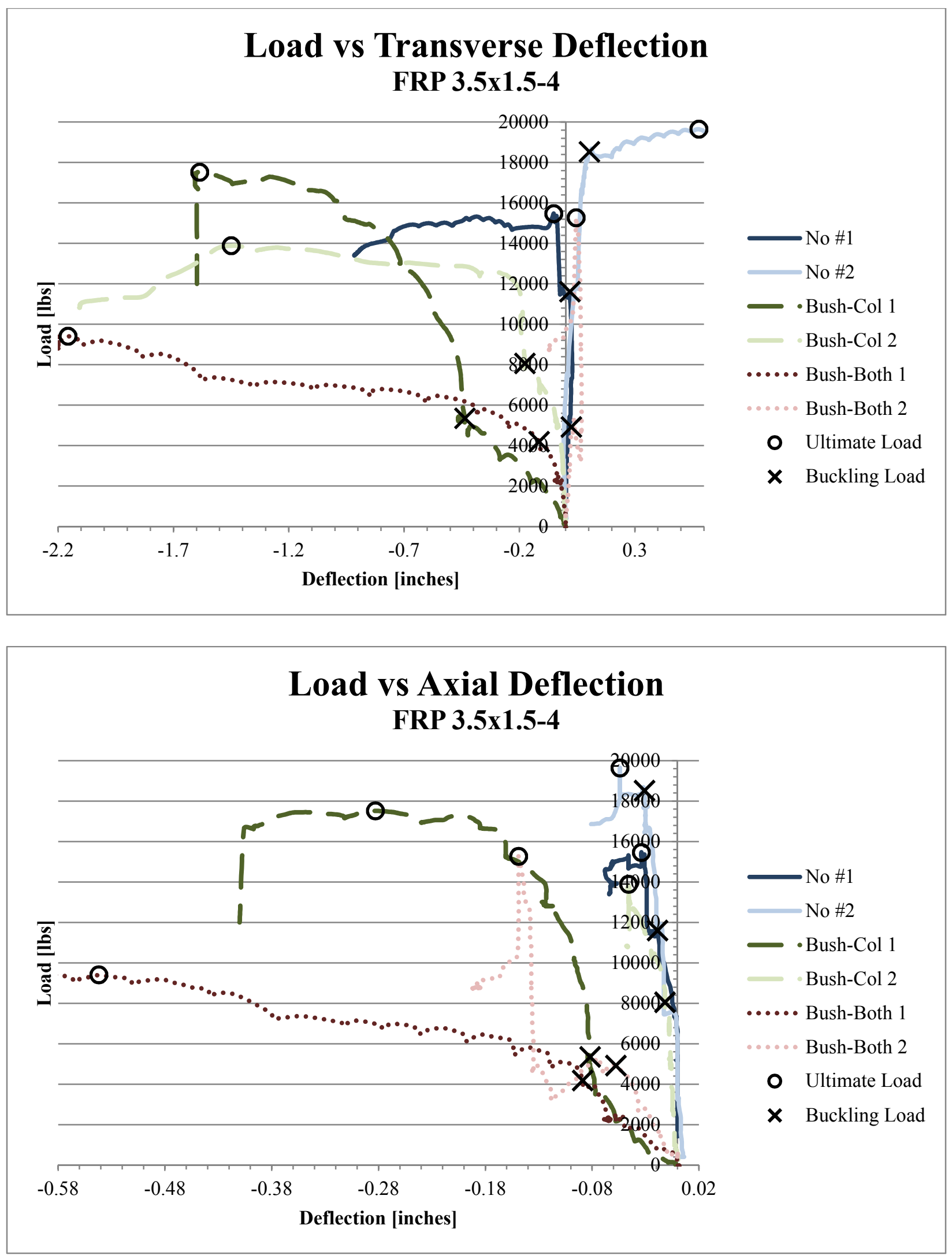


\begin{tabular}{|c|c|c|c|c|}
\hline Sample & $\begin{array}{c}\text { Buckling } \\
\text { Load } \\
\text { (lb) } \\
\end{array}$ & $\begin{array}{l}\text { Ultimate } \\
\text { Load } \\
(\text { lb) } \\
\end{array}$ & Failure Mode & $\begin{array}{c}\text { Failure } \\
\text { Description }\end{array}$ \\
\hline FRP.3.5x1.5-6.No 1 & 6787 & $9490 *$ & $\begin{array}{l}\text { Distortional } \\
\text { Buckling }\end{array}$ & $\begin{array}{l}\text { Channels bowed } \\
\text { and twisted in same } \\
\text { direction }\end{array}$ \\
\hline FRP.3.5x1.5-6.No 2 & 6171 & $8972 *$ & $\begin{array}{l}\text { Distortional } \\
\text { Buckling }\end{array}$ & $\begin{array}{l}\text { Channels bowed } \\
\text { and twisted in same } \\
\text { direction }\end{array}$ \\
\hline No Bush Average = & 6479 & 9231 & & $N / A$ \\
\hline FRP.3.5x1.5-6.Bush-Col 1 & 3432 & $6191 *$ & $\begin{array}{l}\text { Local } \\
\text { Instability }\end{array}$ & Channels bowed \\
\hline FRP.3.5x1.5-6.Bush-Col 2 & 6487 & $11497^{*}$ & $\begin{array}{l}\text { Local } \\
\text { Instability }\end{array}$ & $\begin{array}{l}\text { Channels bowed } \\
\text { inwards toward } \\
\text { each other }\end{array}$ \\
\hline $\begin{array}{l}\text { FRP. } 3.5 \times 1.5-6 . \text { Bush-Col } 3 \text { w/ } \\
\mathrm{cb}\end{array}$ & 3417 & $4009 *$ & $\begin{array}{l}\text { Distortional } \\
\text { Buckling }\end{array}$ & $\begin{array}{l}\text { Channels curved in } \\
\text { same direction at } \\
\text { compression block }\end{array}$ \\
\hline Bush-Col Average = & 4445 & 7232 & & $N / A$ \\
\hline FRP.3.5x1.5-6.Bush-Both 1 & 3428 & $5793 *$ & LTB & $\begin{array}{l}\text { Sample twisted } \\
\text { almost } 90^{\circ}\end{array}$ \\
\hline $\begin{array}{l}\text { FRP.3.5x1.5-6.Bush-Both } 2 \\
\text { Test } 1\end{array}$ & 3331 & $4659^{*}$ & LTB & Sample twisted \\
\hline $\begin{array}{r}\text { Bush-Both Average }= \\
\text { Average }(\text { all })=\end{array}$ & $\begin{array}{l}3380 \\
4722\end{array}$ & $\begin{array}{l}4974 \\
7146\end{array}$ & & $\begin{array}{l}N / A \\
N / A\end{array}$ \\
\hline
\end{tabular}

*Ultimate load is maximum load of test, not breaking load. Samples did not fracture. 

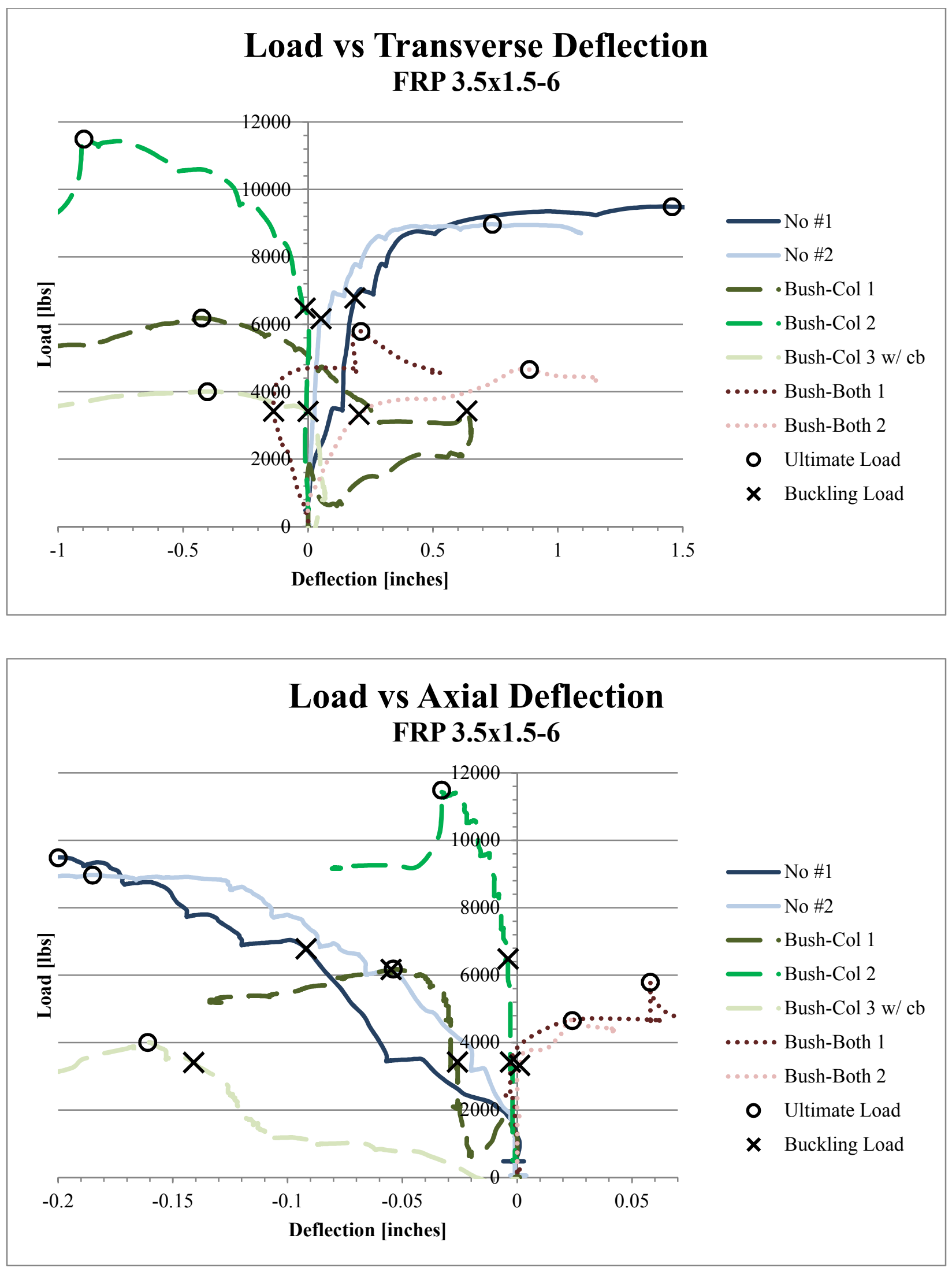


\begin{tabular}{|c|c|c|c|c|}
\hline Sample & $\begin{array}{l}\text { Buckling } \\
\text { Load } \\
\text { (lb) }\end{array}$ & $\begin{array}{l}\text { Ultimate } \\
\text { Load } \\
\text { (lb) }\end{array}$ & Failure Mode & Failure Description \\
\hline FRP.3.5x1.5-8.No 1 & 3086 & $4340 *$ & LTB & $\begin{array}{l}\text { Channels bowed in same } \\
\text { direction }\end{array}$ \\
\hline FRP.3.5x1.5-8.No 2 & 3105 & 3206 & $\begin{array}{c}\text { Distortional } \\
\text { Buckling / } \\
\text { Material Rupture }\end{array}$ & $\begin{array}{l}\text { Channels bowed and } \\
\text { twisted in same } \\
\text { direction, tore along } \\
\text { channel corner above } \\
\text { comp. block }\end{array}$ \\
\hline No Bush Average $=$ & 3096 & 3773 & & $N / A$ \\
\hline $\begin{array}{l}\text { FRP.3.5x1.5-8.Bush- } \\
\text { Col } 1\end{array}$ & 4480 & $6666^{*}$ & Local Instability & $\begin{array}{l}\text { Channels curved in same } \\
\text { direction at comp. block, } \\
\text { no obvious twisting }\end{array}$ \\
\hline $\begin{array}{l}\text { FRP.3.5x1.5-8.Bush- } \\
\text { Col } 2\end{array}$ & 3927 & $5458 *$ & Local Instability & $\begin{array}{l}\text { Channels curved in same } \\
\text { direction at comp. block, } \\
\text { no twisting showed }\end{array}$ \\
\hline $\begin{array}{l}\text { FRP.3.5x1.5-8.Bush- } \\
\text { Col } 3\end{array}$ & 2976 & $4547 *$ & $\begin{array}{l}\text { Distortional } \\
\text { Buckling }\end{array}$ & $\begin{array}{l}\text { Channels curved in same } \\
\text { direction at comp. block }\end{array}$ \\
\hline Bush-Col Average $=$ & 3794 & 5557 & & N/A \\
\hline $\begin{array}{l}\text { FRP.3.5x1.5-8.Bush- } \\
\text { Both } 1\end{array}$ & 3530 & $5384 *$ & $\begin{array}{l}\text { Distortional } \\
\text { Buckling }\end{array}$ & $\begin{array}{l}\text { Channels bowed and } \\
\text { twisted in same direction }\end{array}$ \\
\hline $\begin{array}{l}\text { FRP.3.5x1.5-8.Bush- } \\
\text { Both } 2\end{array}$ & 4305 & $6074 *$ & Local Instability & $\begin{array}{l}\text { Channels bowed in same } \\
\text { direction }\end{array}$ \\
\hline $\begin{array}{l}\text { FRP.3.5x1.5-8.Bush- } \\
\text { Both } 3\end{array}$ & 3132 & $4547^{*}$ & Local Instability & $\begin{array}{l}\text { Channels bowed in same } \\
\text { direction at comp. block }\end{array}$ \\
\hline $\begin{array}{r}\text { Bush-Both Average }= \\
\text { Average (all) }=\end{array}$ & $\begin{array}{l}3656 \\
3568\end{array}$ & $\begin{array}{l}5335 \\
4888\end{array}$ & & $\begin{array}{l}N / A \\
N / A\end{array}$ \\
\hline
\end{tabular}

*Ultimate load is maximum load of test, not breaking load. Samples did not fracture. 

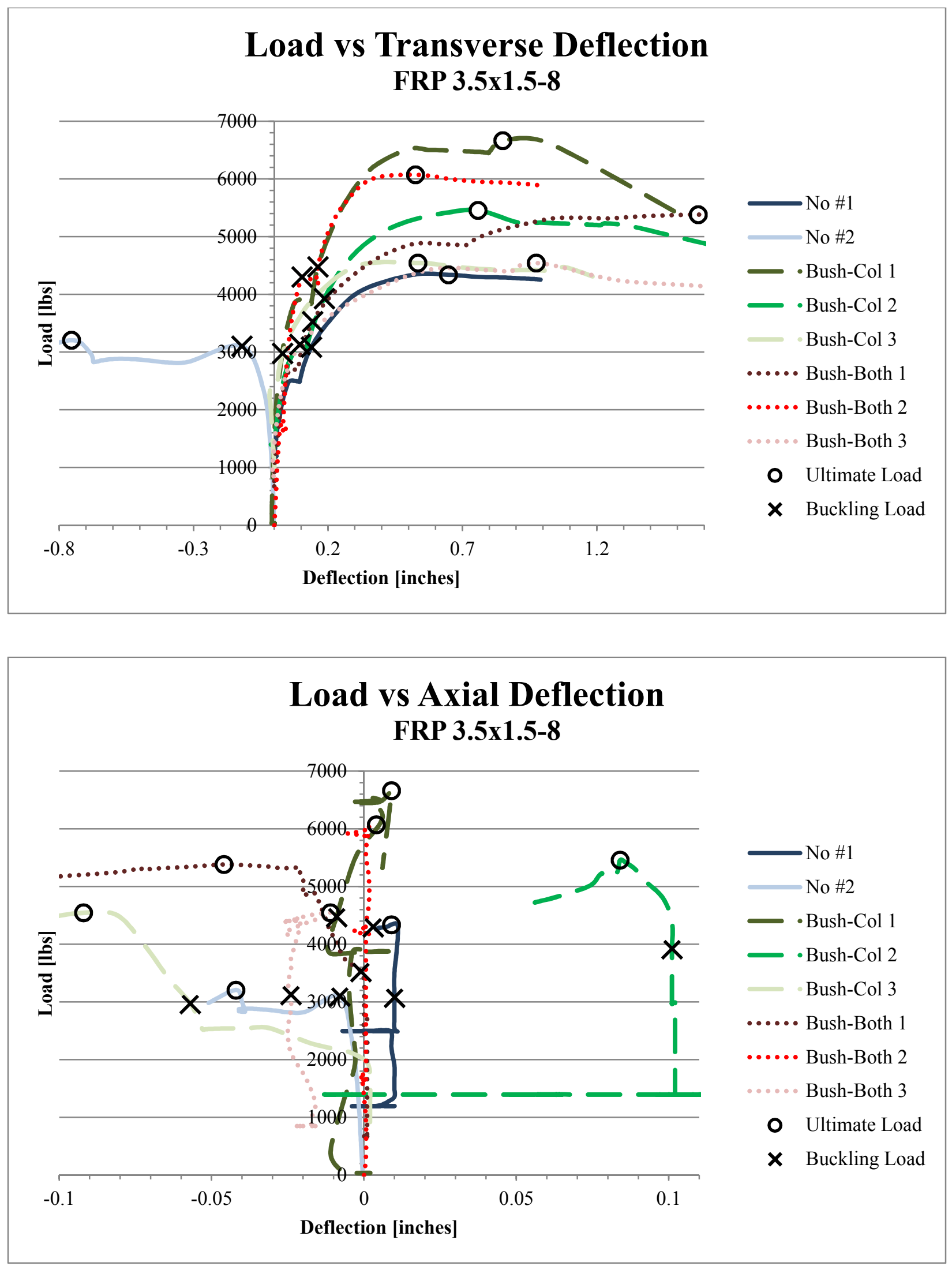


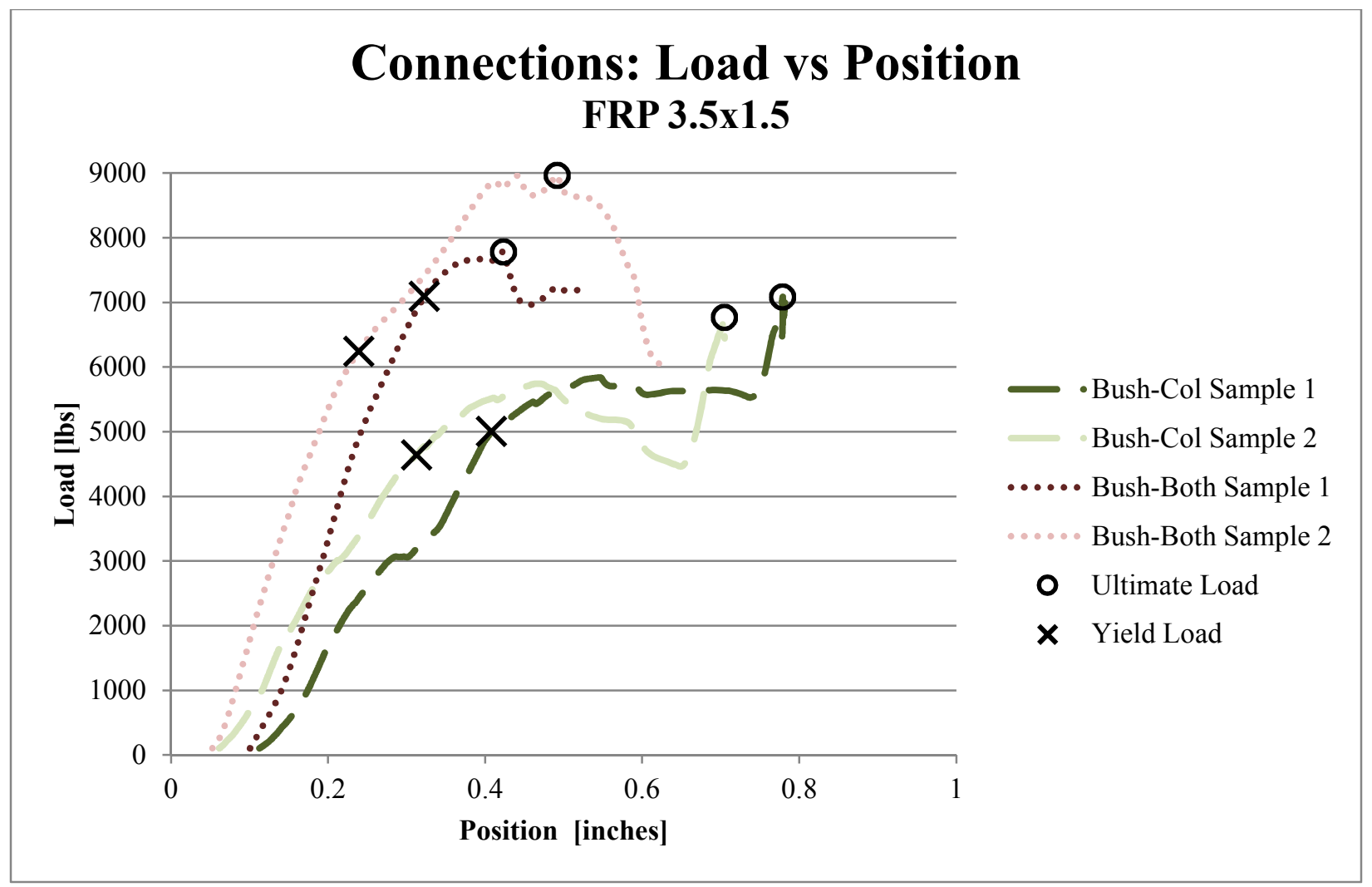




\begin{tabular}{|c|c|c|c|c|}
\hline Sample & $\begin{array}{l}\text { Buckling } \\
\text { Load } \\
\text { (lb) }\end{array}$ & $\begin{array}{l}\text { Ultimate } \\
\text { Load } \\
\text { (lb) }\end{array}$ & Failure Mode & Failure Description \\
\hline FRP.4x1.25-4.No 1 & 11462 & 13367 & $\begin{array}{l}\text { Local Instability/ } \\
\text { Material Rupture }\end{array}$ & $\begin{array}{l}\text { Channels bowed apart, } \\
\text { ripping at flanges of } \\
\text { channel }\end{array}$ \\
\hline FRP.4x1.25-4.No 2 & 8072 & $11123^{*}$ & Local Instability & $\begin{array}{l}\text { Channels bowed in same } \\
\text { direction }\end{array}$ \\
\hline $\begin{array}{l}\text { FRP.4x1.25-4.No Bush } \\
1\end{array}$ & 9750 & $11047^{*}$ & Local Instability & Channels bowed \\
\hline No Bush Average = & 9761 & 11845 & & $N / A$ \\
\hline FRP.4x1.25-4.Bush-Col & 8657 & $9685^{*}$ & Local Instability & $\begin{array}{l}\text { Channels bowed in same } \\
\text { direction }\end{array}$ \\
\hline $\begin{array}{l}\text { FRP.4x1.25-4.Bush-Col } \\
2\end{array}$ & 7348 & $11049 *$ & Local Instability & $\begin{array}{l}\text { Channels bowed in same } \\
\text { direction, one slightly } \\
\text { more while the other } \\
\text { stayed fairly straight }\end{array}$ \\
\hline $\begin{array}{l}\text { FRP.4x1.25-4.Bush-Col } \\
3\end{array}$ & 9000 & $11886^{*}$ & Local Instability & $\begin{array}{l}\text { Channels slightly bowed } \\
\text { in same direction }\end{array}$ \\
\hline Bush-Col Average $=$ & 8335 & 10873 & & $N / A$ \\
\hline $\begin{array}{l}\text { FRP.4x1.25-4.Bush- } \\
\text { Both } 1\end{array}$ & 8552 & $10125^{*}$ & Local Instability & $\begin{array}{l}\text { Channels bowed } \\
\text { together, one more than } \\
\text { the other }\end{array}$ \\
\hline $\begin{array}{l}\text { FRP.4x1.25-4.Bush- } \\
\text { Both } 2\end{array}$ & 9751 & $11477 *$ & $\begin{array}{l}\text { Local Instability/ } \\
\text { Connection }\end{array}$ & $\begin{array}{l}\text { Channels bowed apart, } \\
\text { pulled at connections }\end{array}$ \\
\hline $\begin{array}{r}\text { Bush-Both Average }= \\
\text { Average }(\text { all })=\end{array}$ & $\begin{array}{l}9152 \\
9074\end{array}$ & $\begin{array}{l}10801 \\
11173\end{array}$ & & $\begin{array}{l}N / A \\
N / A\end{array}$ \\
\hline
\end{tabular}

*Ultimate load is maximum load of test, not breaking load. Samples did not fracture. 

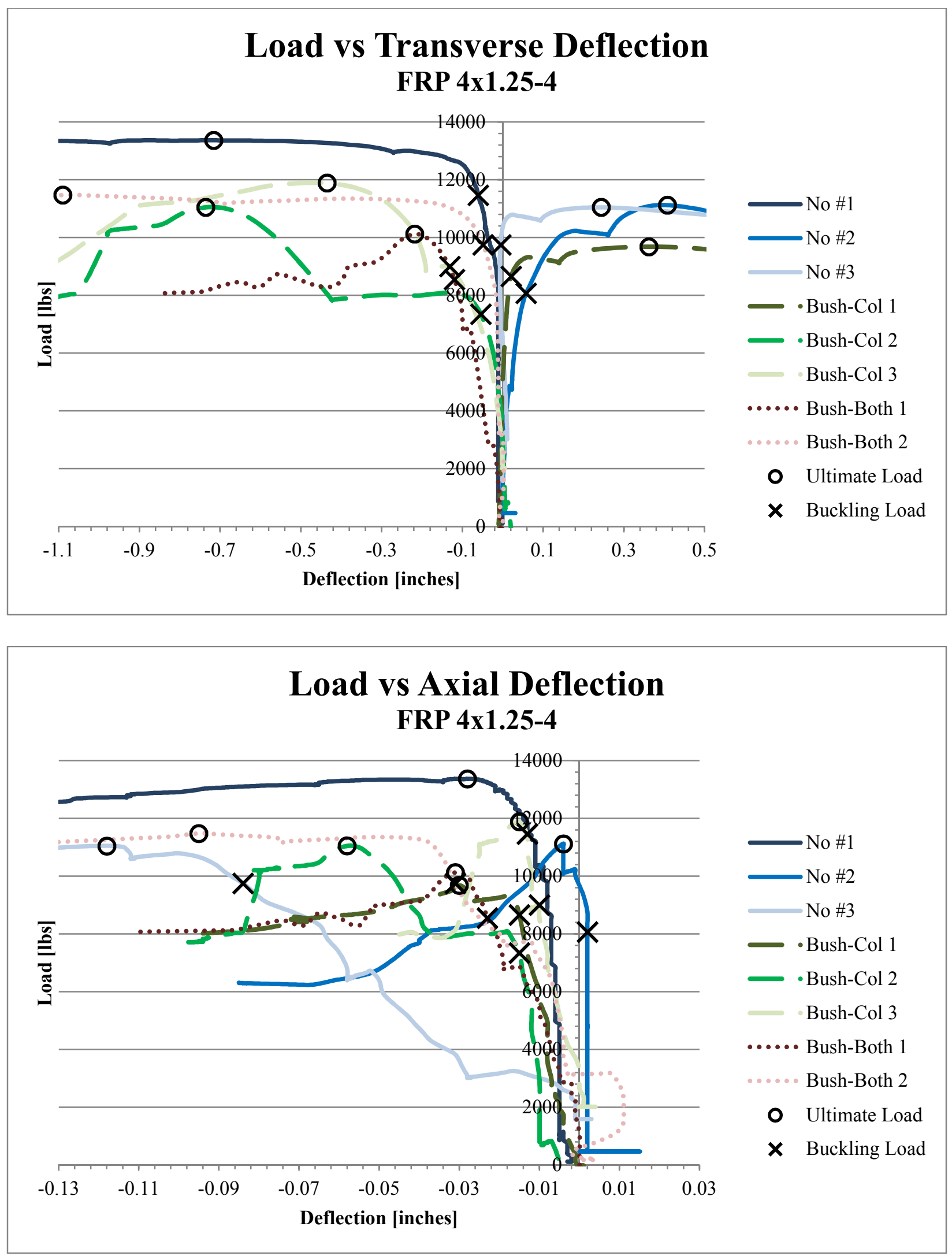


\begin{tabular}{|c|c|c|c|c|}
\hline Sample & $\begin{array}{c}\text { Buckling } \\
\text { Load } \\
\text { (lb) } \\
\end{array}$ & $\begin{array}{l}\text { Ultimate } \\
\text { Load } \\
\text { (lb) } \\
\end{array}$ & Failure Mode & Failure Description \\
\hline FRP.4x1.25-6.No 1 & 3880 & $4239 *$ & Local Instability & $\begin{array}{l}\text { Channels slightly bowed } \\
\text { together, one more so } \\
\text { than other }\end{array}$ \\
\hline FRP.4x1.25-6.No 2 & 4153 & $4691 *$ & $\begin{array}{l}\text { Distortional } \\
\text { Buckling }\end{array}$ & $\begin{array}{l}\text { Channels bowed and } \\
\text { twisted }\end{array}$ \\
\hline FRP. $4 \times 1.25-6$. No 3 & 3822 & $5595^{*}$ & Local Instability & $\begin{array}{l}\text { Channels bowed } \\
\text { together }\end{array}$ \\
\hline No Bush Average = & 3952 & 4841 & & $N / A$ \\
\hline $\begin{array}{l}\text { FRP.4x1.25-6.Bush-Col } \\
1\end{array}$ & 4609 & $6019 *$ & Local Instability & $\begin{array}{l}\text { One channel remained } \\
\text { almost straight, other } \\
\text { bowed inward }\end{array}$ \\
\hline $\begin{array}{l}\text { FRP.4x1.25-6.Bush-Col } \\
2\end{array}$ & 3292 & $3619 *$ & Local Instability & $\begin{array}{l}\text { Channels bowed } \\
\text { together, one more } \\
\text { exaggerated }\end{array}$ \\
\hline $\begin{array}{l}\text { FRP. } 4 \times 1.25-6 . \text { Bush-Col } \\
3 \mathrm{w} / \mathrm{cb}\end{array}$ & 6393 & $8349 *$ & Local Instability & $\begin{array}{l}\text { Channels bowed in same } \\
\text { direction, curved at } \\
\text { compression block }\end{array}$ \\
\hline Bush-Col Average $=$ & 4765 & 5996 & & $N / A$ \\
\hline $\begin{array}{l}\text { FRP. } 4 \times 1.25-6 . \text { Bush- } \\
\text { Both } 1\end{array}$ & 4741 & $5443^{*}$ & Local Instability & $\begin{array}{l}\text { Channels slightly bowed } \\
\text { apart }\end{array}$ \\
\hline $\begin{array}{l}\text { FRP. } 4 \times 1.25-6 . \text { Bush- } \\
\text { Both } 2\end{array}$ & 2454 & $4028^{*}$ & $\begin{array}{l}\text { Distortional } \\
\text { Buckling }\end{array}$ & $\begin{array}{l}\text { Channels twisted and } \\
\text { bowed in same direction, } \\
\text { one only slightly while } \\
\text { other more exaggerated }\end{array}$ \\
\hline $\begin{array}{l}\text { FRP. } 4 \times 1.25-6 . \text { Bush- } \\
\text { Both } 3\end{array}$ & 2786 & $3931 *$ & Local Instability & $\begin{array}{l}\text { Channels bowed in same } \\
\text { direction }\end{array}$ \\
\hline Bush-Both Average $=$ & 3327 & 4467 & & $N / A$ \\
\hline Average $($ all $)=$ & 4015 & 5101 & & $N / A$ \\
\hline
\end{tabular}

*Ultimate load is maximum load of test, not breaking load. Samples did not fracture. 

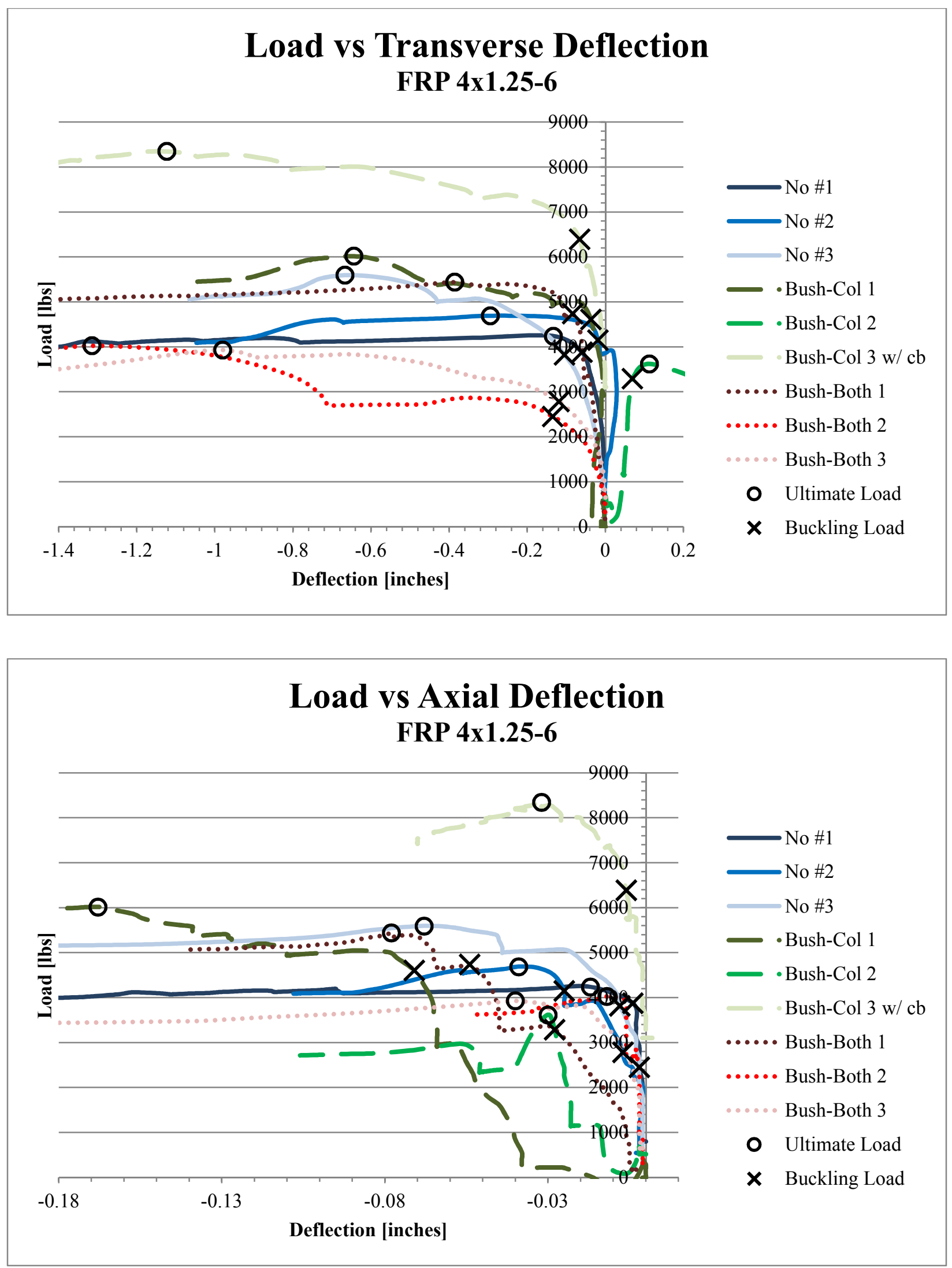


\begin{tabular}{|c|c|c|c|c|}
\hline Sample & $\begin{array}{c}\text { Buckling } \\
\text { Load } \\
\text { (lb) }\end{array}$ & $\begin{array}{c}\text { Ultimate } \\
\text { Load } \\
\text { (lb) } \\
\end{array}$ & Failure Mode & Failure Description \\
\hline FRP.4x1.25-8.No 1 & 1032 & $3931 *$ & Local Instability & $\begin{array}{l}\text { Channels bowed } \\
\text { together, curved at } \\
\text { compression block }\end{array}$ \\
\hline $\begin{array}{l}\text { FRP.4x1.25-8.No } 2 \text { Test } \\
2\end{array}$ & 4021 & $4854^{*}$ & Local Instability & $\begin{array}{l}\text { Channels bowed } \\
\text { together, curved at } \\
\text { comp. block }\end{array}$ \\
\hline No Bush Average = & 2527 & 4393 & & $N / A$ \\
\hline $\begin{array}{l}\text { FRP.4x1.25-8.Bush-Col } \\
1\end{array}$ & 2793 & $4554^{*}$ & Local Instability & $\begin{array}{l}\text { Channels bowed } \\
\text { together, curved at } \\
\text { comp. block }\end{array}$ \\
\hline $\begin{array}{l}\text { FRP.4x1.25-8.Bush-Col } \\
2\end{array}$ & 2112 & $5622 *$ & Local Instability & $\begin{array}{l}\text { Channels bowed } \\
\text { together, curved at } \\
\text { comp. block }\end{array}$ \\
\hline Bush-Col Average $=$ & 2453 & 5088 & & $N / A$ \\
\hline $\begin{array}{l}\text { FRP.4x1.25-8.Bush- } \\
\text { Both } 1\end{array}$ & 5805 & $6152 *$ & Local Instability & $\begin{array}{l}\text { Channels bowed } \\
\text { together, curved at } \\
\text { comp. block }\end{array}$ \\
\hline $\begin{array}{l}\text { FRP.4x1.25-8.Bush- } \\
\text { Both } 2\end{array}$ & 1843 & $2357^{*}$ & Local Instability & $\begin{array}{l}\text { Channels bowed } \\
\text { together, curved at } \\
\text { comp. block }\end{array}$ \\
\hline Bush-Both Average = & 3824 & 4254 & & $N / A$ \\
\hline Average $($ all $)=$ & 2934 & 4578 & & $N / A$ \\
\hline
\end{tabular}

*Ultimate load is maximum load of test, not breaking load. Samples did not fracture. 

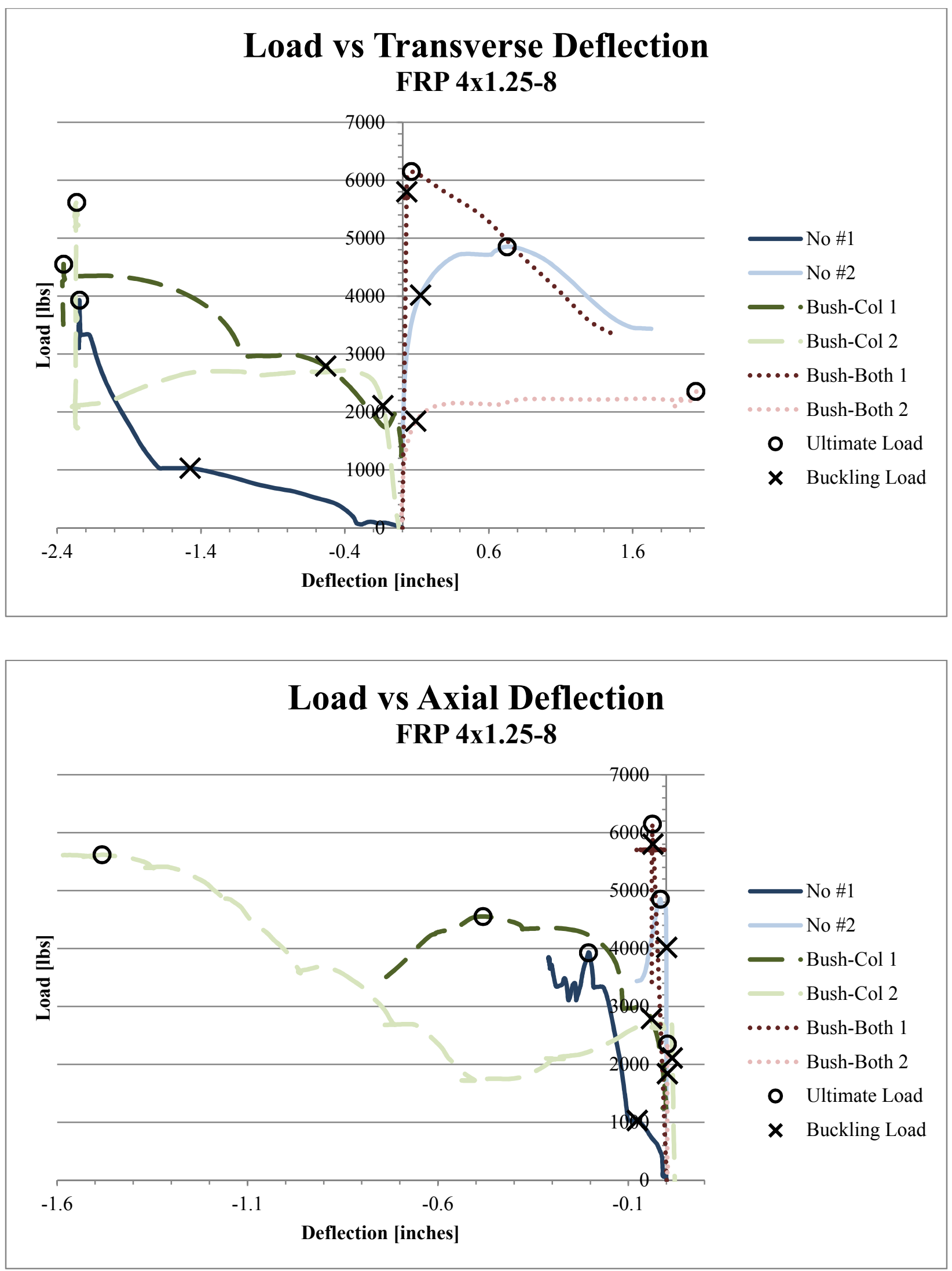

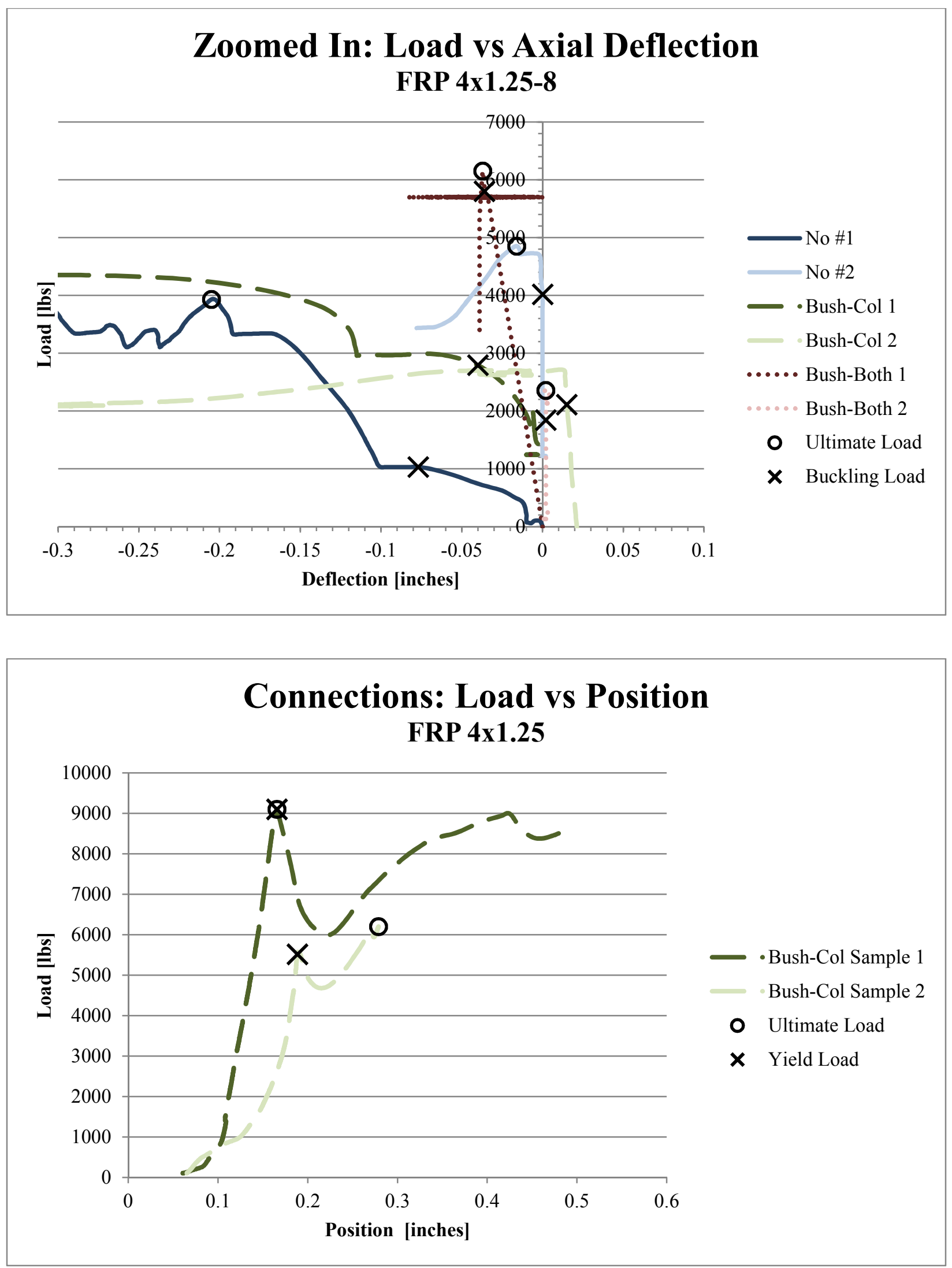


\begin{tabular}{|c|c|c|c|c|}
\hline Sample & $\begin{array}{l}\text { Buckling } \\
\text { Load } \\
\text { (lb) }\end{array}$ & $\begin{array}{l}\text { Ultimate } \\
\text { Load } \\
\text { (lb) }\end{array}$ & Failure Mode & Failure Description \\
\hline FRP.4x1.375-4.No 1 & 14204 & $16133 *$ & Local Instability & $\begin{array}{l}\text { Channels bowed } \\
\text { slightly together }\end{array}$ \\
\hline FRP.4x1.375-4.No 2 & 9428 & 12369 & $\begin{array}{l}\text { Local } \\
\text { Instability/ } \\
\text { Material } \\
\text { Rupture }\end{array}$ & $\begin{array}{l}\text { One channel bowed and } \\
\text { bent in toward other } \\
\text { with creasing of flanges } \\
\text { at bend, other channel } \\
\text { stayed fairly straight }\end{array}$ \\
\hline No Bush Average = & 11816 & 14251 & & $N / A$ \\
\hline $\begin{array}{l}\text { FRP.4x1.375-4.Bush-Col } \\
1\end{array}$ & 11984 & 17758 & $\begin{array}{l}\text { Local } \\
\text { Instability/ } \\
\text { Material } \\
\text { Rupture }\end{array}$ & $\begin{array}{l}\text { One channel bowed and } \\
\text { bent towards other with } \\
\text { tearing along channel } \\
\text { corner and flanges, } \\
\text { other stayed fairly } \\
\text { straight }\end{array}$ \\
\hline $\begin{array}{l}\text { FRP.4x1.375-4.Bush-Col } \\
2\end{array}$ & 14539 & 16055 & Local Instability & $\begin{array}{l}\text { One channel bowed and } \\
\text { bent towards other with } \\
\text { flanges becoming flat at } \\
\text { bend, other stayed } \\
\text { straight }\end{array}$ \\
\hline Bush-Col Average $=$ & 13262 & 16906 & & $N / A$ \\
\hline $\begin{array}{l}\text { FRP.4x1.375-4.Bush- } \\
\text { Both } 1\end{array}$ & 11010 & $14021 *$ & LTB & $\begin{array}{l}\text { Channels bowed, one } \\
\text { corner of channel } \\
\text { twisted out }\end{array}$ \\
\hline $\begin{array}{l}\text { FRP.4x1.375-4.Bush- } \\
\text { Both } 2\end{array}$ & 10994 & 13982 & $\begin{array}{c}\text { Local } \\
\text { Instability/ } \\
\text { Material } \\
\text { Rupture }\end{array}$ & $\begin{array}{l}\text { Channels bowed } \\
\text { together, one bent } \\
\text { forming a sharp bend } \\
\text { with tear along channel } \\
\text { corner }\end{array}$ \\
\hline $\begin{array}{r}\text { Bush-Both Average }= \\
\text { Average }(\text { all })=\end{array}$ & $\begin{array}{l}11002 \\
12027\end{array}$ & $\begin{array}{l}14002 \\
15053\end{array}$ & & $\begin{array}{l}N / A \\
N / A\end{array}$ \\
\hline
\end{tabular}

*Ultimate load is maximum load of test, not breaking load. Samples did not fracture. 

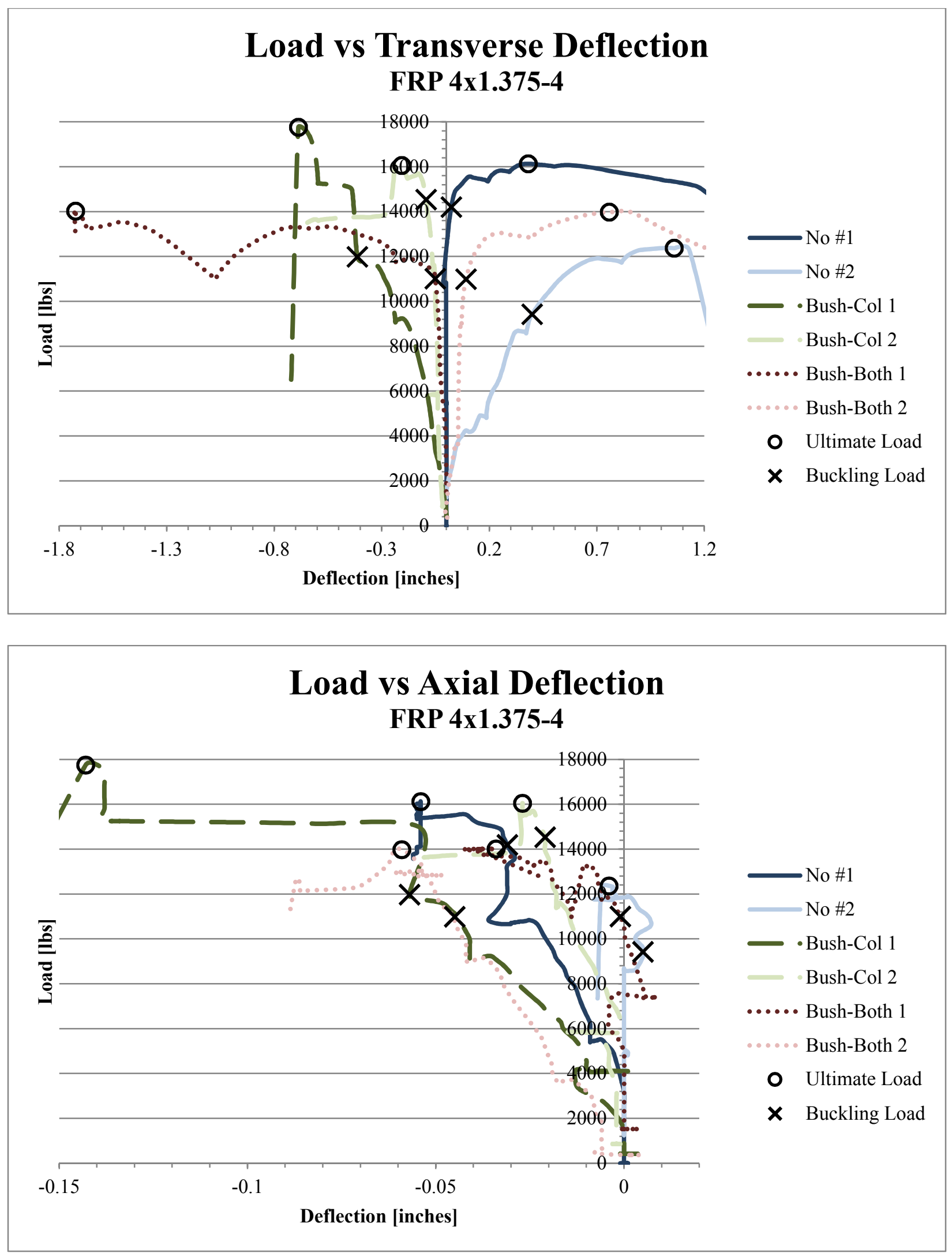


\begin{tabular}{|c|c|c|c|c|}
\hline Sample & $\begin{array}{c}\text { Buckling } \\
\text { Load } \\
\text { (lb) } \\
\end{array}$ & $\begin{array}{c}\text { Ultimate } \\
\text { Load } \\
\text { (lb) } \\
\end{array}$ & Failure Mode & Failure Description \\
\hline $\begin{array}{l}\text { FRP. } 4 \times 1.375-6 . \text { No } 1 \mathrm{w} / \\
\mathrm{cb}\end{array}$ & 4792 & $5820^{*}$ & Local Instability & $\begin{array}{l}\text { Channels bowed, } \\
\text { curved at compression } \\
\text { block }\end{array}$ \\
\hline FRP. $4 \times 1.375-6$. No 2 & 4640 & $5622 *$ & Local Instability & $\begin{array}{l}\text { Channels bowed } \\
\text { slightly together }\end{array}$ \\
\hline No Bush Average = & 4716 & 5721 & & $N / A$ \\
\hline $\begin{array}{l}\text { FRP.4x1.375-6.Bush-Col } \\
1\end{array}$ & 5595 & $5789 *$ & Local Instability & $\begin{array}{l}\text { Channels bowed } \\
\text { slightly, one stayed } \\
\text { fairly straight, other } \\
\text { bowed inwards }\end{array}$ \\
\hline $\begin{array}{l}\text { FRP.4x1.375-6.Bush-Col } \\
2\end{array}$ & 5536 & $9151^{*}$ & Local Instability & $\begin{array}{l}\text { Channels bowed } \\
\text { slightly, one stayed } \\
\text { fairly straight, other } \\
\text { bowed inwards }\end{array}$ \\
\hline $\begin{array}{l}\text { FRP.4x1.375-6.Bush-Col } \\
3\end{array}$ & 3323 & $5665^{*}$ & LTB & $\begin{array}{l}\text { Channels bowed and } \\
\text { twisted away from each } \\
\text { other }\end{array}$ \\
\hline Bush-Col Average $=$ & 4818 & 6868 & & $N / A$ \\
\hline $\begin{array}{l}\text { FRP.4x1.375-6.Bush- } \\
\text { Both } 1\end{array}$ & 5252 & $7862 *$ & Local Instability & $\begin{array}{l}\text { Channels bowed } \\
\text { together }\end{array}$ \\
\hline $\begin{array}{l}\text { FRP. } 4 \times 1.375-6 . \text { Bush- } \\
\text { Both } 2\end{array}$ & 3997 & $5937^{*}$ & Local Instability & $\begin{array}{l}\text { Channels bowed } \\
\text { together }\end{array}$ \\
\hline $\begin{array}{l}\text { FRP. } 4 \times 1.375-6 . \text { Bush- } \\
\text { Both } 3\end{array}$ & 2556 & $6089 *$ & $\begin{array}{l}\text { Distortional } \\
\text { Buckling }\end{array}$ & $\begin{array}{l}\text { Channels bowed and } \\
\text { twisted apart }\end{array}$ \\
\hline Bush-Both Average $=$ & 3935 & 6630 & & $N / A$ \\
\hline Average $($ all $)=$ & 4461 & 6406 & & $N / A$ \\
\hline
\end{tabular}

*Ultimate load is maximum load of test, not breaking load. Samples did not fracture. 

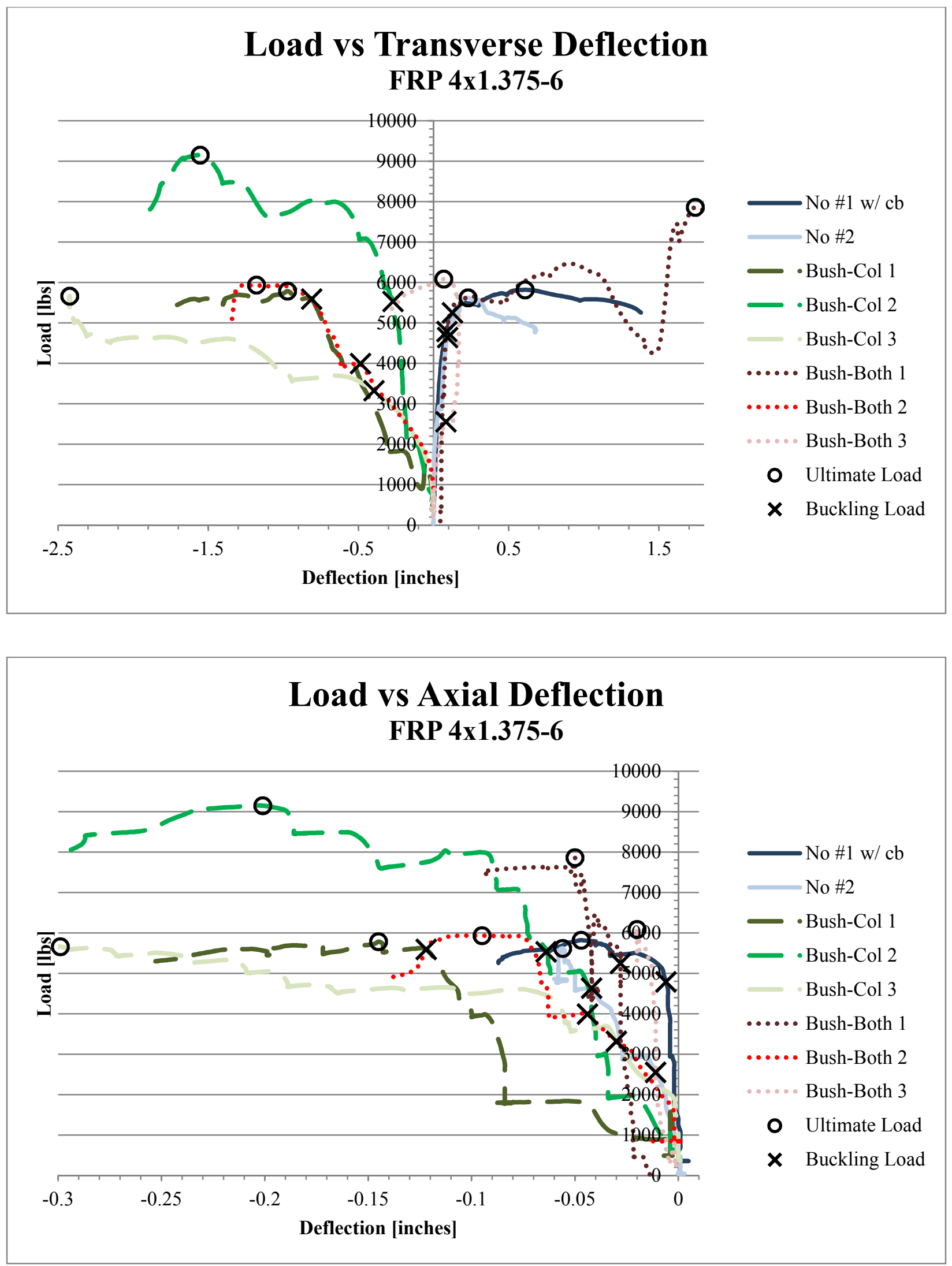


\begin{tabular}{|c|c|c|c|c|}
\hline Sample & $\begin{array}{c}\text { Buckling } \\
\text { Load } \\
\text { (lb) } \\
\end{array}$ & $\begin{array}{c}\text { Ultimate } \\
\text { Load } \\
\text { (lb) } \\
\end{array}$ & Failure Mode & Failure Description \\
\hline FRP.4x1.375-8.No 1 & 2610 & $3117^{*}$ & $\begin{array}{l}\text { Distortional } \\
\text { Buckling }\end{array}$ & $\begin{array}{l}\text { Channels bowed, } \\
\text { sample twisted above } \\
\text { compression block }\end{array}$ \\
\hline FRP.4x1.375-8.No 2 & 2712 & $3752 *$ & Local Instability & $\begin{array}{l}\text { Channels bowed at } \\
\text { comp. block }\end{array}$ \\
\hline No Bush Average $=$ & 2661 & 3434 & & $N / A$ \\
\hline $\begin{array}{l}\text { FRP.4x1.375-8.Bush-Col } \\
1\end{array}$ & 1126 & $5579 *$ & Local Instability & $\begin{array}{l}\text { Channels bowed, } \\
\text { curved at comp. block }\end{array}$ \\
\hline $\begin{array}{l}\text { FRP.4x1.375-8.Bush-Col } \\
2\end{array}$ & 5828 & $6089 *$ & Local Instability & $\begin{array}{l}\text { Channels bowed, } \\
\text { curved at comp. block }\end{array}$ \\
\hline $\begin{array}{l}\text { FRP.4x1.375-8.Bush-Col } \\
3\end{array}$ & 1699 & $3066^{*}$ & Local Instability & $\begin{array}{l}\text { Channels bowed, } \\
\text { curved at comp. block }\end{array}$ \\
\hline Bush-Col Average $=$ & 2884 & 4911 & & $N / A$ \\
\hline $\begin{array}{l}\text { FRP.4x1.375-8.Bush- } \\
\text { Both } 1\end{array}$ & 3502 & $4137^{*}$ & $\begin{array}{l}\text { Distortional } \\
\text { Buckling }\end{array}$ & $\begin{array}{l}\text { Channels bowed, } \\
\text { twisted above comp. } \\
\text { block }\end{array}$ \\
\hline $\begin{array}{l}\text { FRP. } 4 \times 1.375-8 . \text { Bush- } \\
\text { Both } 2\end{array}$ & 2345 & 3089 & $\begin{array}{l}\text { Distortional } \\
\text { Buckling }\end{array}$ & $\begin{array}{l}\text { Channels bowed, one } \\
\text { bent into other above } \\
\text { comp. block and tore } \\
\text { along corner of channel }\end{array}$ \\
\hline $\begin{array}{l}\text { FRP.4x1.375-8.Bush- } \\
\text { Both } 3\end{array}$ & 1200 & $2525^{*}$ & $\begin{array}{l}\text { Distortional } \\
\text { Buckling }\end{array}$ & $\begin{array}{l}\text { Channels bowed at } \\
\text { comp. block, above } \\
\text { comp. block twisted } \\
\text { almost } 90^{\circ}\end{array}$ \\
\hline Bush-Both Average $=$ & 2349 & 3250 & & $N / A$ \\
\hline Average $($ all $)=$ & 2628 & 3865 & & $N / A$ \\
\hline
\end{tabular}

*Ultimate load is maximum load of test, not breaking load. Samples did not fracture. 

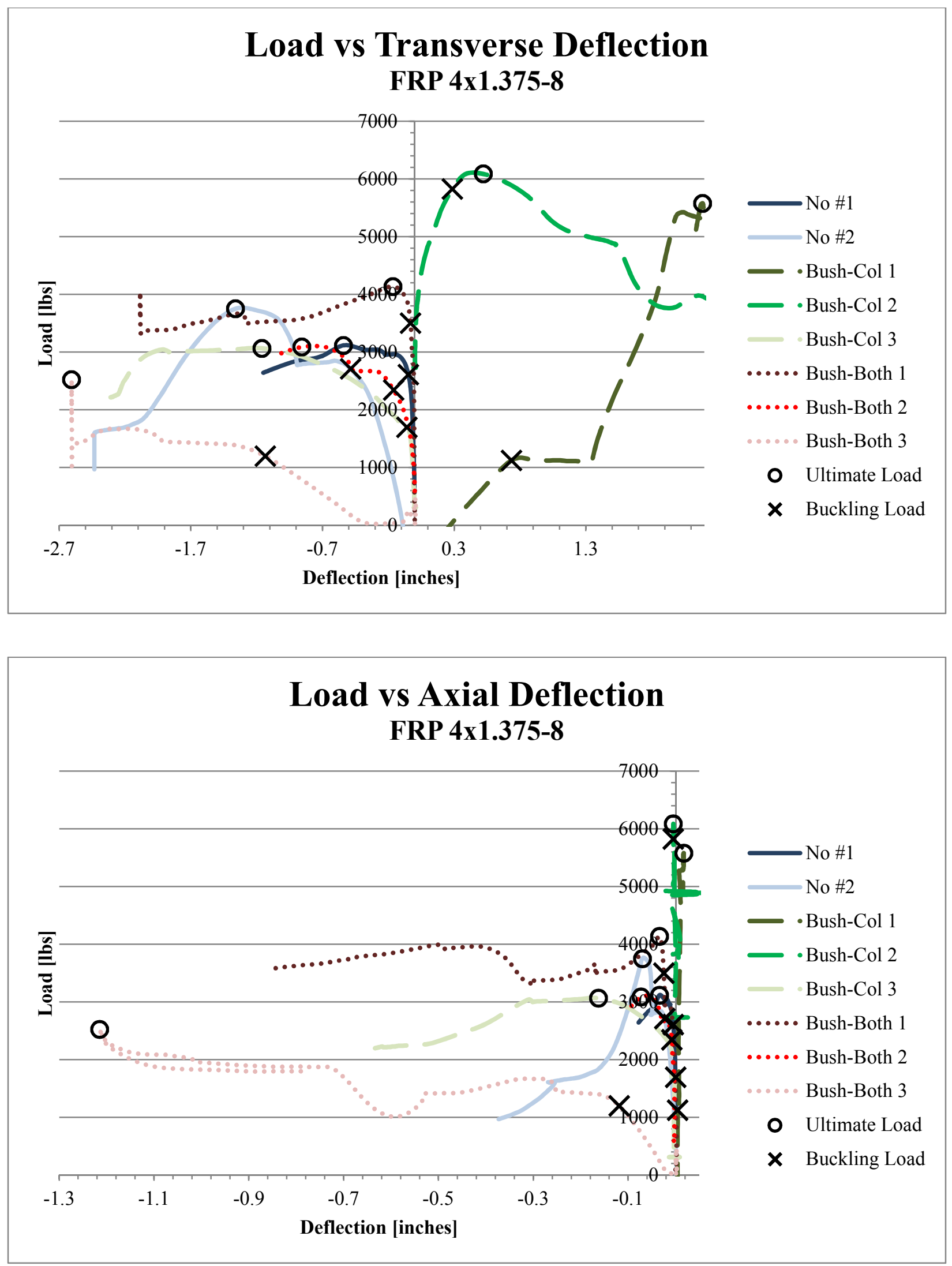

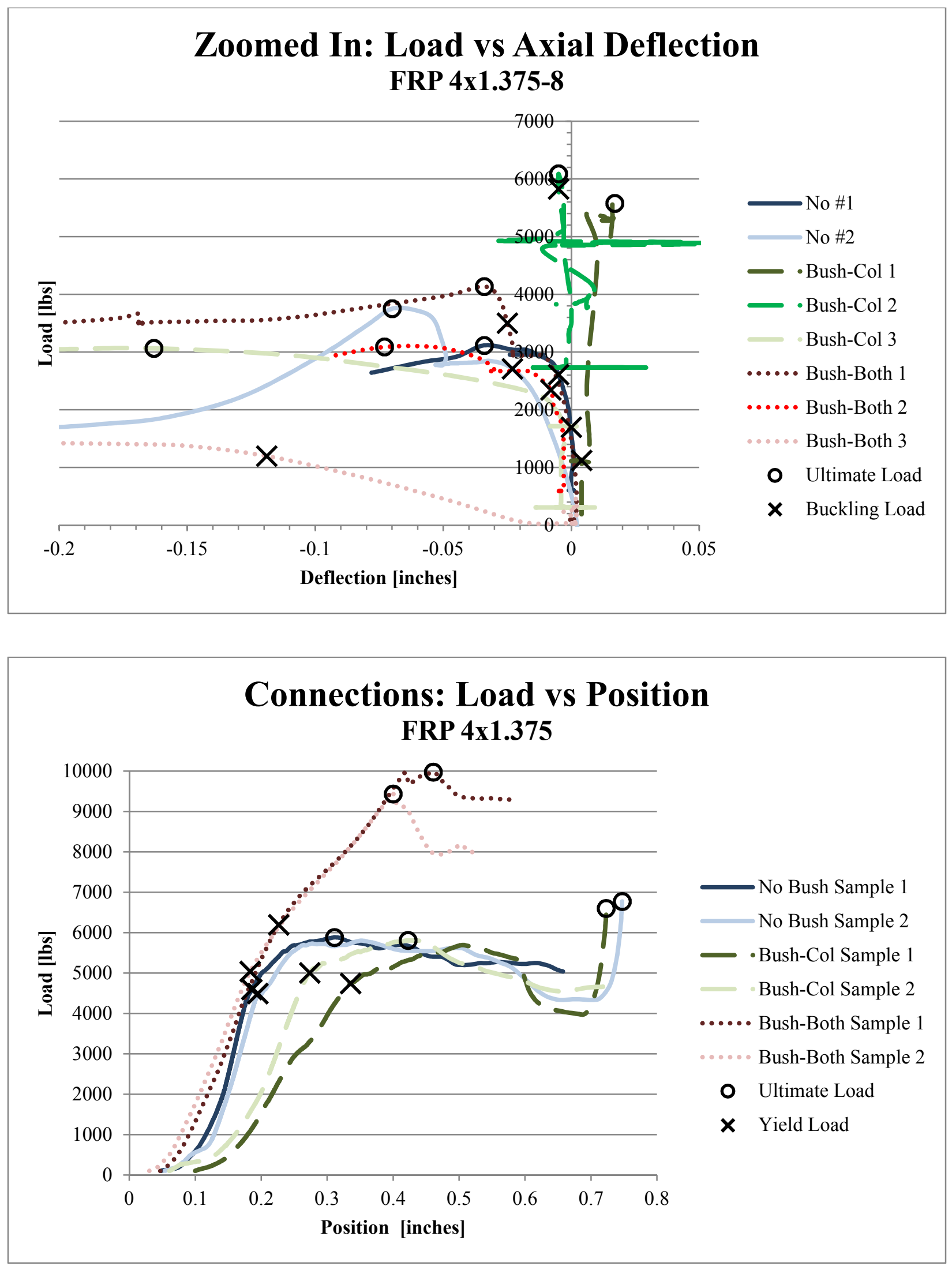
FRP $-5.5 \times 1.5$ Ties

\begin{tabular}{|c|c|c|c|c|}
\hline Sample & $\begin{array}{l}\text { Buckling } \\
\text { Load } \\
\text { (lb) }\end{array}$ & $\begin{array}{l}\text { Ultimate } \\
\text { Load } \\
(\text { lb) } \\
\end{array}$ & Failure Mode & Failure Description \\
\hline FRP.5.5x1.5-6.No 1 & 4430 & $8298 *$ & $\begin{array}{l}\text { Local } \\
\text { Instability }\end{array}$ & $\begin{array}{l}\text { Channels bowed } \\
\text { together }\end{array}$ \\
\hline FRP.5.5x1.5-6.No 2 & 10032 & $11703 *$ & $\begin{array}{l}\text { Local } \\
\text { Instability }\end{array}$ & $\begin{array}{l}\text { Channels bowed } \\
\text { together }\end{array}$ \\
\hline FRP.5.5x1.5-6.No 3 & 11170 & $12077 *$ & $\begin{array}{l}\text { Local } \\
\text { Instability }\end{array}$ & $\begin{array}{l}\text { Channels bowed } \\
\text { together, one channel } \\
\text { bowed more than } \\
\text { other }\end{array}$ \\
\hline No Bush Average = & 8544 & 10693 & & $N / A$ \\
\hline FRP.5.5x1.5-6.Bush-Col 1 & 4465 & $9307^{*}$ & $\begin{array}{l}\text { Local } \\
\text { Instability }\end{array}$ & Channels bowed apart \\
\hline FRP.5.5x1.5-6.Bush-Col 2 & 7648 & $9159 *$ & $\begin{array}{l}\text { Local } \\
\text { Instability }\end{array}$ & $\begin{array}{l}\text { Channels bowed only } \\
\text { slightly, appeared } \\
\text { almost straight }\end{array}$ \\
\hline $\begin{array}{l}\text { FRP.5.5x1.5-6.Bush-Col } 3 \\
\mathrm{w} / \mathrm{cb}\end{array}$ & 3974 & $7772 *$ & $\begin{array}{l}\text { Local } \\
\text { Instability }\end{array}$ & $\begin{array}{l}\text { Channels slightly } \\
\text { bowed at compression } \\
\text { block }\end{array}$ \\
\hline Bush-Col Average = & 5362 & 8746 & & $N / A$ \\
\hline FRP.5.5x1.5-6.Bush-Both 1 & 4137 & $5963 *$ & $\begin{array}{l}\text { Distortional } \\
\text { Buckling }\end{array}$ & $\begin{array}{l}\text { Channels bowed and } \\
\text { twisted, one bent into } \\
\text { other }\end{array}$ \\
\hline FRP.5.5x1.5-6.Bush-Both 2 & 7492 & $8590 *$ & $\begin{array}{l}\text { Distortional } \\
\text { Buckling }\end{array}$ & $\begin{array}{l}\text { Channels bowed and } \\
\text { twisted }\end{array}$ \\
\hline FRP.5.5x1.5-6.Bush-Both 3 & 7165 & $10176^{*}$ & $\begin{array}{l}\text { Local } \\
\text { Instability }\end{array}$ & $\begin{array}{l}\text { One channel bowed, } \\
\text { other stayed fairly } \\
\text { straight }\end{array}$ \\
\hline $\begin{array}{l}\text { FRP.5.5x1.5-6.Bush-Both } 3 \\
\text { ext }\end{array}$ & 6939 & $8061 *$ & $\begin{array}{l}\text { Local } \\
\text { Instability }\end{array}$ & $\begin{array}{l}\text { Channels bowed } \\
\text { slightly together }\end{array}$ \\
\hline $\begin{array}{r}\text { Bush-Both Average }= \\
\text { Average }(\text { all })=\end{array}$ & $\begin{array}{l}6433 \\
6745 \\
\end{array}$ & $\begin{array}{l}8173 \\
9204 \\
\end{array}$ & & $\begin{array}{l}N / A \\
N / A\end{array}$ \\
\hline
\end{tabular}

*Ultimate load is maximum load of test, not breaking load. Samples did not fracture. 

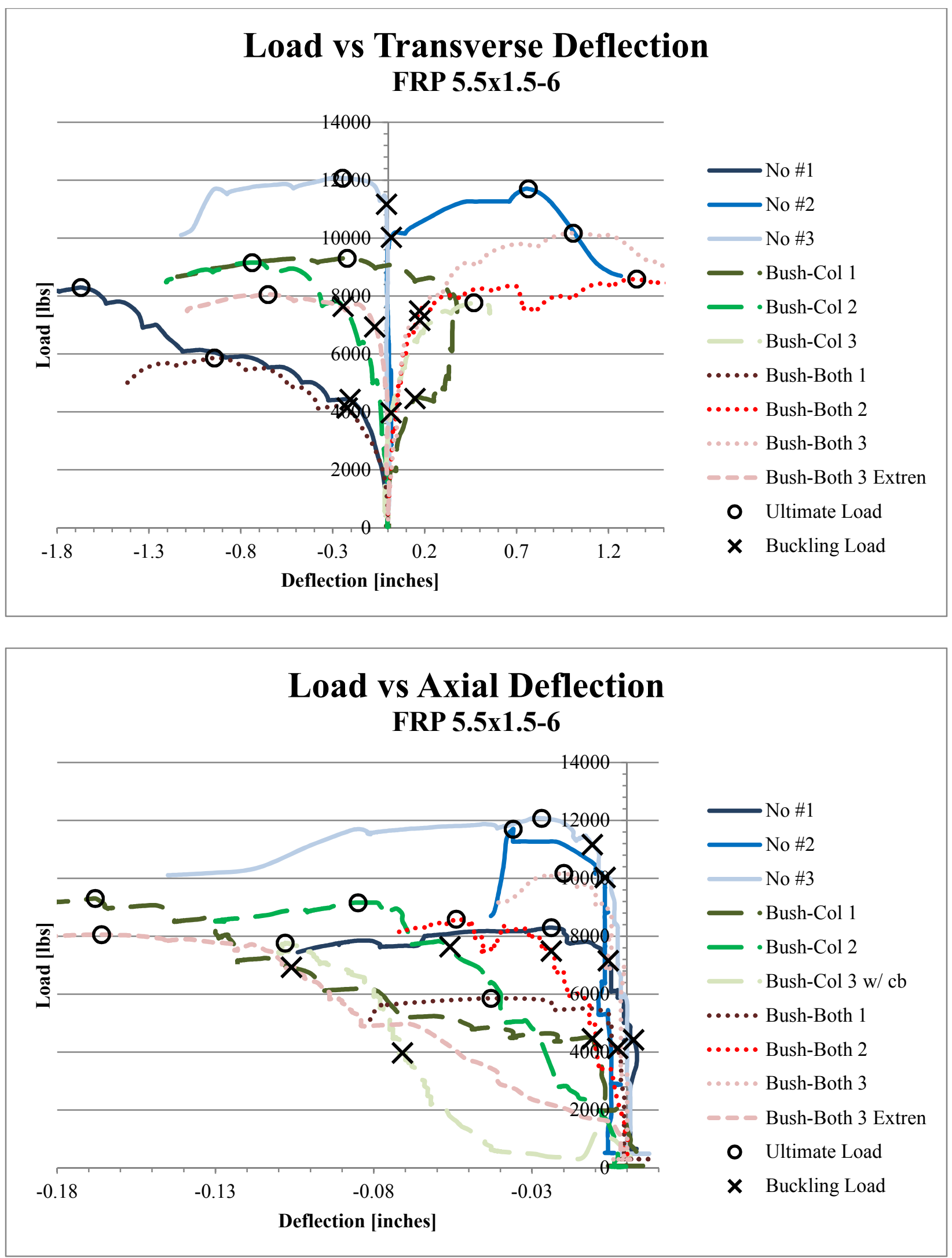


\begin{tabular}{|c|c|c|c|c|}
\hline Sample & $\begin{array}{l}\text { Buckling } \\
\text { Load } \\
\text { (lb) }\end{array}$ & $\begin{array}{l}\text { Maximum } \\
\text { Load (lb) }\end{array}$ & Failure Mode & Failure Description \\
\hline FRP.5.5x1.5-8.No 1 & 4324 & $9436^{*}$ & Local Instability & $\begin{array}{l}\text { Channels bowed, curved } \\
\text { at compression block }\end{array}$ \\
\hline FRP.5.5x1.5-8.No 2 & 6097 & $6826^{*}$ & Local Instability & $\begin{array}{l}\text { Channels bowed, curved } \\
\text { at comp. block }\end{array}$ \\
\hline No Bush Average = & 5211 & 8131 & & $N / A$ \\
\hline $\begin{array}{l}\text { FRP.5.5x1.5-8.Bush- } \\
\text { Col } 1\end{array}$ & 4422 & $10737 *$ & Local Instability & $\begin{array}{l}\text { Channels bowed and } \\
\text { curved at comp. block }\end{array}$ \\
\hline $\begin{array}{l}\text { FRP.5.5x1.5-8.Bush- } \\
\text { Col } 2\end{array}$ & 5115 & 8750 & $\begin{array}{c}\text { Local } \\
\text { Instability/ } \\
\text { Material } \\
\text { Rupture }\end{array}$ & $\begin{array}{l}\text { Channels bowed at } \\
\text { comp. block, tore along } \\
\text { channel flange just } \\
\text { below comp. block }\end{array}$ \\
\hline Bush-Col Average $=$ & 4769 & 9744 & & $N / A$ \\
\hline $\begin{array}{l}\text { FRP.5.5x1.5-8.Bush- } \\
\text { Both } 1\end{array}$ & 6627 & $7165^{*}$ & Local Instability & $\begin{array}{l}\text { Channels bowed and } \\
\text { curved at comp. block }\end{array}$ \\
\hline $\begin{array}{l}\text { FRP. } 5.5 \times 1.5-8 . \text { Bush- } \\
\text { Both } 2\end{array}$ & 5182 & $6670^{*}$ & Local Instability & $\begin{array}{l}\text { Channels bowed and } \\
\text { curved at comp. block }\end{array}$ \\
\hline Bush-Both Average = & 5905 & 6917 & & $N / A$ \\
\hline Average $($ all $)=$ & 5295 & 8264 & & $N / A$ \\
\hline
\end{tabular}

*Ultimate load is maximum load of test, not breaking load. Samples did not fracture. 

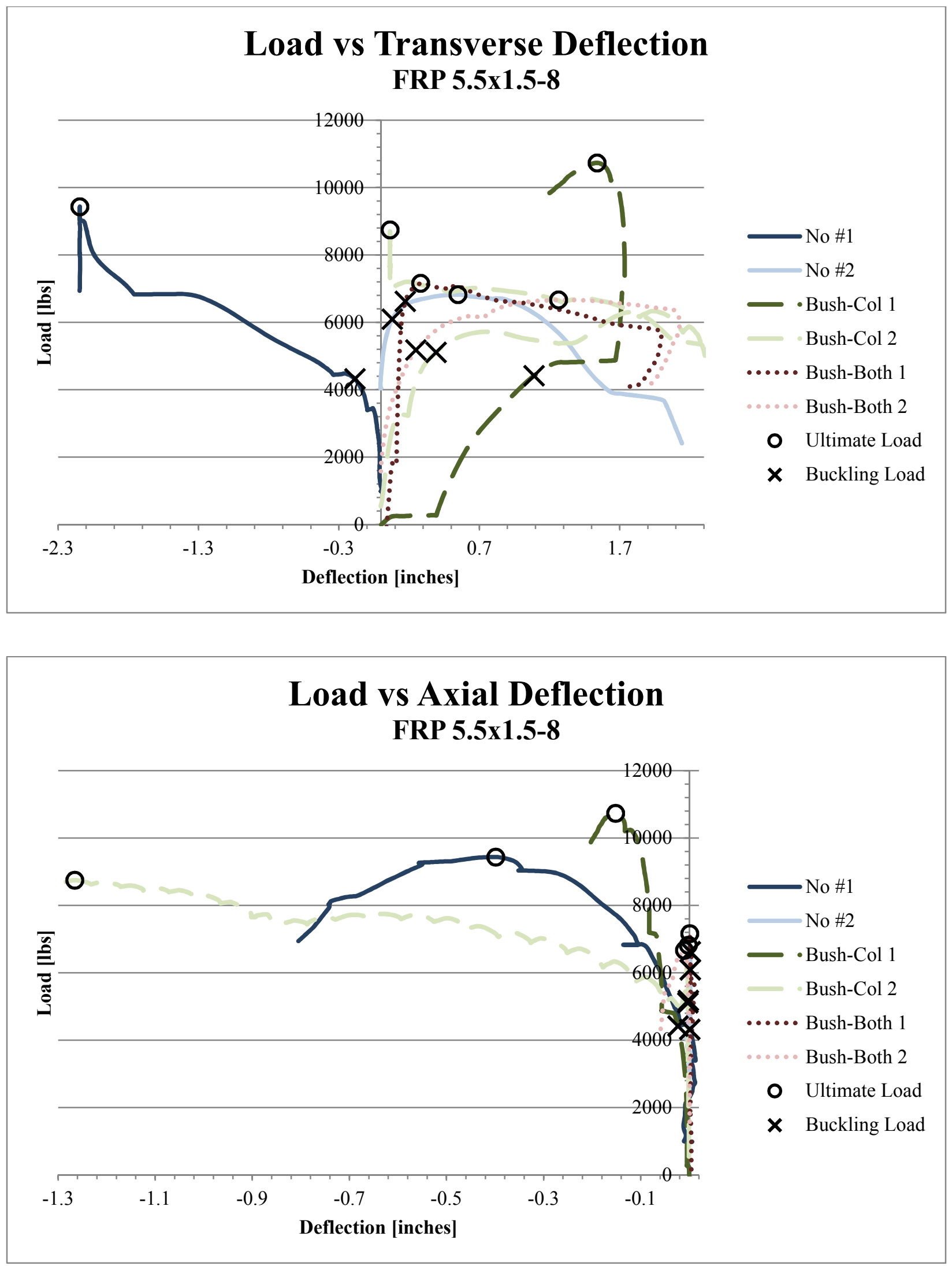

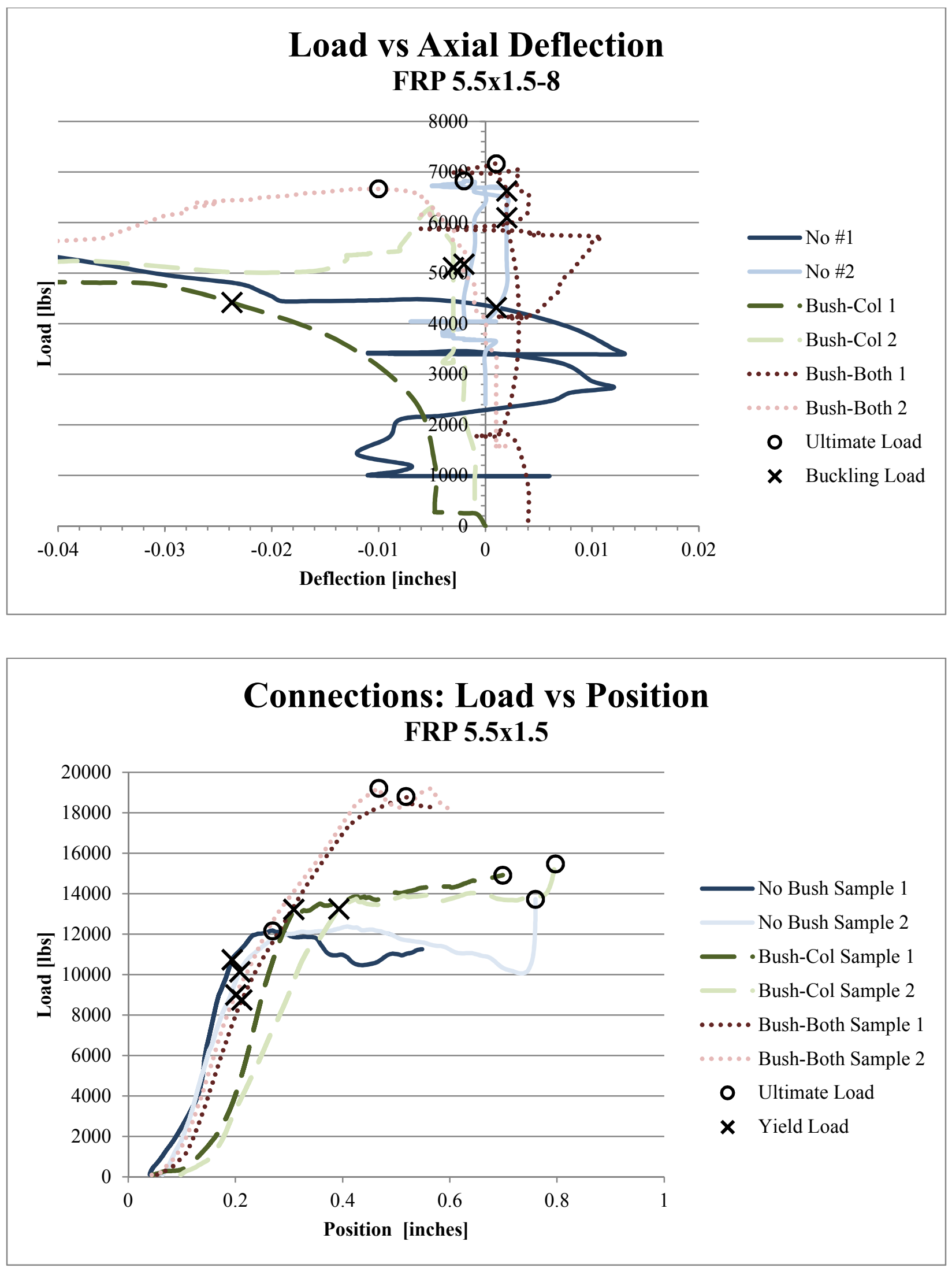


\begin{tabular}{|c|c|c|c|c|}
\hline Sample & $\begin{array}{l}\text { Buckling } \\
\text { Load } \\
\text { (lb) }\end{array}$ & $\begin{array}{l}\text { Ultimate } \\
\text { Load } \\
\text { (lb) }\end{array}$ & Failure Mode & Failure Description \\
\hline FRP.6x1.625-6.No 1 & 14002 & $16156^{*}$ & $\begin{array}{l}\text { Distortional } \\
\text { Buckling }\end{array}$ & $\begin{array}{l}\text { Channels bowed and } \\
\text { twisted in same } \\
\text { direction }\end{array}$ \\
\hline FRP.6x1.625-6.No 2 & 13589 & $16499 *$ & $\begin{array}{l}\text { Distortional } \\
\text { Buckling }\end{array}$ & $\begin{array}{l}\text { Channels slightly } \\
\text { bowed and twisted in } \\
\text { same direction }\end{array}$ \\
\hline No Bush Average = & 13796 & 16328 & & $N / A$ \\
\hline $\begin{array}{l}\text { FRP.6x1.625-6.Bush-Col } \\
1\end{array}$ & 8302 & $10012 *$ & $\begin{array}{l}\text { Distortional } \\
\text { Buckling }\end{array}$ & $\begin{array}{l}\text { Channels bowed and } \\
\text { twisted slightly }\end{array}$ \\
\hline $\begin{array}{l}\text { FRP.6x1.625-6.Bush-Col } \\
2\end{array}$ & 8489 & $9074 *$ & $\begin{array}{l}\text { Distortional } \\
\text { Buckling }\end{array}$ & $\begin{array}{l}\text { Channels bowed and } \\
\text { twisted slightly in same } \\
\text { direction }\end{array}$ \\
\hline Bush-Col Average = & 8396 & 9543 & & $N / A$ \\
\hline $\begin{array}{l}\text { FRP.6x1.625-6.Bush- } \\
\text { Both } 1\end{array}$ & 8477 & $9498 *$ & $\begin{array}{l}\text { Distortional } \\
\text { Buckling }\end{array}$ & $\begin{array}{l}\text { Channels bowed and } \\
\text { twisted slightly in same } \\
\text { direction }\end{array}$ \\
\hline $\begin{array}{l}\text { FRP.6x1.625-6.Bush- } \\
\text { Both } 2\end{array}$ & 13410 & $14504 *$ & $\begin{array}{l}\text { Distortional } \\
\text { Buckling }\end{array}$ & $\begin{array}{l}\text { Channels bowed and } \\
\text { twisted in same } \\
\text { direction }\end{array}$ \\
\hline Bush-Both Average = & 10944 & 12001 & & $N / A$ \\
\hline Average $($ all $)=$ & 11045 & 12624 & & $N / A$ \\
\hline
\end{tabular}

*Ultimate load is maximum load of test, not breaking load. Samples did not fracture. 

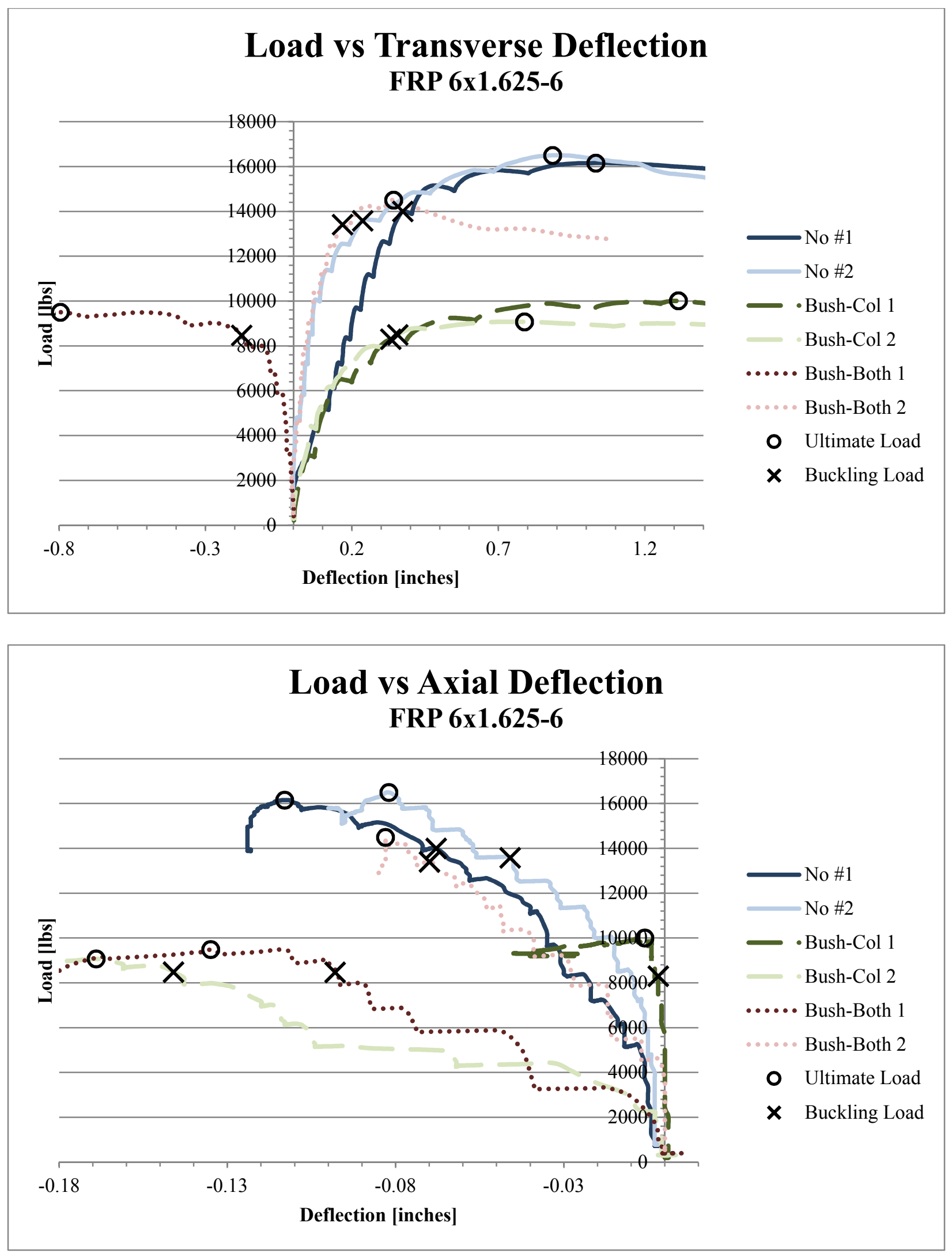


\begin{tabular}{|c|c|c|c|c|}
\hline Sample & $\begin{array}{c}\text { Buckling } \\
\text { Load } \\
\text { (lb) }\end{array}$ & $\begin{array}{l}\text { Ultimate } \\
\text { Load } \\
\text { (lb) }\end{array}$ & Failure Mode & Failure Description \\
\hline FRP.6x1.625-8.No 1 & 8474 & $9522 *$ & Local Instability & $\begin{array}{l}\text { Channels bowed and } \\
\text { curved at compression } \\
\text { block }\end{array}$ \\
\hline FRP.6x1.625-8.No 2 & 3089 & $5692 *$ & $\begin{array}{l}\text { Distortional } \\
\text { Buckling }\end{array}$ & $\begin{array}{l}\text { Channels bowed and } \\
\text { curved at comp. block, } \\
\text { twisted above comp. } \\
\text { block }\end{array}$ \\
\hline FRP.6x1.625-8.No 3 & 7765 & $9958^{*}$ & Local Instability & $\begin{array}{l}\text { Channels bowed and } \\
\text { curved at comp. block }\end{array}$ \\
\hline No Bush Average = & 6443 & 8390 & & $N / A$ \\
\hline $\begin{array}{l}\text { FRP.6x1.625-8.Bush-Col } \\
1\end{array}$ & 5376 & $9868^{*}$ & $\begin{array}{l}\text { Distortional } \\
\text { Buckling }\end{array}$ & $\begin{array}{l}\text { Channels bowed and } \\
\text { curved at comp. block, } \\
\text { twisted above comp. } \\
\text { block }\end{array}$ \\
\hline $\begin{array}{l}\text { FRP.6x1.625-8.Bush-Col } \\
2\end{array}$ & 7453 & $15112 *$ & Local Instability & $\begin{array}{l}\text { Channels bowed and } \\
\text { curved at comp. block }\end{array}$ \\
\hline $\begin{array}{l}\text { FRP.6x1.625-8.Bush-Col } \\
3\end{array}$ & 6389 & $8298^{*}$ & Local Instability & $\begin{array}{l}\text { Channels bowed and } \\
\text { curved at comp. block }\end{array}$ \\
\hline Bush-Col Average $=$ & 6406 & 11093 & & $N / A$ \\
\hline $\begin{array}{l}\text { FRP.6x1.625-8.Bush- } \\
\text { Both } 1\end{array}$ & 7258 & $9229 *$ & Local Instability & $\begin{array}{l}\text { Channels bowed in } \\
\text { same direction, curved } \\
\text { at comp. block }\end{array}$ \\
\hline $\begin{array}{l}\text { FRP.6x1.625-8.Bush- } \\
\text { Both } 2\end{array}$ & 7854 & $8544^{*}$ & Local Instability & $\begin{array}{l}\text { Channels bowed in } \\
\text { same direction, curved } \\
\text { at comp. block }\end{array}$ \\
\hline $\begin{array}{l}\text { FRP.6x1.625-8.Bush- } \\
\text { Both } 3\end{array}$ & 8715 & $13332 *$ & $\begin{array}{l}\text { Distortional } \\
\text { Buckling }\end{array}$ & $\begin{array}{l}\text { Channels bowed in } \\
\text { same direction, curved } \\
\text { at comp. block, slightly } \\
\text { twisted }\end{array}$ \\
\hline $\begin{array}{r}\text { Bush-Both Average }= \\
\text { Average }(\text { all })=\end{array}$ & $\begin{array}{l}7942 \\
6930\end{array}$ & $\begin{array}{c}10368 \\
9951\end{array}$ & & $\begin{array}{l}N / A \\
N / A\end{array}$ \\
\hline
\end{tabular}

*Ultimate load is maximum load of test, not breaking load. Samples did not fracture. 

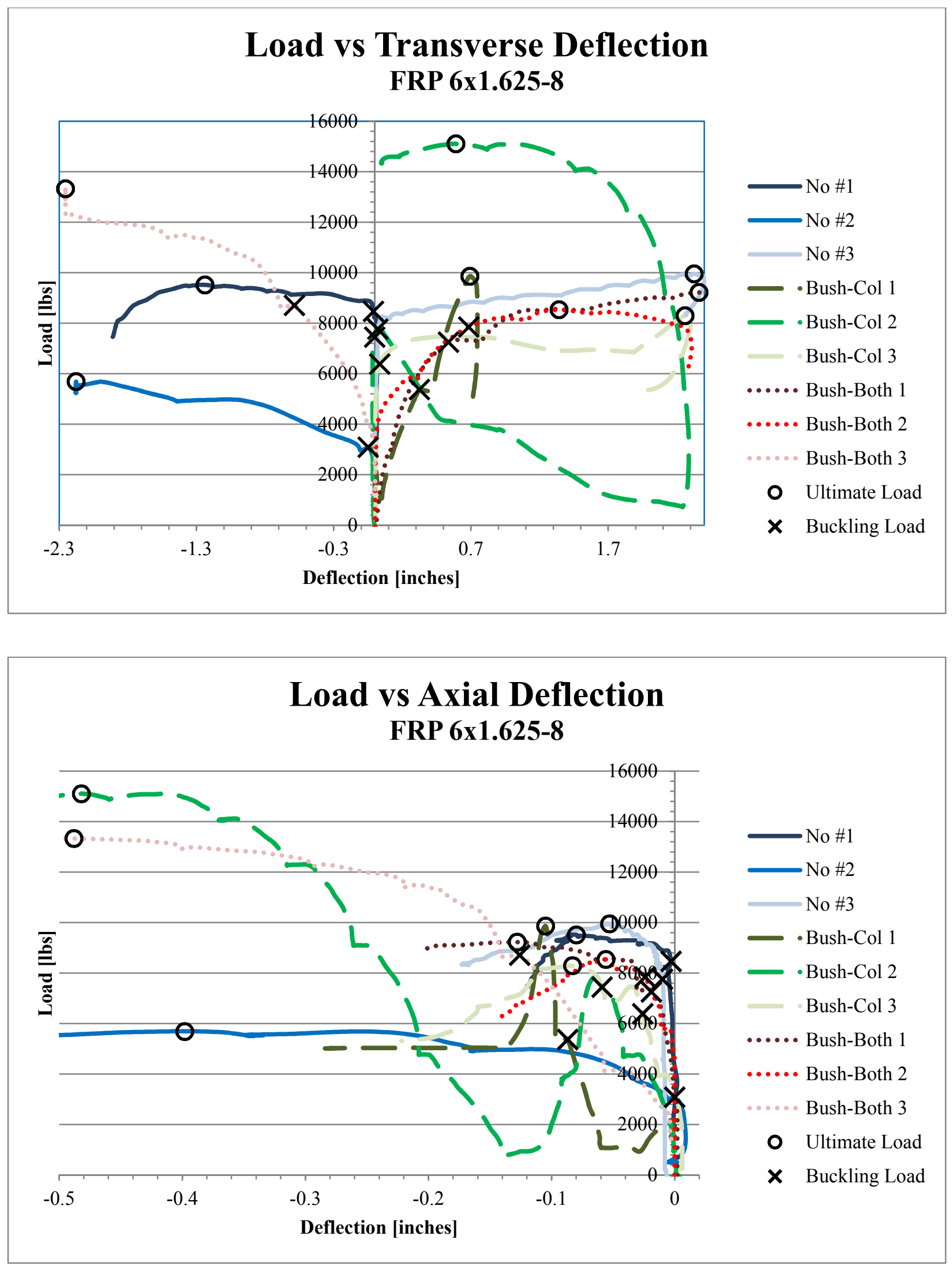


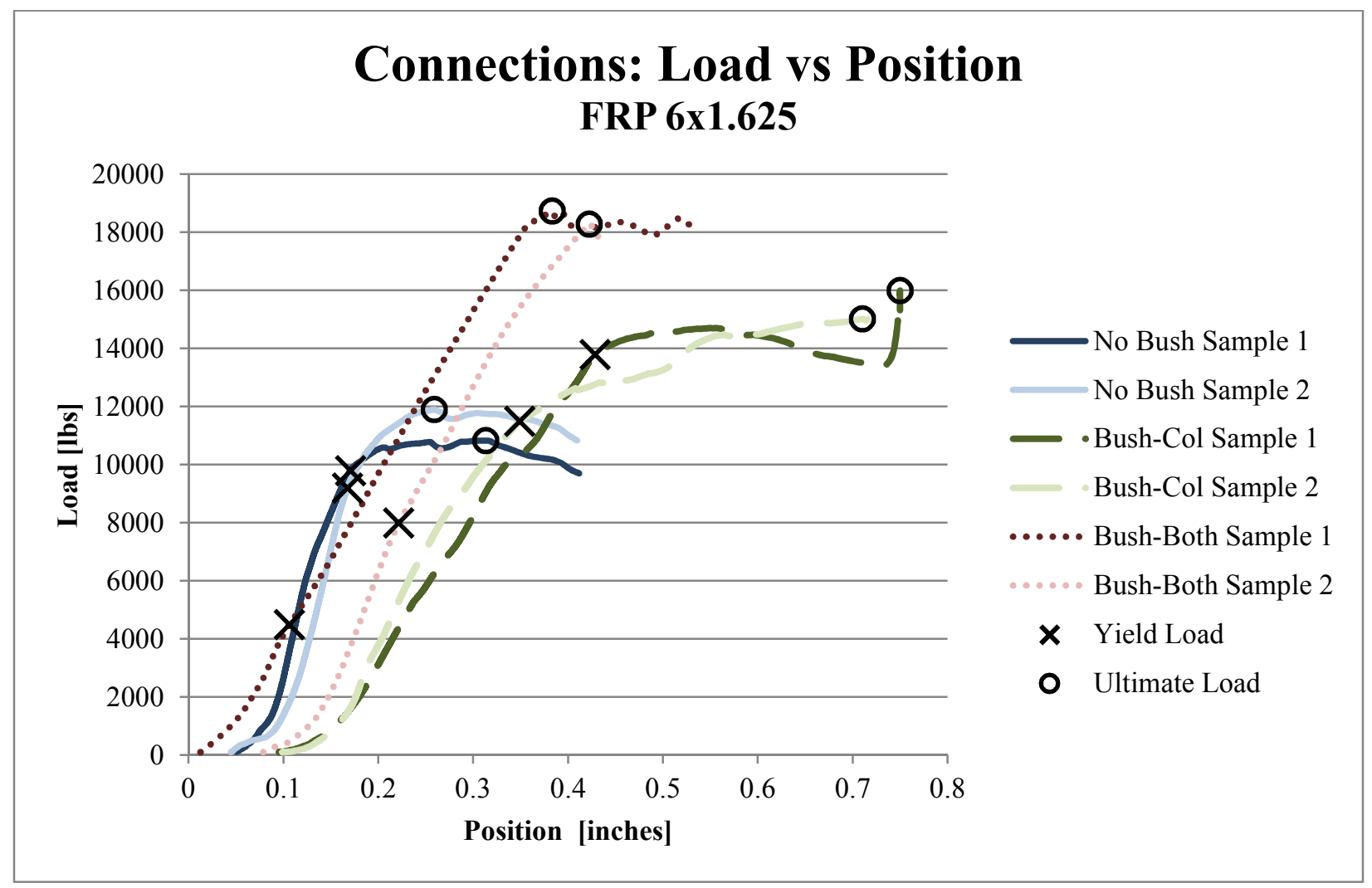




\section{APPENDIX B - DIAGRAMS OF SAMPLE CONSTRUCTION}

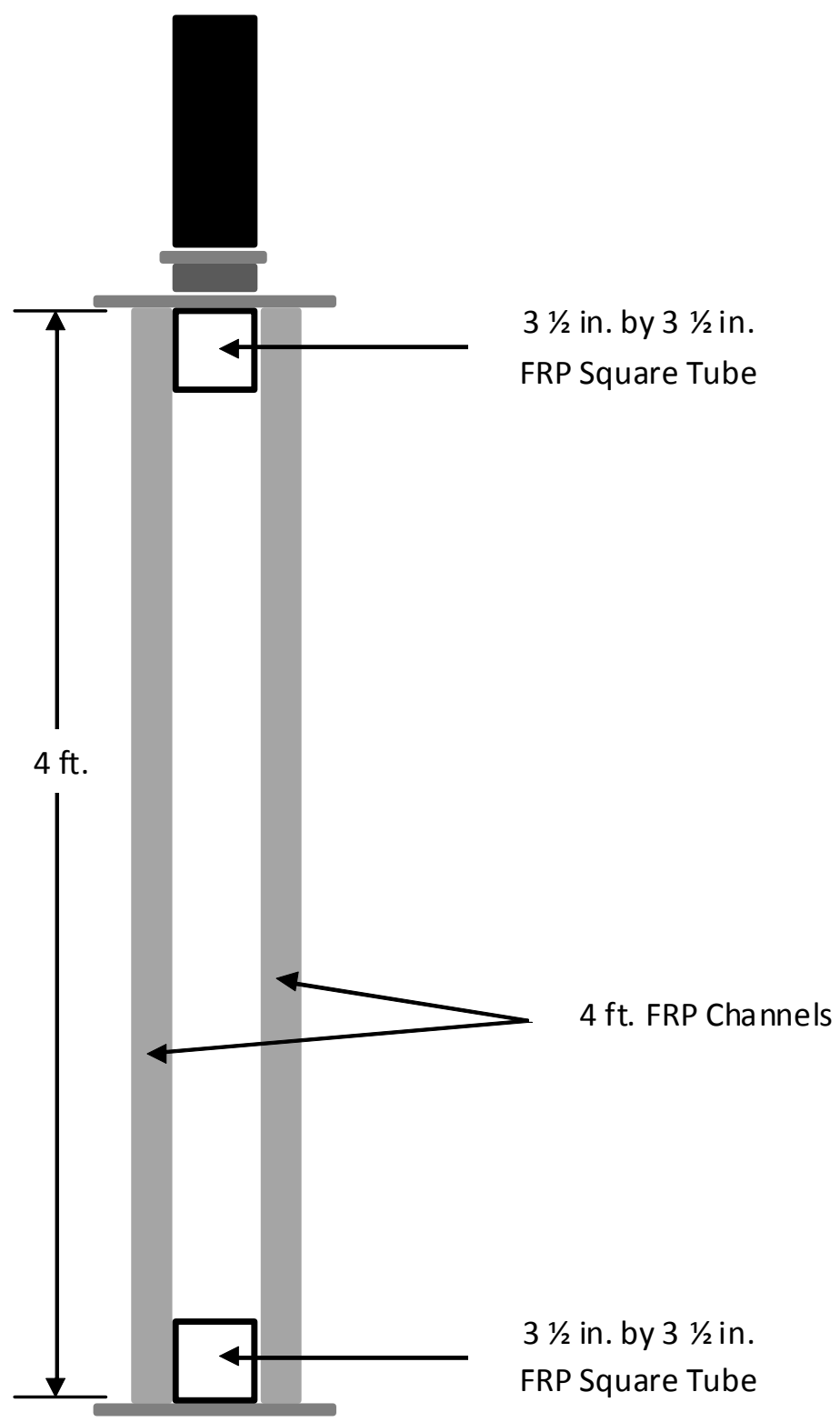



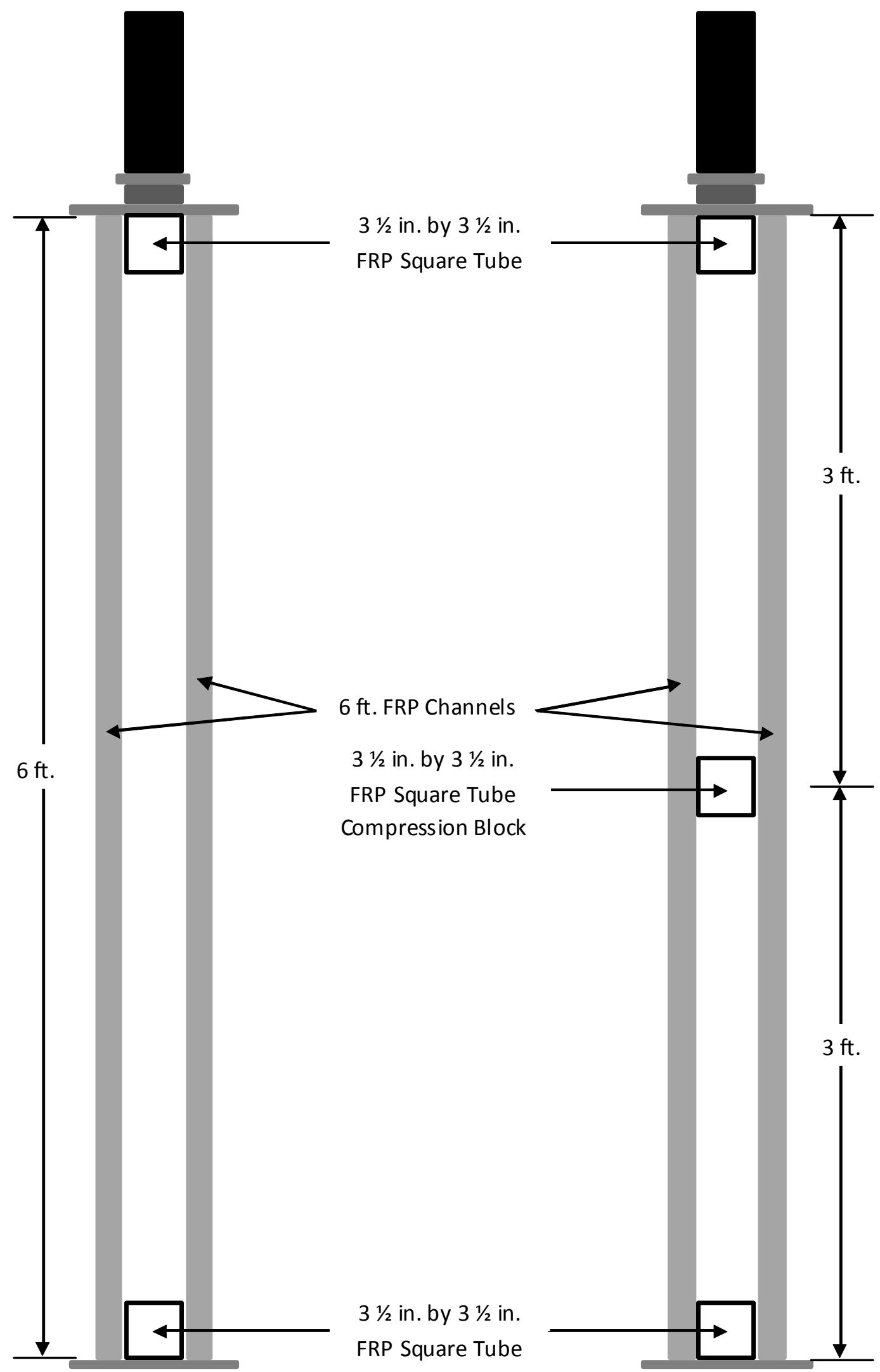


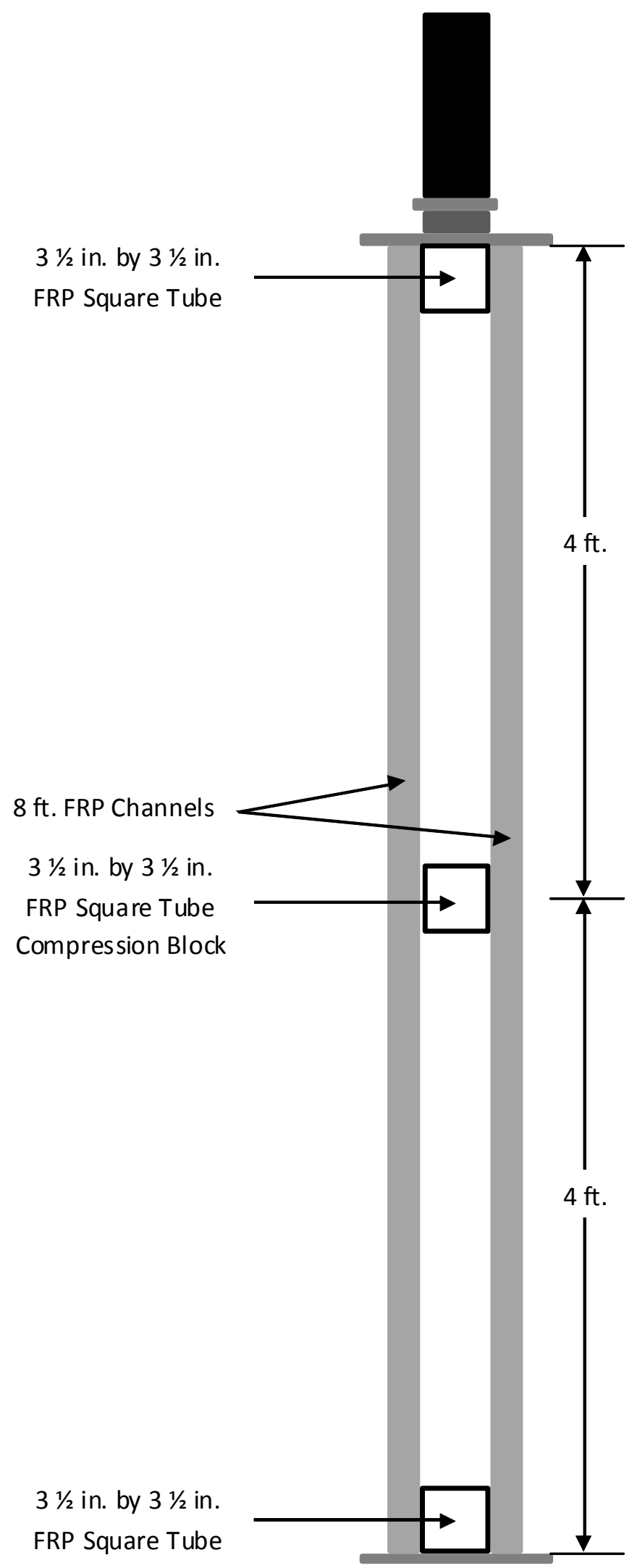




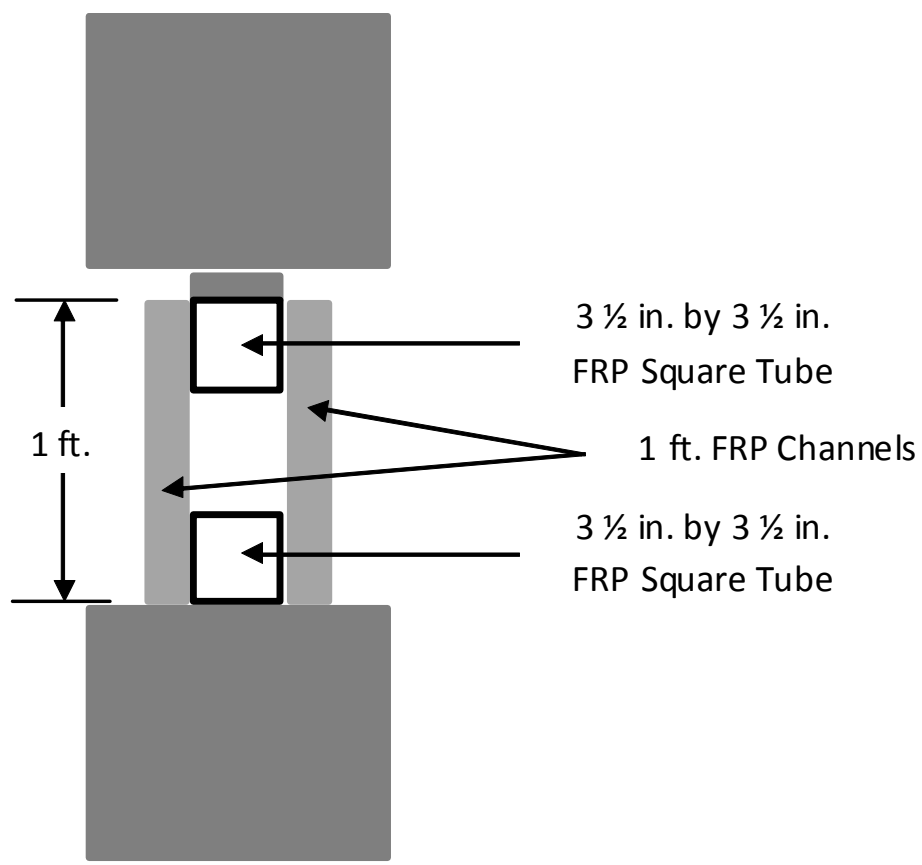




\section{APPENDIX C - PHOTOGRAPHS (SAMPLES UNDER}

\section{LOADING)}

\section{FRP $-3.5 \times 1.5$ Ties}

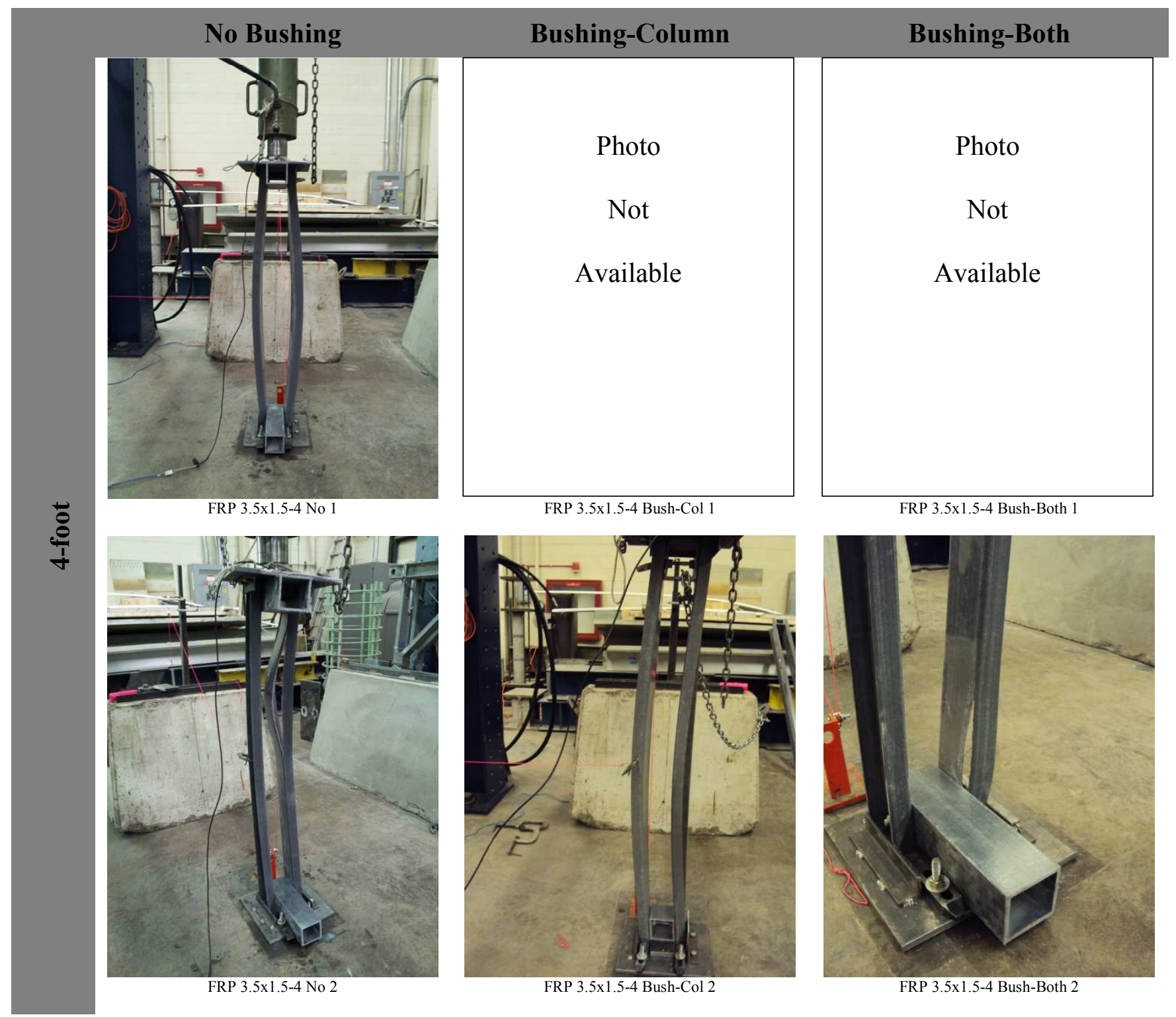




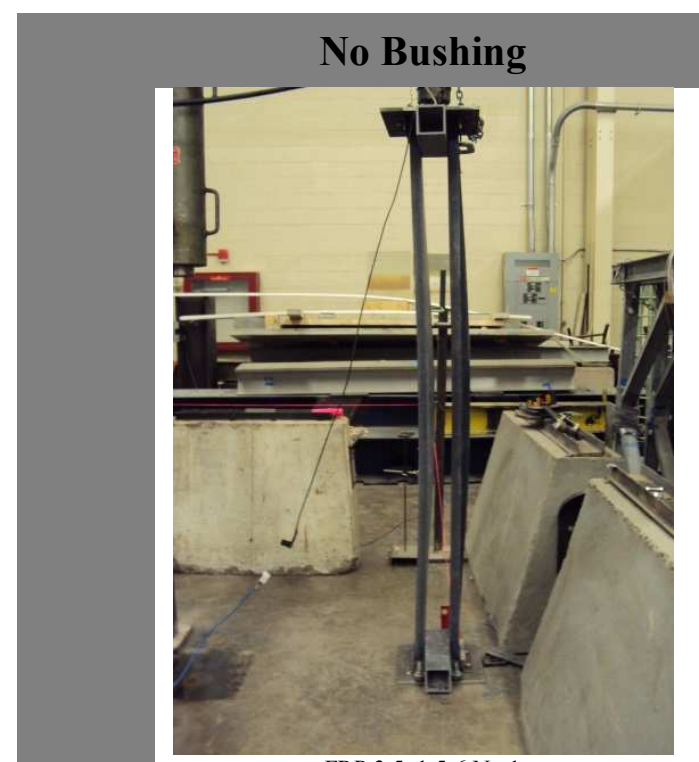

FRP $3.5 \times 1.5-6$ No 1

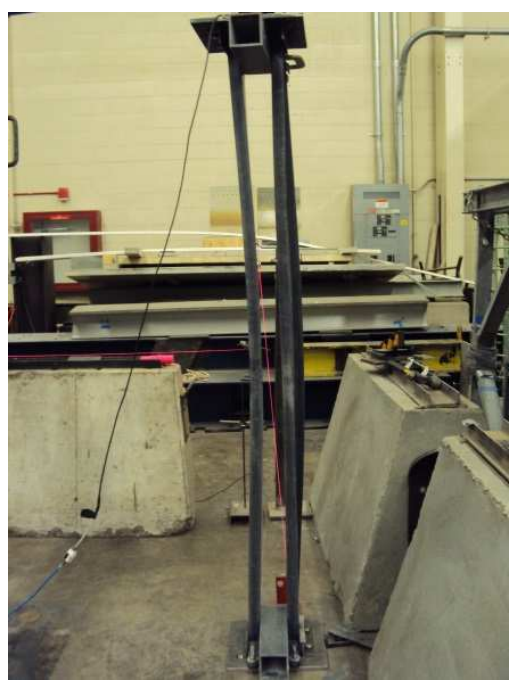

FRP 3.5x1.5-6 No 2
Bushing-Column

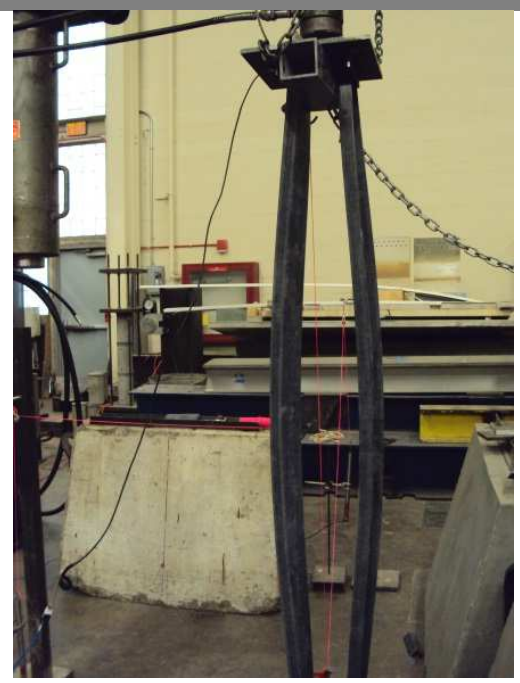

FRP 3.5x1.5-6 Bush-Col 1

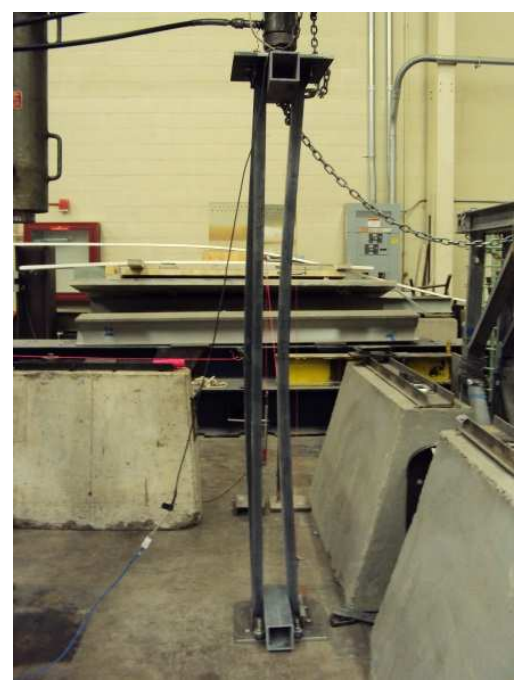

FRP 3.5x1.5-6 Bush-Col 2

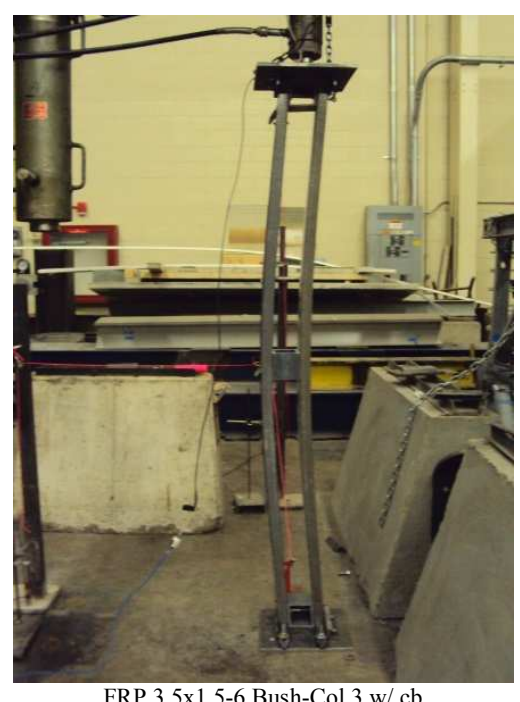

FRP 3.5x1.5-6 Bush-Col $3 \mathrm{w} / \mathrm{cb}$
Bushing-Both

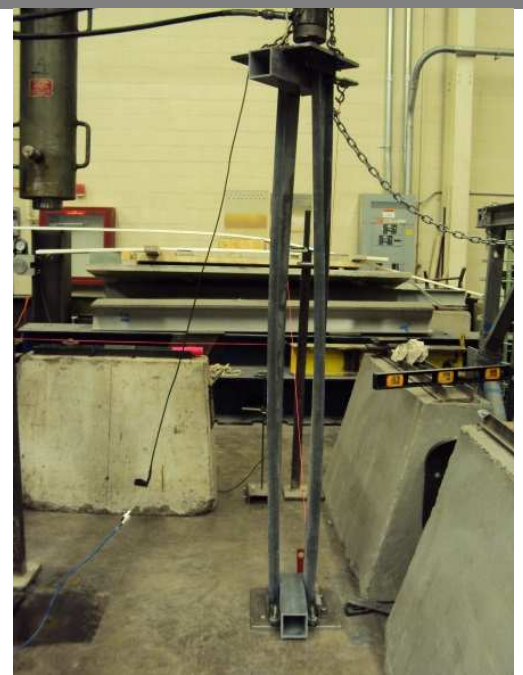

FRP 3.5x1.5-6 Bush-Both 1

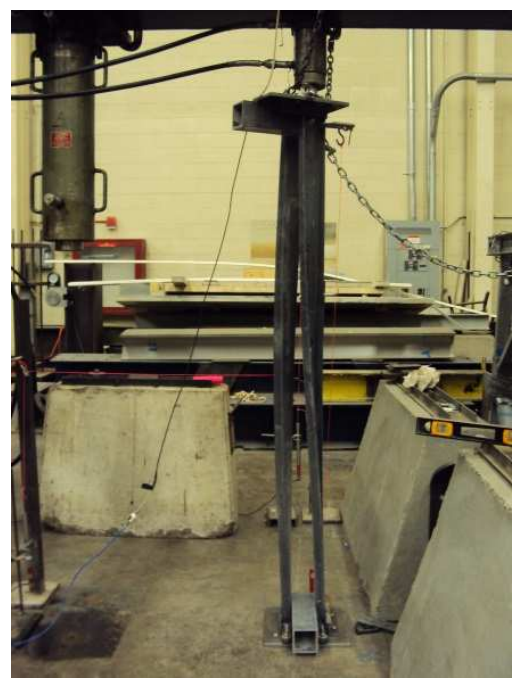

FRP 3.5x1.5-6 Bush-Both 2 


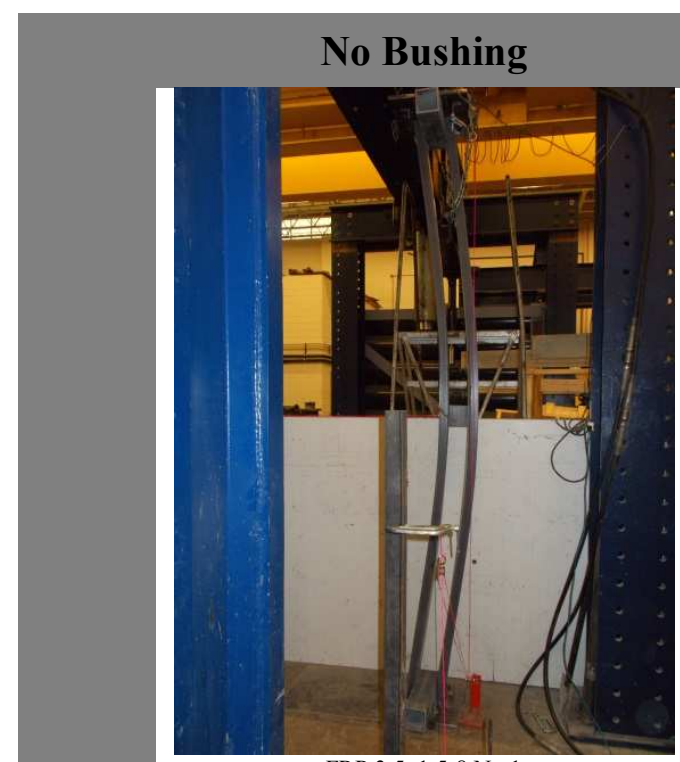

FRP $3.5 \times 1.5-8$ No 1

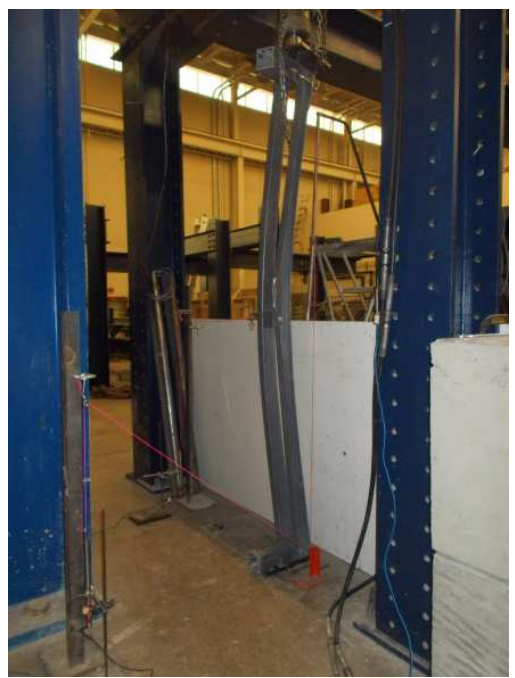

FRP $3.5 \times 1.5-8$ No 2
Bushing-Column

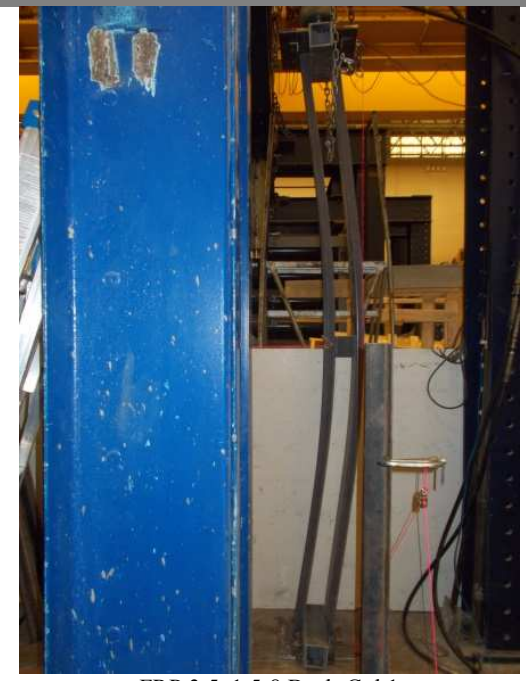

FRP 3.5x1.5-8 Bush-Col 1

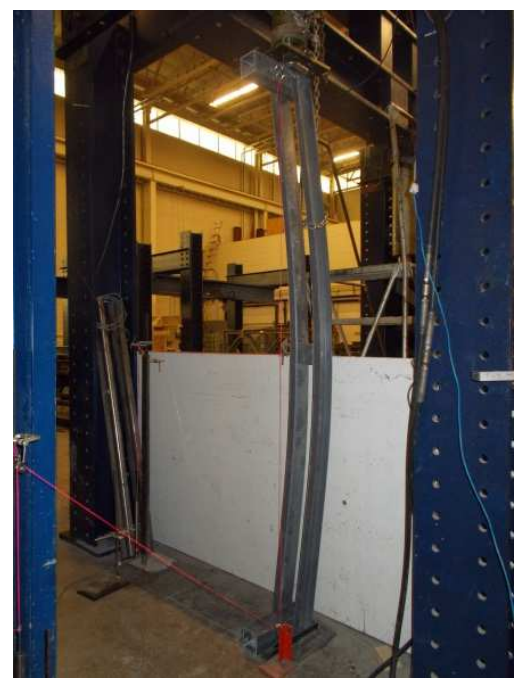

FRP 3.5x1.5-8 Bush-Col 1

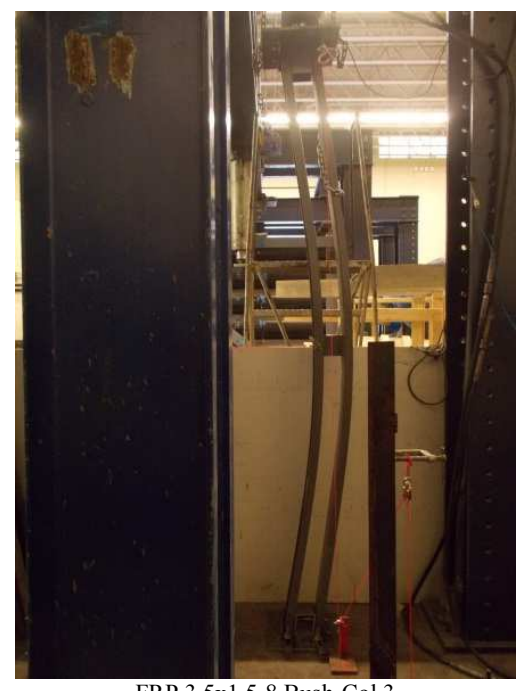

FRP 3.5x1.5-8 Bush-Col 3
Bushing-Both

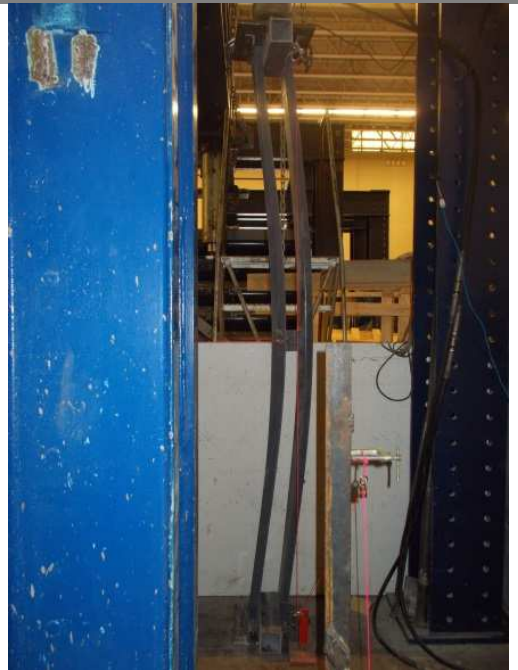

FRP 3.5x1.5-8 Bush-Both 1

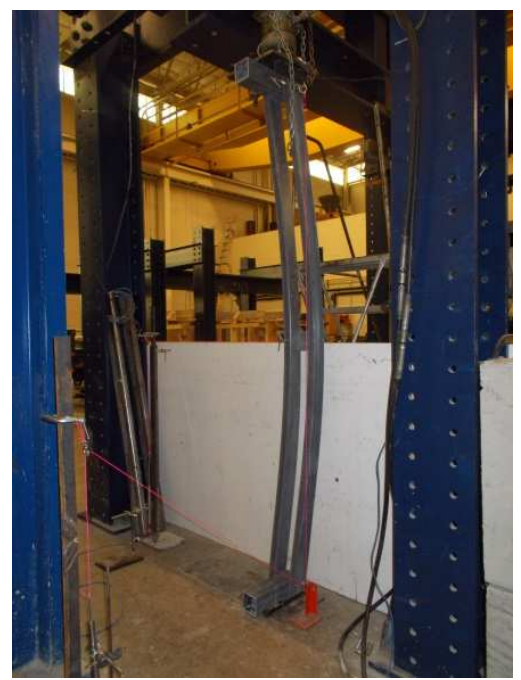

FRP 3.5x1.5-8 Bush-Both 2

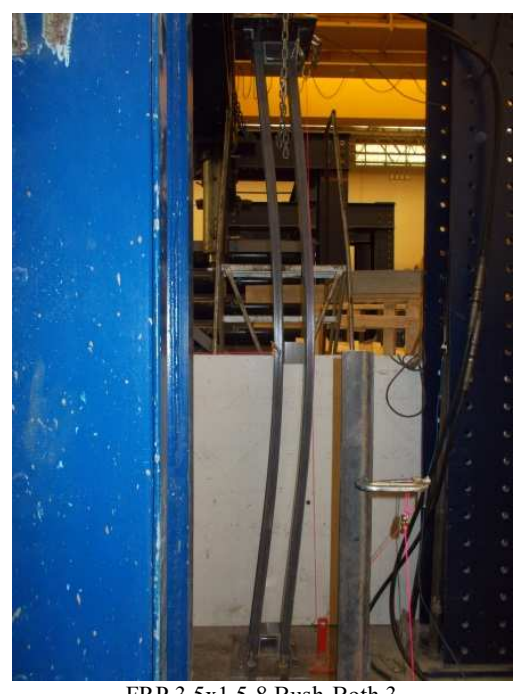

FRP 3.5x1.5-8 Bush-Both 3 
FRP 3.5x1.5 Connection Tests

\section{Bush-Col Connection Sample 1}
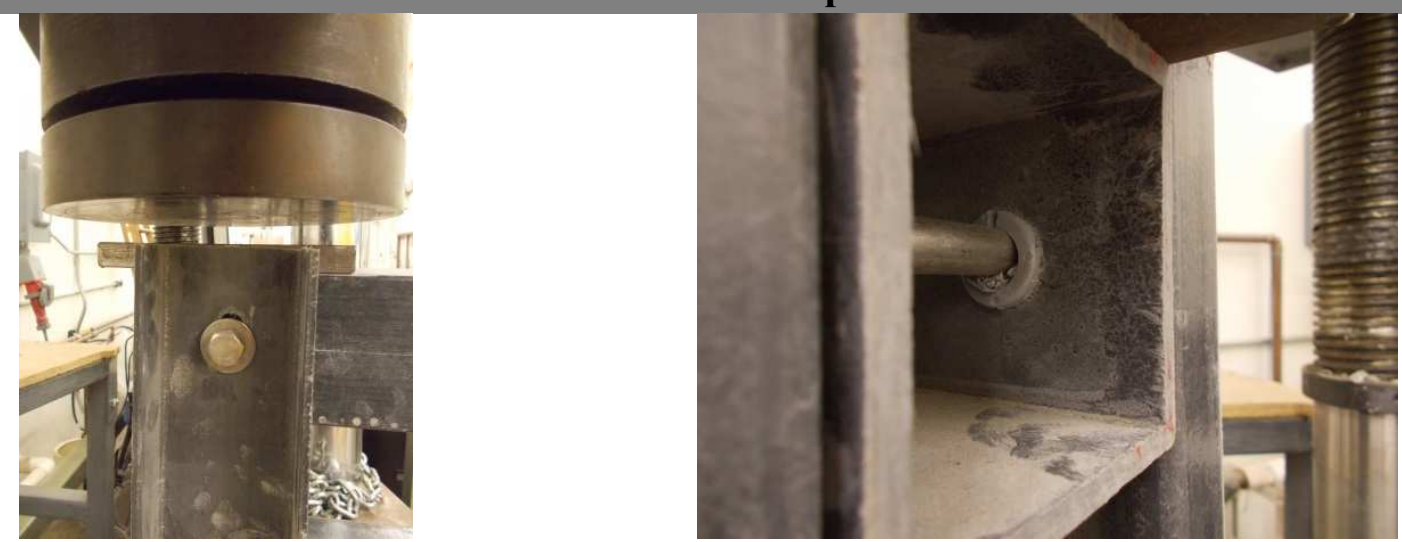

Bush-Col Connection Sample 2
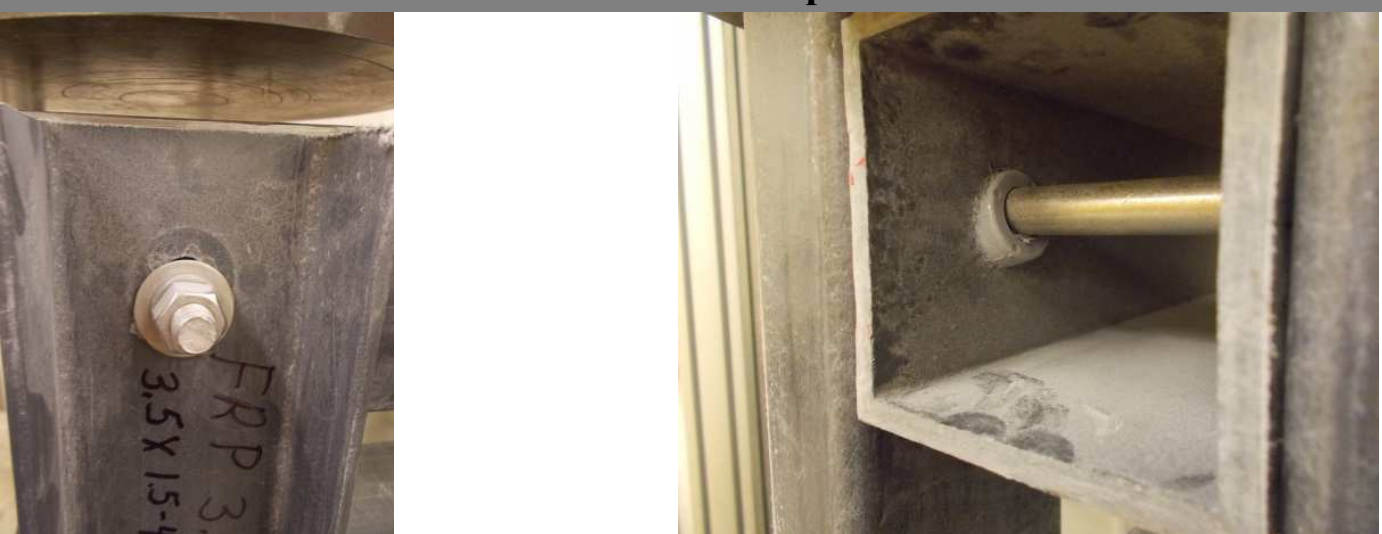

Bush-Both Connection Sample 1
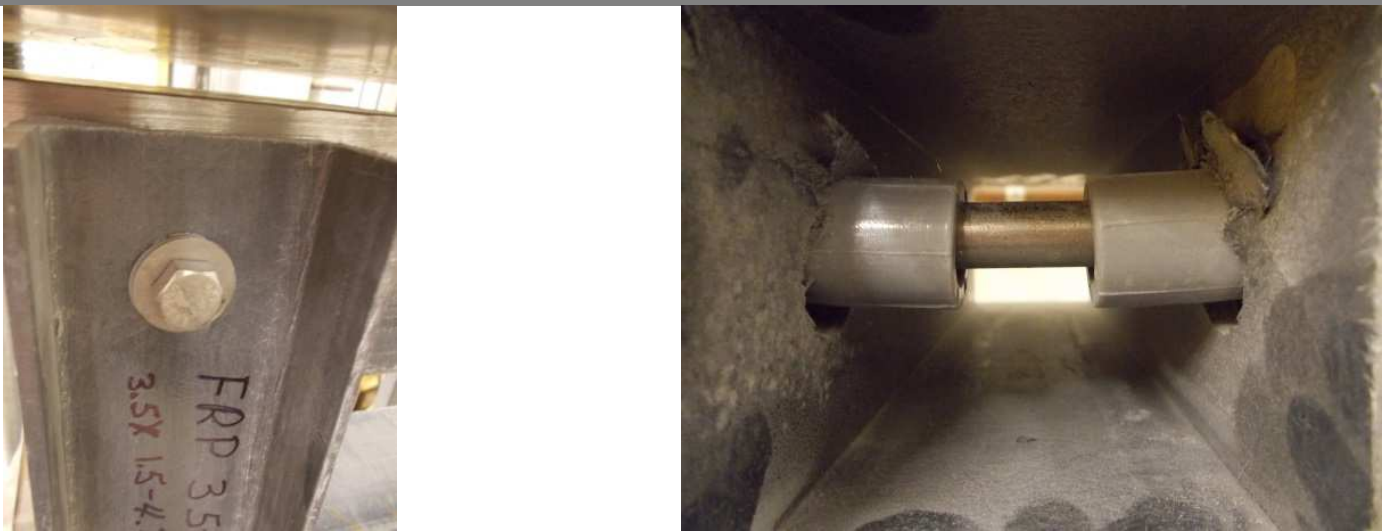


\section{Bush-Both Connection Sample 2}
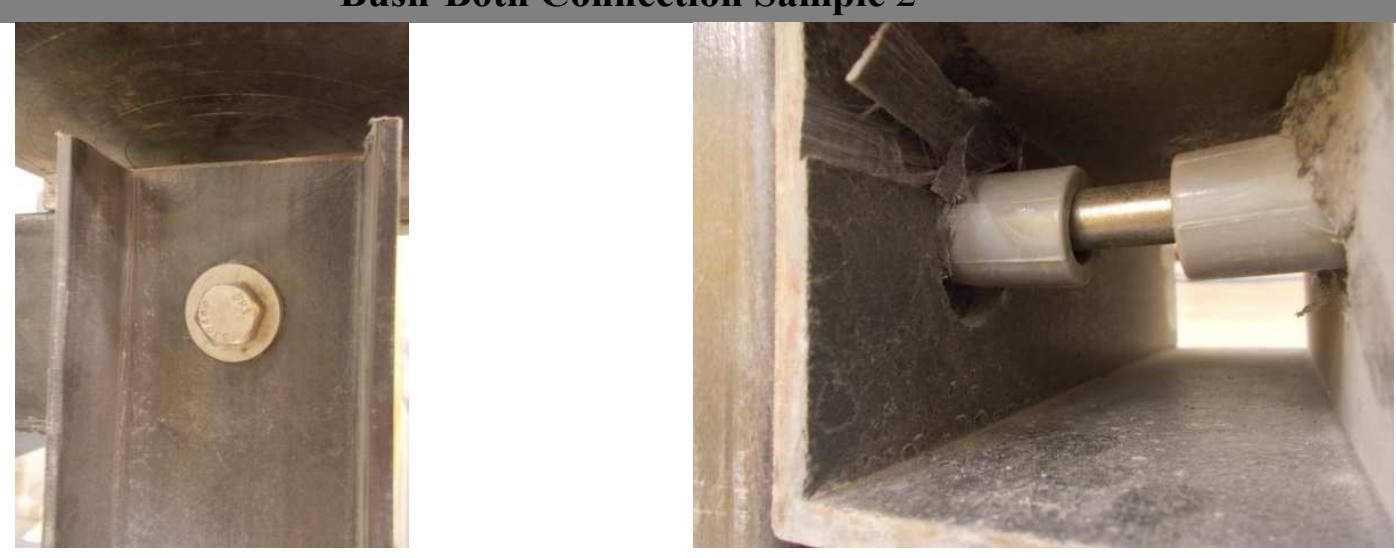


\section{FRP - 4x1.25 Ties}

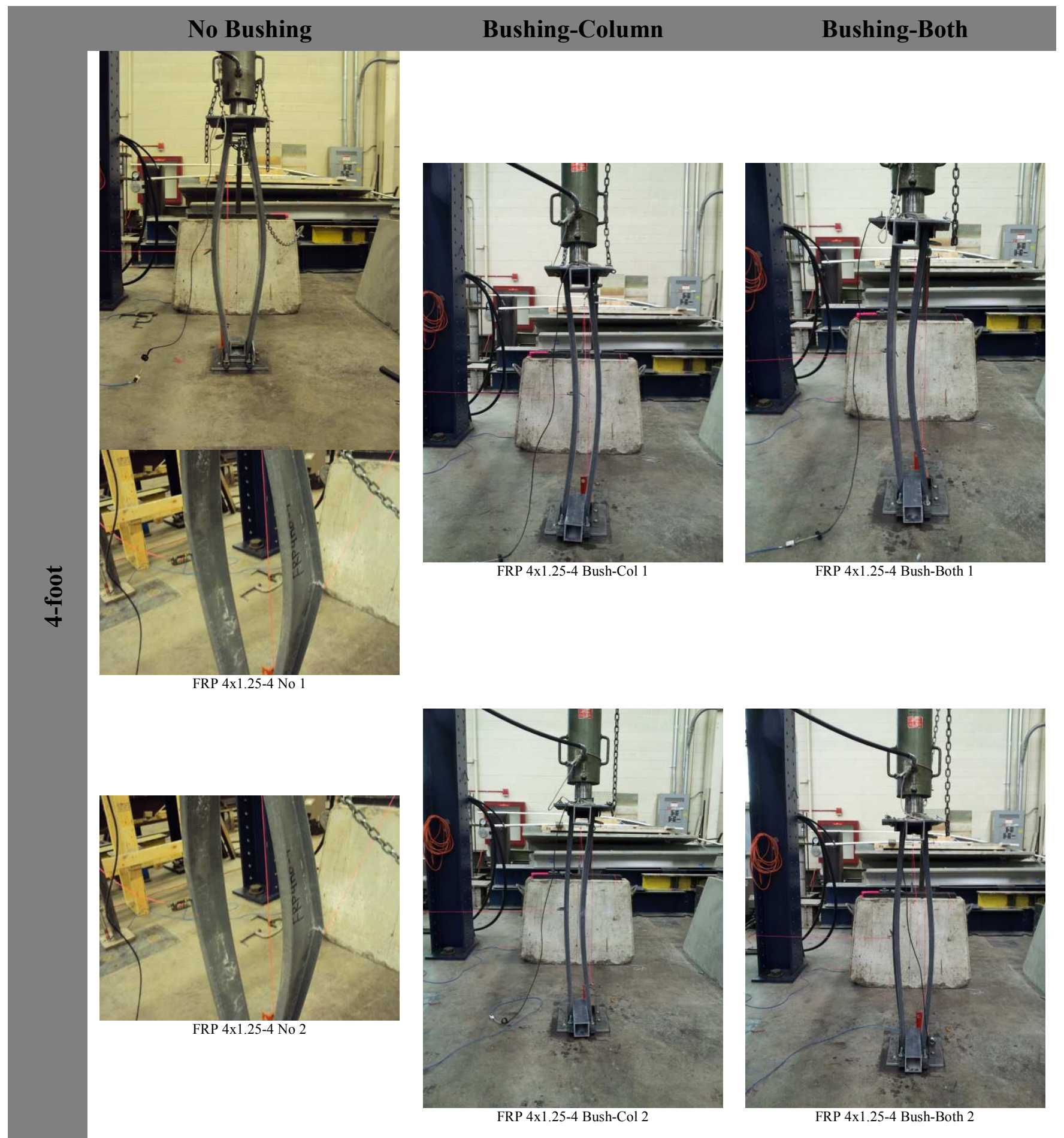



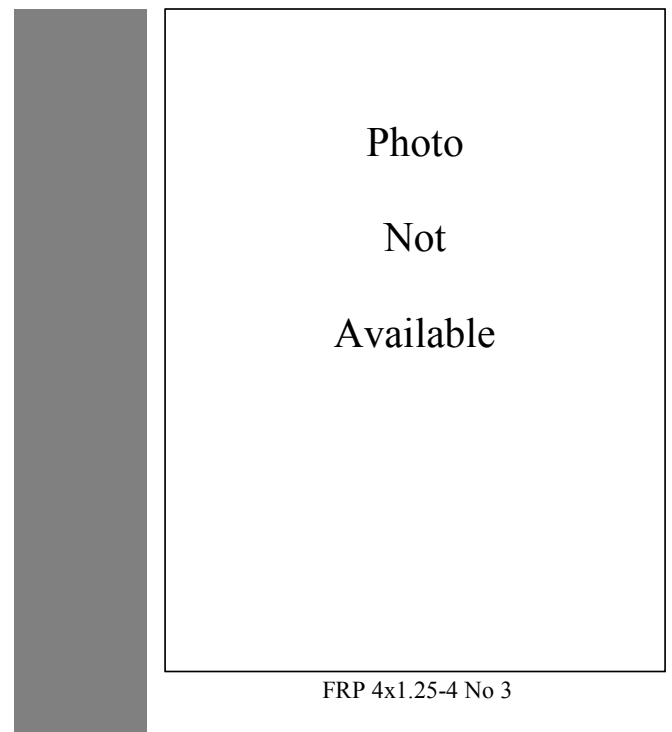

FRP $4 \times 1.25-4$ No 3

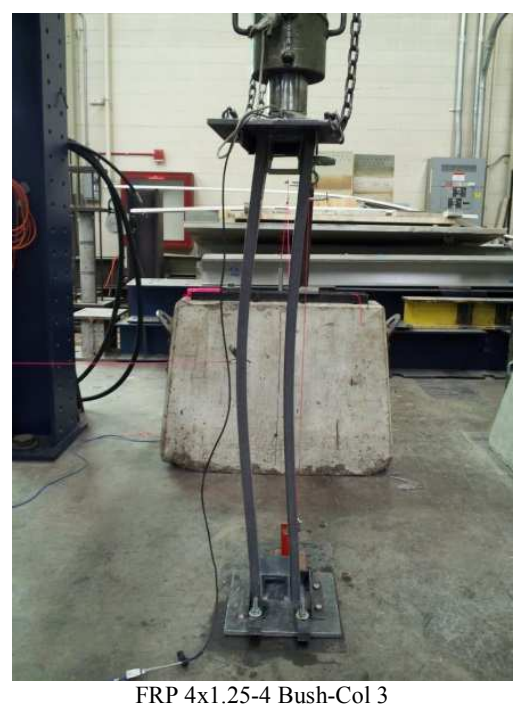




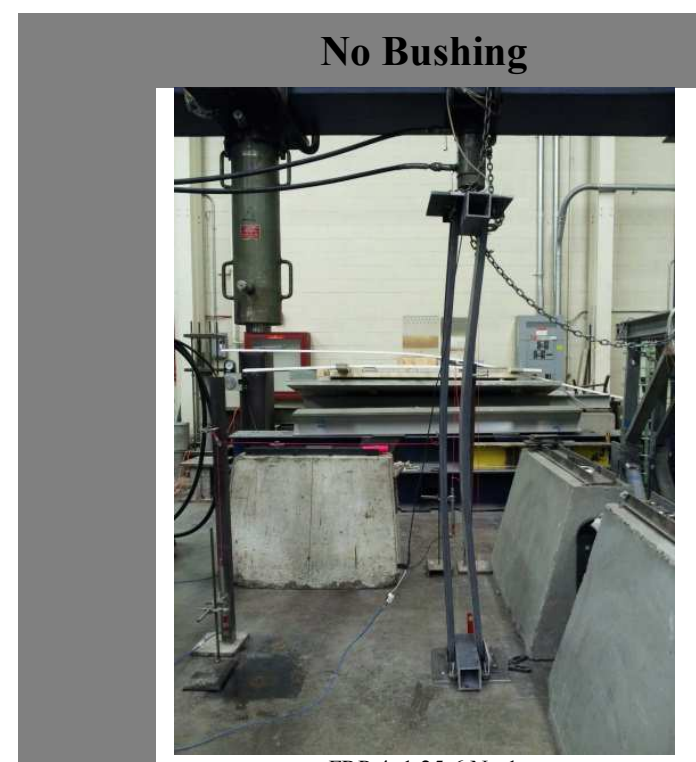

FRP 4x1.25-6 No 1

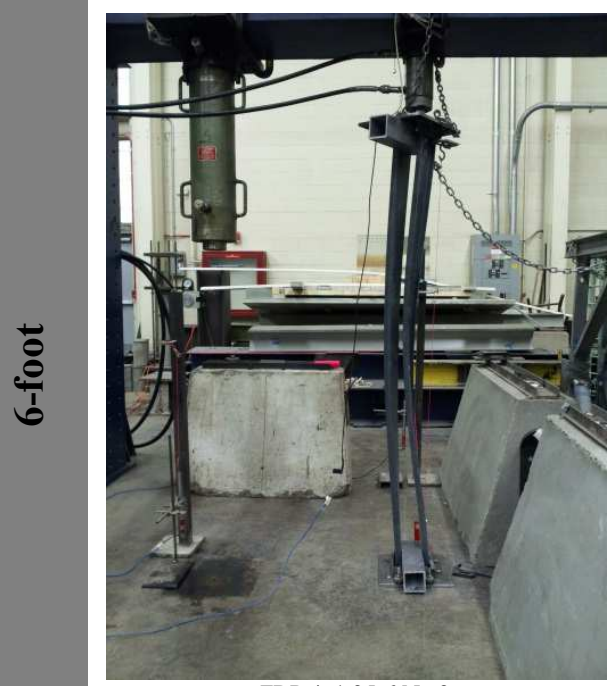

FRP 4x1.25-6 No 2

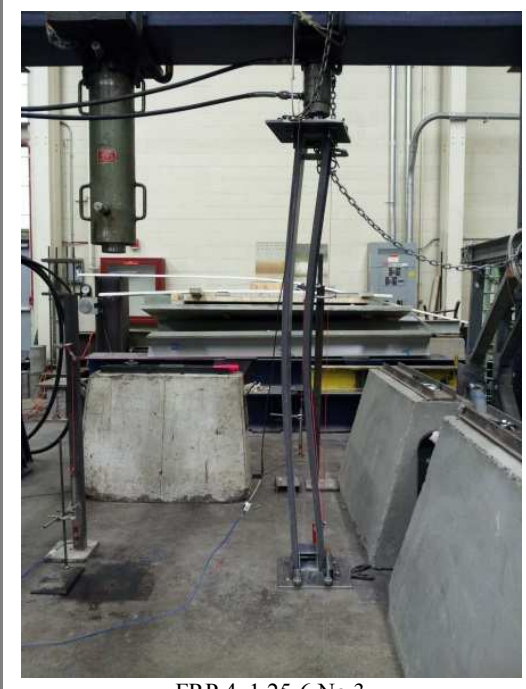

FRP 4x1.25-6 No 3
Bushing-Column

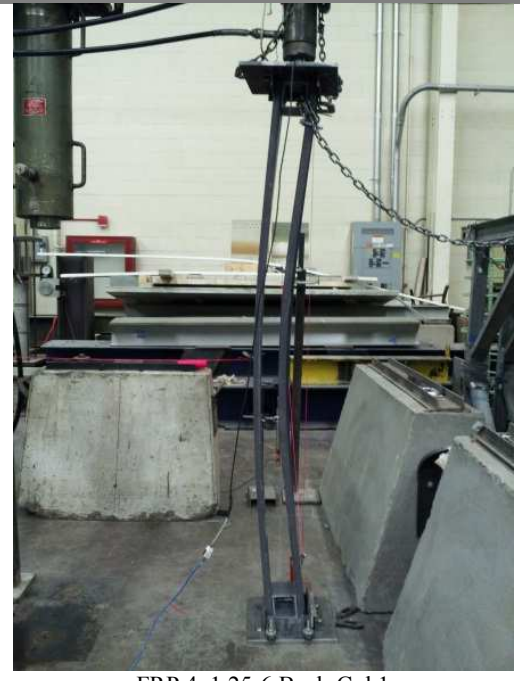

FRP 4x1.25-6 Bush-Col 1

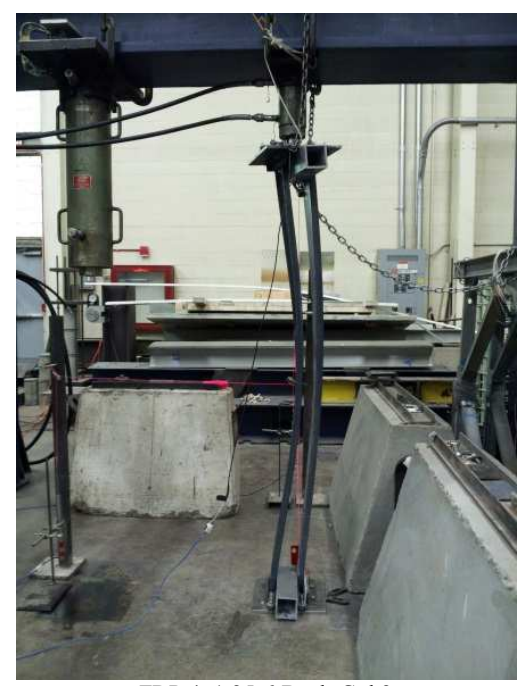

FRP 4x1.25-6 Bush-Col 2

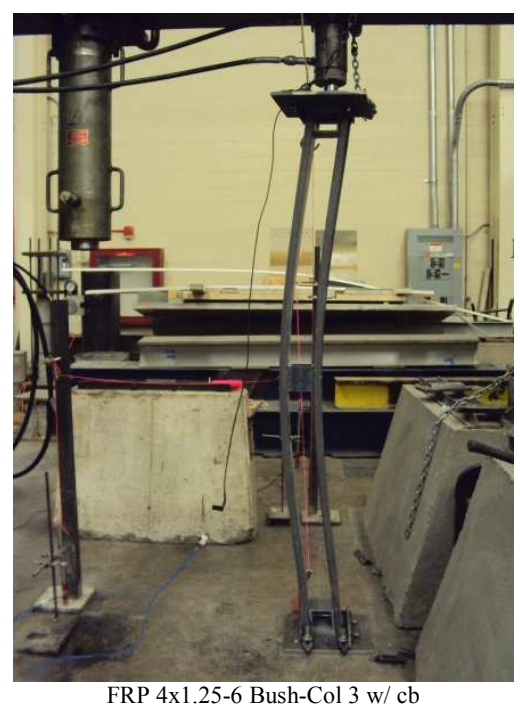

FRP 4x1.25-6 Bush-Col 3 w/ cb
Bushing-Both

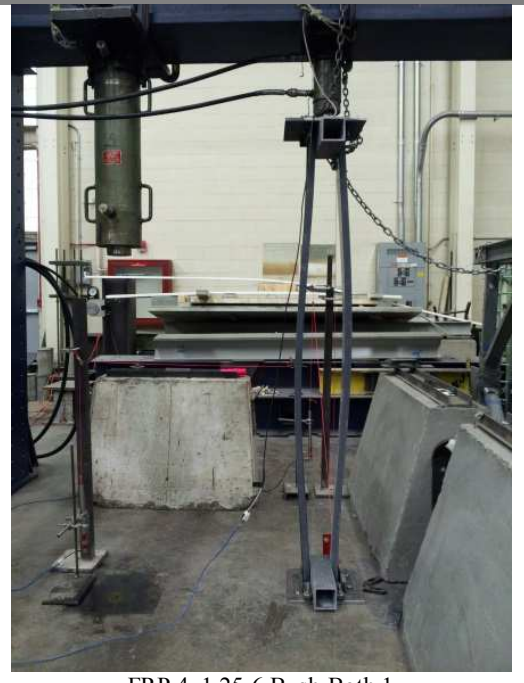

FRP 4x1.25-6 Bush-Both 1

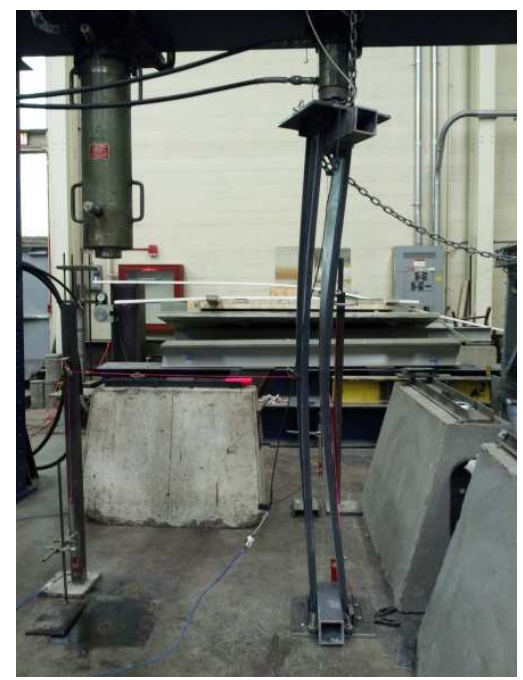

FRP 4x1.25-6 Bush-Both 2

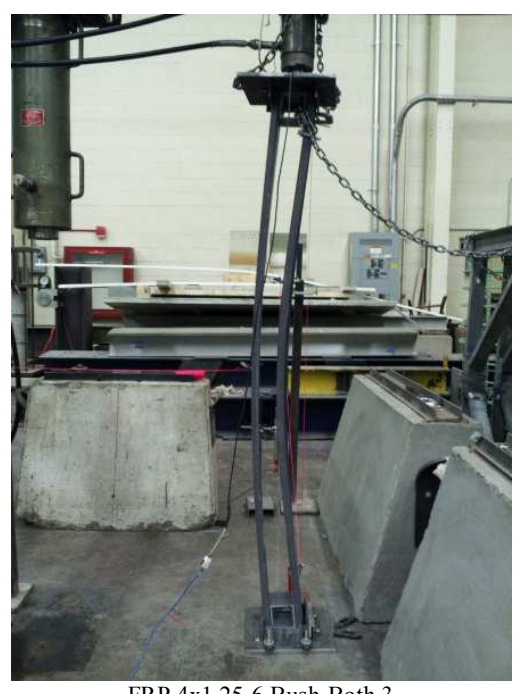

FRP 4x1.25-6 Bush-Both 3 


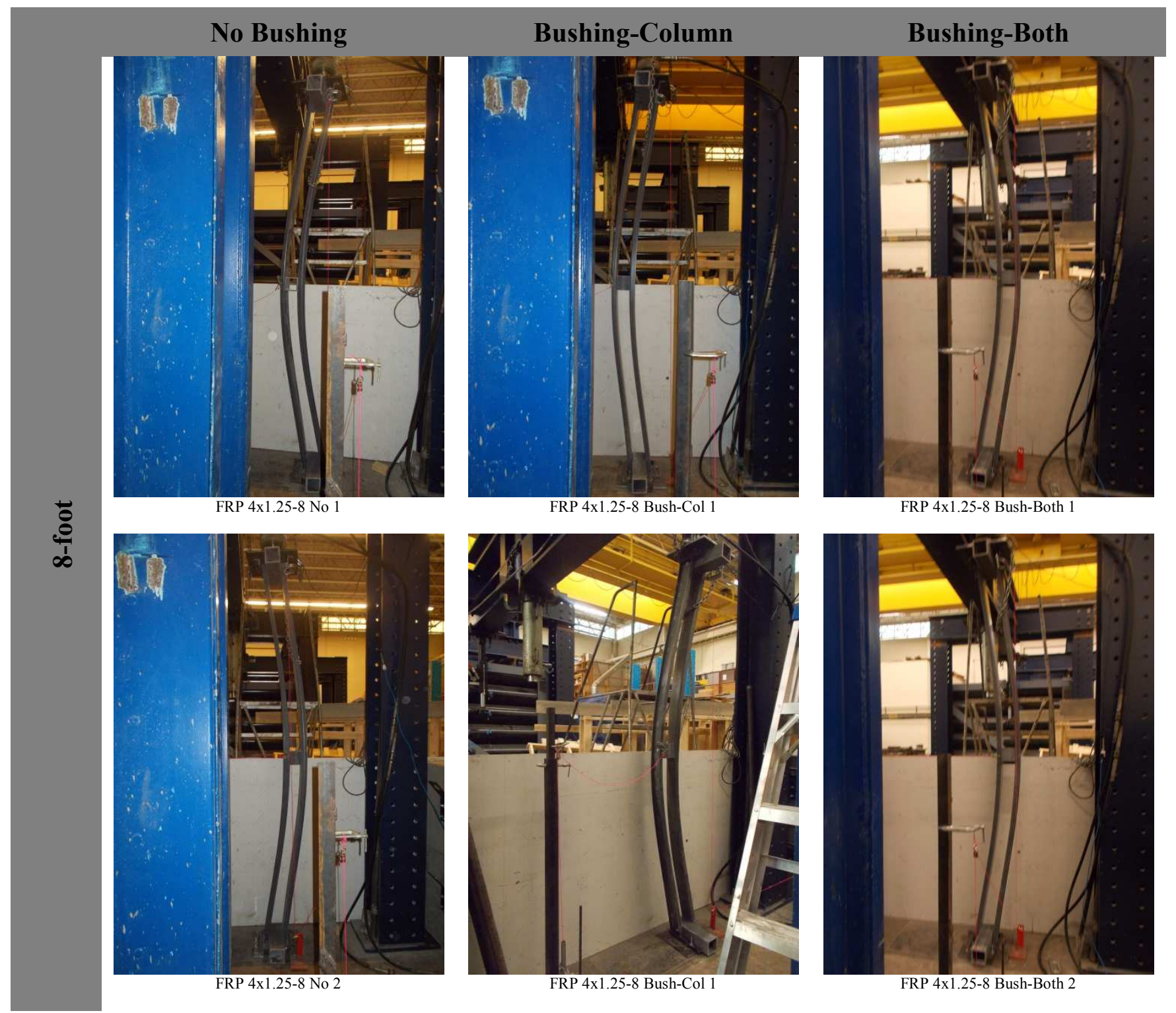


FRP 4x1.25 Connection Tests

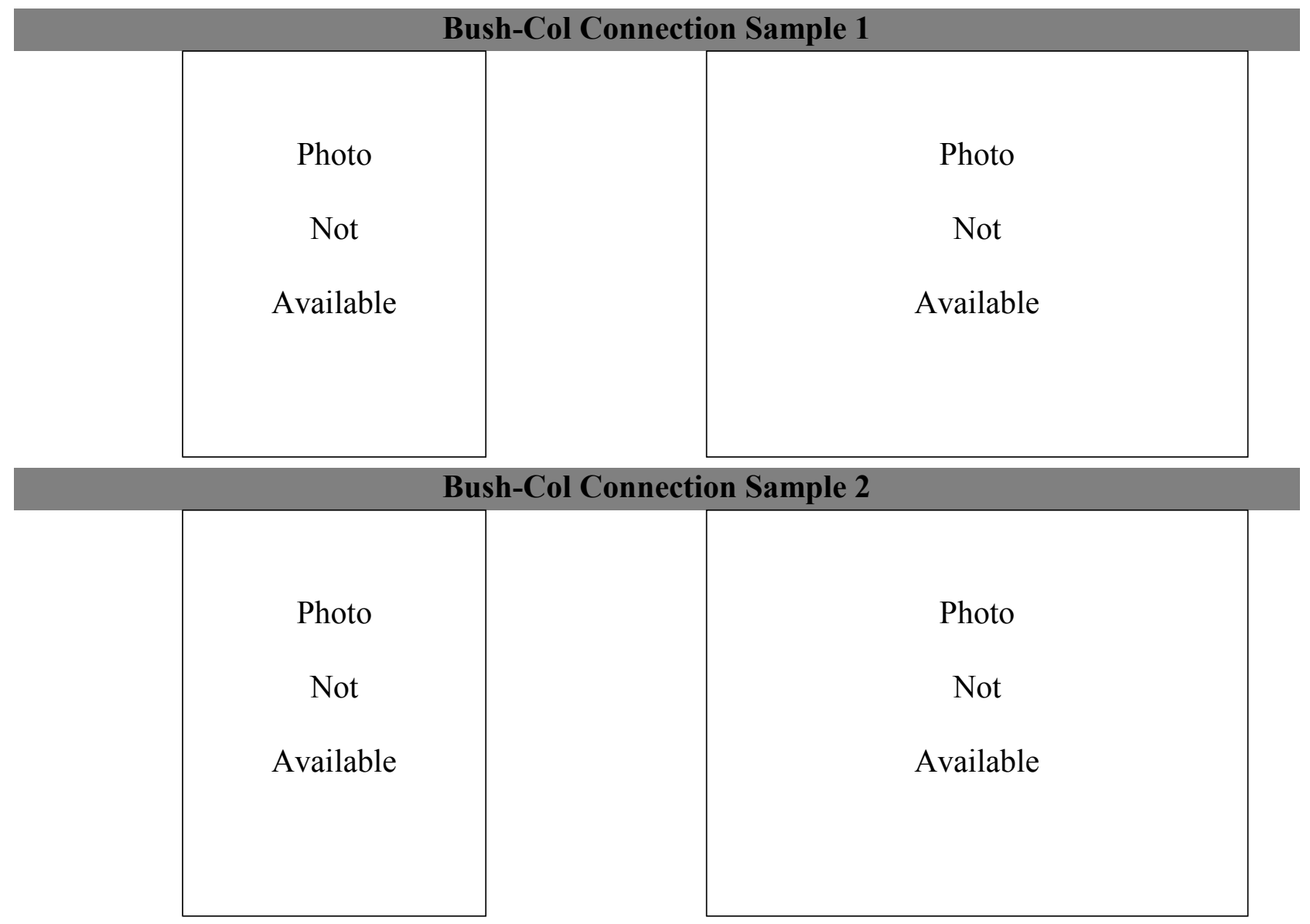




\section{FRP - 4x1.375 Ties}

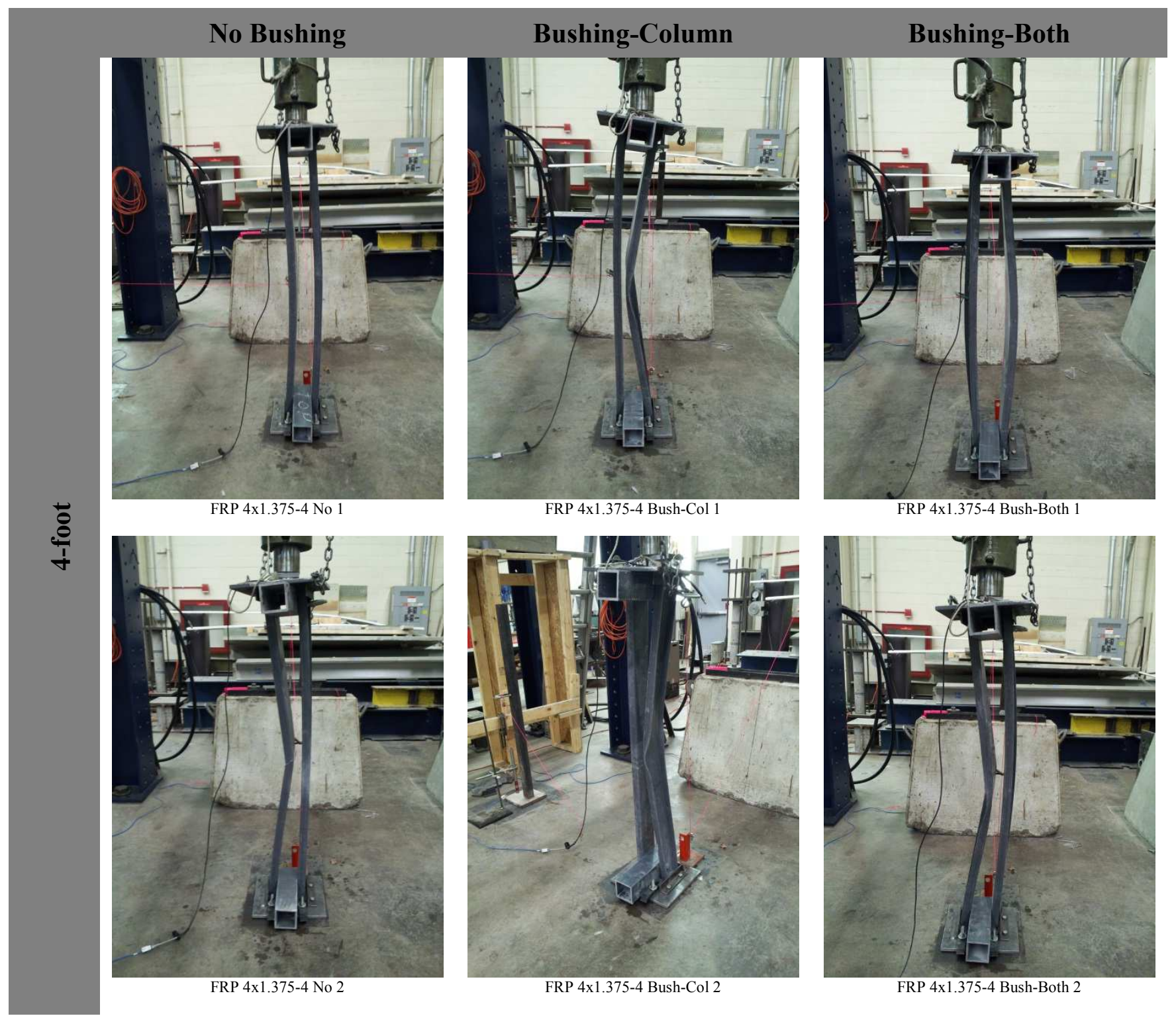




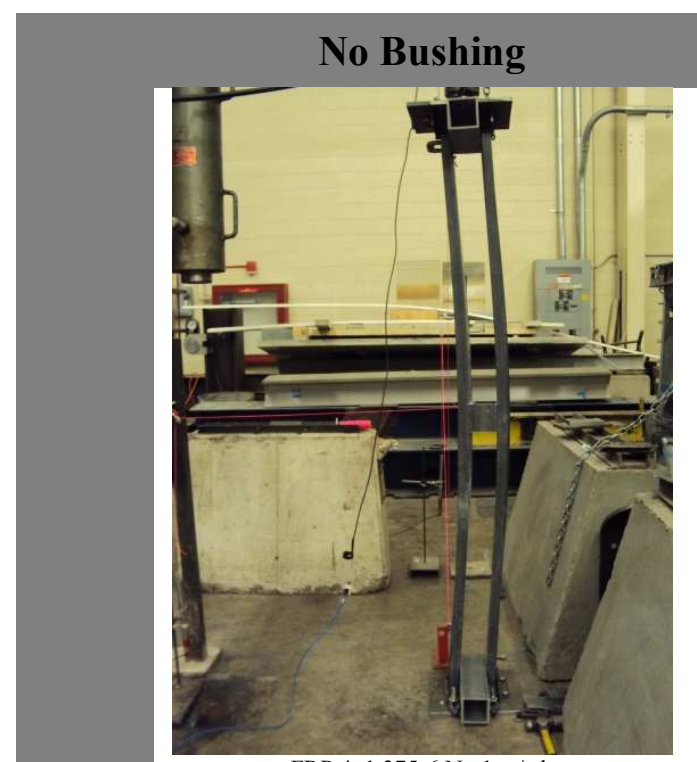

FRP 4x1.375-6 No $1 \mathrm{w} / \mathrm{cb}$

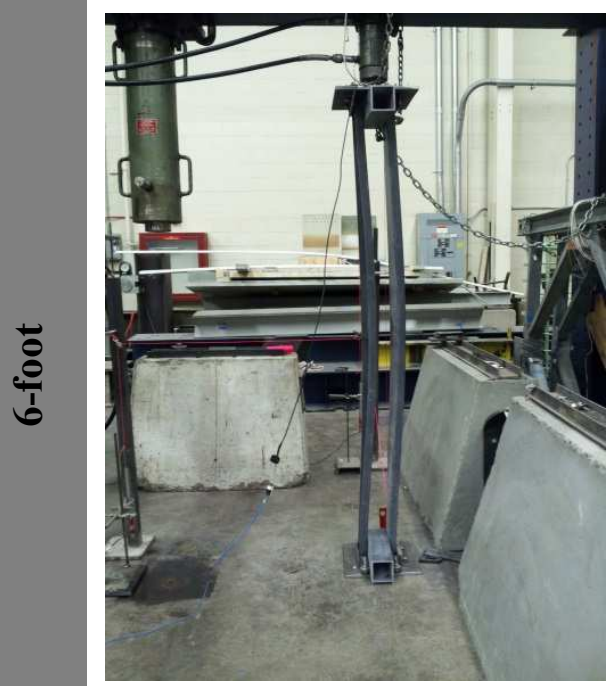

FRP 4x1.375-6 No 2

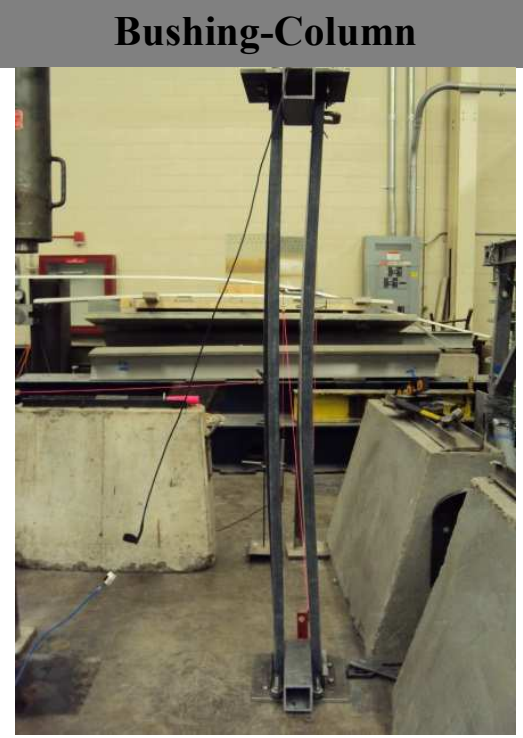

FRP 4x1.375-6 Bush-Col 1

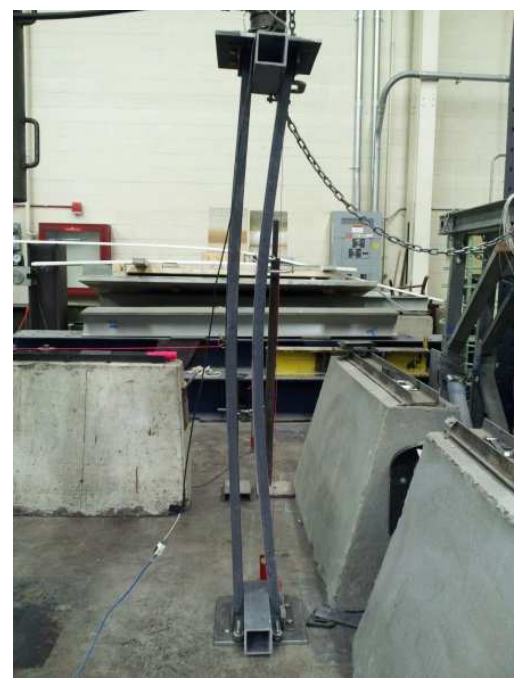

FRP 4x1.375-6 Bush-Col 2

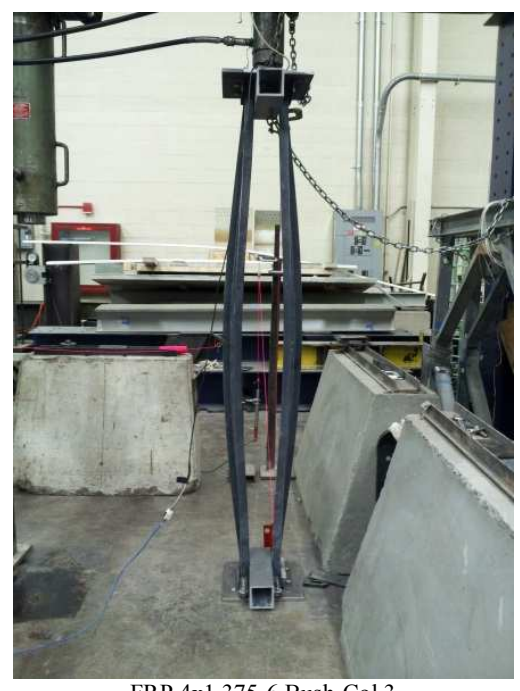

FRP 4x1.375-6 Bush-Col 3
Bushing-Both

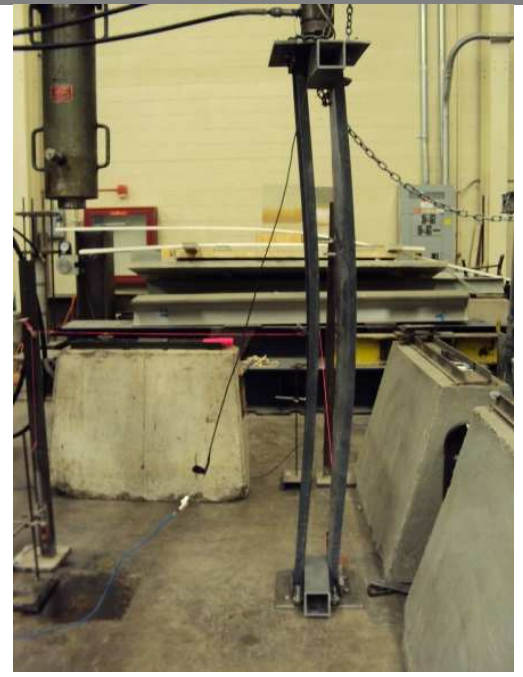

FRP 4x1.375-6 Bush-Both

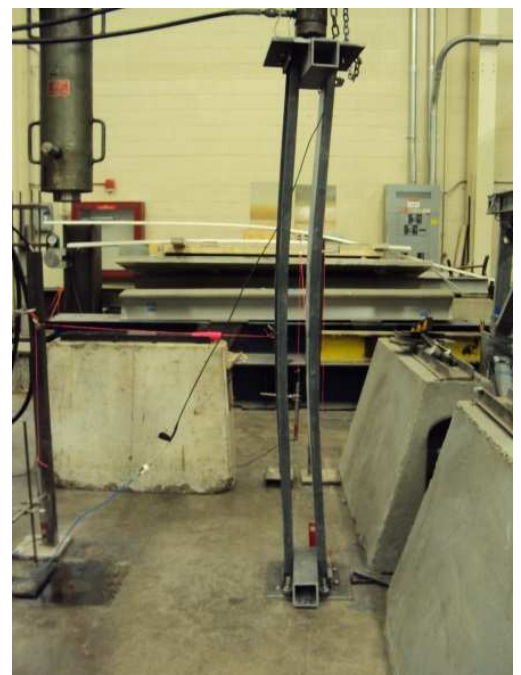

FRP 4x1.375-6 Bush-Both 2

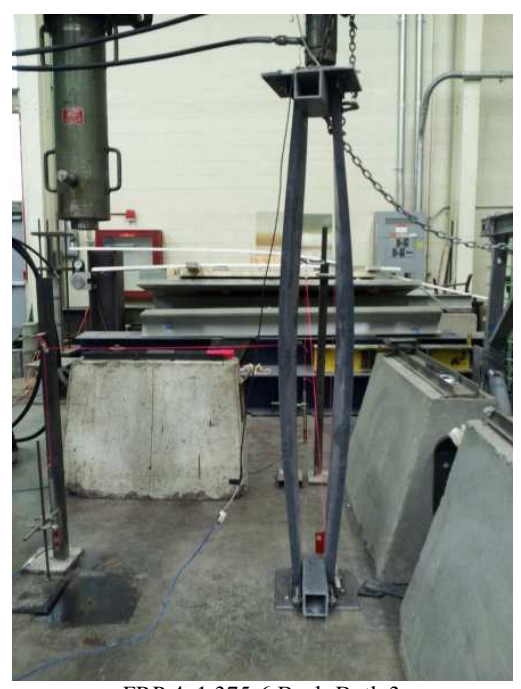

FRP 4x1.375-6 Bush-Both 3 


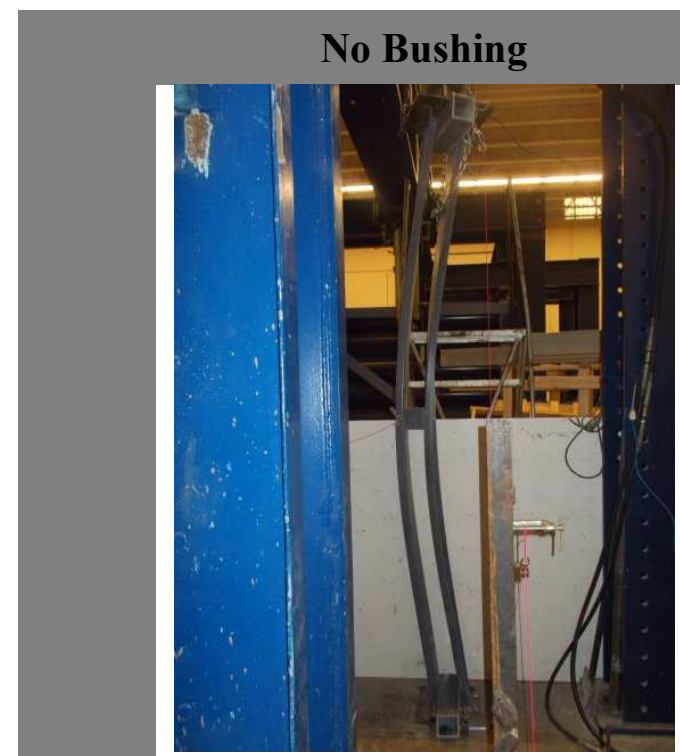

FRP 4x1.375-8 No 1

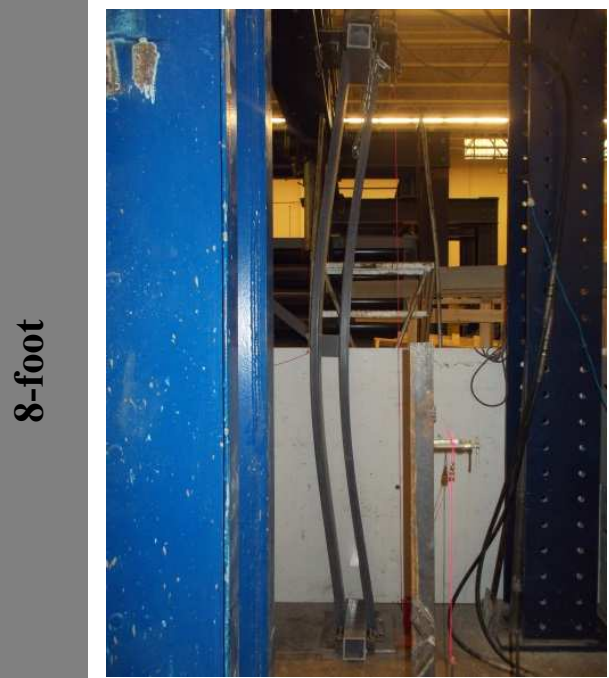

FRP 4x1.375-8 No 2
Bushing-Column

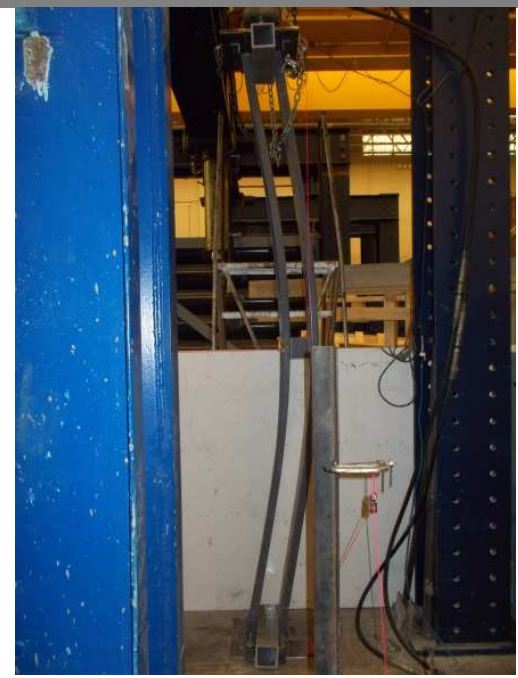

FRP 4x1.375-8 Bush-Col 1

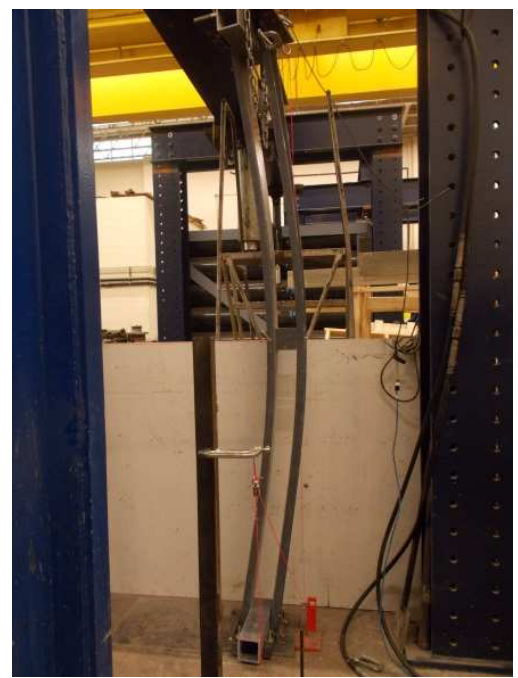

FRP 4x1.375-8 Bush-Col 1

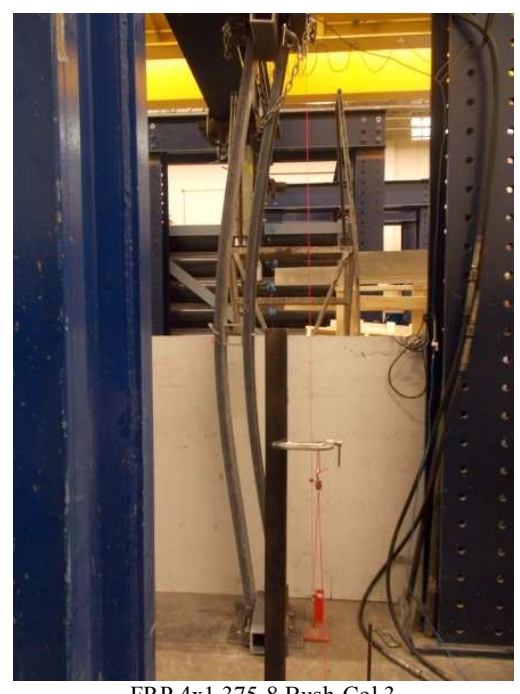

FRP 4x1.375-8 Bush-Col 3
Bushing-Both

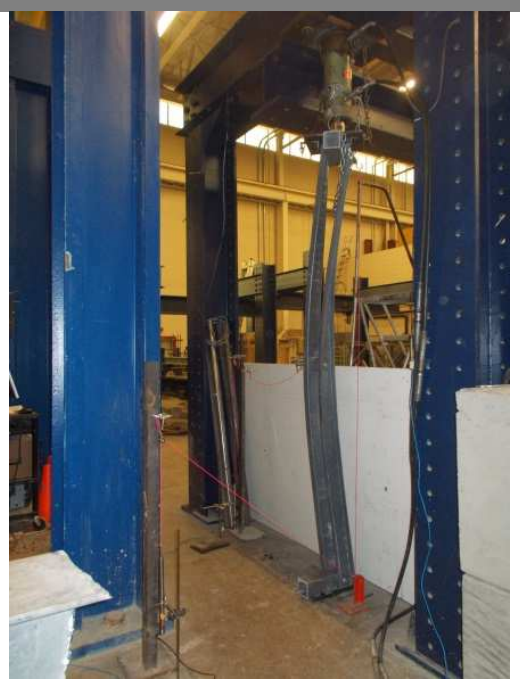

FRP 4x1.375-8 Bush-Both 1

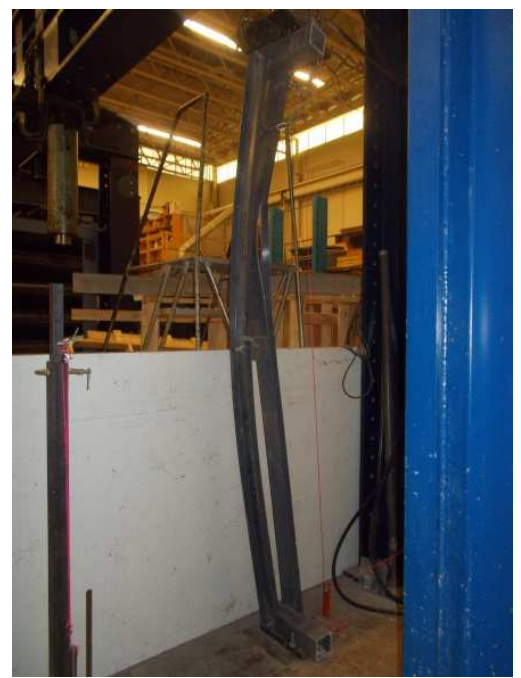

FRP 4x1.375-8 Bush-Both 2

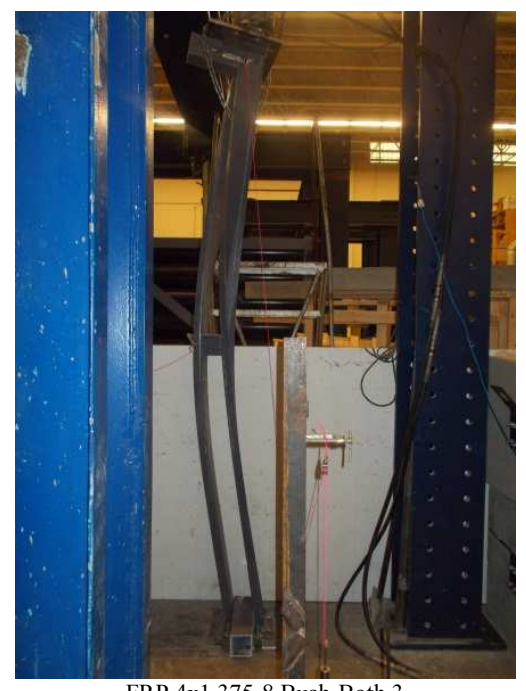

FRP 4x1.375-8 Bush-Both 3 
FRP 4x1.375 Connection Tests

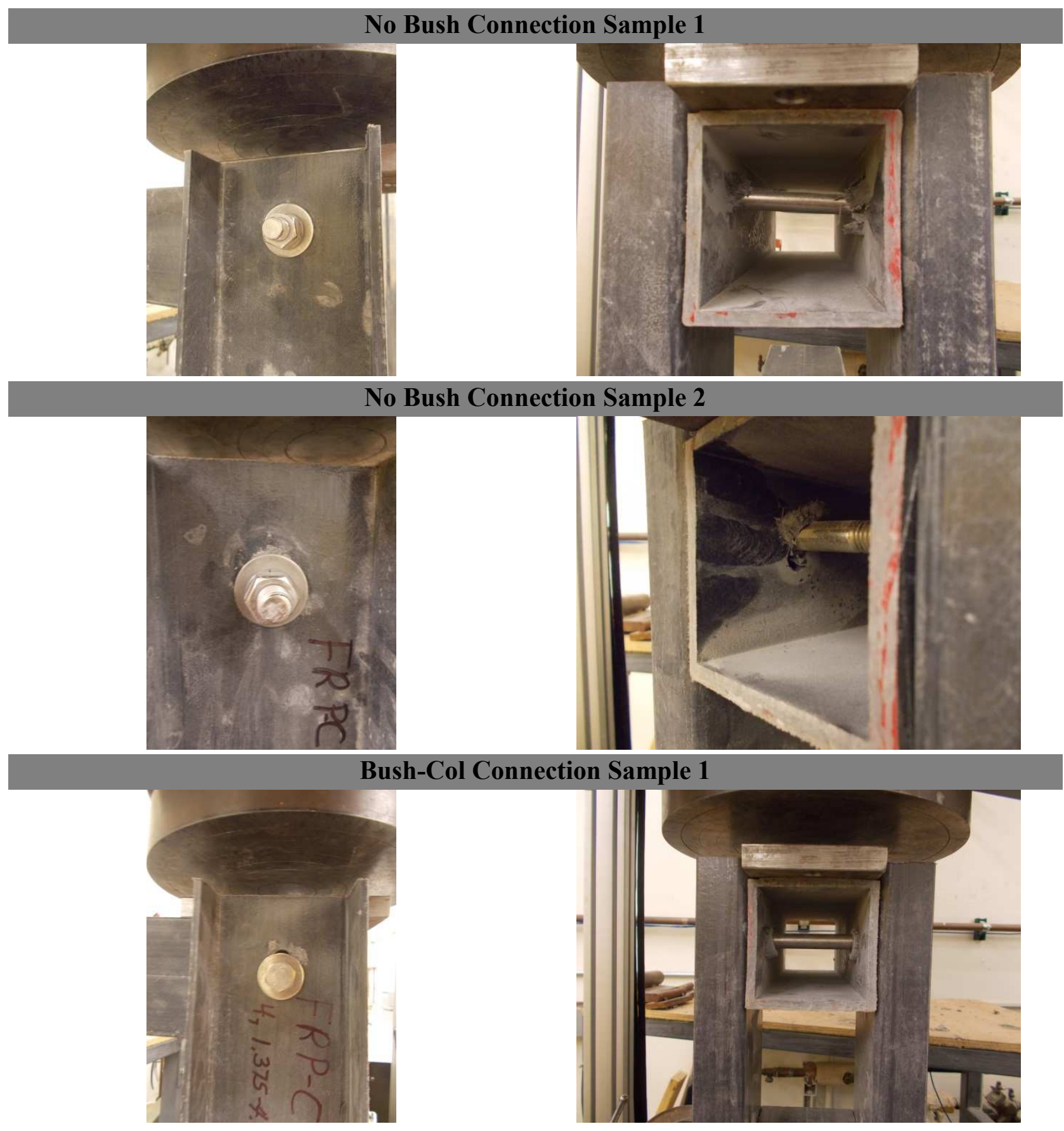




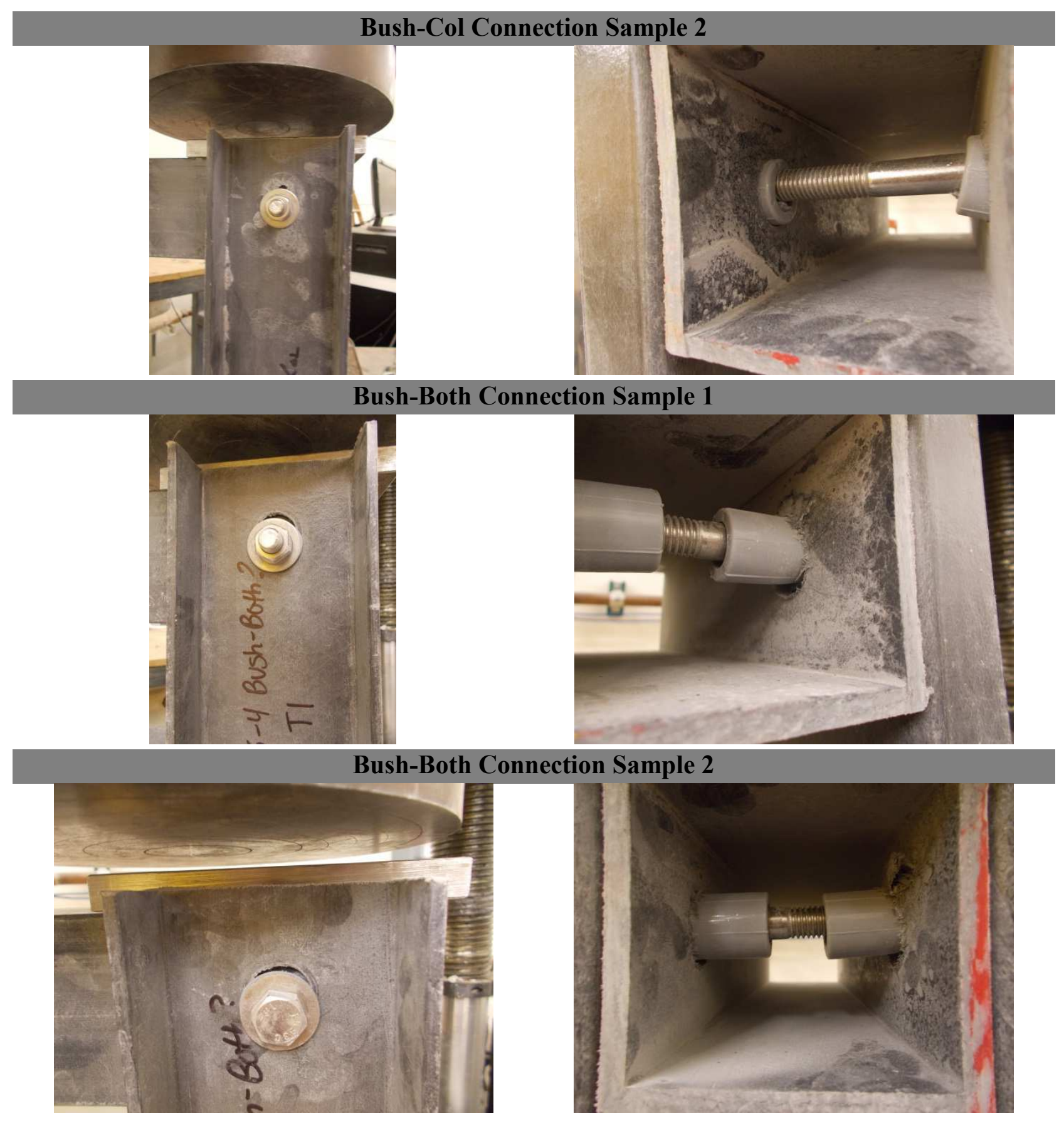




\section{FRP - 5.5x1.5 Ties}

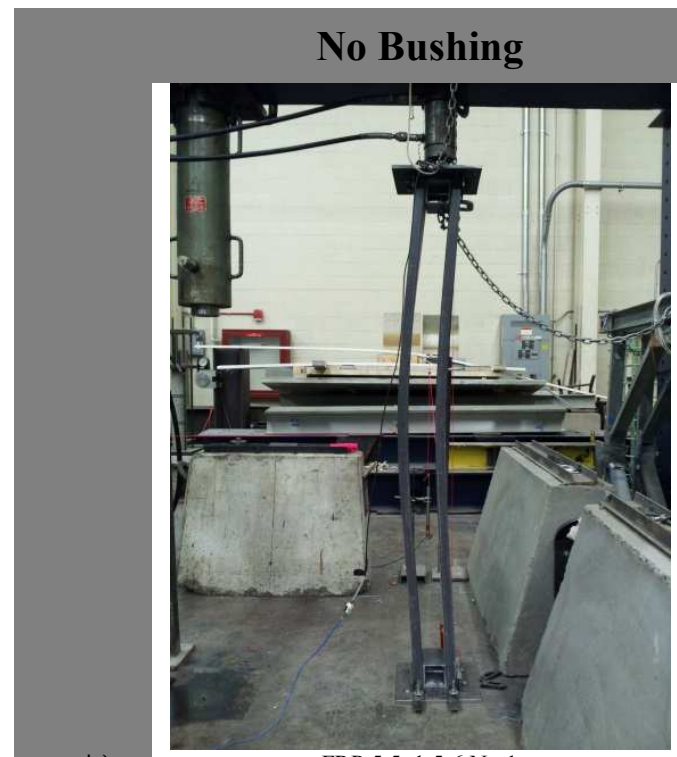

$\frac{\ddot{0}}{6}$

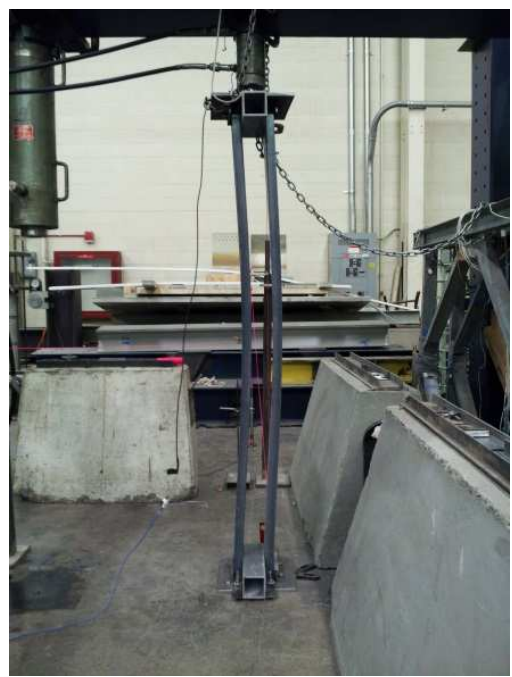

FRP 5.5x1.5-6 No 2
Bushing-Column

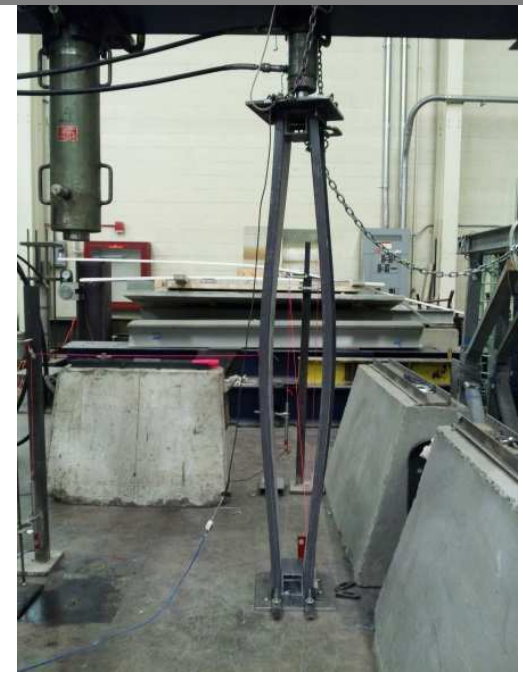

FRP 5.5x1.5-6 Bush-Col 1

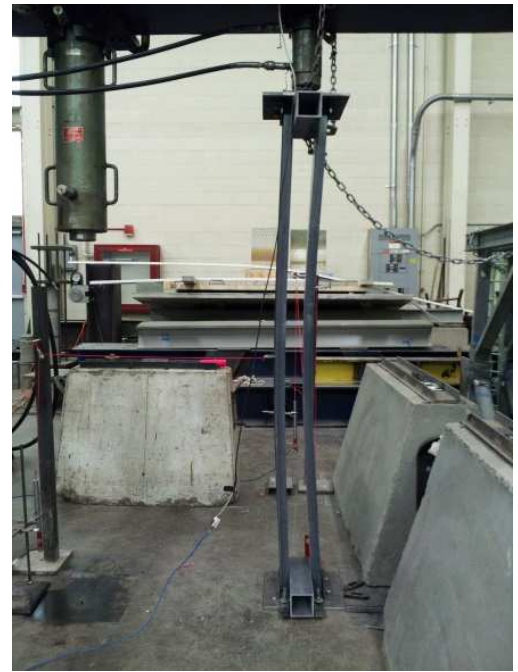

FRP 5.5x1.5-6 Bush-Col 2
Bushing-Both

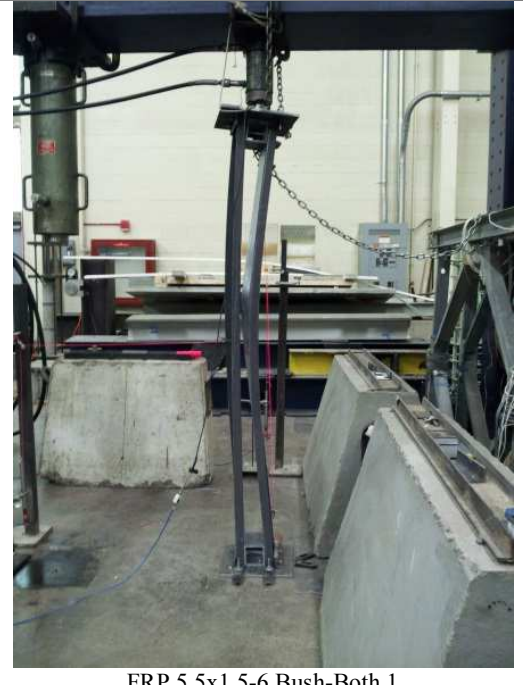

FRP 5.5x1.5-6 Bush-Both

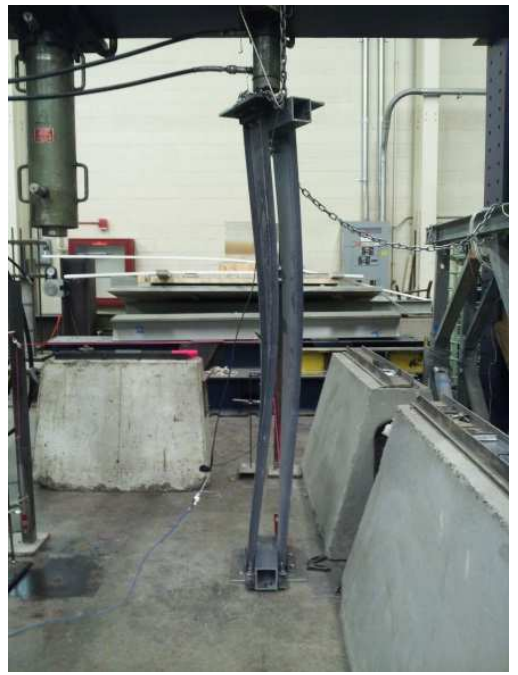

FRP 5.5x1.5-6 Bush-Both 2 


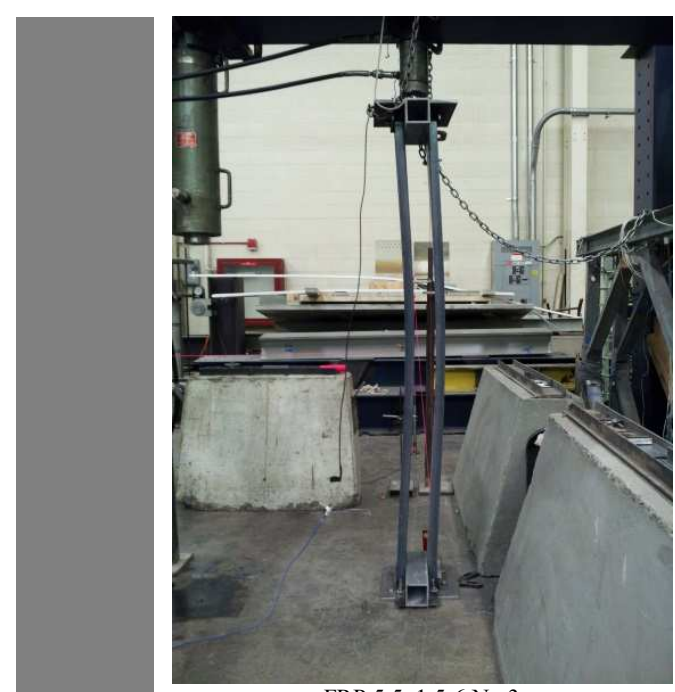

FRP $5.5 \times 1.5-6$ No 3

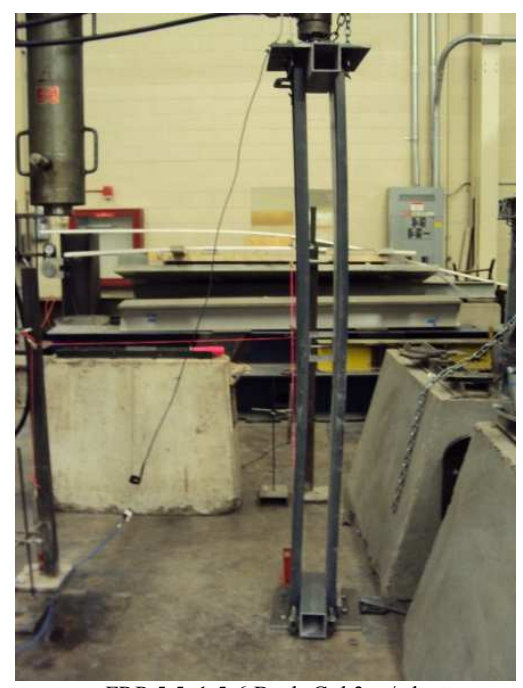

FRP 5.5x1.5-6 Bush-Col $3 \mathrm{w} / \mathrm{cb}$

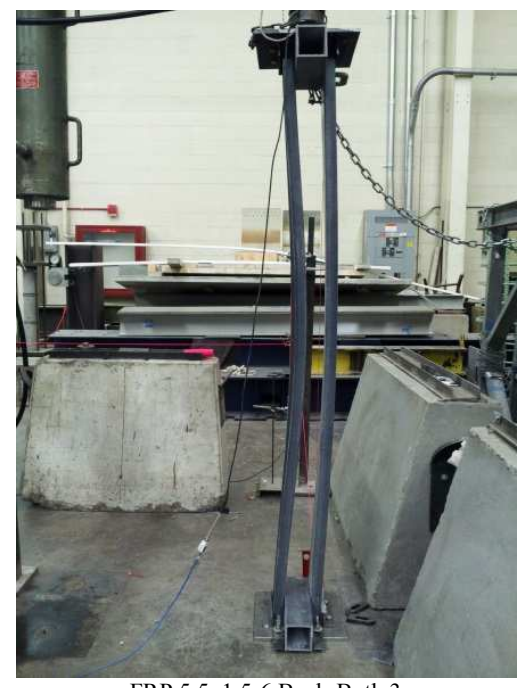

FRP 5.5x1.5-6 Bush-Both 3

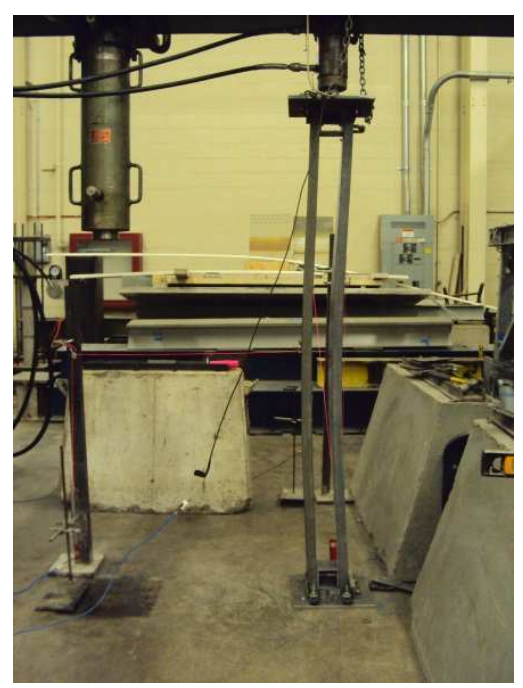

FRP 5.5x1.5-6 Bush-Both 3 ext 


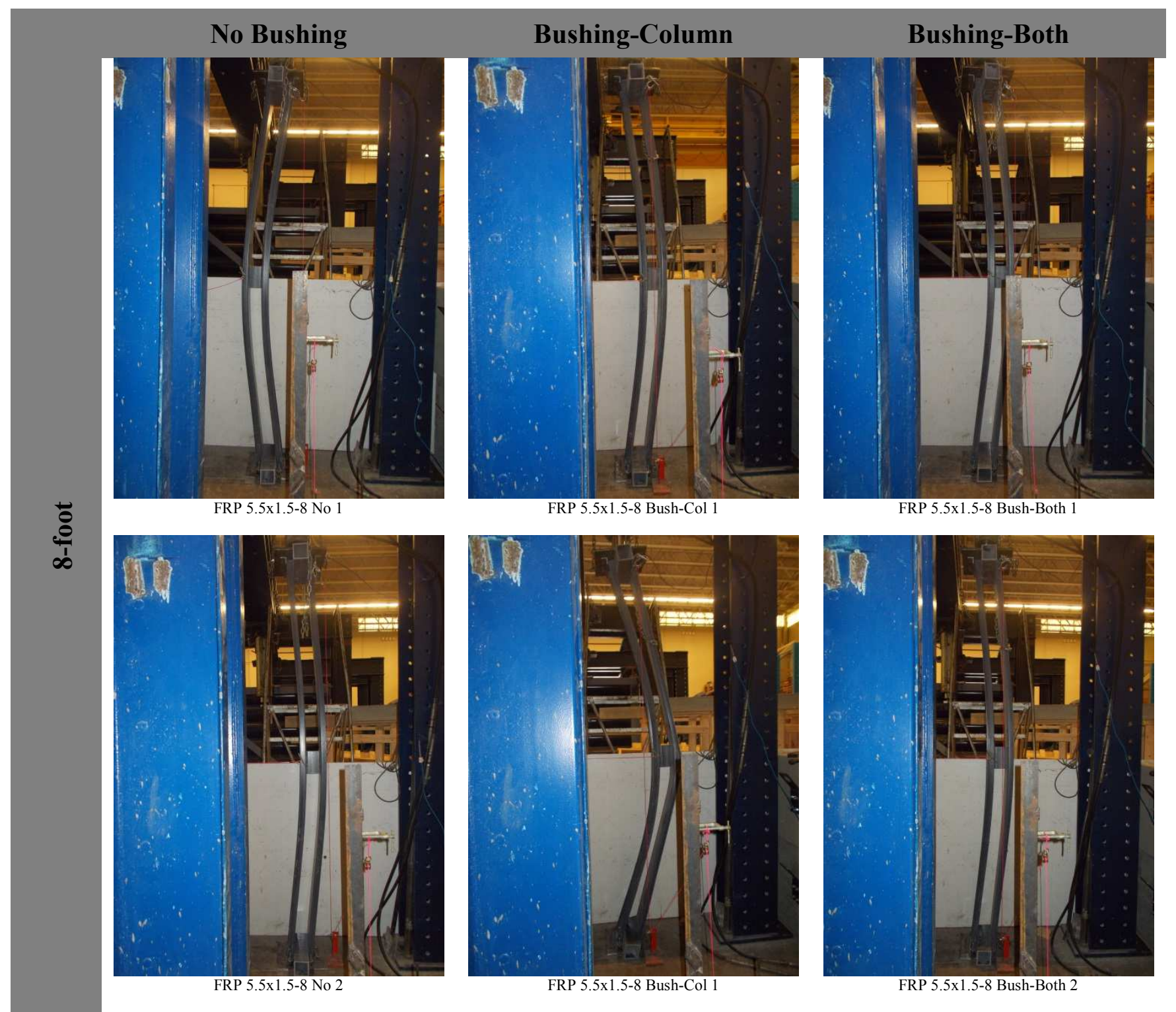


FRP 5.5x1.5 Connection Tests

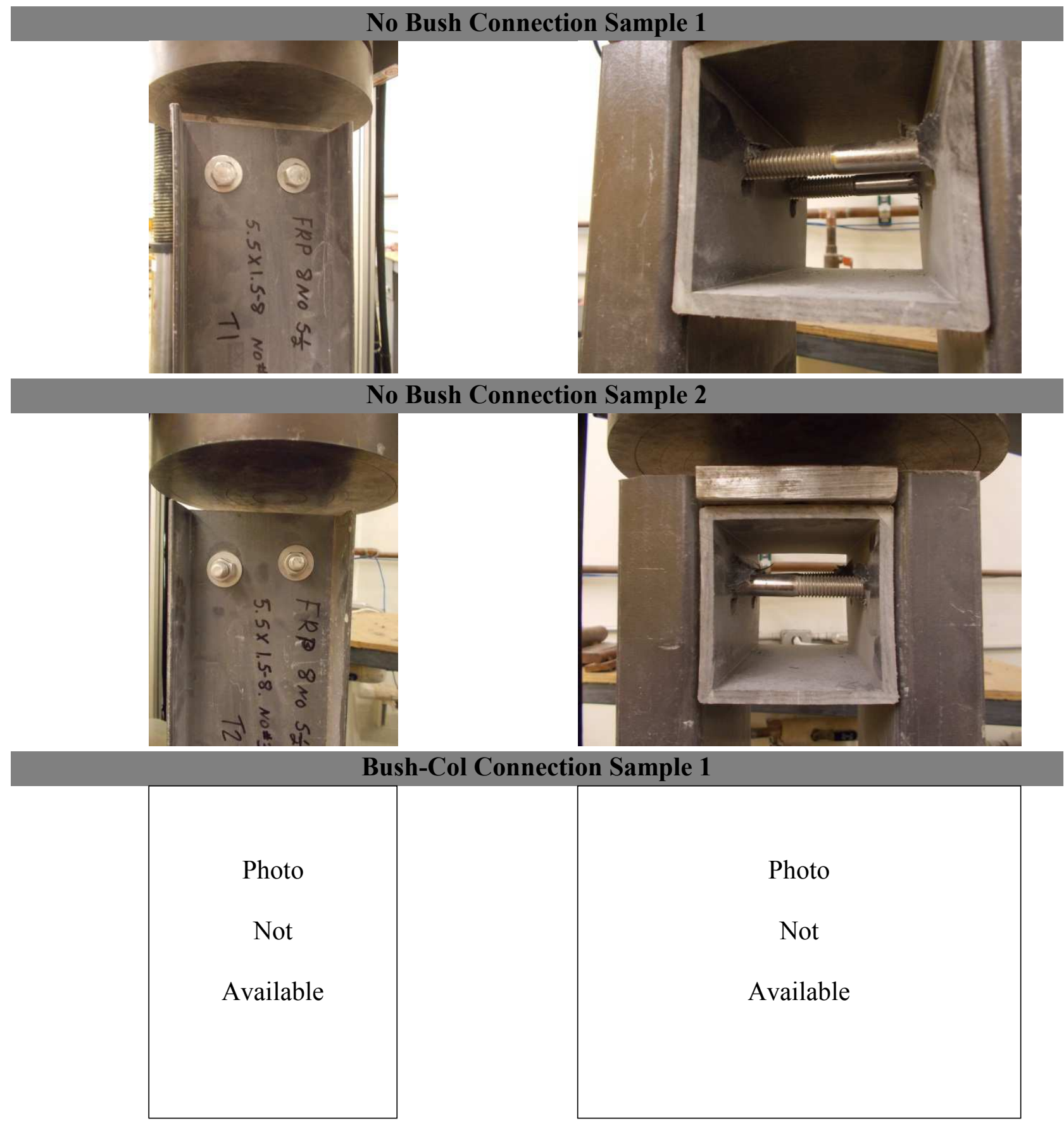




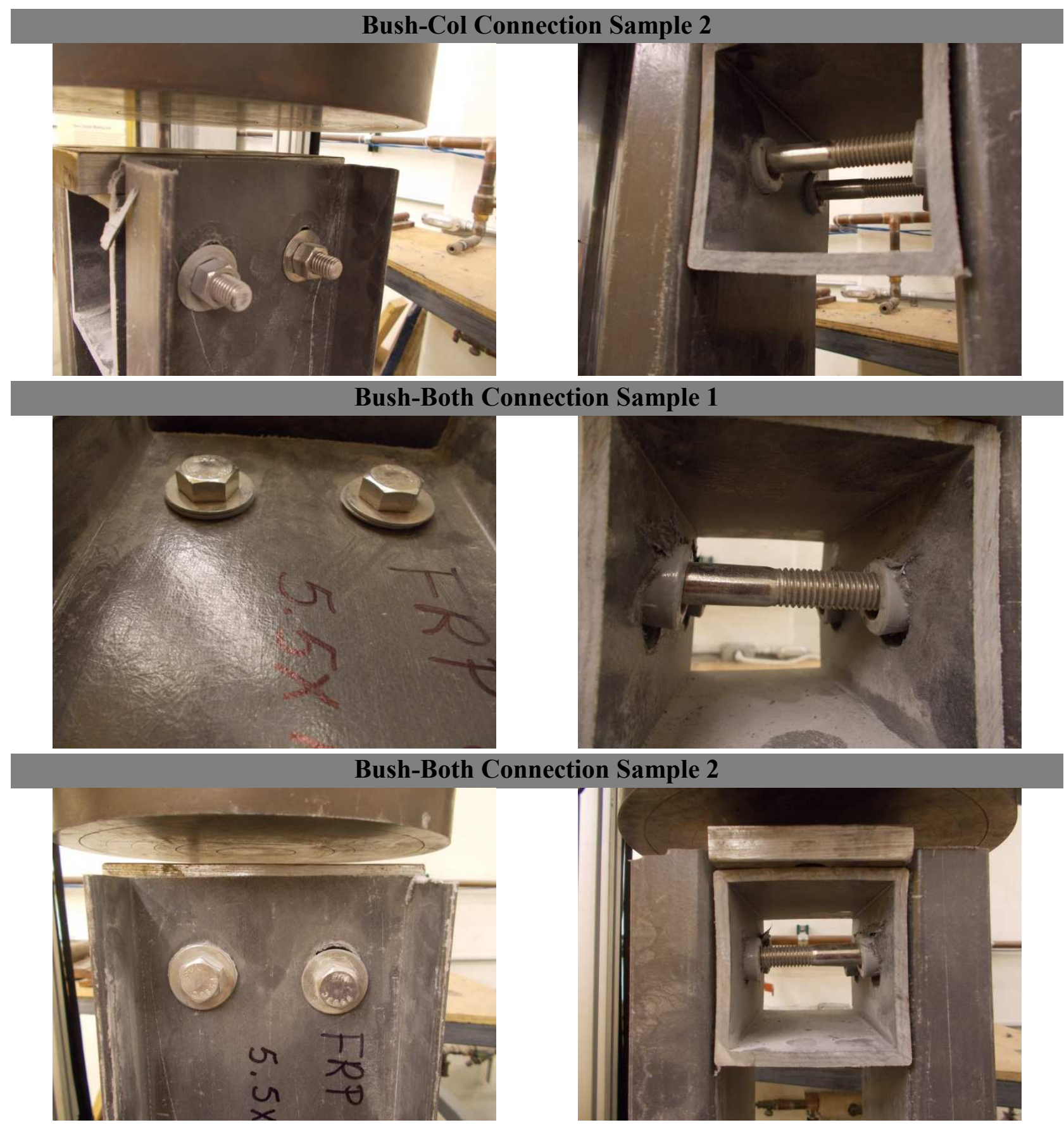




\section{FRP - 6x1.625 Ties}

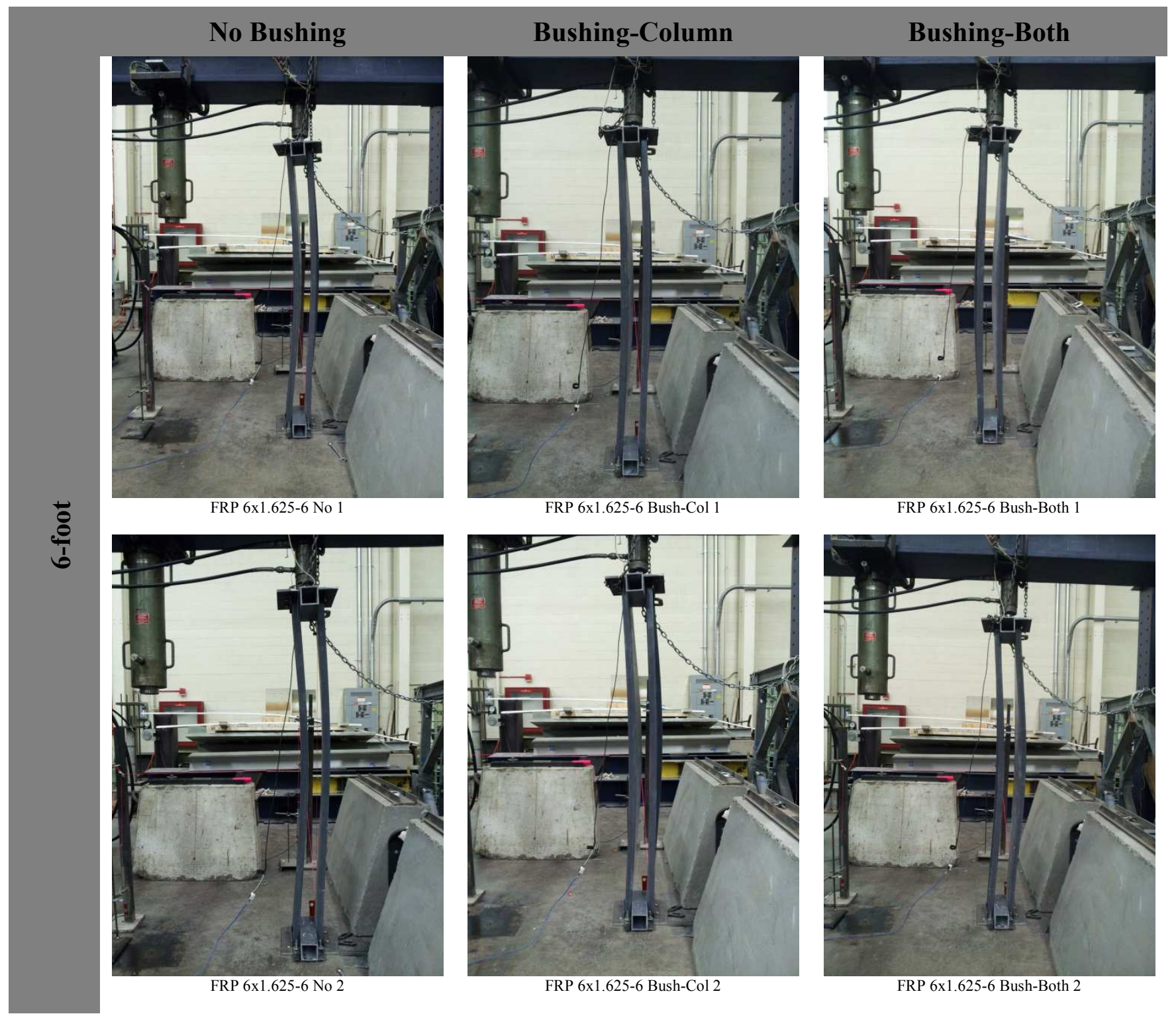




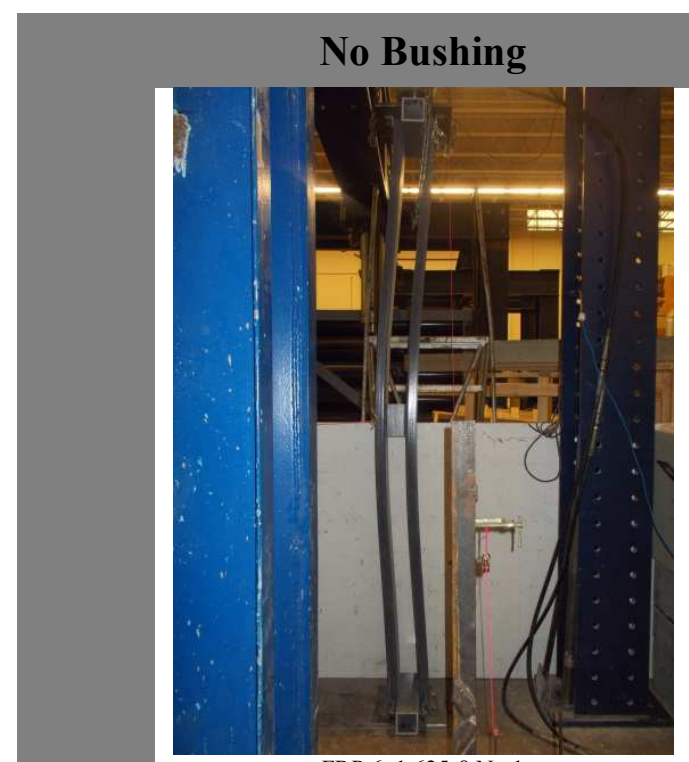

FRP 6x1.625-8 No 1

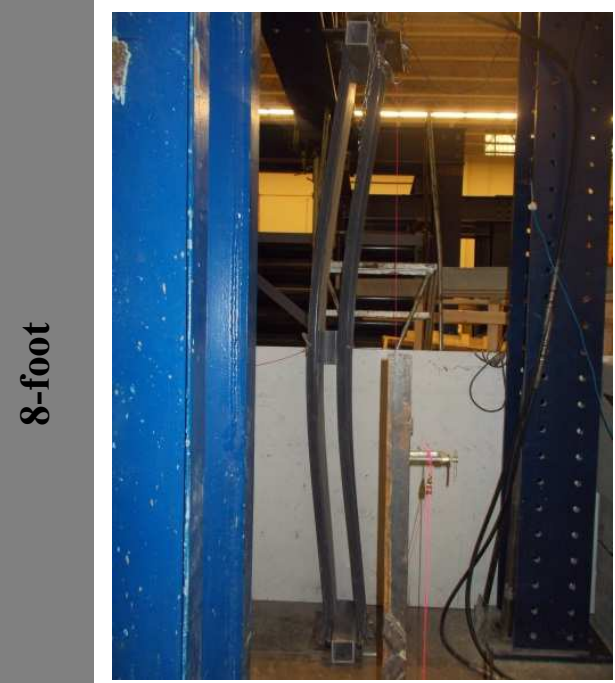

FRP 6x1.625-8 No 2

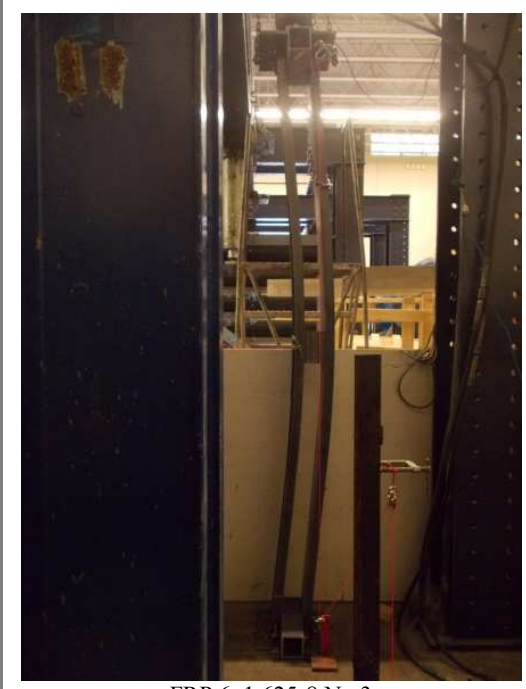

FRP 6x1.625-8 No 3
Bushing-Column

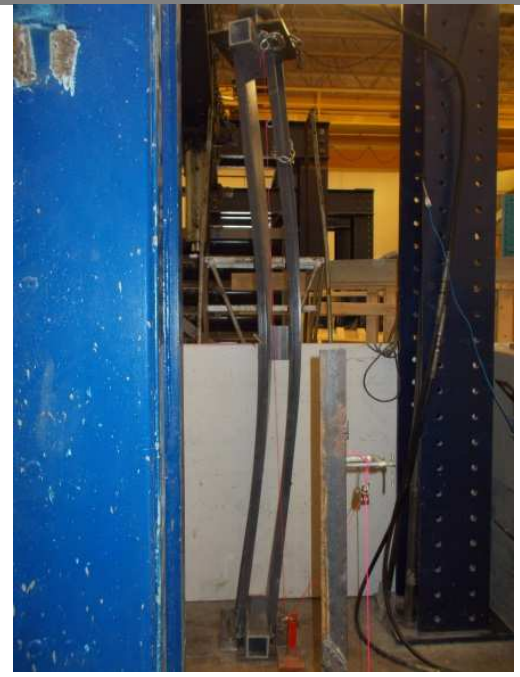

FRP 6x1.625-8 Bush-Col 1

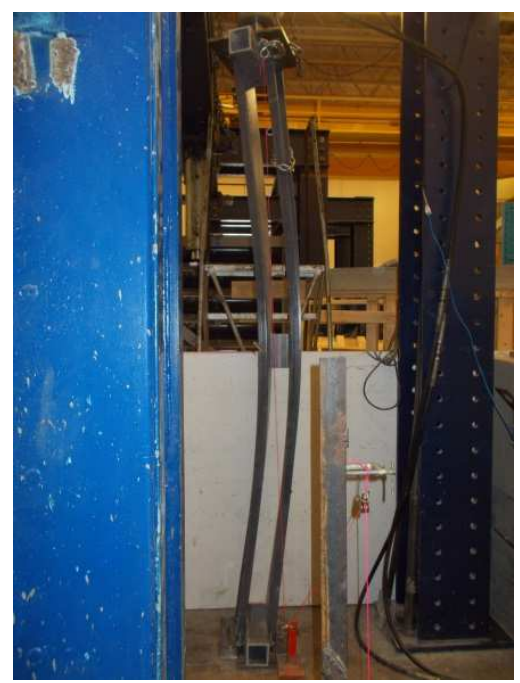

FRP 6x1.625-8 Bush-Col 1

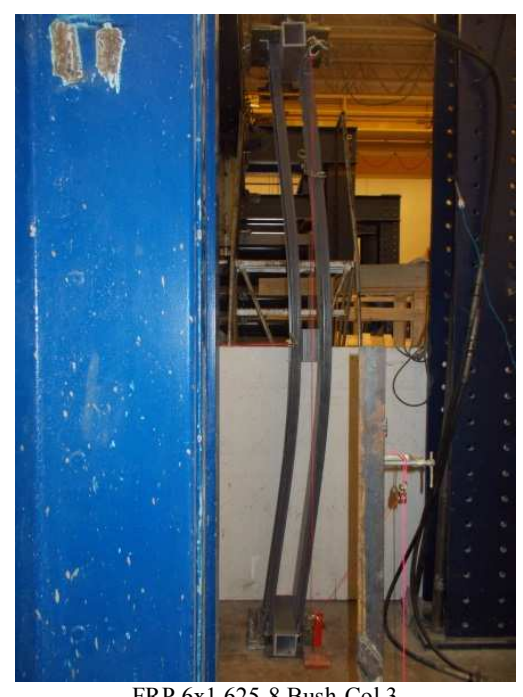

FRP 6x1.625-8 Bush-Col 3
Bushing-Both

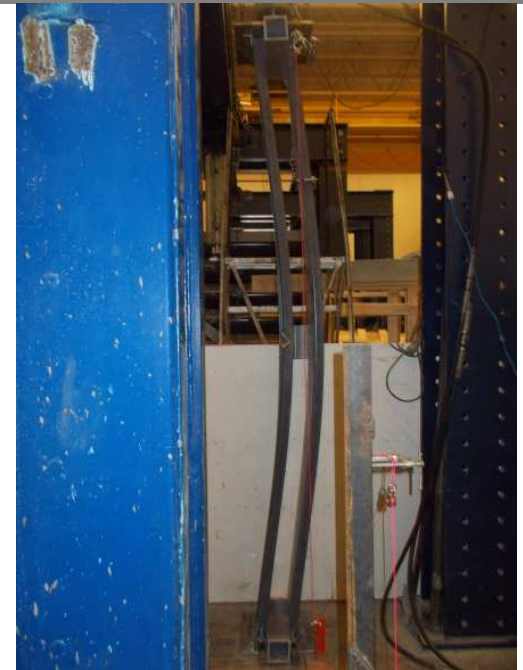

FRP 6x1.625-8 Bush-Both 1

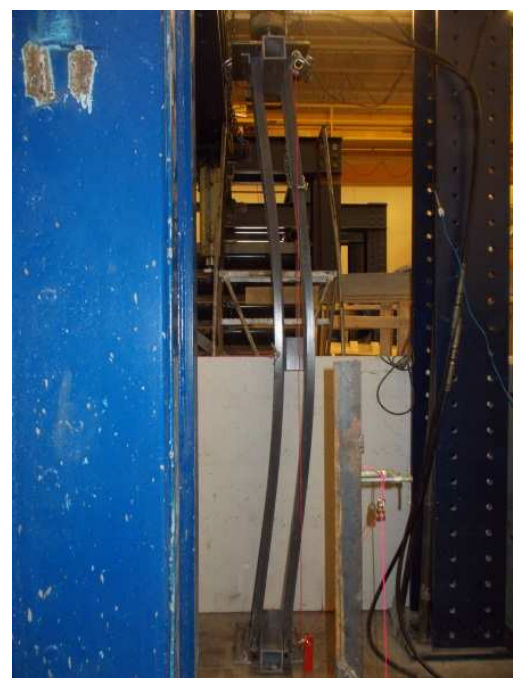

FRP 6x1.625-8 Bush-Both 2

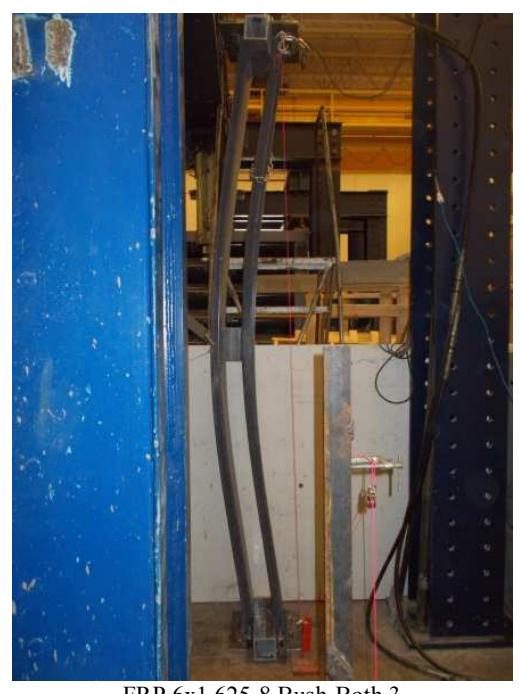

FRP 6x1.625-8 Bush-Both 3 


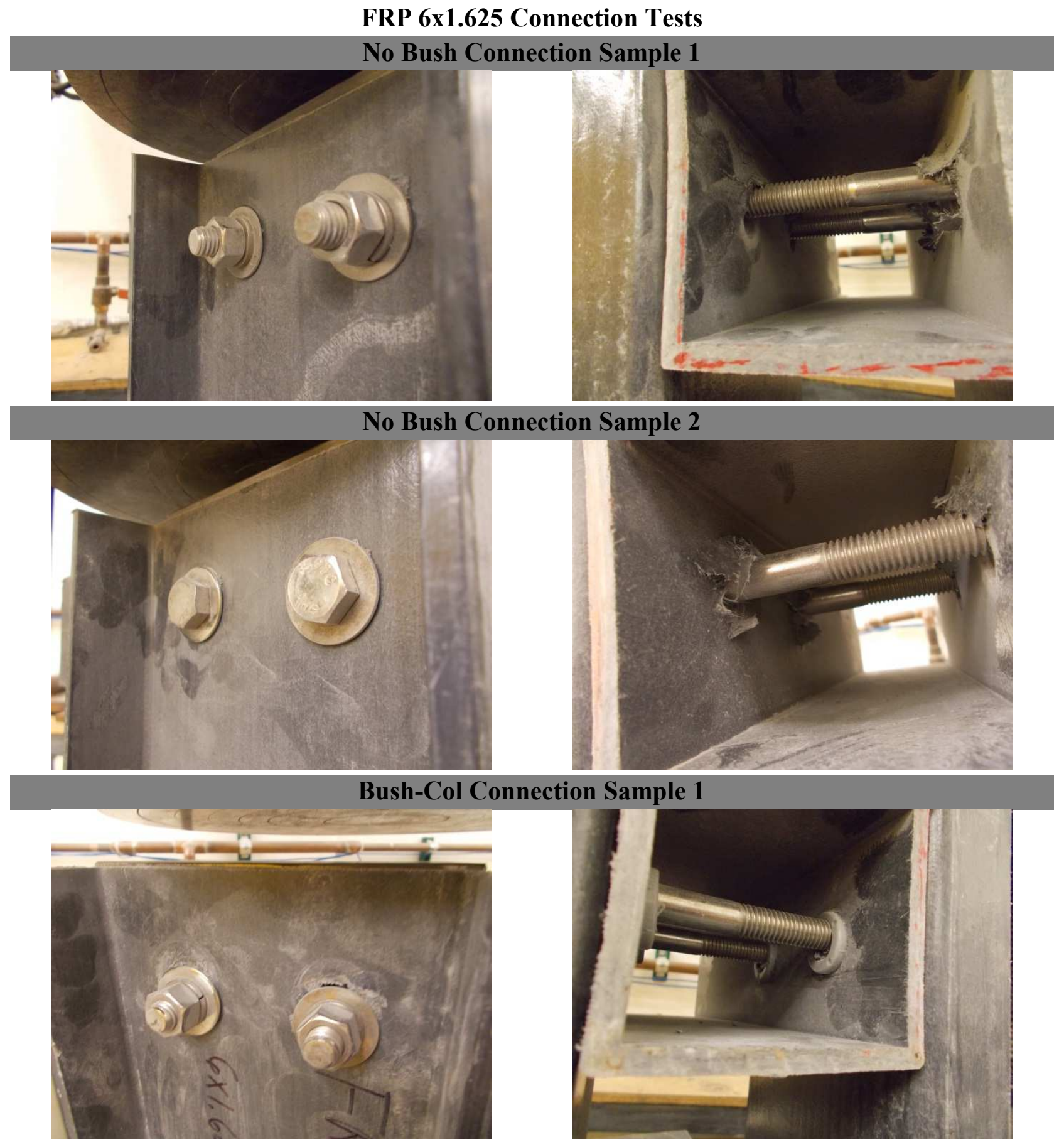




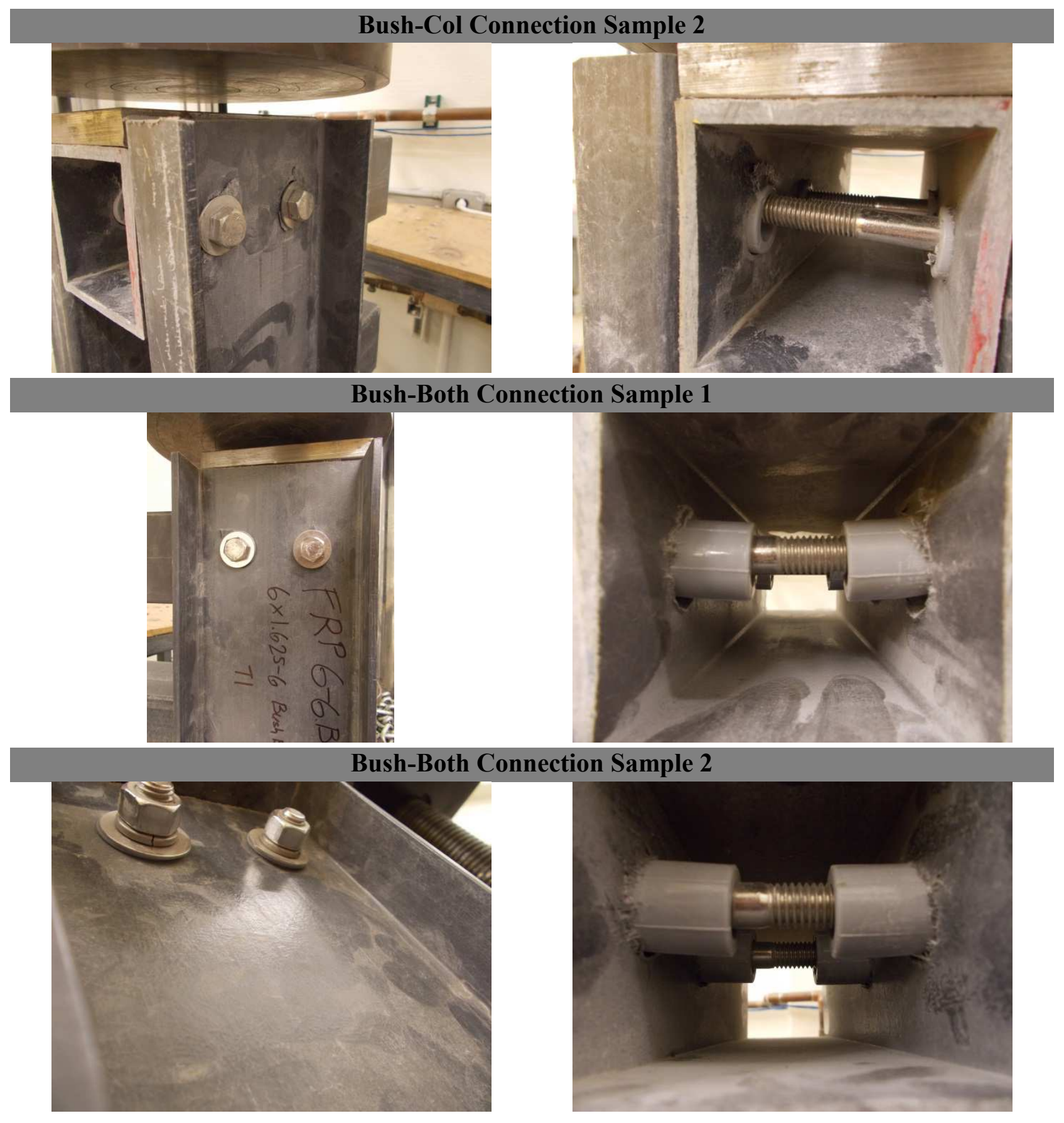




\section{APPENDIX D - BEARING STRENGTH DATA FROM BEDFORD REINFORCED PLASTICS}

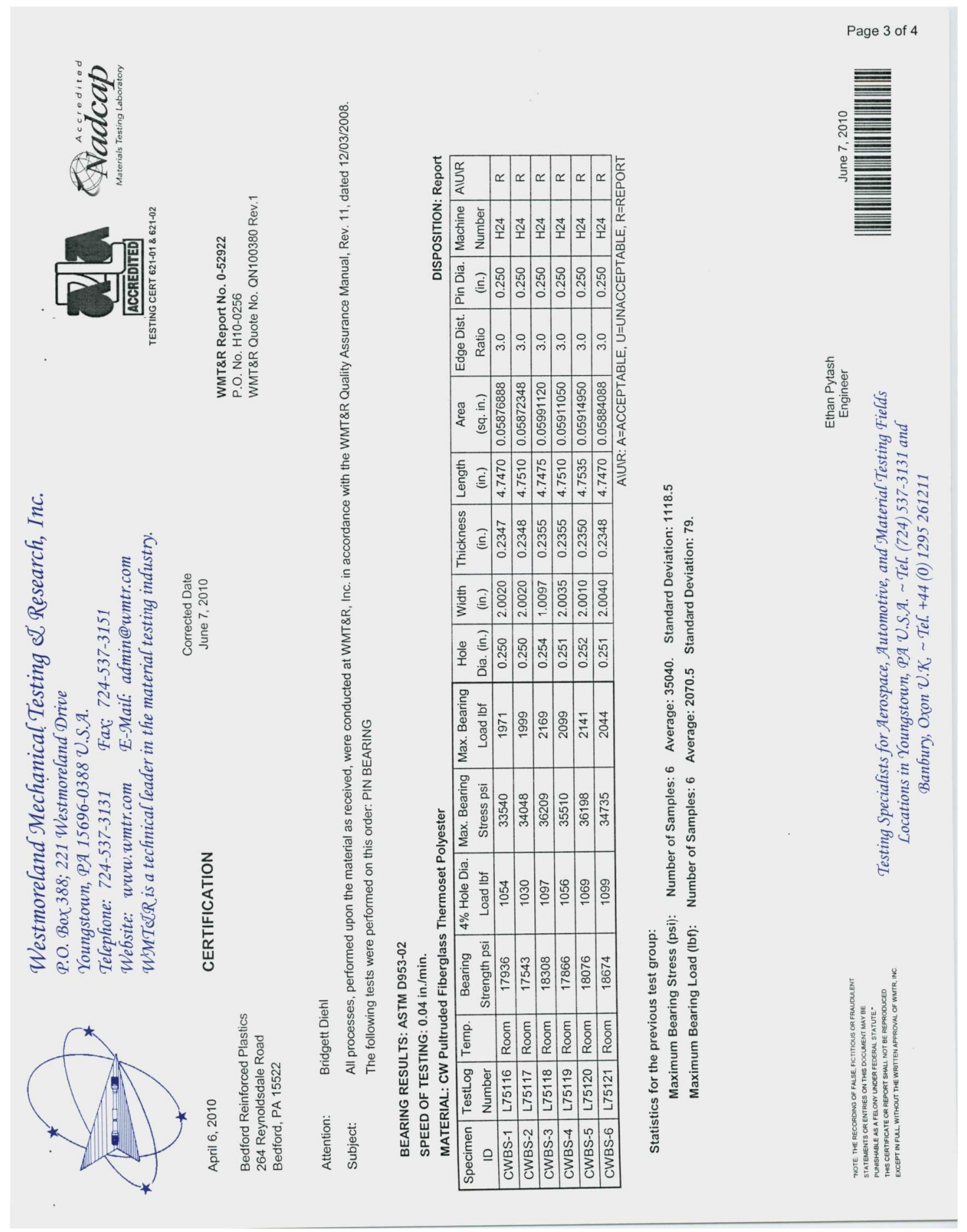




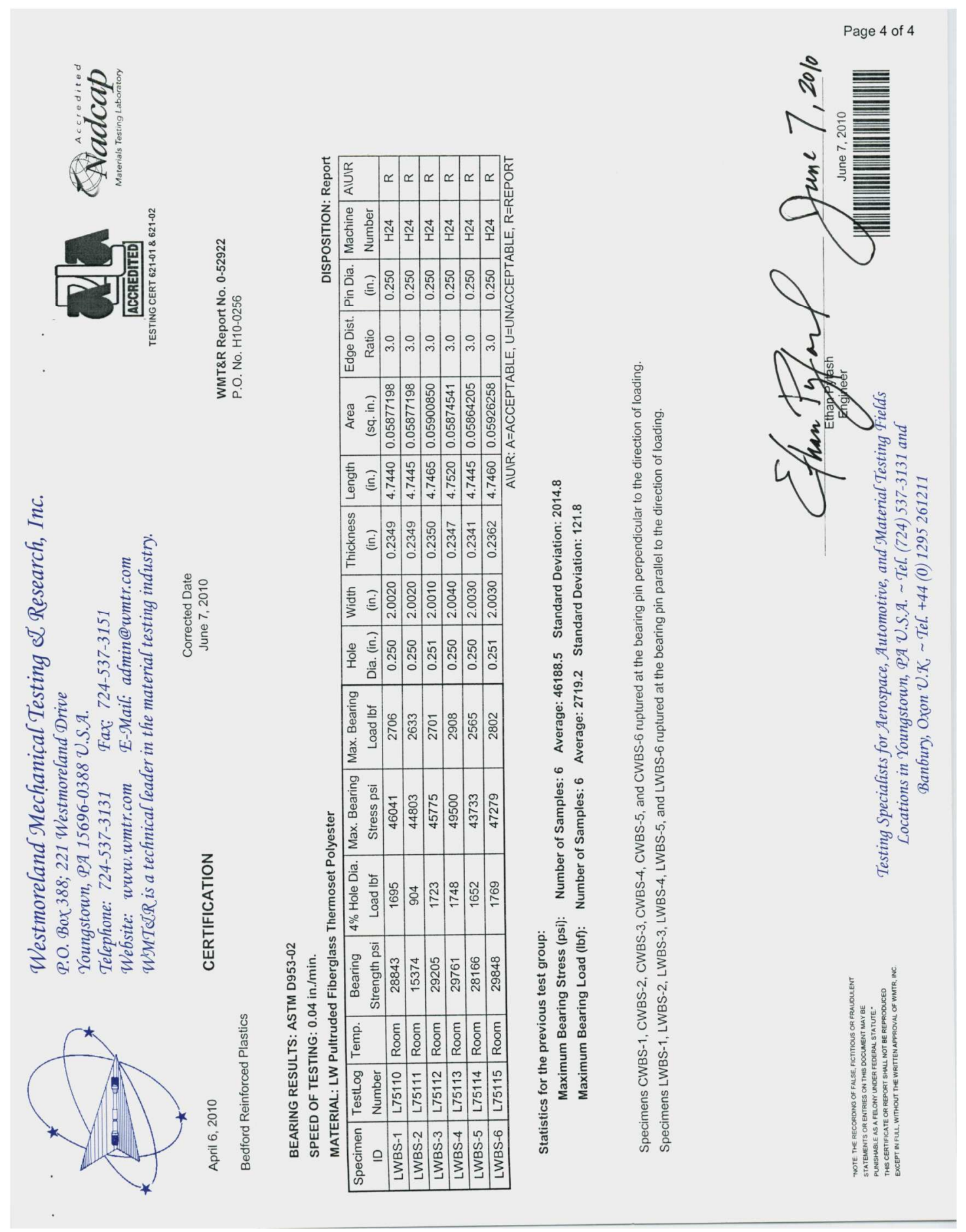

